Universidad de Lima

Facultad de Ciencias Empresariales y Económicas

Carrera de Administración

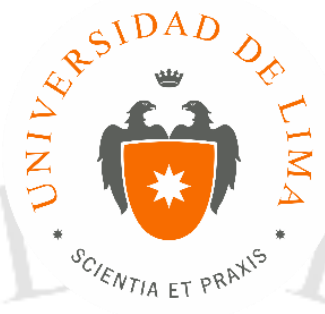

\title{
ESTUDIO DE FACTIBILIDAD PARA LA PRODUCCIÓN Y COMERCIALIZACIÓN DE CALZADO PARA DAMAS PERSONALIZADO Y A LA MEDIDA
}

Trabajo de investigación para optar el Título Profesional de Licenciado en Administración

\section{Melanie Pamela Solis Huamán Código: 20030792 \\ Nery Marjorie Serna Purizaca \\ Código: 20041058}

Asesor

Arata Llona, Juan Andrés

\author{
Lima - Perú \\ Junio del 2018
}




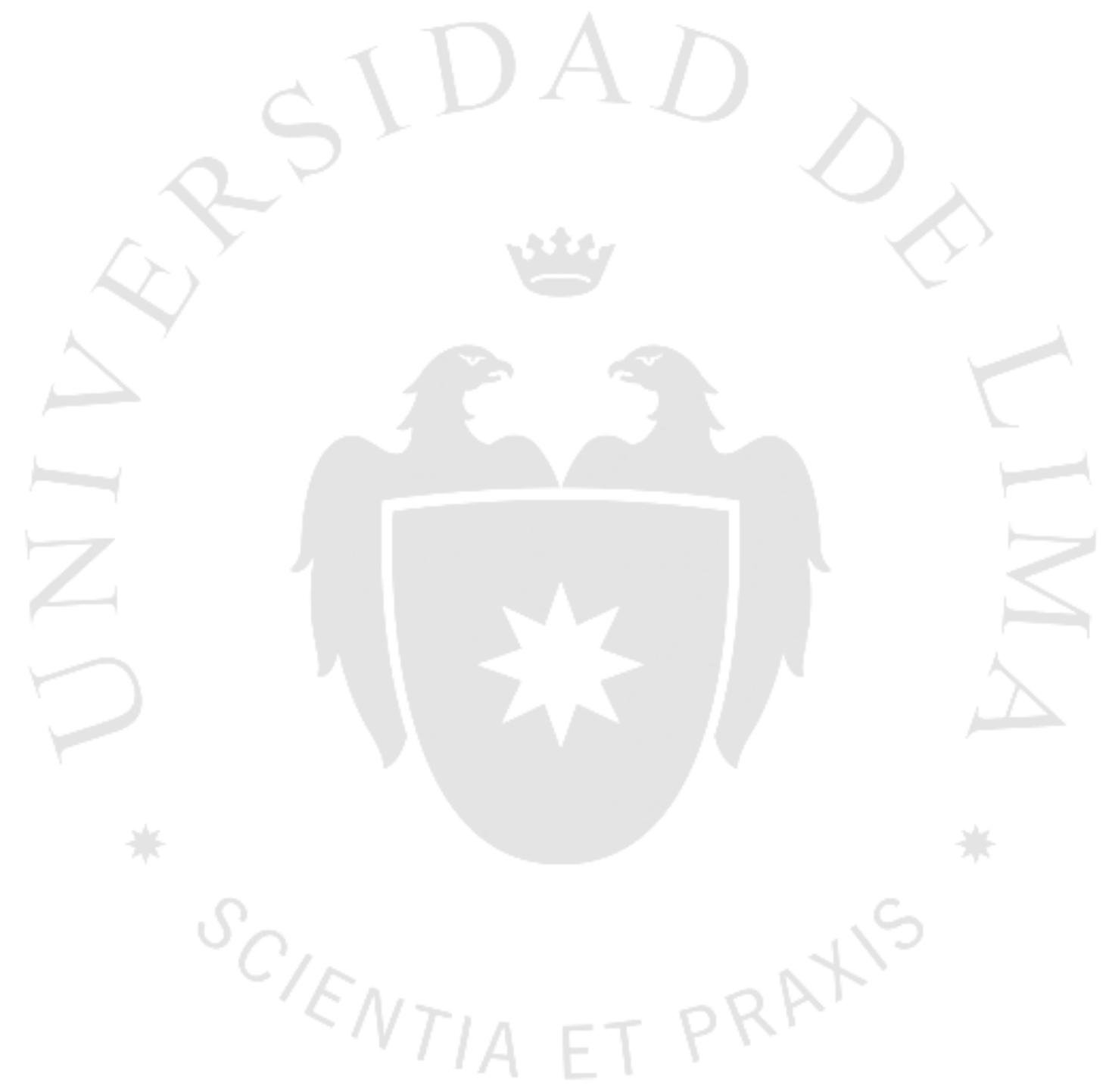




\section{ESTUDIO DE FACTIBILIDAD PARA LA PRODUCCIÓN Y COMERCIALIZACIÓN DE CALZADO PARA DAMAS PERSONALIZADO Y A LA MEDIDA}




\section{DEDICATORIA}

La presente tesis está dedicada a nuestras familias. Muchas gracias por el soporte y el esfuerzo que implicó culminar nuestra carrera profesional. 


\section{AGRADECIMIENTOS}

Un agradecimiento especial a mis padres Luz Huaman y Melanio Solis por enseñarme todo sobre el rubro en el cuál se desarrolla el presente trabajo- Melanie Solis-

Un agradecimiento especial a mis padres Felipe Serna y María Purizaca por brindarme el apoyo en todos los aspectos de mi vida tanto en el ámbito personal y profesional- Nery Serna- 


\section{ÍNDICE GENERAL}

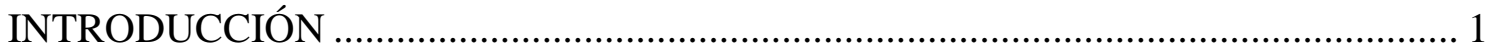

\section{CAPÍTULO I. MARCO CONCEPTUAL Y ESTUDIO DEL MERCADO ................... 2}

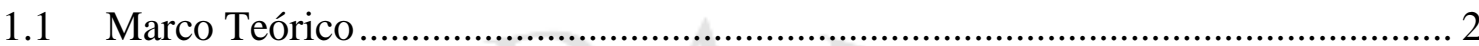

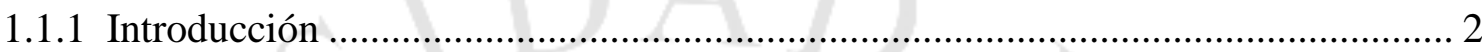

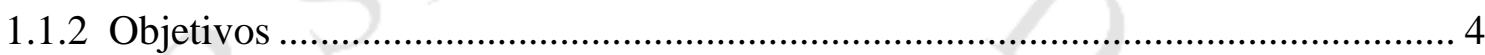

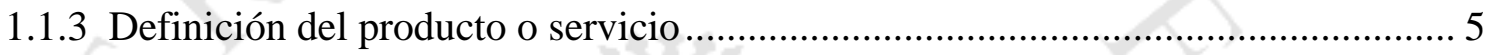

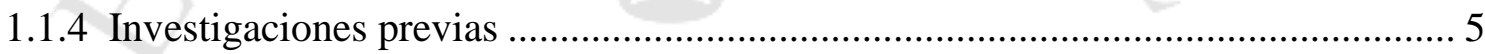

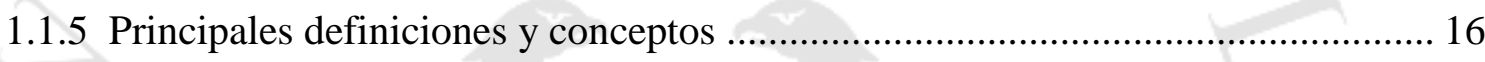

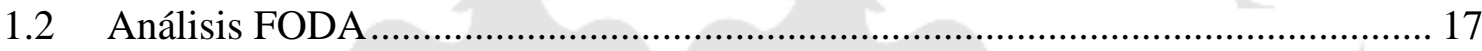

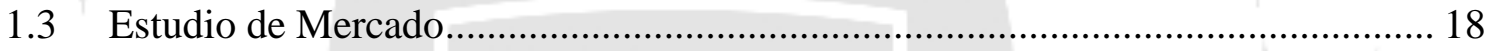

1.3.1 Principales características de los productos o servicios .................................. 18

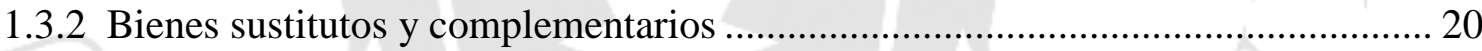

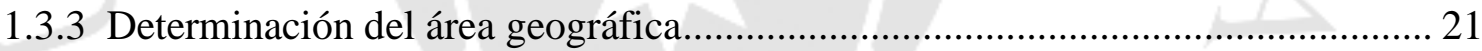

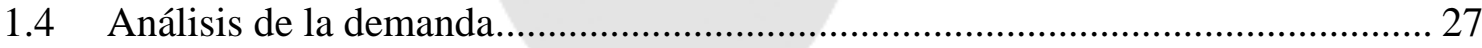

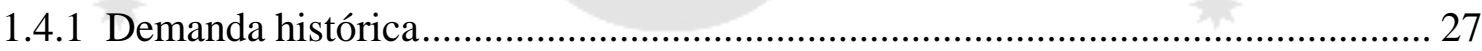

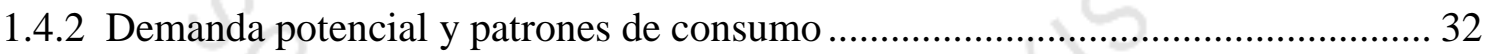

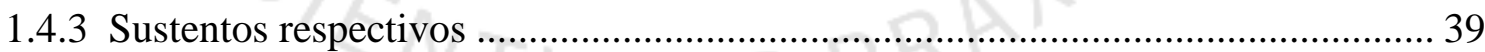

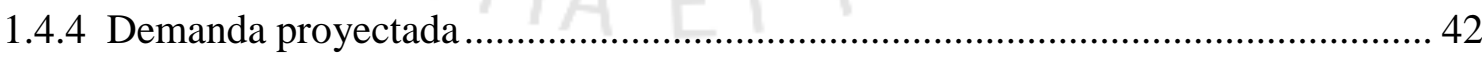

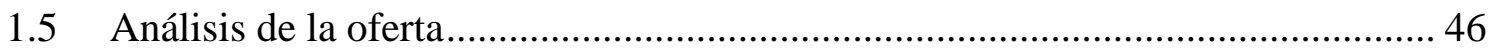

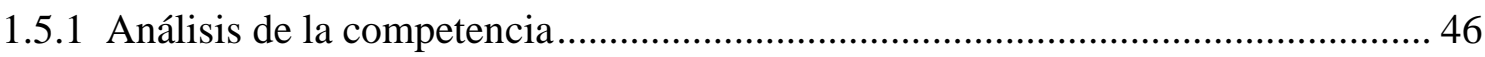

1.5.2 Empresas que ofrecen el producto o servicio............................................... 48

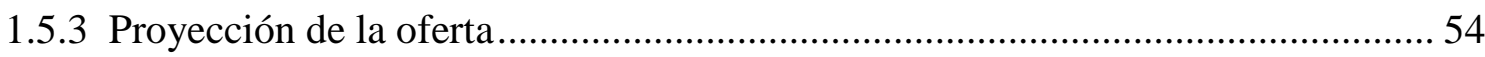

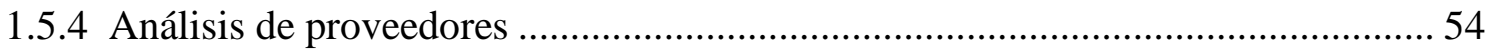




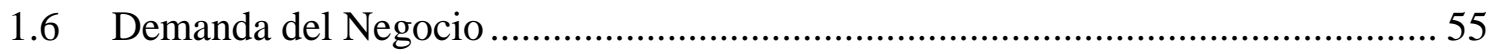

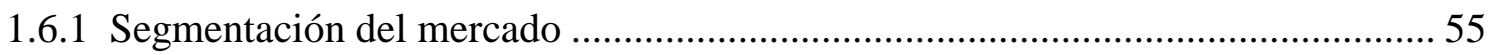

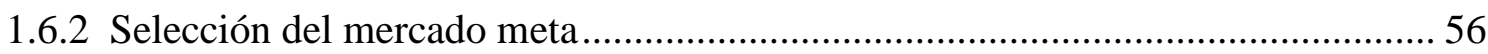

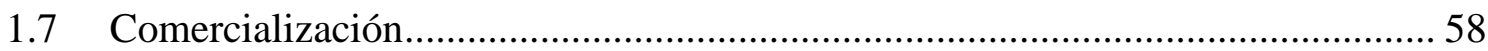

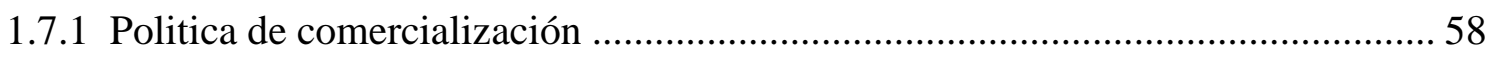

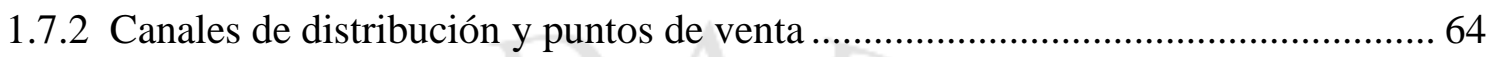

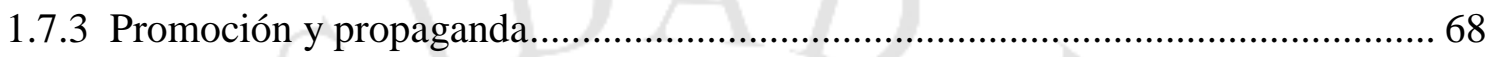

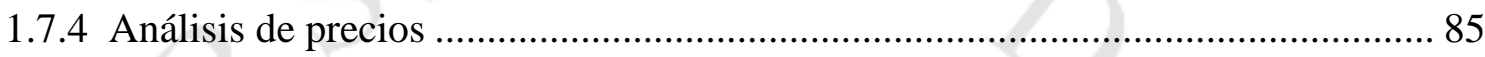

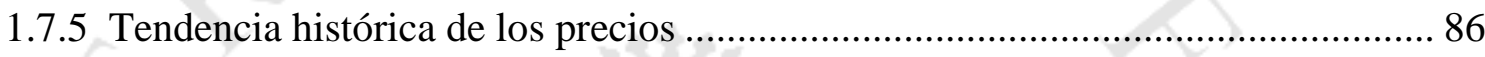

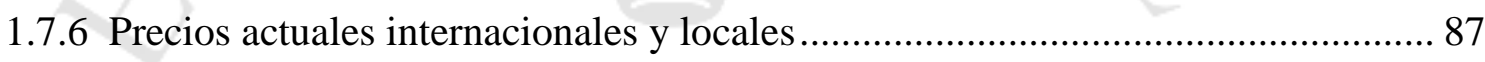

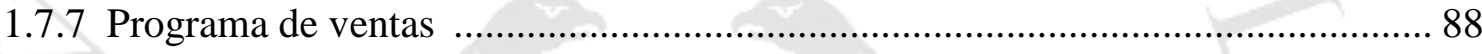

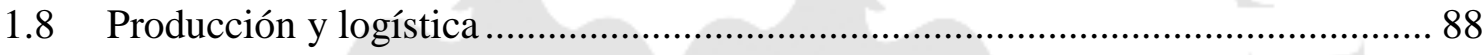

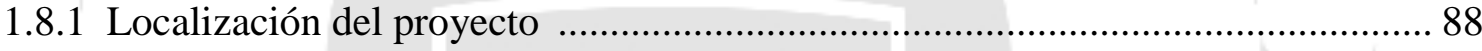

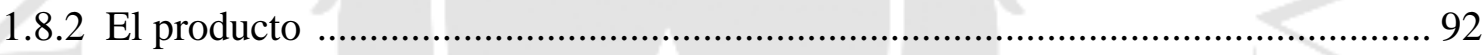

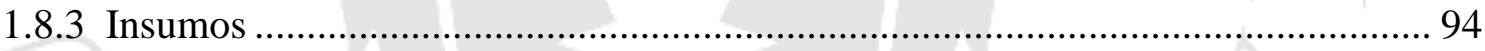

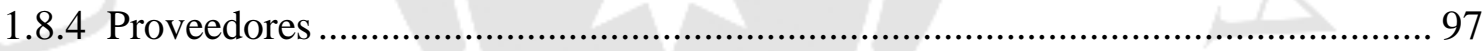

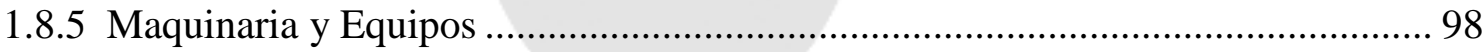

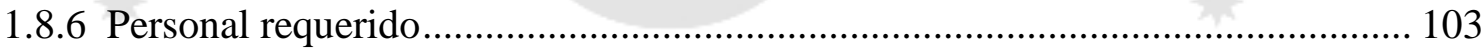

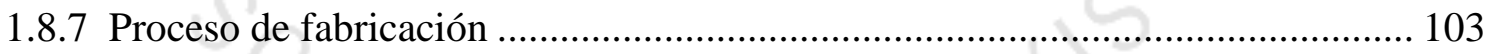

1.8.8 Tiempo de proceso de producción del modelo de negocio ............................... 115

1.8.9 Capacidad de producción .......................................................................... 119

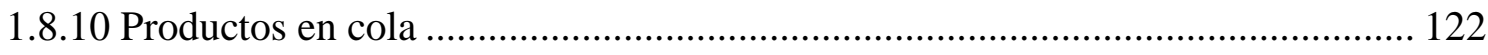

1.8.11 Diseño y distribución de planta.............................................................. 123

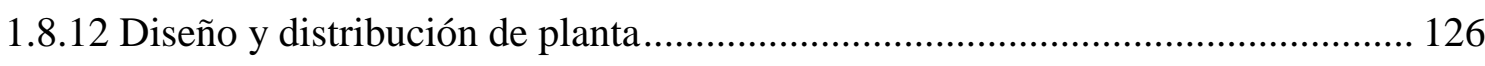

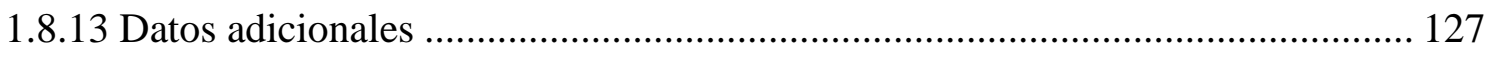

CAPÍTULO II. ESTRUCTURA DE LA ORGANIZACIÓN .......................................... 129 
2.1 Análisis de la organización

2.1.1 Organización de los puestos de trabajo ........................................................... 129

2.1.2 Análisis de la estructura propuesta................................................................ 133

2.1.3 Requerimiento de recurso humano necesario anualmente ................................ 134

2.2 Misión, visión y objetivos estratégicos ........................................................ 135

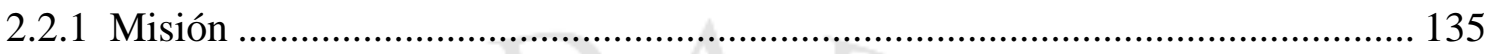

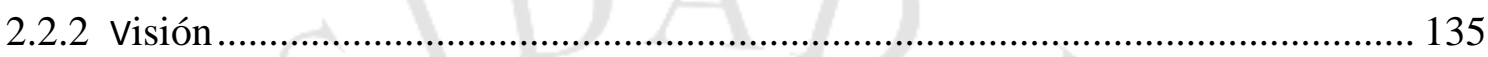

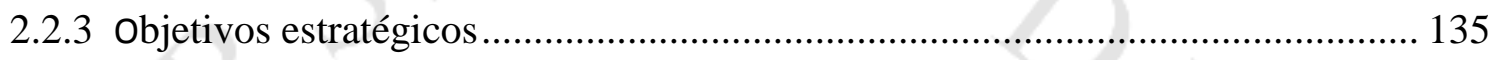

2.3 Aspectos legales de constitución................................................................ 135

2.3.1 Determinación de la forma societaria …........................................................ 135

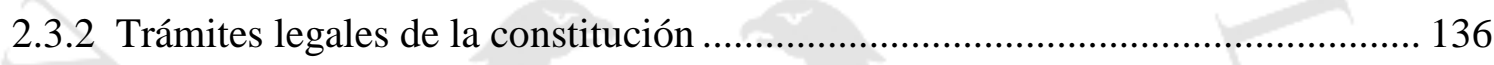

CAPÍTULO III: EVALUACIÓN ECONÓMICA Y FINANCIERA............................ 145

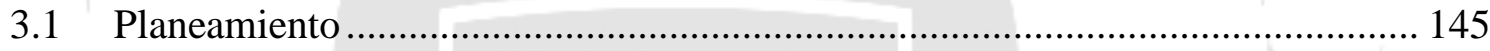

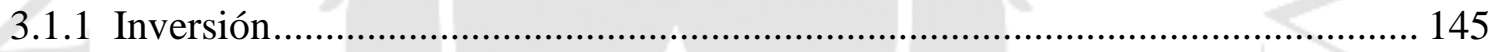

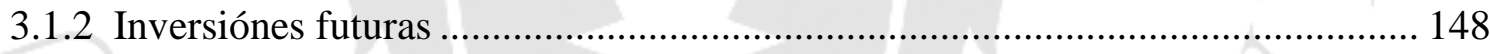

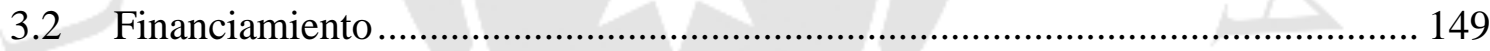

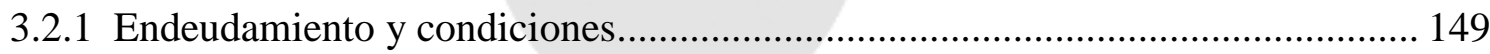

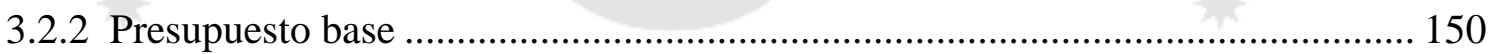

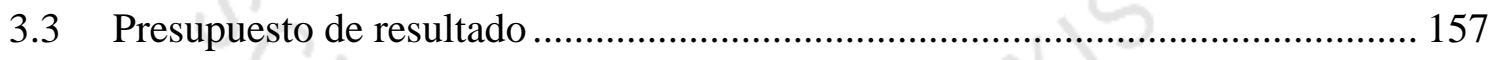

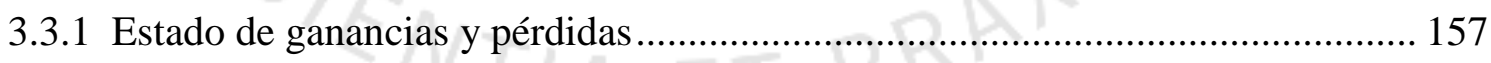

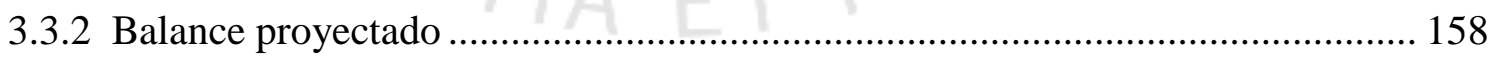

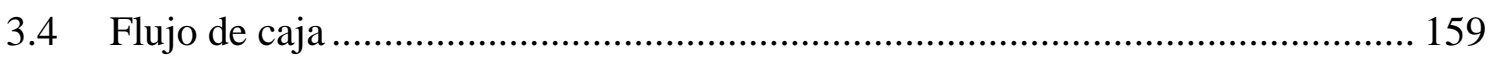

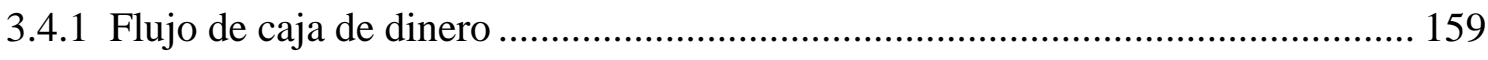

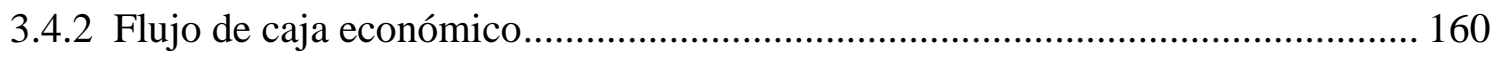

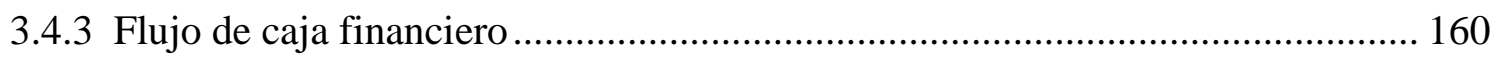

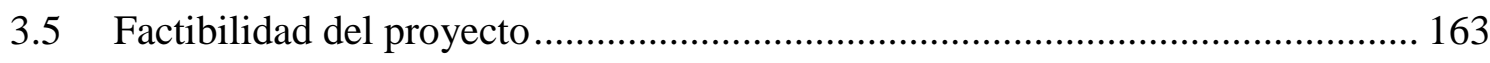




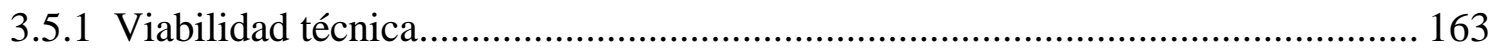

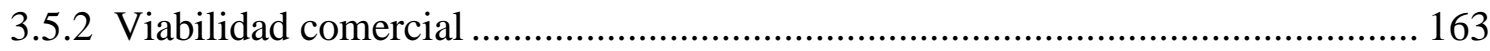

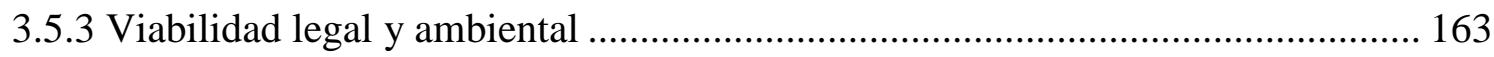

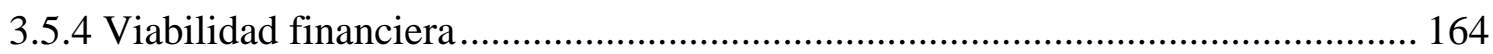

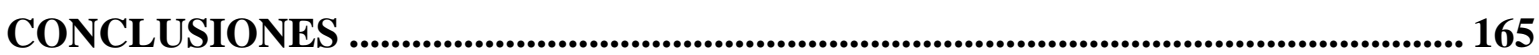

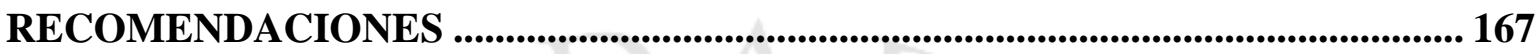

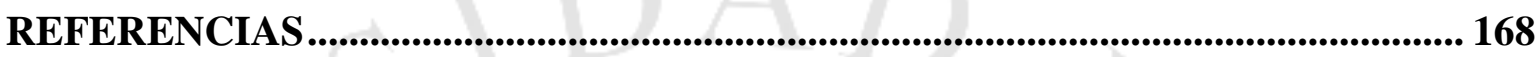

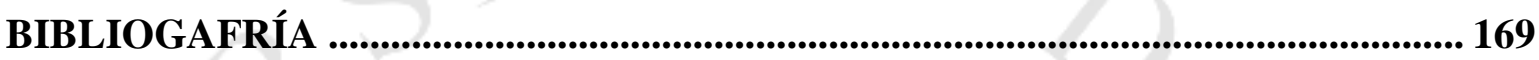

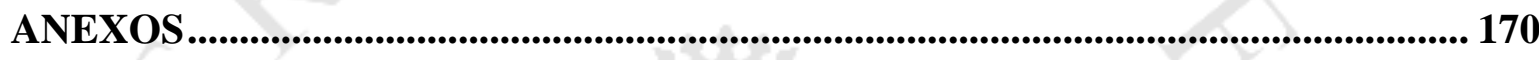




\section{ÍNDICE DE TABLAS}

\section{CAPÍTULO I. MARCO CONCEPTUAL Y ESTUDIO DEL MERCADO}

Tabla 1.1 Variación anual de producción de calzado .......................................................... 28

Tabla 1.2 Descripción de las principales partidas arancelarias de calzado ..........................2 29

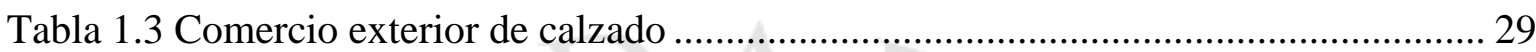

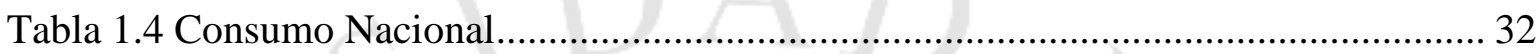

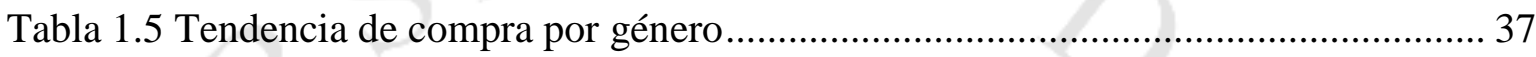

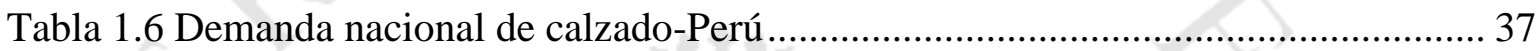

Tabla 1.7 Demanda nacional de calzado por género - Perú............................................... 38

Tabla 1.8 Demanda de calzado femenino-Lima Metropolitana ........................................ 38

Tabla 1.9 Mercado Potencial de pares de calzado ................................................................ 39

Tabla 1.10 Grupos de estudio-Rango de edades ............................................................. 40

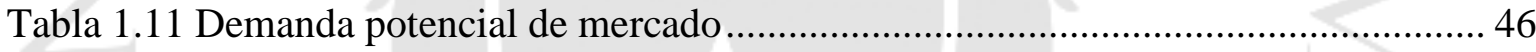

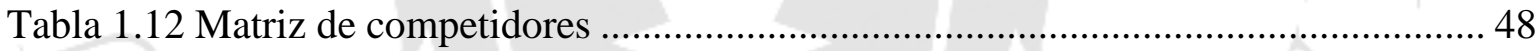

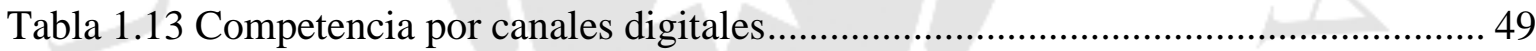

Tabla 1.14 Competencia-alcance por canales digitales .................................................. 50

Tabla 1.15 Matriz de indicadores de Facebook ................................................................. 50

Tabla 1.16 Matriz de indicadores de Instagram............................................................... 52

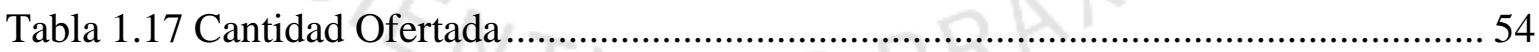

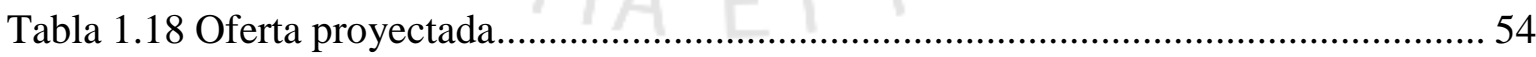

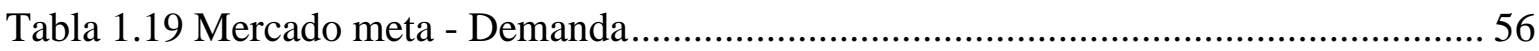

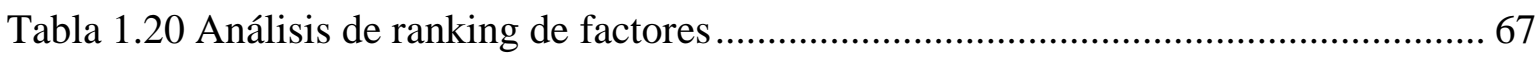

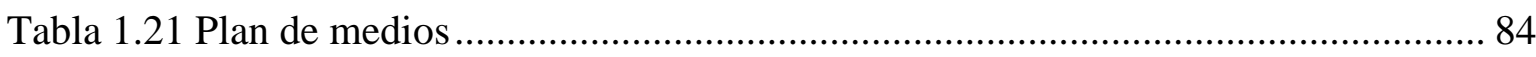

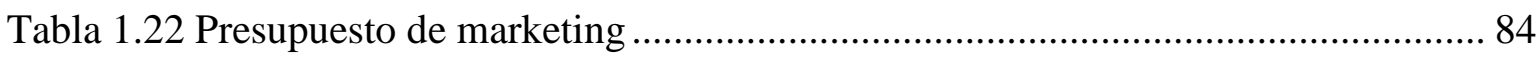

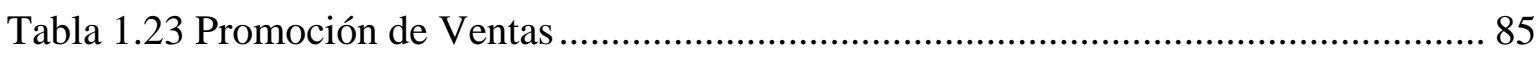


Tabla 1.24 Análisis de precios

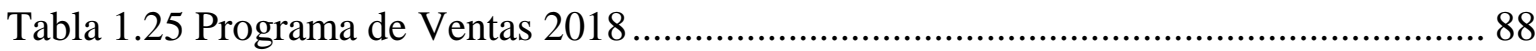

Tabla 1.26 Análisis de Ranking de Factores........................................................................ 91

Tabla 1.27 Comparación de indicadores de producción por estilos de calzado ...................93

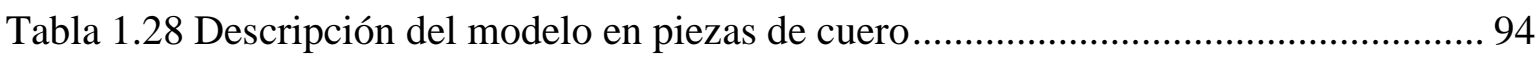

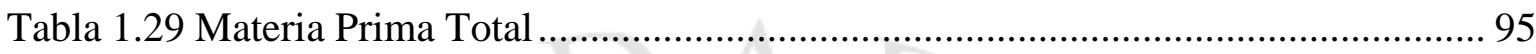

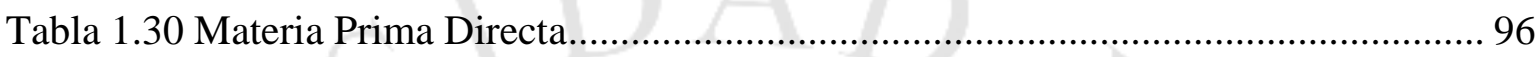

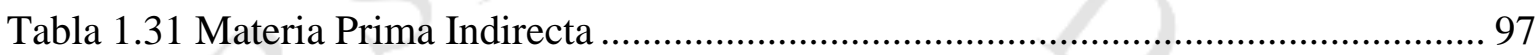

Tabla 1.32 Maquinaria de producción ......................................................................... 98

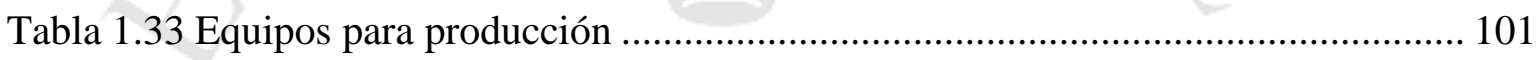

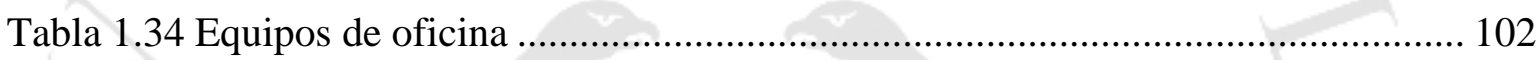

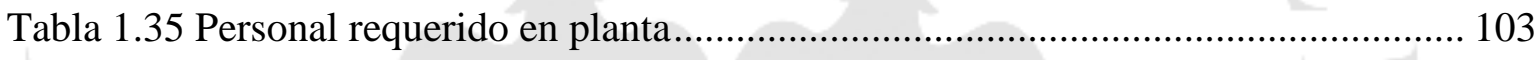

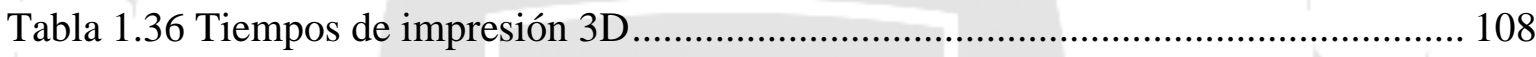

Tabla 1.37 Resumen de tiempo de proceso de proceso de producción fabricado con

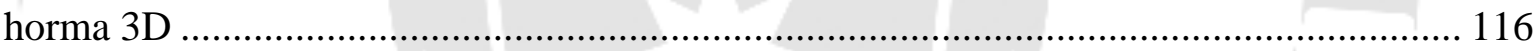

Tabla 1.38 Diagrama DAP calzado fabricado con horma 3D ....................................... 117

Tabla 1.39 Resumen de tiempo de proceso de proceso de producción fabricado con

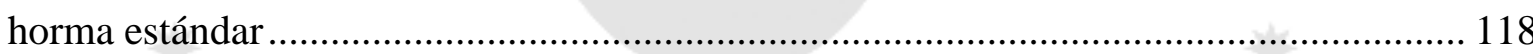

Tabla 1.40 Diagrama DAP calzado fabricado con horma estándar .................................. 118

Tabla 1.41 Análisis de tiempos de producción de cada proceso productivo ..................... 119

Tabla 1.42 Capacidad de producción en pares por mes.................................................. 121

Tabla 1.43 Producción de pares por día ......................................................................... 122

Tabla 1.44 Plan de producción de pares por semana ...................................................... 122

Tabla 1.45 Exceso de capacidad mensual ................................................................... 123

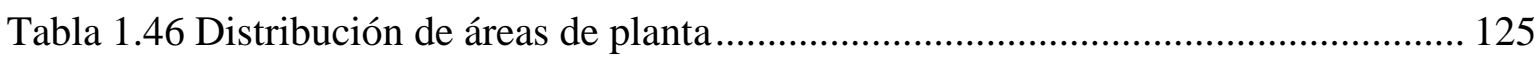

Tabla 1.47 Distribución de las áreas de punto de venta............................................... 127 


\section{CAPÍTULO II. ESTRUCTURA DE LA ORGANIZACIÓN}

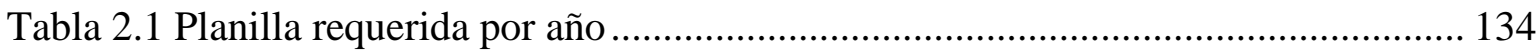

Tabla 2.2 Personal de destajeros requerido por año .................................................... 134

\section{CAPÍTULO III: EVALUACIÓN ECONÓMICA Y FINANCIERA}

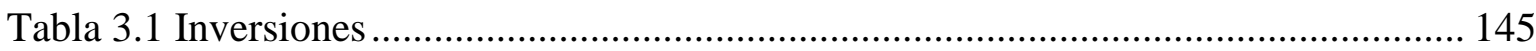

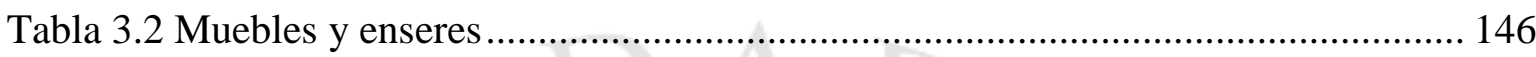

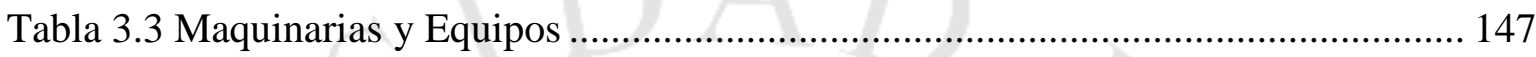

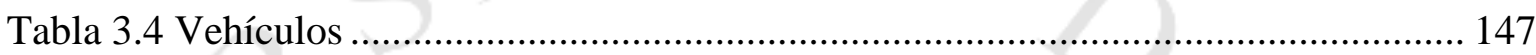

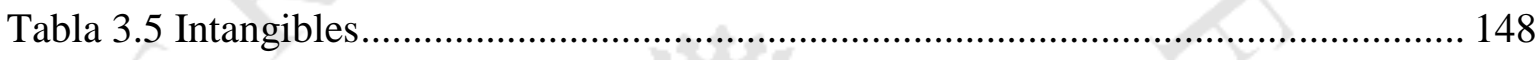

Tabla 3.6 Inversión futura en materia prima............................................................. 148

Tabla 3.7 Inversión futura en impresora 3D ............................................................ 149

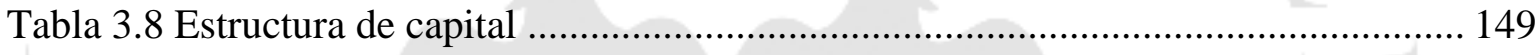

Tabla 3.9 Estructura de amortización de la deuda .................................................... 150

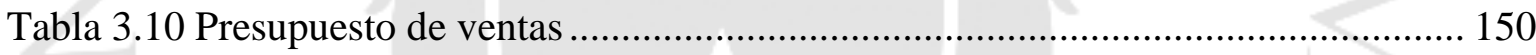

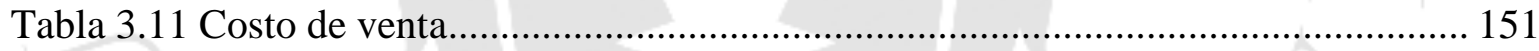

Tabla 3.12 Presupuesto de costo de venta ................................................................. 152

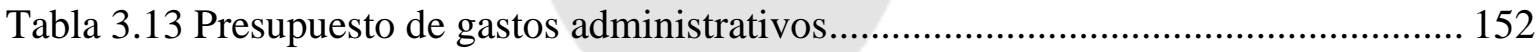

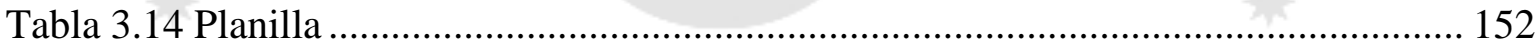

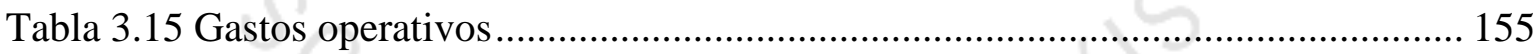

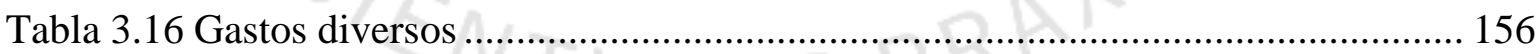

Tabla 3.17 Depreciación y Amortización ........................................................................ 157

Tabla 3.18 Estado de ganancias y pérdidas ............................................................... 158

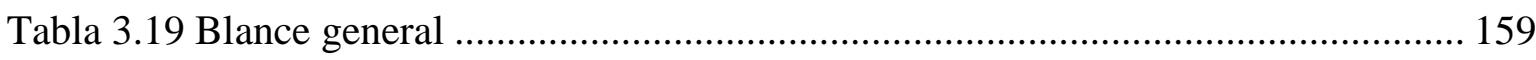

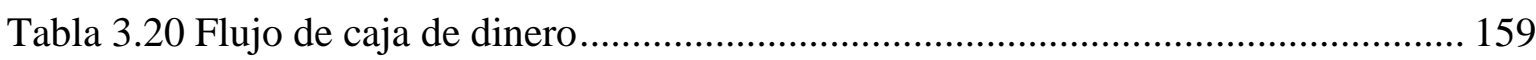

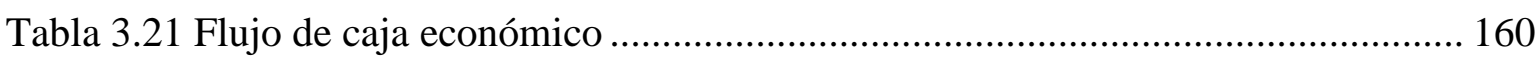

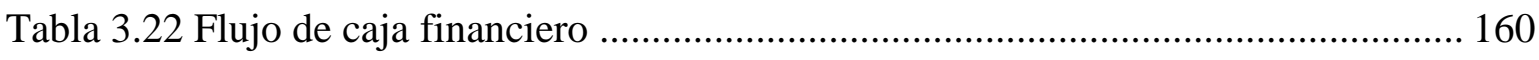


Tabla 3.23 Análisis de escenarios 161

Tabla 3.24 Estimación de la tasa de descuento del plan de negocio COK y WACC 161

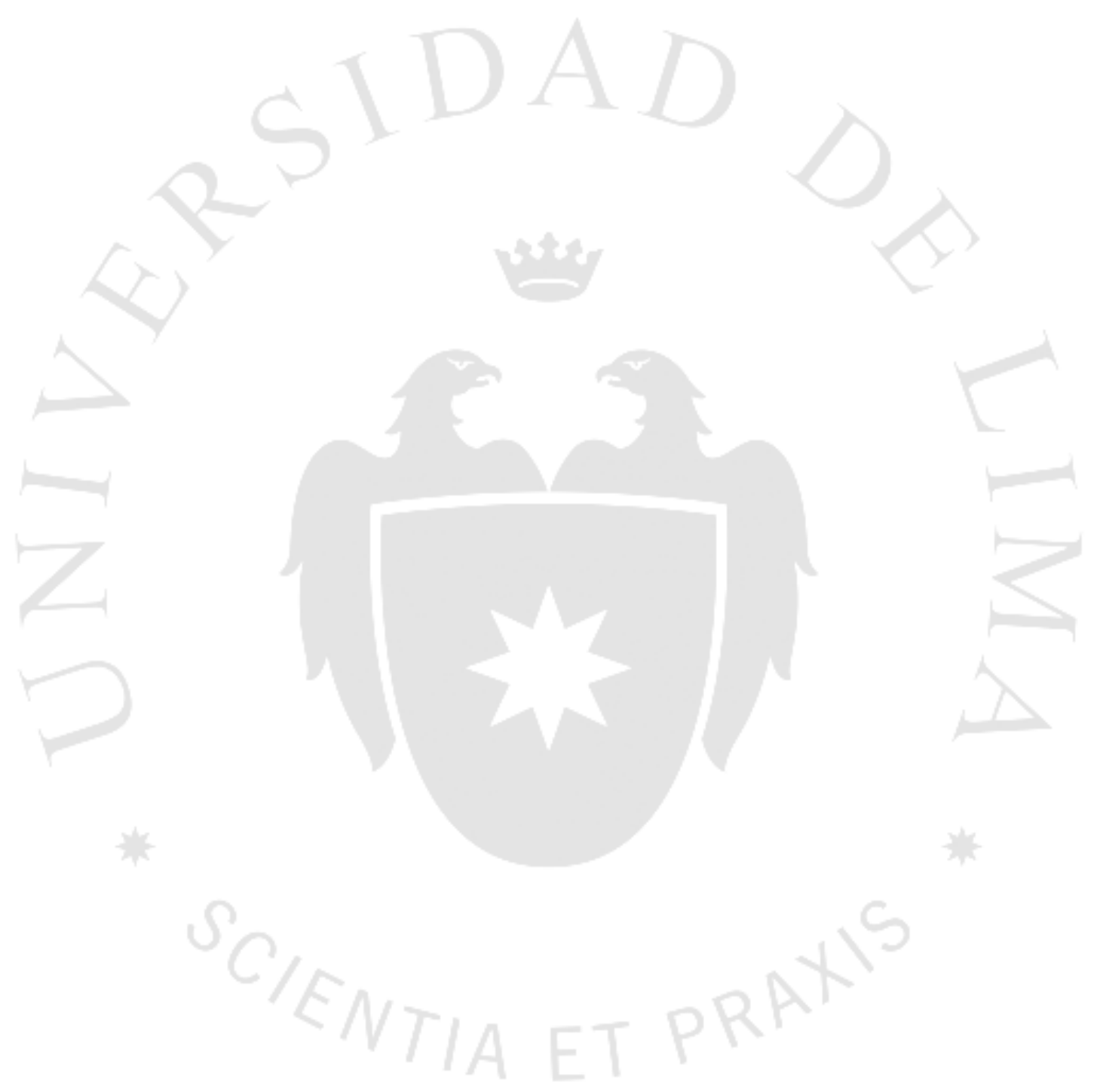




\section{ÍNDICE DE FIGURAS}

\section{CAPÍTULO I. MARCO CONCEPTUAL Y ESTUDIO DEL MERCADO}

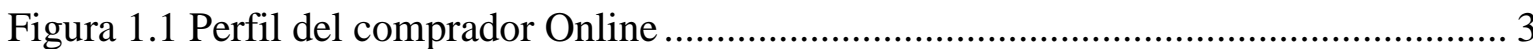

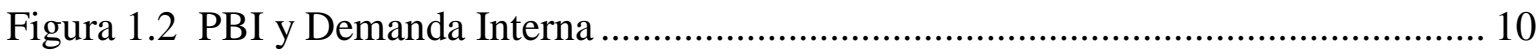

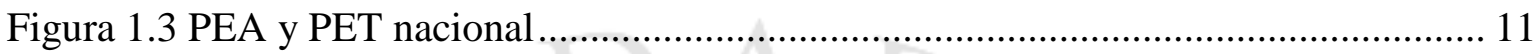

Figura 1.4 Análisis por edad, NSE y ocupación del internauta peruano ............................ 14

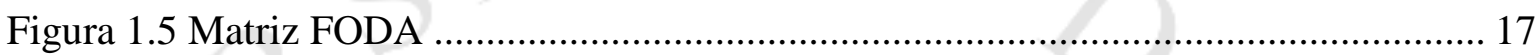

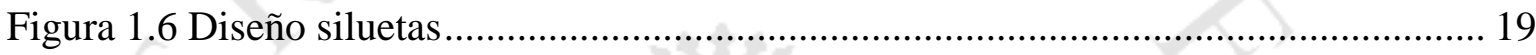

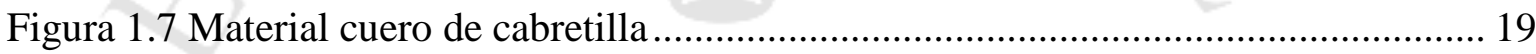

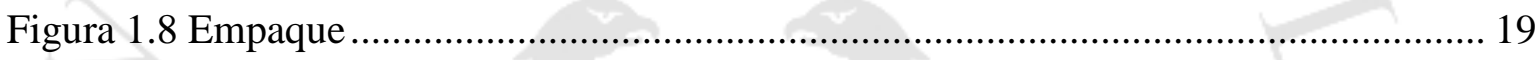

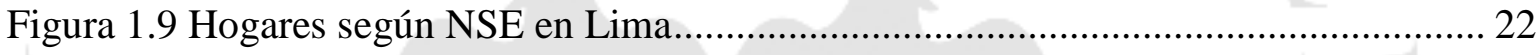

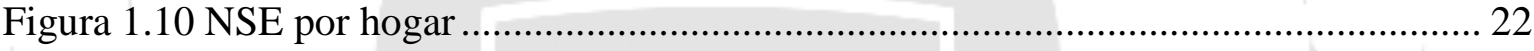

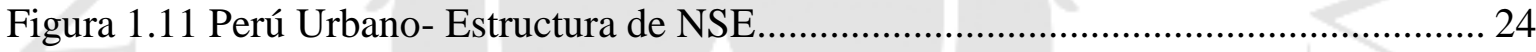

Figura 1.12 Estructura de Ingresos en Perú ................................................................... 25

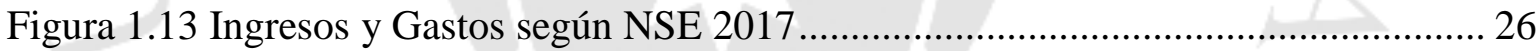

Figura 1.14 Ingreso Promedio Mensual por Genero 2016............................................. 27

Figura 1.15 Variación Producción Manufacturera de Calzado............................................ 28

Figura 1.16 Importación de calzados, por país de origen en el 2016 ................................ 30

Figura 1.17 Importación de calzados, por país de origen en el 2016 (Porcentaje) .............. 31

Figura 1.18 Demanda de la Producción de Calzado ........................................................ 33

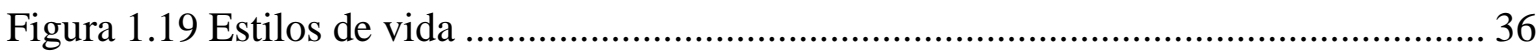

Figura 1.120 Encuesta ¿Utilizarías una aplicación virtual para personalizar y diseñar tus

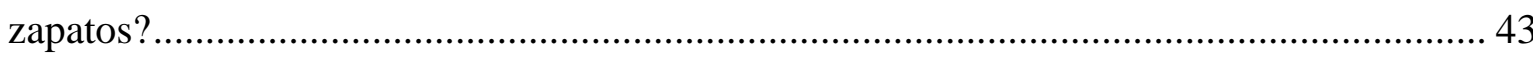

Figura 1.21 ¿Comprarías tus zapatos por Internet? ........................................................ 44

Figura 1.22 ¿Cuántos pares de calzado de cuero compras al año? ................................... 45 
Figura 1.23 Competidores

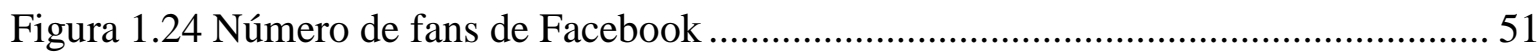

Figura 1.25 Nivel de compromiso Facebook ............................................................ 51

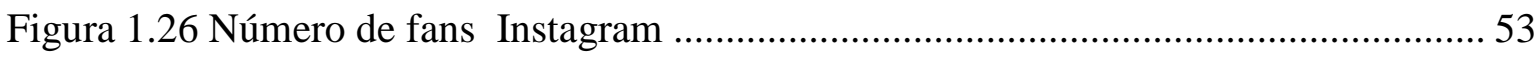

Figura 1.27 Nivel de Compromiso Instagram ................................................................ 53

Figura 1.28 Factores de segmentación de mercado ..................................................... 55

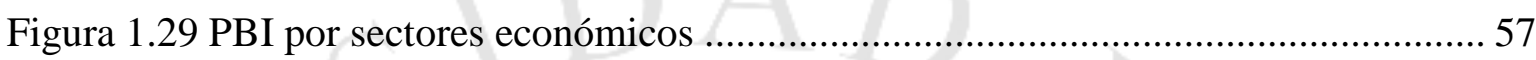

Figura 1.30 Encuesta ¿Que atributos considera importante al momento de comprar un

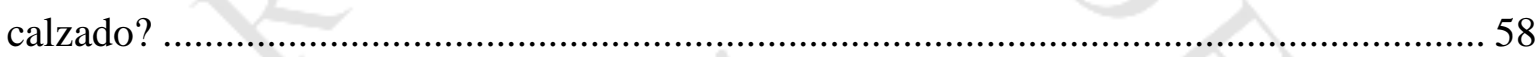

Figura 1.31 Encuesta ¿Comprarías tus zapatos por internet? ......................................... 59

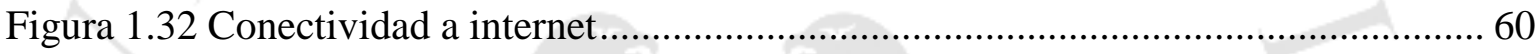

Figura 1.33 Encuesta ¿Por qué no comprarías tus zapatos por internet? ............................. 60

Figura 1.34 Propuesta de valor del modelo de negocio ................................................. 61

Figura 1.35 Cuadro Flujograma del Proceso de Personalización del Calzado .................... 63

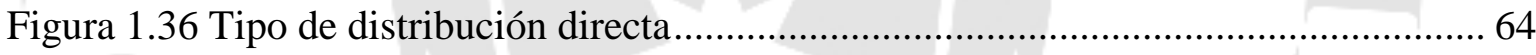

Figura 1.37 ¿Qué canal de venta prefieres para comprar tus zapatos? .............................. 65

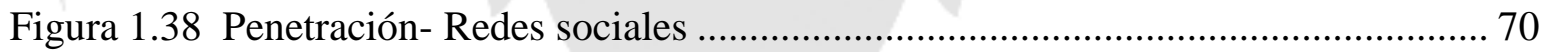

Figura 1.39 Plantilla de Facebook de Artesanas .......................................................... 72

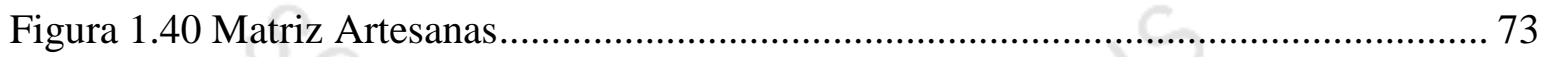

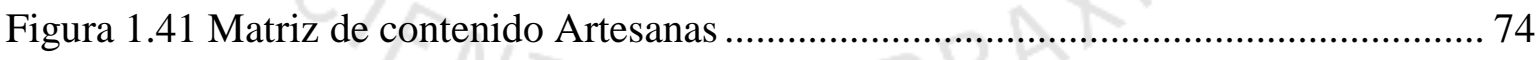

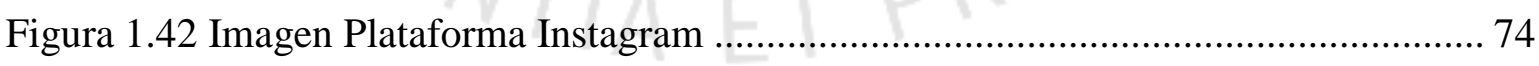

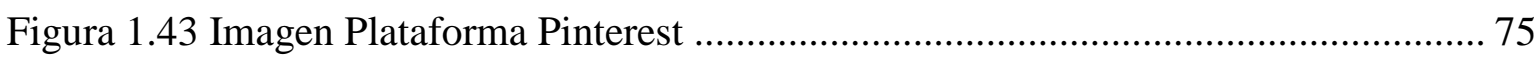

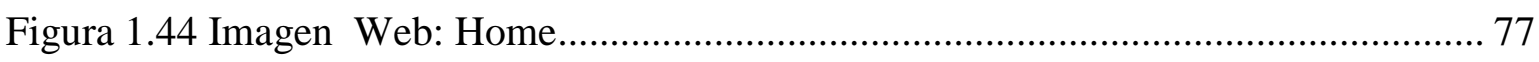

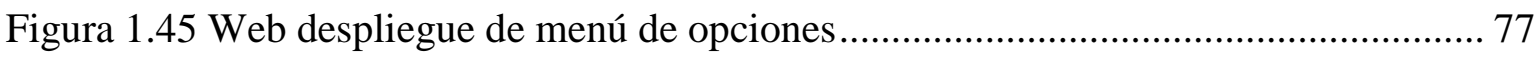

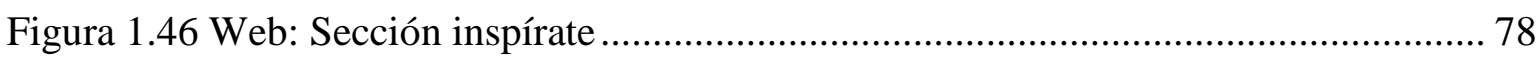

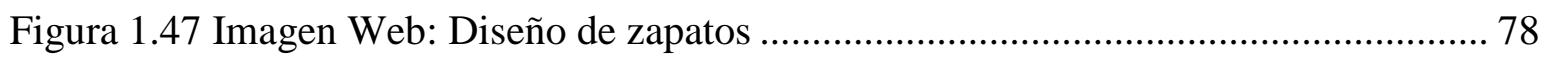


Figura 1.48 Web: Selección de tipo de horma

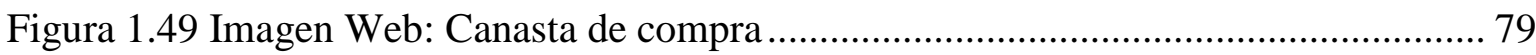

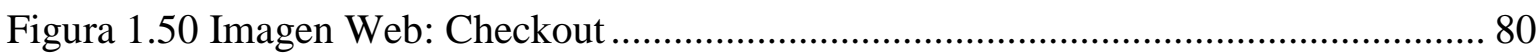

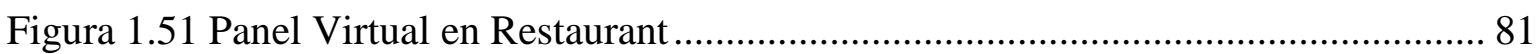

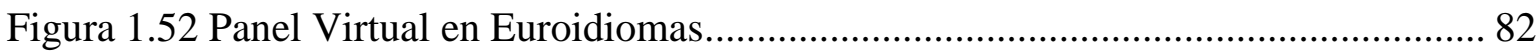

Figura 1.53 Target de la revista Peruvian de Media ....................................................... 83

Figura 1.54 Precios al consumidor de Calzado en Lima Metropolitana............................. 87

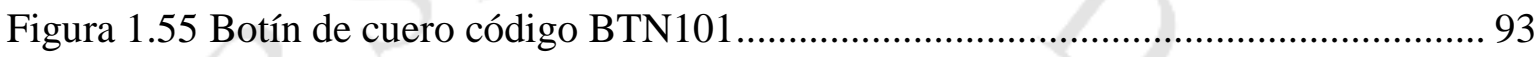

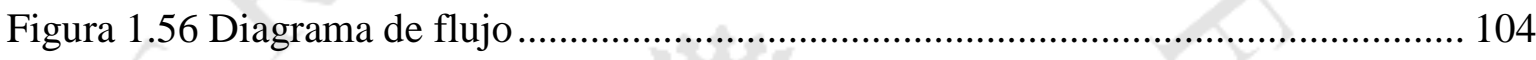

Figura 1.57 Software Rhinoceros para diseño de calzado ............................................ 105

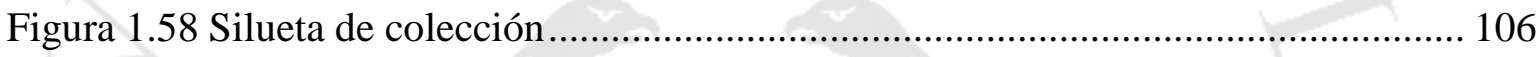

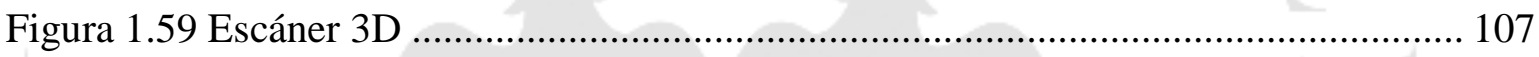

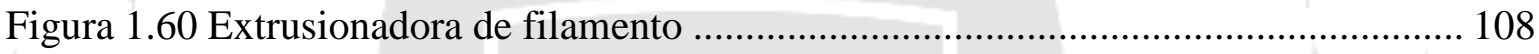

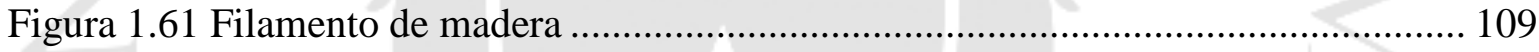

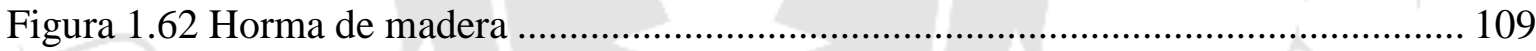

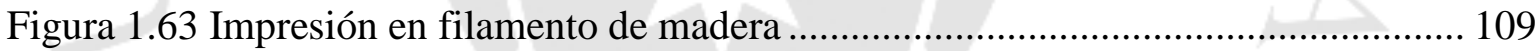

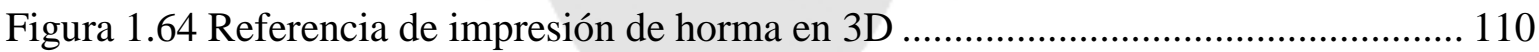

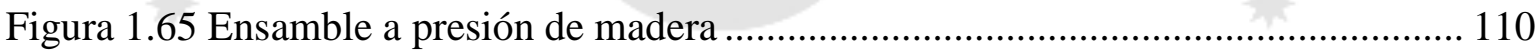

Figura 1.66 Ahorro de impresión por capas .......................................................... 111

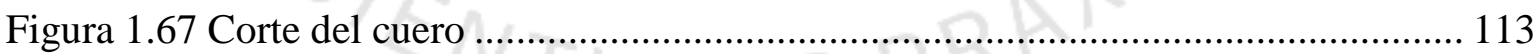

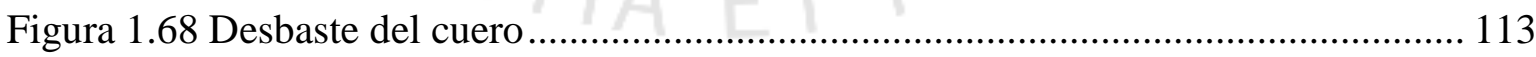

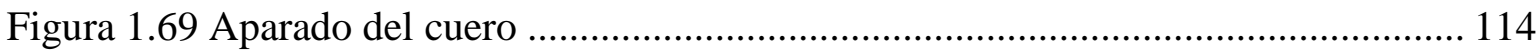

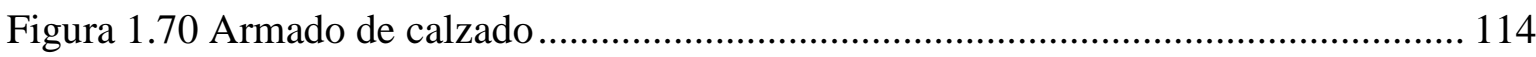

Figura 1.71 Acabado de calzado ............................................................................... 115

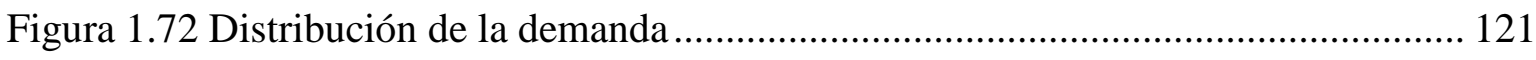

Figura 1.73 Diseño de plano de planta de producción.................................................. 124 


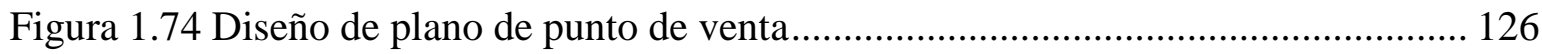

Figura 1.75 Impresión de tacos en 3D en filamento de PVC ......................................... 128

\section{CAPÍTULO II. ESTRUCTURA DE LA ORGANIZACIÓN}

Figura 2.1 Organigrama 


\section{INDICE DE ANEXOS}

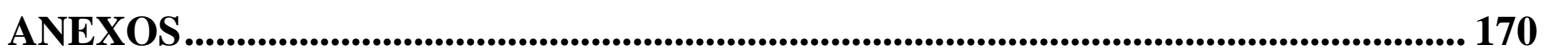

ANEXO 1: Guía de Indagación para el Focus Group ..................................................... 171

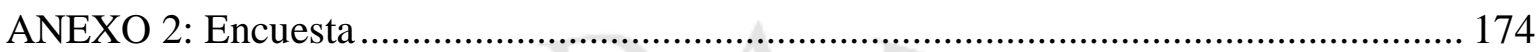

ANEXO 3: Proyección de pares vendidos por año..................................................... 178

ANEXO 4: Costo de producción de horma 3D ............................................................ 179

ANEXO 5: Costo de producción horma estándar........................................................... 180 


\section{INTRODUCCIÓN}

El proyecto presentado consiste en la producción y personalización de calzado femenino a través de una plataforma web, que permite al cliente diseñar su calzado de acuerdo a su estilo y gustos, donde el producto final será percibido como único.

Esta propuesta de negocio surgió de la idea de combinar el proceso de producción tradicional del calzado con la tecnología, para lo cual se realizó un estudio de mercado donde las encuestas indicaron que un $81 \%$ aceptaría personalizar y/o diseñar su calzado por medio de una plataforma virtual.

Nuestra propuesta incluye la tecnología, como factor principal para la creación, personalización y compra de calzado, debido a que en la actualidad el consumidor vive en un mundo totalmente digitalizado y busca herramientas que lo ayuden a ahorrar esfuerzo y tiempo en cualquier proceso de compra.

Artesanas busca desarrollar un producto que ayude a satisfacer una necesidad latente en el mercado, que es obtener una experiencia de creación y compra distinta, donde las mujeres podrán desarrollar su creatividad y plasmar su sello en cada diseño.

Nuestra propuesta de valor se basa en brindar al cliente la experiencia de la creación de su propio calzado a través de una plataforma virtual que permita al consumidor convertirse en el diseñador de su producto. 


\section{CAPÍTULO I. MARCO CONCEPTUAL Y ESTUDIO DE MERCADO}

\subsection{Marco Teórico}

\subsubsection{Introducción}

"En el 14vo Congreso Internacional de Retail 2017, donde el e-commerce y su situación en el 2017, fue uno de los temas más destacados. Se compartió que en el Perú ya son 3 millones de compradores online según el último estudio de IPSOS Apoyo. La tendencia de compradores, según se presentó en el congreso, ha venido en aumento desde el 2015 y a pesar de no ser una cifra tan alta, nos dice que el comercio electrónico se encuentra en movimiento. La penetración de los e-commerce ha crecido de manera importante en los NSE B y C, ya no es exclusivo del nivel socioeconómico AB."

"El comprador online peruano presentado en el Estudio de Ipsos Apoyo es del NSE $\mathrm{AB}$ y se encuentra en un rango de edad 25 a 35 años. Es trabajador dependiente y más del $50 \%$ son Millenials que viven conectados al mundo digital a través de un smartphone." 


\section{Figura $\mathrm{N}^{\circ} 1.1$}

\section{Perfil del comprador Online}

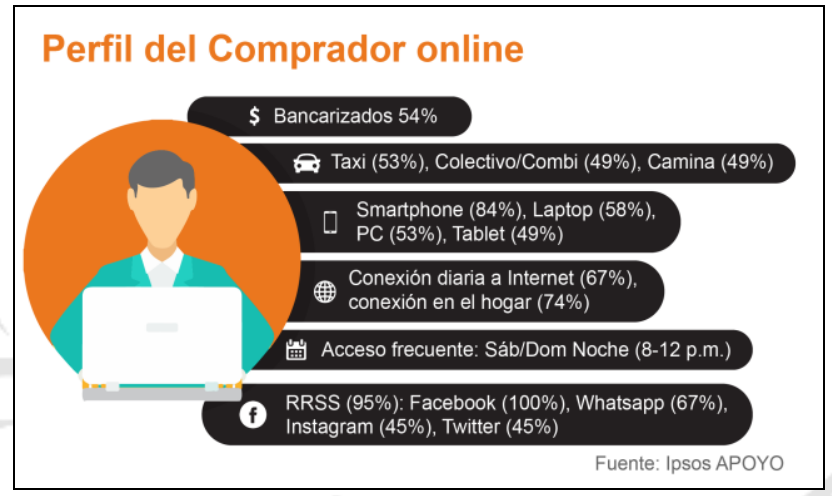

Fuente: Ipsos

“Las categorías más compradas en Internet según el estudio de Ipsos Apoyo son”:
a) Moda (calzado y ropa)
b) Electrónica (celulares y accesorios)
c) Hogar (juguetes y electrodomésticos)
d) Viajes (boletos de avión).

\section{“GFK presentó un estudio enfocado a los Millennials y el Ecommerce. Un resumen} de los hallazgos nos muestra que el $69 \%$ de los Millennials ${ }^{1}$ están conectados y de estos, la mayoría son Limeños del NSE AB."

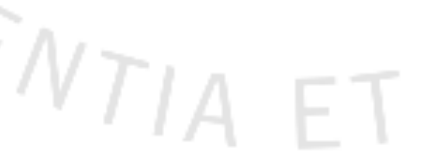

1 Millennias: También denominados Generación Y o Generación Peter Pan, los Millennials (Milenio) son las personas nacidas entre 1980 y 2000. Para los antropólogos del parentesco esta generación es la que le sigue a las Generación X y Baby Boomers, aquellas que se criaron entre conflictos bélicos e inestabilidad económica. 
"Los Millenials investigan en Internet antes de comprar (69\%) y comparan precios (67\%). Sin embargo, suelen ser menos leales a cualquier retail porque buscan la mejor relación precio-calidad (15\%) por lo que consideran que realizan una compra inteligente."

Bajo esta premisa, es una realidad que los smarthphone se han vuelto un canal común de comercio, lo cual se logra a través de aplicaciones que se componen de una interfaz amigable y práctica. Estas se mantienen en constante actualización e innovación con el fin de mantener el interés del usuario.

Esta nueva tendencia obliga a los comercios tradicionales a innovar en e-commerce con el objetivo de obtener su pedazo de la torta en participación de mercado.

Considerando estos hechos, la presente tesis busca realizar un estudio de prefactibilidad para la puesta de un negocio que consiste en la creación de una plataforma web que permita personalizar y diseñar calzado para damas en cuero para su posterior fabricación y entrega al usuario.

El planteamiento de este nuevo esquema de compra persigue romper el esquema tradicional de oferta en retail Push y convertirlo en Pull, el cual se centra en adaptarse a las necesidades del consumidor.

\subsubsection{Objetivos}

El presente proyecto tiene como objetivo, generar la puesta en marcha de un negocio empresarial a corto plazo en la ciudad de Lima.

\footnotetext{
${ }^{2}$ Fuente: http://blogs.gestion.pe/innovaciondisrupcion/2017/03/comercio-electronico-en-el-peru-2017.html
} 
Los objetivos específicos incluyen:

- Obtener un margen bruto de $70 \%$ por par de calzado.

- Conseguir un crecimiento anual del $7 \%$.

- Optimizar y modernizar el proceso productivo de calzado tradicional para que permita mayor flexibilidad de producción con el fin lograr una merma inferior al $1 \%$.

\subsubsection{Definición del producto o servicio}

El negocio busca comercializar calzado para damas en cuero cabretilla, también conocido como cuero guante, con interior de badana dirigido a damas que conforman la PEA, B y C a nivel de Lima Metropolitana entre 25 y 59 años, en los estilos sandalia de planta casual y de vestir para la temporada de verano y botines y botas en la temporada de invierno, mediante la personalización de los productos a través de una plataforma web.

Para darle un mayor valor agregado al cliente, el modelo de negocio de la presente tesis propone fabricar un calzado, además de ser personalizado, fabricarlo a la medida utilizando un scanner 3D para obtener las medidas del pie del cliente, para posteriormente imprimir su horma en filamento de madera en una impresora 3D.

Para la consecución de precios competitivos y buenos márgenes se plantea implementar un taller de producción que cuente con las maquinarias y herramientas básicas necesarias para el abastecimiento de productos.

\subsubsection{Investigaciones previas}

Actualmente existen dos empresas (Made in me y Custom and chic) que ejecutan el modelo de negocio de fabricar calzado personalizado a través de una plataforma web en España, 
sin embargo, ambas trabajan con un alto margen de error y devolución debido a que utilizan hormas estándar para la elaboración de los productos.

El modelo de negocio en propuesta a la fecha no ha sido aplicado por ninguna empresa a nivel nacional. Sólo existe la alternativa de acudir a las renovadoras de calzado si se desea un calzado con medidas y colores especiales. Servicio que en su mayoría toma hasta dos semanas y con alto grado de imprecisión sobre el producto puesto que el proceso es íntegramente manual, empezando desde la horma.

La deficiencia del servicio que se encuentra en el mercado nacional y los altos precios y margen de error ofrecidos por las empresas extranjeras conlleva a observar que existe una demanda insatisfecha para los consumidores que deseen adquirir un par de zapatos personalizados y a la medida.

- Análisis del Micro Entorno

\section{Amenaza de ingreso de nuevos competidores (Media)}

Las barreras de ingreso pueden considerarse bajas, puesto que iniciar en el negocio no requiere de una alta inversión, ya sea para comercializar o producir. Amenaza Alta.

El costo de cambio en la industria de calzado es bajo para los clientes finales, ya que existe una gran variedad de oferta. Amenaza Alta.

Existen algunas marcas reconocidas en la comercialización de calzado de cuero y son reconocidas por nuestro público objetivo y por lo que tienen su lealtad. Amenaza Baja. 
En la industria de calzado existen economías a escala. Producir volúmenes mayores reduce el costo unitario del producto. Amenaza Baja.

Las empresas actuales tienen poca experiencia en la producción de calzado personalizado a la medida. Amenaza Alta.

\section{- Rivalidad entre empresas competidoras (Media)}

La industria de calzado en el Perú es fragmentada. De acuerdo con el censo nacional de industrias del Ministerio de Producción del año 2007, el universo de fabricantes de calzado era de 3765 , del cual el 42.2 por ciento se concentra en Lima. Adicionalmente debe considerarse los talleres informales de fabricación a nivel nacional. Esto demuestra que existe un gran número de micro, medianas y grandes empresas las cuales dirigen sus productos a diferentes sectores económicos. Rivalidad Alta.

Según un informe brindado por el Gerente de exportación de Azaleia Claudiomiro de Vargas en el 2014, el consumo per cápita de calzado en el Perú era de 2,2 pares al año, lo cual es bajo en comparación de las demás plazas de la región. En Chile y Brasil el promedio per cápita de calzados es de cuatro pares y en Estados Unidos de 7, precisó. Por lo que se puede deducir que la demanda es baja en nuestro país. Rivalidad Alta.

Por otra parte, se estila a que las tiendas o fabricantes renueven su colección cada estación e imponen la tendencia en colores o combinaciones. En nuestro caso si bien también se manejará una colección por temporada, los clientes tendrán la posibilidad de personalizar el modelo a través de la web. Este modelo de negocio nos diferenciará de la rivalidad de participación que en la actualidad mantiene el mercado. Rivalidad Baja. 
La inversión en la planta de producción, es moderada y la mano de obra es a destajo, lo cual resulta una barrera de salida baja. Rivalidad Baja.

\section{- Poder de negociación de los proveedores (Bajo)}

En el mercado existe una gran cantidad de proveedores de materias primas, los cuales brindan variedad en precio y calidad. Es por esta razón que su poder de negociación es bajo, puesto que se puede cambiar de proveedor sin que afecte al proceso productivo en costos como en tiempos.

Para el caso de servicios de costura del cuero o fresado de neolite, los proveedores si tienen un relativo poder de negociación en las tarifas de costo, debido a que son pocos los artesanos que pueden realizar un trabajo calificado. Poder de negociación alto.

- Amenaza de productos sustitutos (Alta)

Los productos sustitutos que se pueden encontrar en el mercado son:

- Calzado sintético de procedencia China, que se venden en retail, mercados mayoristas o cadenas de tiendas independientes. Estos tienden a ser económicos y de atractivos diseños, pero son reconocidos también por ser de baja calidad y durabilidad.

- Calzados de marcas reconocidas. Las marcas que están posicionadas en el mercado son las que marcan la referencia de precios tanto en calzado sintético como en cuero.

- Fabricantes de calzado Trujillano. Durante los últimos cinco años, los fabricantes trujillanos han buscado la especialización y han conseguido 
fabricar un producto con menor lead time y mejores acabados. Esto se ve reflejado en sus bajos costos. Generalmente se dedican a la venta mayorista.

Se puede llegar a la conclusión que existe una amenaza alta de los productos sustitutos, ya que tienen un precio bajo y pueden satisfacer de manera similar la necesidad del cliente, por lo que el costo de cambio es bajo. Es por ello que nuestro modelo de negocio tiene como ventaja el diseño personalizado resaltando la esencia del estilo del cliente, lo cual hace que nuestro producto sea único.

\section{- Poder de negociación de los clientes (Medio)}

La fidelidad del cliente puede ser volátil debido a que éste espera altos estándares de calidad al comprar calzado de cuero y puede cambiar de marca con facilidad si no encuentra la relación precio-producto.

El poder de los clientes del sector calzado en general es alto, ya que existe una gran oferta para la demanda.

Las empresas que fabrican calzado de alto diseño se concentran en un mercado en específico donde el poder de los consumidores es mediano ya que la finalidad de la empresa no es ser accesible a todo el mercado sino a un sector económico alto. El tamaño del mercado se reduce por lo que los compradores tienen un mayor poder. 


\section{- Análisis del Macro Entorno}

\section{- Factor económico}

\section{Oportunidad}

A pesar del decrecimiento económico del último año hasta el primer trimestre del presente año 2017, el segundo trimestre culminó con un incremento del $2.4 \%$ con respecto al mismo periodo del año anterior, explicado principalmente por el aumento del consumo final privado y las exportaciones de bienes y servicios.

Lo anterior refleja también un escenario positivo para la PEA que arroja una variación del $3.4 \%$ con respecto a segundo trimestre del año anterior.

Esto refleja un entorno económico positivo donde el poder adquisitivo de la población se ve beneficiado y abierto a consumir bienes y servicios fuera de los que corresponden a productos de primera necesidad.

Figura $\mathrm{N}^{\circ} 1.2$

PBI y Demanda Interna del 2008-I al 2017-II

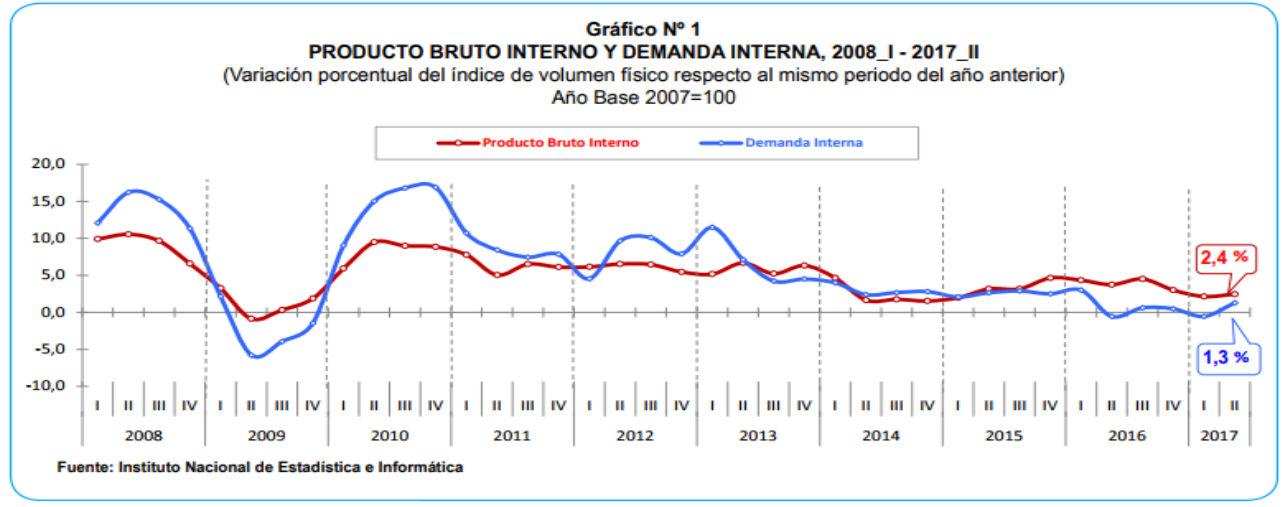

Fuente: INEI 
Figura $\mathrm{N}^{\circ} 1.3$

PEA y PET nacional

Lima Metropolitana: Población en edad de trabajar según condición de actividad Trimestre móvil: Junio-Julio-Agosto 2016 y 2017

(Miles de personas)

\begin{tabular}{|c|c|c|c|c|}
\hline \multirow{2}{*}{ Condición de actividad } & \multirow{2}{*}{$\begin{array}{c}\begin{array}{c}\text { Jun-Jul-Ago } \\
2016\end{array} \\
\text { Valor estimado }\end{array}$} & \multirow{2}{*}{$\begin{array}{c}\begin{array}{c}\text { Jun-Jul-Ago } \\
2017\end{array} \\
\begin{array}{c}\text { Valor } \\
\text { estimado }\end{array}\end{array}$} & \multicolumn{2}{|c|}{$\begin{array}{c}\text { Var. } \\
\text { Trimestre móvil }\end{array}$} \\
\hline & & & $\begin{array}{l}\text { Absoluta } \\
\text { (Miles) }\end{array}$ & (\%) \\
\hline Total de población en edad de trabajar (PET) & 7491,9 & 7604,7 & 112,8 & 1,5 \\
\hline Población económicamente activa (PEA) & 5080,2 & 5251,0 & 170,8 & 3,4 \\
\hline Ocupada & 4734,2 & 4900,5 & 166,3 & 3,5 \\
\hline Desocupada & 346,0 & 350,6 & 4,6 & 1,3 \\
\hline Población económicamente no activa (NO PEA) & 2411,7 & 2353,7 & $-58,0$ & $-2,4$ \\
\hline
\end{tabular}

Fuente: INEI

\section{Amenaza}

"Scotiabank revisó que desde noviembre de 2016 (S/ 3.44) el tipo de cambio ha configurado una tendencia descendente ubicándose en S/ 3.24, muy por debajo de las proyecciones del consenso del mercado (S/ 3.48 según la mediana de Focus Economics de enero 2017), pero en línea con su proyección (S/3.25) “.

“A pesar que los analistas han ajustado sus proyecciones para el 2017 hacia la baja, para el 2018 lo siguen viendo hacia el alza. Las proyecciones más recientes apuntan a un rango de entre $\mathrm{S} / 3.15$ y $\mathrm{S} / 3.66$, con una mediana de S/ 3.34, superior al S/ 3.30 del 2017. Este sesgo se repite en los sondeos realizados por el BCR entre analistas, sistema financiero $y$ empresas. "3

${ }^{3}$ Fuente: Diario Gestión Link:

http://gestion.pe/mercados/scotiabank-tipo-cambio-cerrara-2017-s-320-2199295 
La volatilidad del tipo del cambio puede afectar el precio del producto final, puesto que los insumos pueden verse afectados a nivel de costo.

\section{- Factor Social- Cultural}

\section{Oportunidad}

Si bien como mercado objetivo apunta al target mujer ejecutiva entre 25 a 59 años, existe un nicho muy interesante por explotar que es el de la comunidad LGTB. En cuanto a calzado, el colectivo gay, esta desatendido actualmente debido a que son hombres que calzan entre 40 y 44 que requieren de calzado femenino de colores al gusto del cliente.

El modelo de negocio atendería esta necesidad y ganaría terreno de los gastos derivados a compras en el extranjero por parte de este grupo de clientes.

Por otro lado, el promedio la estatura de la mujer en el Perú es de 1.68 metros, y otro nicho importante es el de mujeres de baja estatura que forman parte del intervalo de edad de nuestro público objetivo. Este grupo de clientas pueden llegar a calzar talla 33 o 34, abriendo nuevamente un nicho de mujeres que no encuentran calzado femenino de moda para su talla. Ya que la producción estándar de un taller o fábrica trabajan con la serie de tallas del 35 al 39.

De la misma manera puede cubrir una necesidad de calzado de temporada para mujeres que calzan entre 39 y 42. 


\section{Amenaza}

En el Perú los últimos años ha venido tomando fuerza los colectivos de defensa hacia los animales. Como ejemplo tenemos a la Escuela Vegana de Lima donde explican que ser vegano no solo implica evitar comer animales, sino también vestirlos.

Si bien la concientización es favorable en distintos sentidos para el medio ambiente, resulta una amenaza para el proyecto a futuro, aunque existe la posibilidad de reemplazar el cuero de vaca por cuero vegetal.

\section{- Factor Político}

\section{Oportunidad}

Las firmas de los tratados de libre comercio con los diferentes países es una oportunidad, ya que, a mayores desarrollos de negocio, mayor es la inversión y mayor es el poder adquisitivo de los consumidores.

\section{Amenaza}

Las constantes huelgas, paros y violencia por temas políticos que se dan en nuestro país, dan una imagen de inestabilidad política en el exterior, lo que puede conllevar a la disminución de la inversión por un riesgo político, lo que lleva a un decrecimiento de la economía peruana.

También el alto índice de corrupción a nivel nacional retrasa el desarrollo del país para dejar de ser un país tercermundista. 


\section{- Factor Tecnológico}

\section{Oportunidad}

De acuerdo con Ipsos, la cantidad de internautas que abarca nuestro target, va en ascenso.

Se entiende que existe más disposición año a año del consumidor peruano a la conectividad y a realizar compras virtuales.

Figura $\mathrm{N}^{\circ} 1.4$

Análisis por edad, NSE y ocupación del internauta peruano

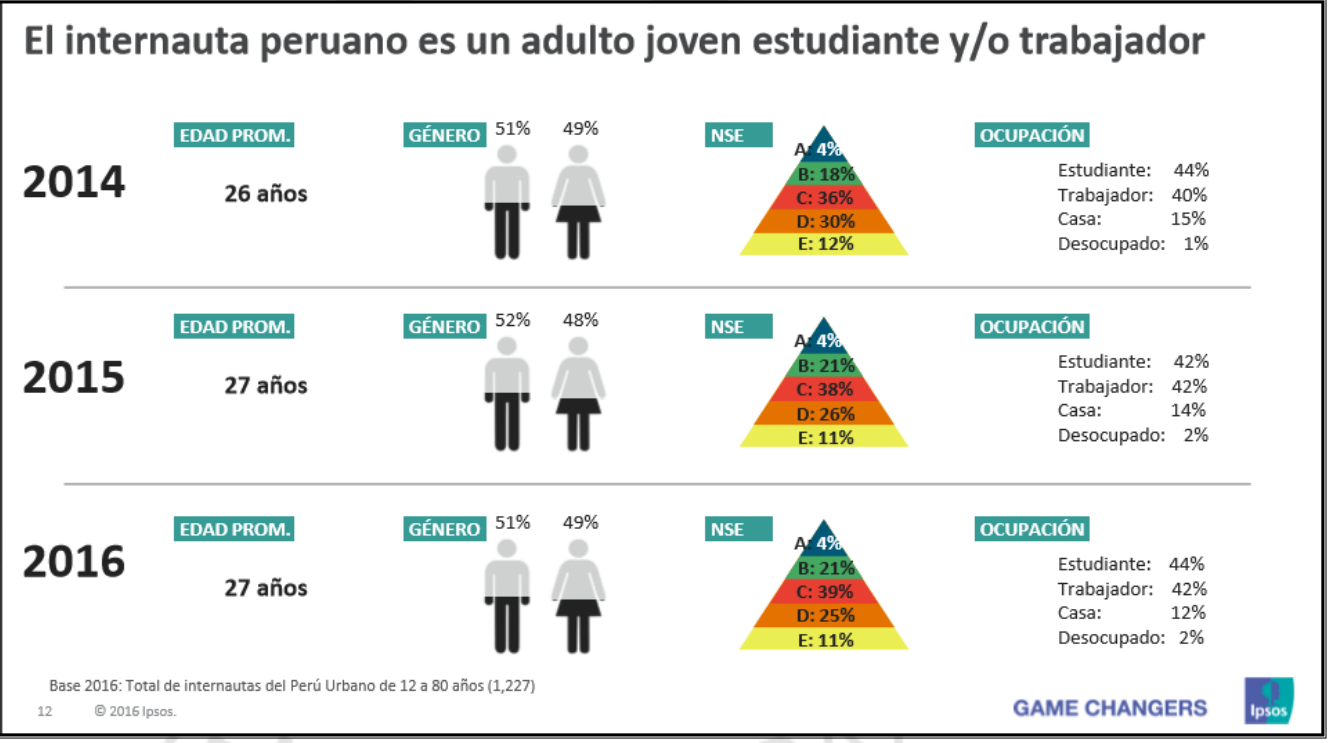

Fuente: Ipsos

\section{Amenaza}

Gracias al internet, las impresoras 3D pueden adquirirse en China a buenos precios, sin embargo, a nivel nacional existen pocas empresas que ofrecen esta tecnología. Esto representa una amenaza en el sentido de que para 
adquirir un repuesto o mantenimiento inmediato se debe recurrir a las empresas nacionales que brindan sus servicios a altos precios.

\section{- Ecológico}

\section{Oportunidad}

La industria del calzado ha tratado de mitigar su impacto ambiental a través de buenas prácticas medio ambientales como reciclaje, mantener limpieza en los procesos y la transformación de residuos en subproductos.

Ahora, la posibilidad de imprimir las hormas y la trituración de las mismas para la creación de filamento de madera, aporta a la conservación del medio ambiente, lo cual convierte el proyecto socialmente responsable.

\section{Amenaza}

La mayor amenaza proviene del impacto ambiental que generan las curtiembres a nivel nacional.

En un informe publicado por Greenpeace basado en un estudio de la UNEP (programa del cuidado del medio ambiente de las Naciones Unidas) menciona lo siguiente:

"Las curtiembres son un ejemplo de industrias con alto potencial de impacto ambiental y sobre la seguridad laboral." 
"Esto es consecuencia principalmente del uso de compuestos químicos para el curtido, solventes, pigmentos, etc. Que suelen ser tóxicos y persistentes, y afectar la salud humana y el medio ambiente. Los impactos incluyen efectos sobre las aguas donde se descargan los efluentes, el suelo, el agua subterránea, los sitios de disposición de los lodos de tratamiento y residuos sólidos, la calidad del aire y la salud humana (UNEP, 1991).”

El Ministerio del ambiente podría detectar como una alta amenaza ambiental la producción de esta materia prima, afectando los índices de fabricación de cuero, calzado y derivados a nivel nacional.

\subsubsection{Principales definiciones y conceptos}

La terminología cotidiana en el rubro de calzado que será expuesta a lo largo de la presente tesis, será explicada a continuación:

1. Modelaje: Diseñar un modelo determinado de calzado en la horma.

2. Seriado: Cantidad de pares por talla de calzado.

3. Cuero cabretilla: Piel fina curtida de un animal pequeño, como el cabrito, el cordero.

4. Badana: Piel curtida, suave y fina, de carnero u oveja. Normalmente utilizado para cubrir el interior del calzado.

5. Pies: Medida del cuero. Un pie equivale a un cuadrado de $30 \mathrm{~cm} \times 30 \mathrm{~cm}$.

6. Latex: Material de contextura suave utilizado en las plantillas.

7. Aparado: Unión de las piezas del cuero a través de la costura.

8. Armado: Moldear el cuero aparado a la horma.

9. Fresado: Proceso de lijar la suela o neolit 


\subsection{Análisis FODA}

Se presenta la matriz FODA a continuación.

Figura $\mathrm{N}^{\circ} 1.5$

Matriz FODA

\begin{tabular}{|c|c|c|}
\hline $\begin{array}{l}\text { MATRIZ } \\
\text { FODA } \\
\end{array}$ & $\begin{array}{l}\text { FUERZAS - F } \\
\text { 1. Know how sobre el proceso de fabricación de } \\
\text { calzado a la medida con uso de nuevas } \\
\text { tecnologias. } \\
\text { 2.Know how y experiencia de } 25 \text { años sobre el } \\
\text { mercado de calzado. } \\
\text { 3. Empresa pionera en ofrecer un producto } \\
\text { personalizado y a la medida. }\end{array}$ & $\begin{array}{l}\text { DEBILIDADES - D } \\
\text { 1. Mano de obra de alta rotación. } \\
\text { Trabajadores a destajo. } \\
\text { 2. Alta cantidad de proveedores informales. } \\
\text { 3. Posibles retrasos por rotación y baja } \\
\text { fidelidad de proveedores. }\end{array}$ \\
\hline $\begin{array}{l}\text { OPORTUNIDADES - O } \\
\text { 1. Existencia de un mercado insatisfecho } \\
\text { 2. Baja competencia. Empresa pionera. } \\
\text { 3. Crecimiento de la industria. }\end{array}$ & $\begin{array}{l}\text { ESTRATEGIAS - FO } \\
\text { 1. Asociarse con nuevos inversionistas para } \\
\text { abarcar en el corto plazo la mayor participación } \\
\text { de mercado. } \\
\text { 2. En el mediano plazo ejecutar estrategias para } \\
\text { expandir nuestro canal de ventas (Lima } \\
\text { Metropolitana, provincias y extranjero) }\end{array}$ & $\begin{array}{l}\text { ESTRATEGIAS - DO } \\
\begin{array}{l}\text { Iniciar programa de evaluación de } \\
\text { desempeño para estimular la permanencia } \\
\text { del personal. }\end{array} \\
\text { 2. Diseñar un programa de fidelización y } \\
\text { recompensas para clientes. }\end{array}$ \\
\hline $\begin{array}{l}\text { AMENAZAS - A } \\
\text { 1. Entrada de nuevos competidores } \\
\text { 2. Negativa de cambio de hábitos de compra } \\
\text { por parte del consumidor. } \\
\text { 3. Muchos productos sustitutos }\end{array}$ & $\begin{array}{l}\text { ESTRATEGIAS - FA } \\
\text { 1. Manejar diversos intervalos de precios para abarcar } \\
\text { clientes de diversos sectores económicos. ( relación } \\
\text { calidad de cuero/precio) } \\
\text { 2. Las acciones de marketing deben reforzar la } \\
\text { estrategia de diferenciación de producto. }\end{array}$ & $\begin{array}{l}\text { ESTRATEGIAS - DA } \\
\text { 1. Diseñar y realizar un programa de } \\
\text { desarrollo de talento humano. } \\
\text { 2. Llegar a acuerdos con proveedores JIT. }\end{array}$ \\
\hline
\end{tabular}




\subsection{Estudio de Mercado}

\subsubsection{Principales características de los productos o servicios}

- Definición del Producto desde el punto de vista de su comercialización

En el mercado local existen muchos productos comercializados que compiten con nosotros, sin embargo, hemos optado por potenciar tres características fundamentales para asegurar el éxito de nuestro negocio:

- Material de Cuero.

- Producto Personalizado.

- Plataforma web para diseñar.

\section{- Producto Central}

Calzado de cuero para damas

- Nos centraremos en dos estilos por temporada:

Invierno. - Botas, botines y zapatos de vestir.

Verano. - Sandalia Casual y zapatos de vestir.

\section{- Producto Real}

Las características básicas del producto son las siguientes:

a) Nombre de la marca: ARTESANAS

b) Material: Cuero Cabretilla, el cual se obtiene de la piel fina curtida de un animal pequeño, como el cabrito, el cordero, etc. Se puede encontrar en diversas texturas como charol, gamuza, napa o labrado. 
c) Diseño: A través de un aplicativo Web el cliente podrá diseñar su propio estilo, eligiendo la textura, color y accesorios.

d) Empaque: Será entregado en una caja especial, en la tapa se dibujará el modelo del zapato y el nombre del cliente, ya que es su creación y se debe mostrar.

Figura $\mathrm{N}^{\circ} 1.6$

Diseño-siluetas

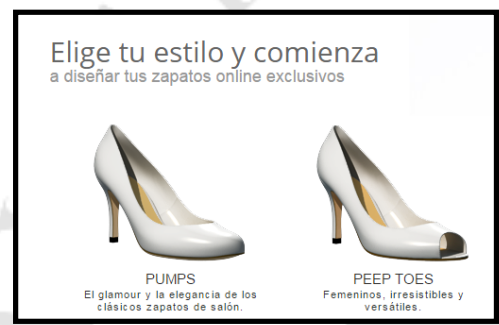

Fuente: Internet
Figura $\mathrm{N}^{\circ} 1.7$

Material-Cuero de Cabretilla

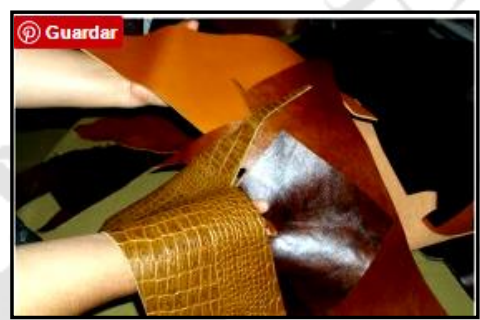

Fuente: Internet

Figura $\mathrm{N}^{\circ} 1.8$

Empaque

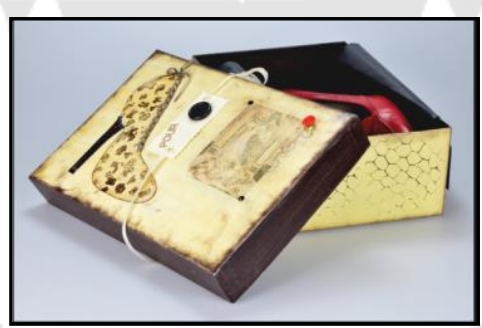

Fuente: Internet 


\section{- Producto Aumentado}

Prueba de calzado: Con la finalidad de reducir errores al obtener las medidas del pie del cliente, planteamos dos alternativas para el usuario:

a) Toma de medida del pie con scanner $3 \mathrm{~d}$ en nuestras instalaciones.

b) Medida a través de una plantilla descargada del aplicativo donde el usuario ingresa sus datos a nuestra base de datos.

c) Entrega a domicilio: En caso el cliente no pueda ir a recoger el producto a nuestras instalaciones, lo enviaremos por medio del servicio Olva Courier, el cual no tendrá un costo adicional.

\subsubsection{Bienes sustitutos y complementarios}

\section{- Sustitutos}

Dentro del rubro, los sustitutos serían el calzado de grandes marcas que ya se encuentran establecidas en el mercado nacional, pero que aún no han fusionado la tecnología con el diseño.

Adicional a ello tenemos los zapatos importados o de procedencia China, los cuales se comercializan a un precio bajo.

Otro sustituto sería los zapatos sintéticos de diferentes materiales como polipiel o cuero vegetal, que son descritos a continuación:

a) Polipiel: Es un material sintético que se usa en la fabricación de prendas de ropa, calzado, decoración y tapicería. Su composición es cien por cien 
sintética (fibras como el poliéster cubiertas de capas de polímero) y presenta una gran elasticidad y resistencia.

b) El cuero Vegetal: Es una manta de látex de caucho con tela de algodón. Se consigue extrayendo el látex de los árboles de Shiringa, mezclándolo con tintes naturales y luego untándolo sobre tela de algodón tensada o secándolo al vapor.

La Shiringa es un árbol que crece exclusivamente en la Amazonía y tiene un su interior un líquido lechoso llamado látex, el cual al ser extraído y mediante un proceso artesanal, es convertido en mantas de látex y algodón, que tiene un parecido al cuero".

\section{- Complementarios}

Los productos complementarios al calzado, son las correas, bolsos y billeteras que pueden combinar con el productor central.

\subsubsection{Determinación del Área Geográfica}

El estudio de mercado está compuesto por las mujeres de los niveles socioeconómicos B y C entre los 25 a 59 años de edad. 
Figura $\mathrm{N}^{\circ} 1.9$

\section{Hogares según NSE en Lima}

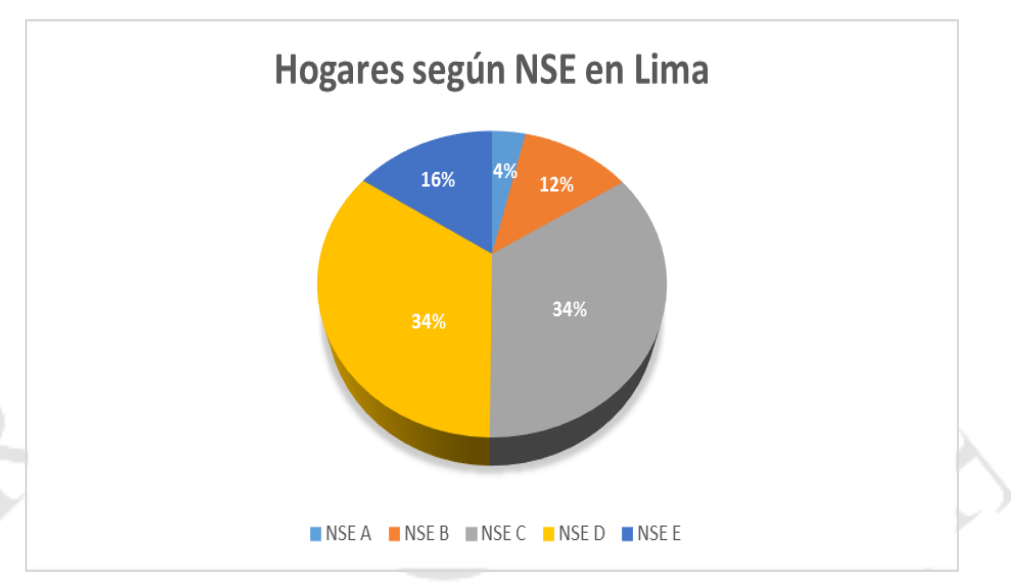

Elaboración: Propia

Figura $\mathrm{N}^{\circ} 1.10$

NSE por hogar

\section{Lima Metropolitana}

Información socioeconómica - NSE predominante en la manzana

\begin{tabular}{|c|c|c|c|c|c|c|c|}
\hline $\begin{array}{l}\text { NSE predominante de la manzana de } \\
\text { vivienda (2) }\end{array}$ & $\begin{array}{c}\text { lima } \\
\text { Metropolitana }\end{array}$ & Lima Norte & Lima Este & Lima Centro & Lima Moderna & Lima Sur & Callao \\
\hline NSE A & 3,104 & 7 & 52 & 8 & 2,872 & 163 & 2 \\
\hline NSE A1 & 511 & 0 & 1 & 0 & 487 & 23 & 0 \\
\hline NSE A2 & 2,593 & 7 & 51 & 8 & 2,385 & 140 & 2 \\
\hline NSE B & 10,129 & 1,013 & 1,308 & 1,211 & 4,660 & 1,144 & 793 \\
\hline NSE B1 & 4,611 & 401 & 599 & 260 & 2,598 & 451 & 302 \\
\hline NSE B2 & 5,518 & 612 & 709 & 951 & 2,062 & 693 & 491 \\
\hline NSE C & 28,383 & 8,341 & 7,793 & 2,599 & 1,156 & 5,735 & 2,759 \\
\hline NSE C1 & 11,274 & 3,598 & 2,431 & 1,117 & 763 & 2,080 & 1,285 \\
\hline NSE C2 & 17,109 & 4,743 & 5,362 & 1,482 & 393 & 3,655 & 1,474 \\
\hline NSE D & 28,314 & 7,914 & 9,356 & 732 & 124 & 6,194 & 3,994 \\
\hline NSE E & 13,025 & 3,720 & 3,128 & 262 & 43 & 4,397 & 1,475 \\
\hline Total & 82,955 & 20,995 & 21,637 & 4,812 & 8,855 & 17,633 & 9,023 \\
\hline
\end{tabular}

Fuente: Ipsos Perú: Mapinse 2017-INEI: Cartografía Oficial 2007 
"El crecimiento económico de los últimos 15 años ha generado profundas transformaciones en la estructura social, a tal punto que en vez de hablar de una pirámide, ahora es más factible encontrarnos con un rombo que aloja en su centro a una gran clase media". 4

En el 2004 apenas el 29\% de los hogares estaban considerados en los sectores socioeconómicos $\mathrm{B}$ y $\mathrm{C}$, es decir, clase media, y una década después la cifra alcanzó el 44\%, refirió Albuquerque al diario El Comercio.

Como se puede apreciar en el estudio realizado por APOYO en el 2017, en la actualidad los hogares pertenecientes a los niveles socioeconómicos $\mathrm{B}$ y C son el $46 \%$ del total de hogares en Lima y para el 2021 puede llegar al 52\% según declaraciones de Víctor Albuquerque director de análisis sectorial de APOYO. ${ }^{5}$

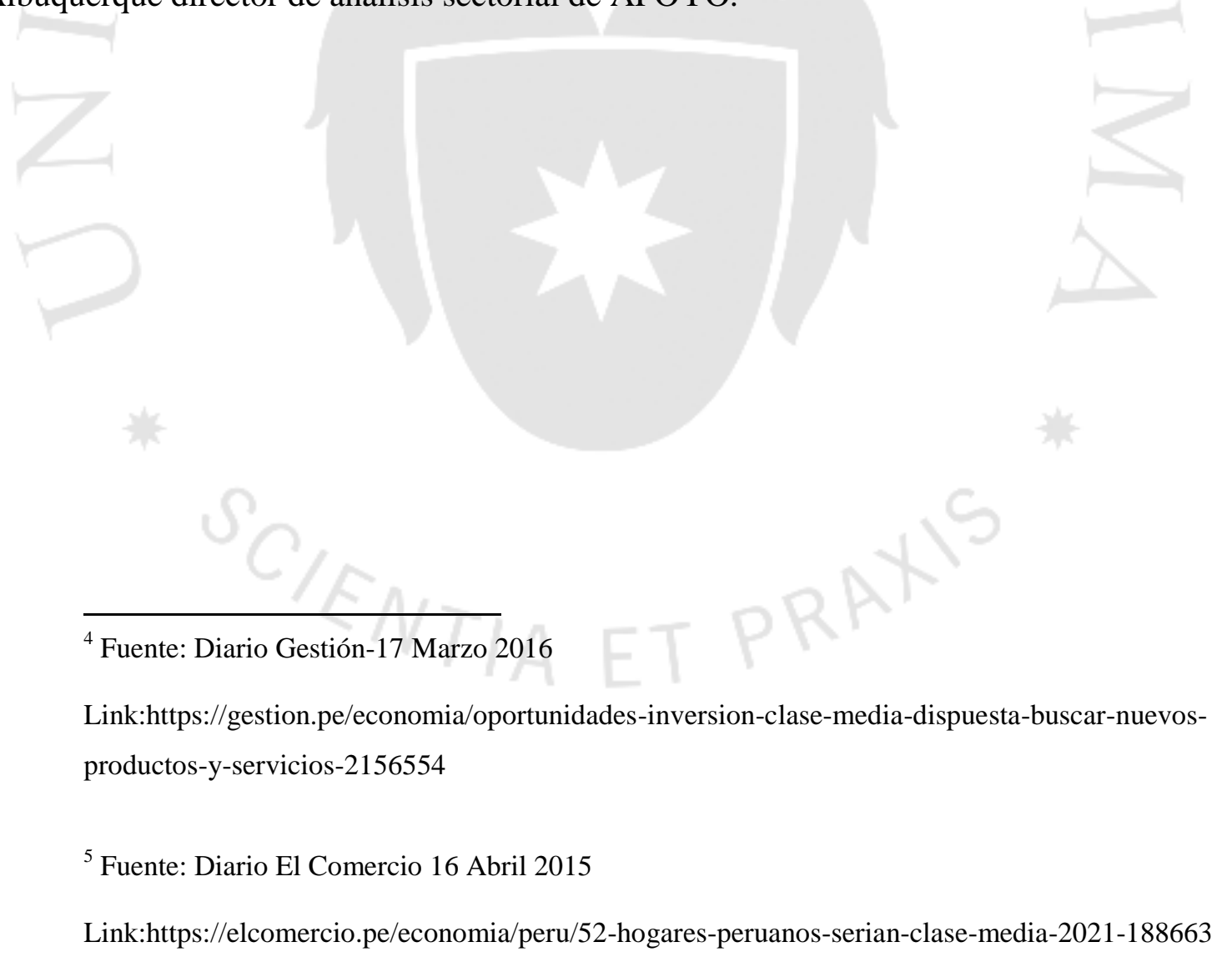


Figura $\mathrm{N}^{\circ} 1.11$

Perú Urbano- Estructura de NSE

Al 2021, la mitad de los hogares urbanos
podría ser de clase media

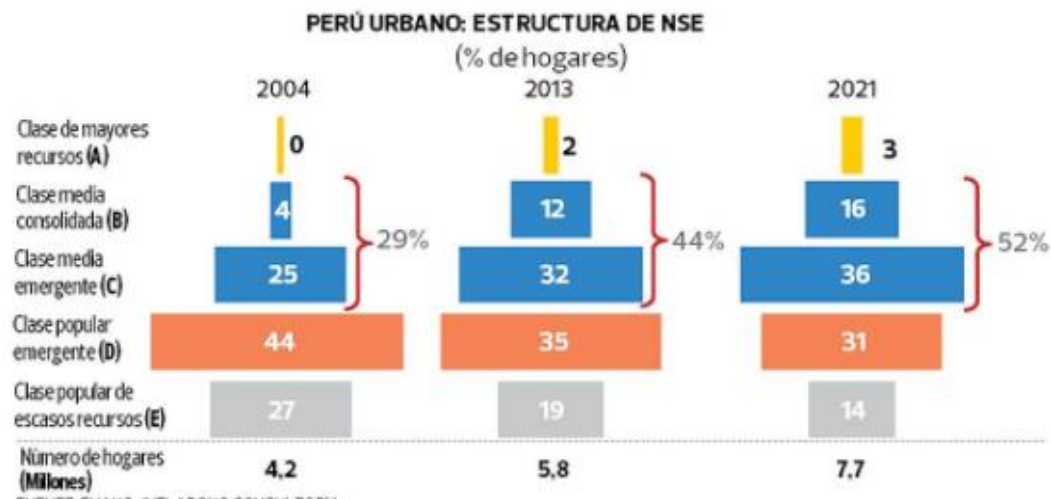

FUENTE: ENAHO-NE, APOYO CONSULTOPAA

Fuente: ENAHO-INEI-APOYO CONSULTORIA

El estudio "Un mercado creciente: descubriendo oportunidades en la base de la pirámide en Perú" elaborado por Arellano Marketing con apoyo del Banco Interamericano de Desarrollo (BID) identifica a un $37 \%$ de clase media consolidada, pero también un $38 \%$ emergente que no encuentra una oferta conforme a sus necesidades. (Marketing, 2016) ${ }^{6}$

\footnotetext{
${ }^{6}$ Fuente: Diario Gestión-17 Marzo 2016

Link:https://gestion.pe/economia/oportunidades-inversion-clase-media-dispuesta-buscar-nuevos-productos-yservicios-2156554
} 


\section{Figura $\mathrm{N}^{\circ} 1.12$}

Estructura de Ingresos en Perú

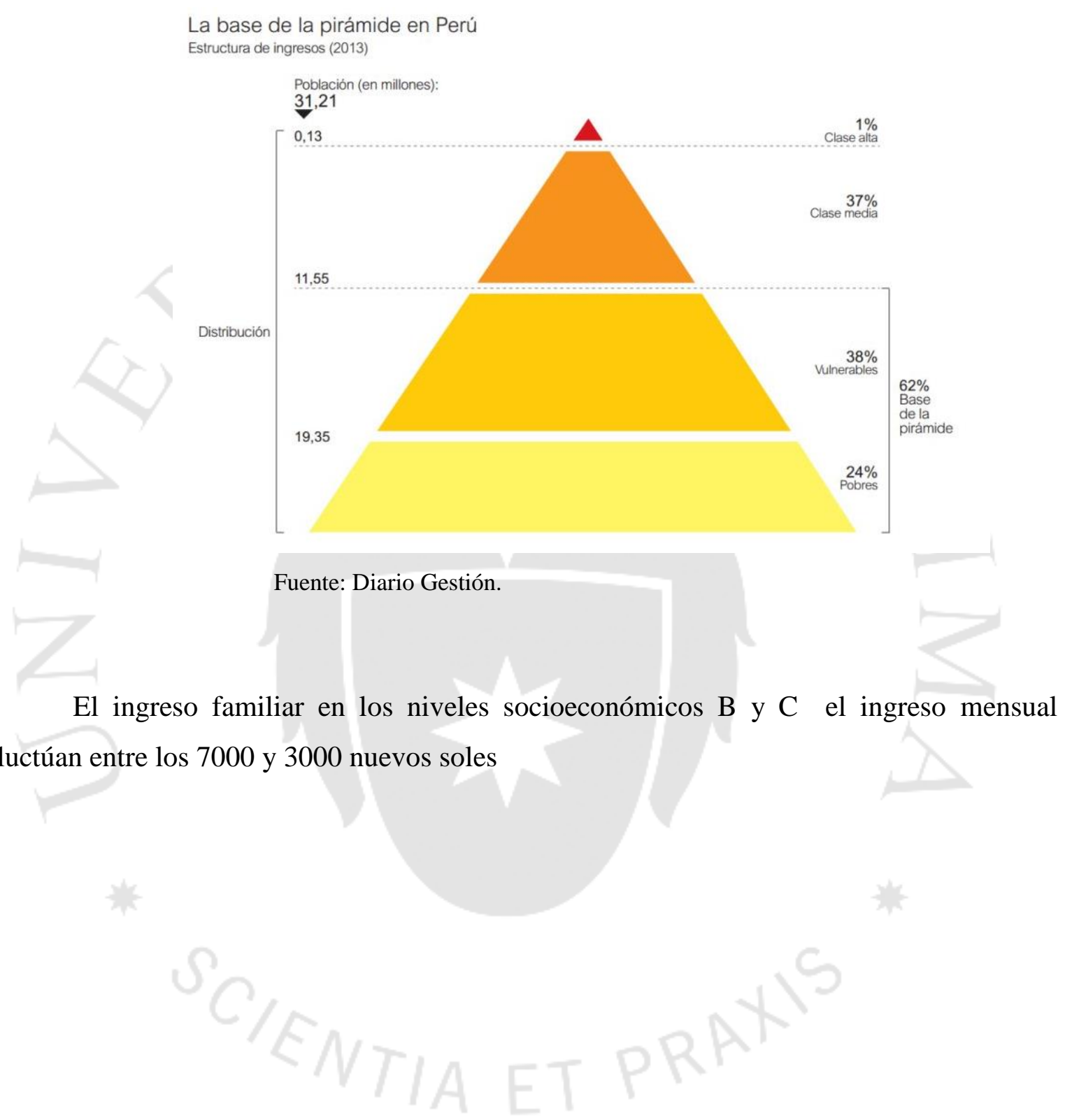


Figura $\mathrm{N}^{\circ} 1.13$

Ingresos y Gastos según NSE 2017

\begin{tabular}{|c|c|c|c|c|c|c|c|c|}
\hline Apeim & GAST & OS SEG & UÚN NS & E 2017 & - LIMA & A METR & OPOLIT & TANA \\
\hline \multirow[t]{2}{*}{ PROMEDIOS } & \multicolumn{8}{|c|}{ Lima Metropolitana } \\
\hline & TOTAL & NSEA & NSE B & NSEC & NSE C1 & NSE C2 & NSED & NSEE \\
\hline Grupo 1: Alimentos - gasto promedio & SI. 1,268 & SI. 1,582 & SI. 1,461 & SI. 1,286 & SI. 1,319 & SI. 1,227 & SI. 1,062 & Sl. 912 \\
\hline Grupo 2: Vesido y Calzado - gasto promedio & SI. 170 & SI. 333 & SI. 242 & Sl. 152 & Sl. 168 & Sl. 123 & Sl. 112 & SI. 98 \\
\hline $\begin{array}{l}\text { Grupo } 3 \text { : Alquiler de vivienda, Combustible, Electricidad y } \\
\text { Conservación de la Vivienda - gasto promedio } \\
\end{array}$ & SI. 472 & Sl. 998 & SI. 690 & SI. 429 & Sl. 453 & S1. 386 & Sl. 281 & Sl. 190 \\
\hline $\begin{array}{l}\text { Grupo } 4 \text { : Muebles, Enseres y Mantenimiento de la vivienda - gasto } \\
\text { promedio }\end{array}$ & S1. 205 & Sl. 1,068 & Sl. 293 & $\mathrm{Sl} .130$ & Sl. 140 & Sl. 112 & SI. 95 & \$1.78 \\
\hline $\begin{array}{l}\text { Grupo } 5 \text { : Cuidado, Conservación de la Salud y Servicios Médicos - } \\
\text { gasto promedio }\end{array}$ & S1. 253 & Sl. 609 & Sl. 355 & SI. 230 & SI. 262 & \$l. 173 & SI. 151 & S1. 100 \\
\hline Grupo 6 : Transportes y Comunicaciones - gasto promedio & S1. 405 & SI. 1,424 & SI. 668 & SI. 320 & SI. 355 & SI. 256 & SI. 147 & SI. 90 \\
\hline $\begin{array}{l}\text { Grupo } 7 \text { : Esparcimientio, Diversion, Servicios Culturales y de } \\
\text { Enseflanza - gasto promedio }\end{array}$ & SI. 475 & Sl. 1,321 & SI. 800 & SI. 380 & S1.423 & SI. 302 & \$l.219 & SI. 112 \\
\hline Grupo 8 : Otros bienes y servicios - gasto promedio & S1. 220 & SI. 465 & SI. 307 & Sl. 195 & S1. 209 & Sl. 169 & Sl. 142 & SI. 140 \\
\hline PROMEDIO GENERAL DE GASTO FAMILIAR MENSUAL & S1. 3,468 & $51.7,800$ & SI. 4,815 & S/. 3,122 & S1. 3,329 & SI. 2,748 & SI. 2,211 & SI. 1,719 \\
\hline PROMEDIO GENERAL DE INGRESO FAMILIAR MENSUAL* & S1. 5,006 & SI. 14,205 & S1.7,297 & SI.4,193 & \$1. 4,586 & SI. 3,483 & SI. 2,851 & S1. 2,120 \\
\hline
\end{tabular}

Fuente: Apeim 2017

Otro factor es la edad que se encuentra entre los 25 a 45 años, donde el último estudio del Instituto Nacional de Estadística e Informática indica que en el trimestre de setiembre a noviembre del 2016 en Lima Metropolitana, señala que el ingreso promedio de las mujeres aumentó en 7.8\% (S/ 100.6) siendo mayor que el de los hombres en 3.9\% (S/ 72.1), pero se sigue manteniendo la brecha pues las mujeres ganan el $72 \%$ del ingreso de los hombres. (INE, 2016). 
Figura $\mathrm{N}^{\circ} 1.14$

Ingreso Promedio Mensual por Genero 2016

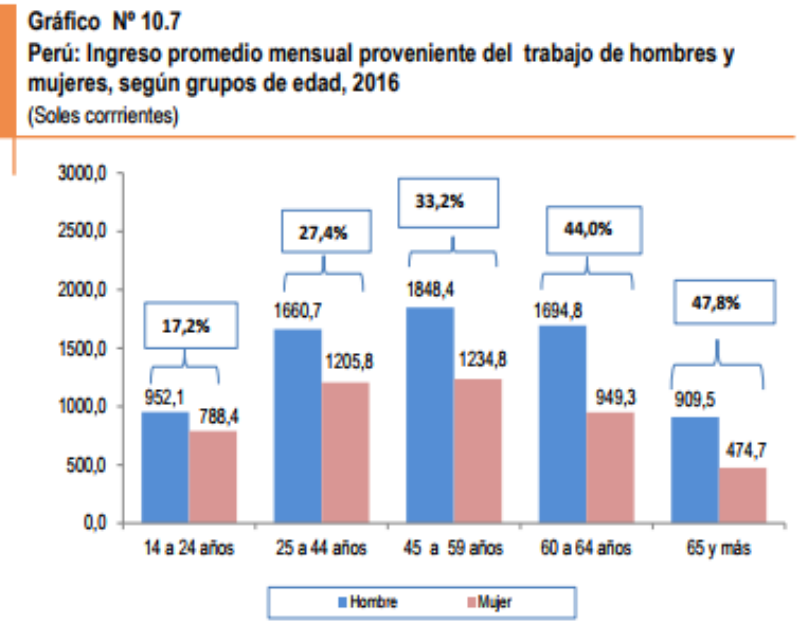

Fuente: Instituto Nacional de Estadistica e Informática-Encuesta Nacional de Hogares.

Fuente INEI

\subsection{Análisis de la demanda}

\subsubsection{Demanda histórica}

Durante los últimos años, la evolución de la producción de calzado ha tenido un comportamiento variable. Presentando las tasas de crecimiento negativas más significativas en los años 2005 y 2006. Entre el 2007 y 2009, experimentan tasas de crecimiento altamente positivas. Posteriormente, los años 2010 y 2011 obtuvieron resultados negativos, al igual que en el año 2014 y 2016. Los años 2012, 2013 y 2015 muestran tasas de crecimiento que fluctúan entre $3 \%$ y $7 \%$. Todo ello gráfica un comportamiento irregular en los últimos 10 años. (Reporte-Sectorial-de-Calzado-Enero-2017). ${ }^{7}$

\footnotetext{
${ }^{7}$ Fuente: Reporte Sectorial de Calzado-Enero-2017
} 
Figura $\mathrm{N}^{\circ} 1.15$

Variación Producción Manufacturera de Calzado

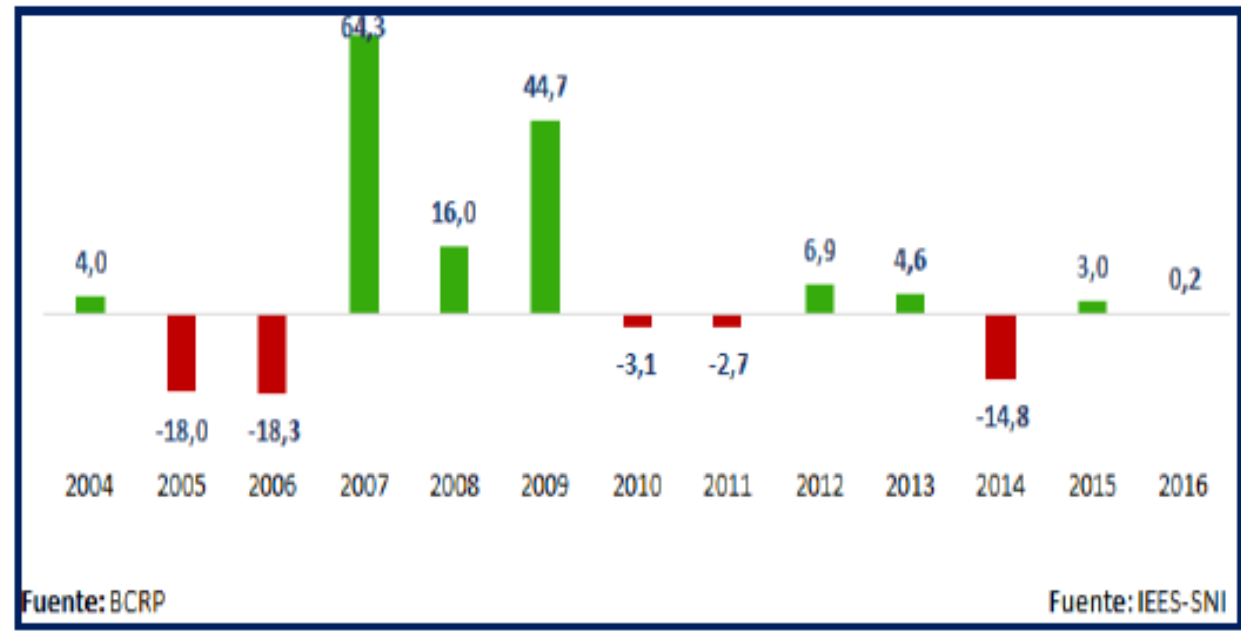

Fuente: BCRP-IEES.SNI

Para la elaboración del siguiente cuadro, la producción ha sido proyectada a partir del 2014 con la variación anual del índice de volumen físico de la producción manufacturera del calzado, según el Reporte-Sectorial de Calzado Enero-2017

Tabla $\mathrm{N}^{\circ} 1.1$

Variación anual de producción de calzado

\begin{tabular}{|c|c|c|c|c|c|}
\hline Fabricación de calzado & $\begin{array}{l}\text { Unidad } \\
\text { Medida }\end{array}$ & 2013 & 2014 & 2015 & 2016 \\
\hline Zapatos & par & $1,276,135$ & $1,172,072$ & $1,207,234$ & $1,209,649$ \\
\hline Zapatillas & par & $4,880,329$ & $4,696,644$ & $4,837,543$ & $4,847,218$ \\
\hline Botas, Botines & par & $3,392,964$ & $2,951,808$ & $3,040,362$ & $3,046,443$ \\
\hline Sandalias & par & $1,104,196$ & $1,211,328$ & $1,247,668$ & $1,250,163$ \\
\hline Total & par & $10,653,624$ & $10,031,852$ & $10,332,808$ & $10,353,473$ \\
\hline Variación anual (\%) & $\%$ & $4.60 \%$ & $-14.8 \%$ & $3 \%$ & $0.20 \%$ \\
\hline
\end{tabular}

Fuente: Ministerio de la Producción - Viceministerio de MYPE e Industria.

Fuente: Reporte-Sectorial-de-Calzado-Enero-2017

Elaboración: Propia 


\section{- Importaciones y Exportaciones}

Para analizar las importaciones y exportaciones se ha tomado en cuenta las siguientes partidas arancelarias.

Tabla $\mathrm{N}^{\circ} 1.2$

Descripción de las principales partidas arancelarias de calzado

\begin{tabular}{|c|c|}
\hline & Descripción de Partida \\
\hline 6401 & $\begin{array}{l}\text { Calzado impermeable con suela y parte superior de caucho o plástico cuya parte } \\
\text { superior no se haya unido a la suela por costura o por medio de remaches, clavos, } \\
\text { tornillos, espigas o dispositivos similares; ni se haya formado con diferentes. }\end{array}$ \\
\hline 6402 & Los demás calzados con suela y parte superior de caucho o plástico \\
\hline 6403 & $\begin{array}{l}\text { Calzado con suela de caucho, plástico, cuero natural o regenerado y parte superior de } \\
\text { cuero natural }\end{array}$ \\
\hline 6404 & $\begin{array}{l}\text { Calzado con suela de caucho, plástico, cuero natural o regenerado y parte superior de } \\
\text { cuero téxtil. }\end{array}$ \\
\hline 6405 & Los demás calzados. \\
\hline 6406 & $\begin{array}{l}\text { Partes de calzado( incluidas las partes superiores fijadas a las palmillas distintas de la } \\
\text { suela, plantillas, taloneras y artículo similares amovibles,polainas y artículos similares, } \\
\text { y sus partes }\end{array}$ \\
\hline
\end{tabular}

Fuente: Reporte-Sectorial-de-Calzado-Enero-2017

\section{Tabla $\mathrm{N}^{\circ} 1.3$}

Comercio exterior de calzado

\begin{tabular}{|lcrrr|}
\hline $\begin{array}{c}\text { Importaciones } \mathbf{y} \\
\text { Exportaciones de } \\
\text { Calzado }\end{array}$ & $\begin{array}{c}\text { Unidad } \\
\text { Medida }\end{array}$ & $\mathbf{2 0 1 4}$ & $\mathbf{2 0 1 5}$ & $\mathbf{2 0 1 6}$ \\
\hline Importación & $\mathrm{US} \$$ & $379,183,053$ & $397,170,846$ & $369,561,243$ \\
Exportación & $\mathrm{US} \$$ & $28,446,809$ & $27,274,698$ & $22,397,012$ \\
& $\mathrm{Kg}$ & $26,268,000$ & $27,664,000$ & $25,440,000$ \\
Importación & $\mathrm{kg}$ & $3,413,000$ & $3,844,000$ & $2,830,000$ \\
Exportación & &
\end{tabular}

Fuente: Reporte-Sectorial-de-Calzado-Enero-2017

Elaboración: Propia

Nota: Para la elaboración de este cuadro se ha tomado la suma total de las partidas arancelarias antes mencionadas, en dólares y kilos. 


\section{- Importaciones}

La mayor porción de estas importaciones provino de China, que representó el 54 $\%$ del total, seguido por Vietnam (19\%), Brasil (10\%) e Indonesia (7\%).

El Perú, durante el 2016, importó del mercado chino, especialmente productos del grupo conformado por calzado con suela de caucho, plástico, cuero natural o regenerado y parte superior de material textil (US\$ 90,6 millones). En tanto, las importaciones realizadas a Vietnam predominaron los calzados con suela de caucho, plástico, cuero natural o regenerado y parte superior de cuero textil (US\$ 40,6 millones).

Para el mismo periodo, de Brasil, provino principalmente los demás calzados con suela y parte superior de caucho o plástico (20,8 millones).

En tanto, de Indonesia, durante el 2016, se importó calzado con suela de caucho, plástico, cuero natural o regenerado y parte superior de materia textil (US\$ 13,4 millones). (Reporte-Sectorial-de-Calzado-Enero-2017).

Figura $\mathrm{N}^{\circ} 1.16$

Importación de calzados, por país de origen en el 2016 (Porcentaje)

“El 91,8\% de las importaciones de calzados, proviene de cinco países: China (US\$200,3 millones), Vietnam (US\$ 69,4 millones), Brasil (US\$ 37,6 millones), Indonesia (US\$ $25,9)$ e India (US\$ 5,9 millones)."

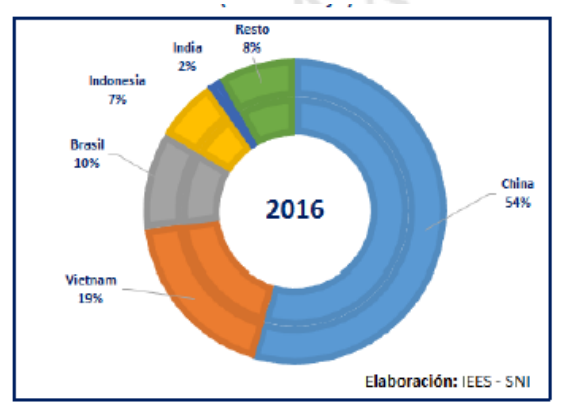

Fuente: Reporte-Sectorial-de-Calzado-Enero-2017 


\section{- Exportaciones}

Durante el 2016, las exportaciones de calzado alcanzaron los US\$ 22,4 millones, cifra menor en $17,9 \%$ a la registrada en el año 2015 , comportamiento que se originó por los menores despachos de calzado con suela de caucho, plástico, cuero natural o regenerado y parte superior de material natural, grupo de productos que descendió en 17,7\%.(Reporte-Sectorial-de-Calzado-Enero2017).

Para determinar la demanda se ha tomado el supuesto que el par de zapatos pesa $1 / 2$ Kilo, a partir de ello se puede calcular el consumo nacional.

Figura $\mathrm{N}^{\circ} 1.17$

Importación de calzados, por país de origen en el 2016 (Porcentaje)

El Gráfico $\mathrm{N}^{\circ} 11$, muestra la distribución de las exportaciones de calzado, según país de destino. En el 2016, la exportación de calzado se destinó principalmente a Chile (US\$ 6,1 millones), Estados Unidos (US\$ 4,2 millones), Colombia (US\$ 4,0 millones), Ecuador (US\$ 3,5 millones) y México (US\$ $730 \mathrm{mil}$ ).

Estos cinco países, concentran el $82,7 \%$ del total exportado de calzado.

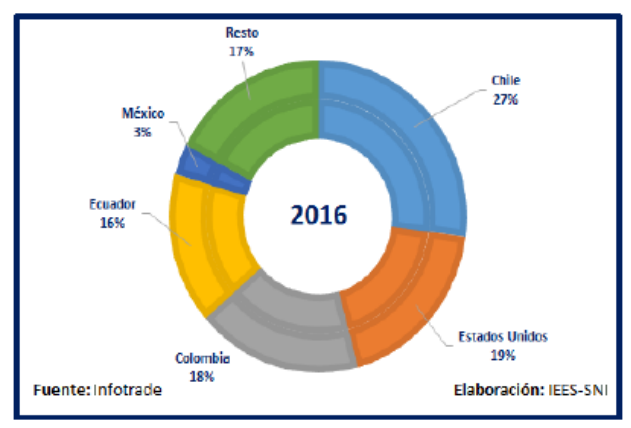

Fuente: Reporte-Sectorial-de-Calzado-Enero-2017 
Tabla $\mathrm{N}^{\circ} 1.4$

Consumo Nacional

\begin{tabular}{|c|c|c|c|c|}
\hline Demanda & $\begin{array}{l}\text { Unidad } \\
\text { Medida }\end{array}$ & 2014 & 2015 & 2016 \\
\hline Fabricacion Nacional & Par & $10,031,852$ & $10,332,808$ & $10,353,473$ \\
\hline Importación & Par & $52,536,000$ & $55,328,000$ & $50,880,000$ \\
\hline Exportación & Par & $6,826,000$ & $7,688,000$ & $5,660,000$ \\
\hline Total Nacional & Par & $55,741,852$ & $57,972,808$ & $55,573,473$ \\
\hline
\end{tabular}

Fuente: Elaboración Propia

Nota: Para proyectar se utilizó el promedio móvil simple.

Para hallar el consumo nacional, se utilizó la fórmula: Producción+ Importaciones-Exportaciones

\subsubsection{Demanda potencial y patrones de consumo}

En el mercado peruano, la producción de calzado, tanto de cuero y otro tipo de calzado, se destina mayoritariamente al mercado interno. Según datos del Cuadro de Oferta Utilización publicado por el INEI, la demanda interna representa el 98,6\% del total producido por la industria de fabricación de calzado de cuero y otro tipo de calzado, dominado en mayor medida por la demanda final (92,3\%). Al mercado externo, sólo se destina el 1,4\% de la producción nacional. Es importante mencionar que, en el Perú, la mayoría de la producción se destina al consumo de los hogares.

Según la empresa Azaleia se estima que el consumo per cápita al año es de 2,2 pares de calzado en promedio, lo cual es bajo en comparación de las demás plazas de la región. En Chile y Brasil el promedio per cápita de calzados al año es de cuatro pares y en Estados Unidos de 7. 


\section{Figura $\mathrm{N}^{\circ} 1.18$}

Demanda de la Producción de Calzado

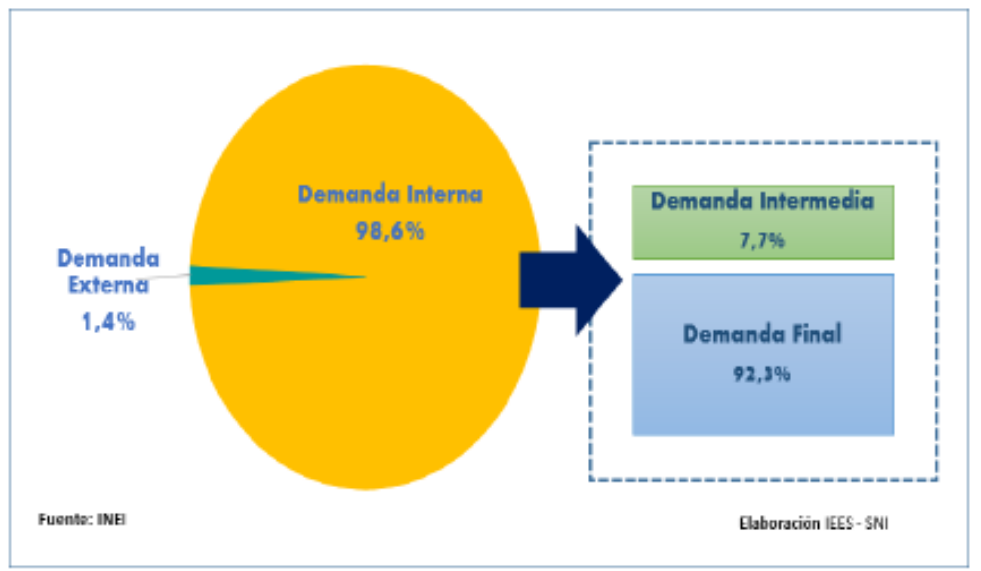

Fuente: Reporte-Sectorial-de-Calzado-Enero-2017

\section{- Patrones de Consumo}

Los estándares de consumo para el prototipo de producto que se va a comercializar son:

\section{a. Edad y Genero}

Las mujeres entre los 25 y 59 años de edad se encuentran en la PEA donde el ingreso promedio de las mujeres aumentó en 7.8\% (S/ 100.6) siendo mayor que el de los hombres en 3.9\% (S/ 72.1), según el último trimestre de Septiembre a Diciembre 2016.

b. Nivel Socioeconómico

Nos vamos a orientar en los NSE B y C, debido a que es donde se concentra la mayor cantidad de población, donde el poder adquisitivo se ha incrementado en este nivel. 


\section{c. Factor Geográfico}

El modelo de negocio se orienta a la mujer sofisticada cuyo estilo de vida es la ejecutiva moderna que no necesita de vestidos recargados para verse bien, una mujer pragmática, sobria sin dejar de lado su feminidad. Por lo que nos hemos orientado en un inicio en la población de Lima Moderna donde se concentra el mayor flujo empresarial. Que abarca los distritos: Barranco, Jesús María, La Molina, Lince, Magdalena de Mar, Miraflores, Pueblo Libre, San Borja, San Isidro, San Miguel, Santiago de Surco y Surquillo.

\section{d. Estilo de Vida}

Las mujeres han modificado su patrón y rol en la sociedad. En la actualidad la realización personal es una de sus prioridades; antes se consideraba que la meta de toda mujer era casarse, tener hijos y administrar eficientemente el hogar. Ahora ellas estudian, trabajan, forman sus propias empresas o buscan alcanzar altos cargos dentro de las corporaciones; todo antes de pensar en formar una familia.

Según un estudio realizado por la empresa de tecnología Intel, el nivel de escolaridad en las mujeres del Perú ha avanzado notoriamente. Reflejándose en un aumento del $40 \%$ en la su participación en el ambiente corporativo, inclusive en las empresas con trabajadores mayoritariamente masculinos. ${ }^{8}$

\footnotetext{
8 Fuente: Blog de Administración y Marketing 12 Octubre 2015 Link: https://blogs.upc.edu.pe/blog-de$\underline{\text { administracion-y-marketing/entorno/los-estilos-de-vida-en-el-peru }}$
} 


\section{- Los Sofisticados}

Son tanto hombres como mujeres por lo general de mediana edad. Confiados en sí mismos, son aquellos innovadores preocupados por su apariencia, tecnológicos, "triunfadores", cosmopolitas, buscan la calidad y el servicio. Por lo general se encuentran en el nivel socio económico A, B y C. Suelen ser líderes de opinión con un alto ingreso y alto nivel de instrucción. Para ellos la marca es un símbolo de diferenciación y los precios altos van de la mano con una buena calidad.

¿Que desean como consumidores?

1. Invierten mucho en su cuidado personal.

2. Evalúan el ambiente del punto de venta y el servicio.

3. Buscan productos de alta calidad.

- Las Modernas

Quienes se encuentran en todos los niveles socio económico, son mujeres con carácter pujante y trabajador que buscan el equilibrio entre su familia y sus aspiraciones económicas y profesionales. Por lo general tienen carreras técnicas. Se preocupan e interesan por su apariencia, dando prioridad en sus compras a la calidad y las marcas. Son abiertas a la innovación, buscan la legitimidad social y ven en las marcas el reconocimiento. El dinero es importante para ellas.

¿Que desean como consumidores?

1. Comprar productos light o saludables.

2. Pasean por malls tiendas por departamento. 
3. Valoran la experiencia en el punto de venta.

Figura $\mathrm{N}^{\circ} 1.19$

Estilos de vida

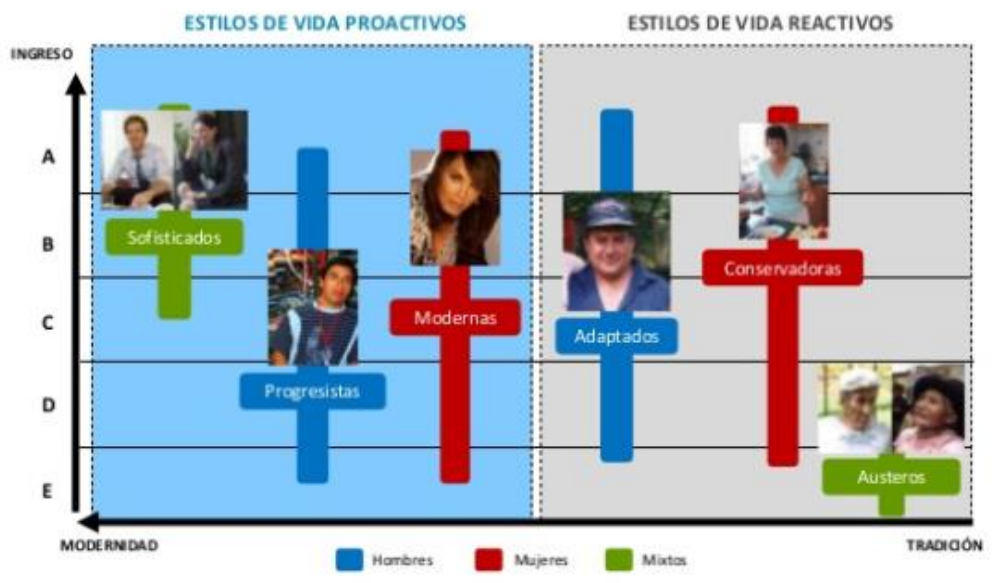

Fuente: http://www.arellanomarketing.com/inicio/estilos-de-vida/

e. Tecnología:

"Las mujeres son personas multitareas por su naturaleza. Ellas llevan muchos roles, responsabilidades y distintas actividades al mismo tiempo. Esta característica fundamental hace que ellas requieran lo mejor de sus equipos en términos de velocidad, poder de desempeño, además de exigir movilidad y buena conexión", señala Gaby Gallardo, Gerente de Marketing de Negocios de Intel para América Latina.

Hoy en día, se estima que el $41 \%$ de las mujeres peruanas trabajan fuera del hogar, además de llevar a la par sus actividades domésticas y familiares. Es por eso que la demanda de dispositivos móviles a este tipo de público ha aumentado. 
Dentro de las redes sociales las mujeres son mayoría, y son las que más comparten los contenidos. Estos espacios y los portales web dedicados a ellas se han convertido en sus mejores aliados, brindándoles datos y consejos de cómo manejar su vida multifacética. En Latinoamérica, son las mayores compradoras de artículos por internet, realizando un 10\% más de compras que los hombres.

\section{- Demanda Potencial}

Para poder determinar la demanda potencial se ha tomado en cuenta la data de venta histórica del año 2016 por género de la empresa de nombre comercial Calza M\&L con RUC: 10418887864 ubicada en Av. Aviación 5111 - Santiago de Surco. Donde en promedio se venden 6000 pares de calzado de damas mientras que para caballero 2000 pares anuales; con lo cual se ha podido determinar que la tendencia de compra tiene una relación de 1 a 3 .

\section{Tabla $\mathrm{N}^{\circ} 1.5$}

Tendencia de compra por género

\begin{tabular}{|c|c|c|c|c|c|c|c|}
\hline Tendenc & & 2017 & 2018 & 2019 & 2020 & 2021 & 2022 \\
\hline Hombre & Par & 1.00 & 1.00 & 1.00 & 1.00 & 1.00 & 1.00 \\
\hline Mujer & Par & 3.00 & 3.00 & 3.00 & 3.00 & 3.00 & 3.00 \\
\hline Total & & 4.00 & 4.00 & 4.00 & 4.00 & 4.00 & 4.00 \\
\hline
\end{tabular}

Fuente: Empresa Calza M\&L - Historial de ventas por género

Elaboración: Propia

Tabla $\mathrm{N}^{\circ} 1.6$

Demanda nacional de calzado-Perú

\begin{tabular}{|lccccccc|}
\hline Demanda & Unidad Medida & 2017 & 2018 & 2019 & 2020 & 2021 & 2022 \\
\hline Total Nacional & Par & $57,796,412$ & $60,108,269$ & $62,512,599$ & $65,013,103$ & $67,613,627$ & $70,318,173$ \\
\hline
\end{tabular}

Elaboración Propia

Nota: Para proyectar la cantidad demandada nacional se utilizó el PBI del sector manufactura que corresponde a un $4 \%$ para el año 2018 
Tabla $\mathrm{N}^{\circ} 1.7$

Demanda nacional de calzado por género - Perú

\begin{tabular}{|lc|cccccc|}
\hline Género & Unidad Medida & $\mathbf{2 0 1 7}$ & $\mathbf{2 0 1 8}$ & $\mathbf{2 0 1 9}$ & $\mathbf{2 0 2 0}$ & $\mathbf{2 0 2 1}$ & $\mathbf{2 0 2 2}$ \\
\hline Hombre & Par & $14,449,103$ & $15,027,067$ & $15,628,150$ & $16,253,276$ & $16,903,407$ & $17,579,543$ \\
Mujer & Par & $43,347,309$ & $45,081,201$ & $46,884,449$ & $48,759,827$ & $50,710,221$ & $52,738,629$ \\
\hline Total & & $57,796,412$ & $60,108,269$ & $62,512,599$ & $65,013,103$ & $67,613,627$ & $70,318,173$ \\
\hline
\end{tabular}

Elaboración: Propia

Nuestro producto a inicios del proyecto se va a llevar a cabo en Lima Metropolitana, donde se ha tomado la proyección de los años 2017 al 2020 de INEI, para poder determinar la cantidad de pares demandados por género.

Tabla $\mathrm{N}^{\circ} 1.8$

Demanda de calzado femenino-Lima Metropolitana

\begin{tabular}{|lcccccc|}
\hline Población & Unidad Medida & $\mathbf{2 0 1 7}$ & $\mathbf{2 0 1 8}$ & $\mathbf{2 0 1 9}$ & $\mathbf{2 0 2 0}$ & $\mathbf{2 0 2 1}$ \\
\hline Lima & Hab. & $10,138,937$ & $10,247,570$ & $10,354,270$ & $10,459,213$ & $10,562,713$ \\
Nacional & Hab. & $31,826,018$ & $32,162,184$ & $32,495,510$ & $32,824,358$ & $33,149,016$ \\
\hline Población Lima & \% & $\mathbf{3 1 . 8 6 \%}$ & $\mathbf{3 1 . 8 6 \%}$ & $\mathbf{3 1 . 8 6 \%}$ & $\mathbf{3 1 . 8 6 \%}$ & $\mathbf{3 1 . 8 6 \%}$ \\
\hline \hline $\begin{array}{l}\text { Mujer Lima } \\
\text { Metropolitana }\end{array}$ & Par & $13,809,319$ & $14,363,470,569$ \\
\hline
\end{tabular}

Elaboración: Propia

Por último, para llegar a la demanda potencial se ha tomado en cuenta los siguientes factores:

Edad: Entre 25 y 59 años.

- Área geográfica: Lima moderna, que representa en promedio un $12 \%$.

- Nivel socio económico: Se ha considerado los niveles B y C, que representan un $67 \%$ de acuerdo con APEIM. 
Tabla $\mathrm{N}^{\circ} 1.9$

Mercado Potencial de pares de calzado

\begin{tabular}{|c|c|c|c|c|c|c|c|}
\hline \multicolumn{2}{|c|}{ AÑO } & 2017 & 2018 & 2019 & 2020 & 2021 & 2022 \\
\hline \multicolumn{2}{|c|}{ Mujeres -Población Lima } & $13,809,319$ & $14,363,849$ & $14,939,118$ & $15,536,919$ & $16,158,474$ & $16,804,839$ \\
\hline \multirow{3}{*}{ Parámetros } & Edad $25<=x<=59$ & $45.71 \%$ & $45.23 \%$ & $44.77 \%$ & $44.32 \%$ & $43.88 \%$ & $43.46 \%$ \\
\hline & Lima Moderna & $12.84 \%$ & $12.54 \%$ & $12.45 \%$ & $12.35 \%$ & $12.20 \%$ & $12.09 \%$ \\
\hline & $\mathrm{NSE} B+\mathrm{C}$ & $67 \%$ & $67 \%$ & $67 \%$ & $67 \%$ & $67 \%$ & $67 \%$ \\
\hline \multicolumn{2}{|c|}{ MCDO. POTENCIAL (PARES) } & 542,986 & 545,888 & 557,813 & 569,831 & 579,616 & 591,820 \\
\hline
\end{tabular}

Fuente: Apoyo - Perfiles zonales 2017

Fuente: Apeim - Niveles socioeconómicos 2017

Elaboración: Propia

\subsubsection{Sustentos respectivos}

\section{- Focus Group}

Es una de las formas de estudios cualitativos en el que se reúnen un grupo de personas para indagar acerca de actitudes y reacciones frente a un producto en este caso sobre el calzado femenino. Las preguntas son respondidas por la interacción del grupo en una dinámica donde los participantes se sienten cómodos, libres de hablar y de comentar sus opiniones, motivaciones, gustos y preferencias.

Los objetivos por el cual necesitamos la realización del Focus Group son los siguientes:

a. Conocer los criterios de compra del consumidor que suele tener al realizar compras de calzado para poder establecer las preferencias de consumo.

b. Indagar sobre las preferencias que se tienen sobre el uso de calzado de vestir de cuero. 
c. Conocer las observaciones del grupo luego de darles a conocer el modelo de negocio, el cual es: Personalización del calzado a través de una aplicación móvil y plataforma web.

d. Sirve para reestructurar la encuesta a través de las opiniones de las personas.

e. Conocer si es viable el modelo de negocios sobre la personalización de calzado a través de una plataforma web.

f. Saber cuáles son las necesidades insatisfechas de las mujeres al buscar comprar un zapato.

g. La guía de indagación se muestra en el anexo 1

h. Perfil del consumidor: Personas entre 18 y $45+$ años de los niveles socioeconómicos B y C.

El Focus Group se ha llevado a cabo en tres grupos de mujeres, donde se ha segmentado por edades:

Tabla $\mathrm{N}^{\circ} 1.10$

Grupos de estudio-Rango de edades

\begin{tabular}{|c|c|c|c|}
\hline Grupos & Edad & Cantidad & Lugar \\
\hline Primer Grupo & 18 a 25 & 4 & Universidad de Lima \\
\hline Segundo Grupo & 26 a 35 & 3 & Restaurante el Tronco \\
\hline Tercer Grupo & 37 a $45+$ & 6 & Av San Boja Sur 888 \\
\hline
\end{tabular}

Elaboración: Propia

\section{Conclusiones}

1. En el primer grupo la moda es el factor relevante para la compra de un calzado; mientras que en el tercer y segundo grupo la comodidad es lo principal. 
2. El segundo grupo es el que está dispuesto a gastar más por un zapato de cuero que el primer y tercer grupo.

3. El diseñar el calzado no representa un problema para las usuarias.

4. En todos los grupos la idea de la personalización del calzado a través de una plataforma web fue aceptada.

5. El segundo y tercer grupo muestran desconfianza en la compra online.

6. El tercer grupo, requiere de un lugar físico para sentir la seguridad en la compra.

- Muestreo

El muestreo establecido es el Muestreo No Probabilística, ya que se desconoce la probabilidad de que las personas sean seleccionadas, por ello no se puede hallar el error muestral.

La selección de la muestra se basó por criterio del grupo, y la elegida fue el muestreo por conveniencia, ya que la población no fue sacada de una muestra real.

Al ser la población de Lima Moderna mayor a cien mil, como si se tratase de una población infinita, se utilizará la siguiente fórmula.

$$
N=\frac{Z^{\wedge} 2^{*} p^{*} q}{E^{\wedge} 2}
$$


Donde:

$\mathrm{N}=$ tamaño de la muestra.

Z=1.96 (el Nivel de Confianza es de 95\%)

$\mathrm{P}=0.76$ (Probabilidad de éxito)

$\mathrm{q}=0.24(1-\mathrm{p})$ (Probabilidad de fracaso)

$\mathrm{E}=0.05$ (Nivel de Error)

$$
\mathrm{n}=280
$$

El total de encuestas recolectadas fue de 387. Todas recogidas de manera presencial en distritos de Lima Moderna y realizadas a nuestro target.

\subsubsection{Demanda Proyectada}

Supuestos para la proyección de la demanda de producto se ha tomado en cuenta los siguientes factores:

\section{- Aceptación de modelo de negocios}

En el mercado peruano, no existe una aplicación para diseñar el calzado de damas, por lo que, para la proyección de la demanda, los resultados del mercado potencial deben ser sometidos a esta variable, la cual nos dio un resultado del $81 \%$. 
Figura $\mathrm{N}^{\circ} 1.20$

Pregunta ¿Utilizarías una aplicación virtual para personalizar y diseñar tus zapatos?

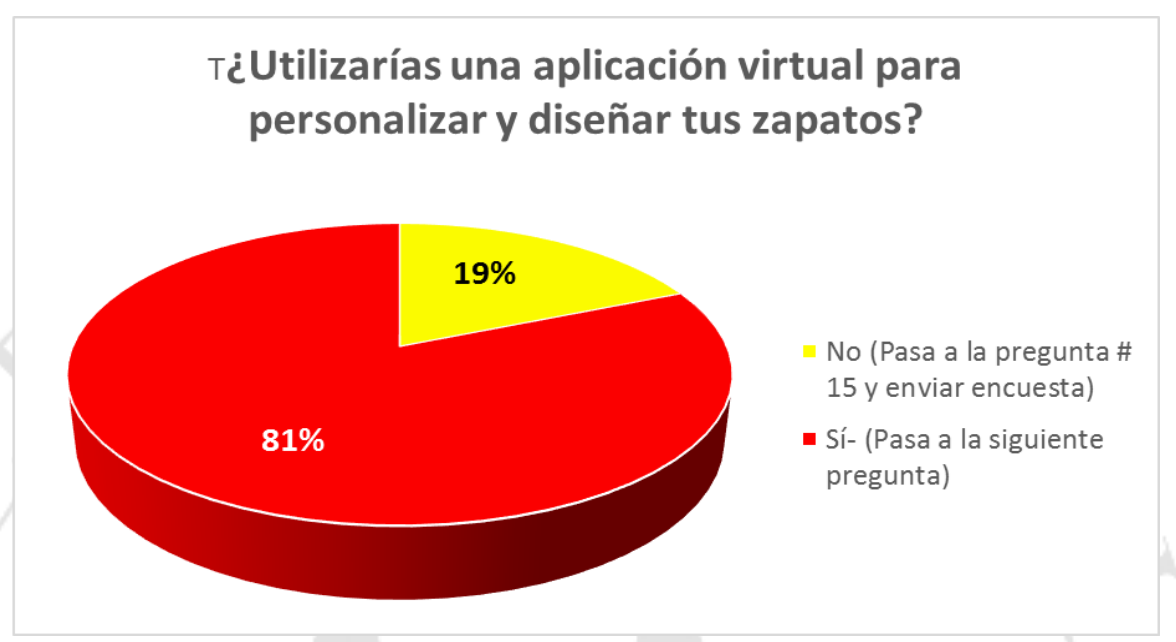

Fuente: Encuestas

Elaboración: Propia

\section{- Intención de Compra}

Otro factor importante es que nuestro producto será comercializado a través online, por lo se manejará el E-commerce, por lo que en las encuestas se consulta si el cliente compraría el producto por internet, donde el resultado fue del $18 \%$. 


\section{Figura $\mathrm{N}^{\circ} 1.21$}

Pregunta ¿Comprarías tus zapatos por Internet?

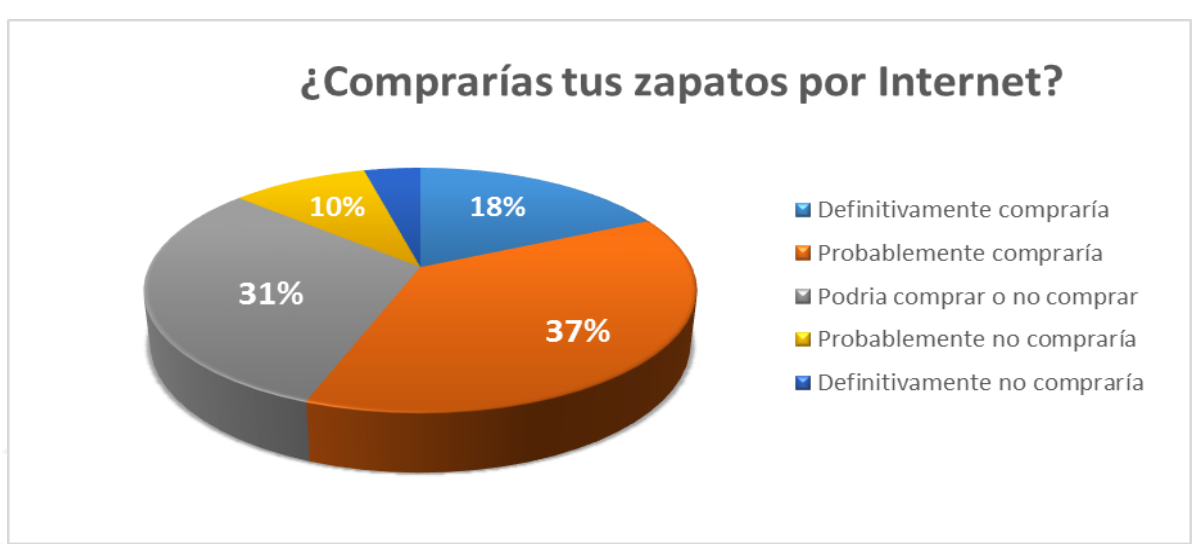

Fuente: Encuestas

Elaboración: Propia

\section{- Consumo Per Cápita de Calzado}

Otro factor por el que debe ser discriminado el mercado potencial, es el consumo per cápita de calzado de cuero, en el siguiente cuadro se puede apreciar que $63 \%$ compra de 0 a 4 pares al año, por lo que la media es 2 pares al año. 
Figura $\mathrm{N}^{\circ} 1.22$

Pregunta ¿Cuántos pares de calzado de cuero compras al año?

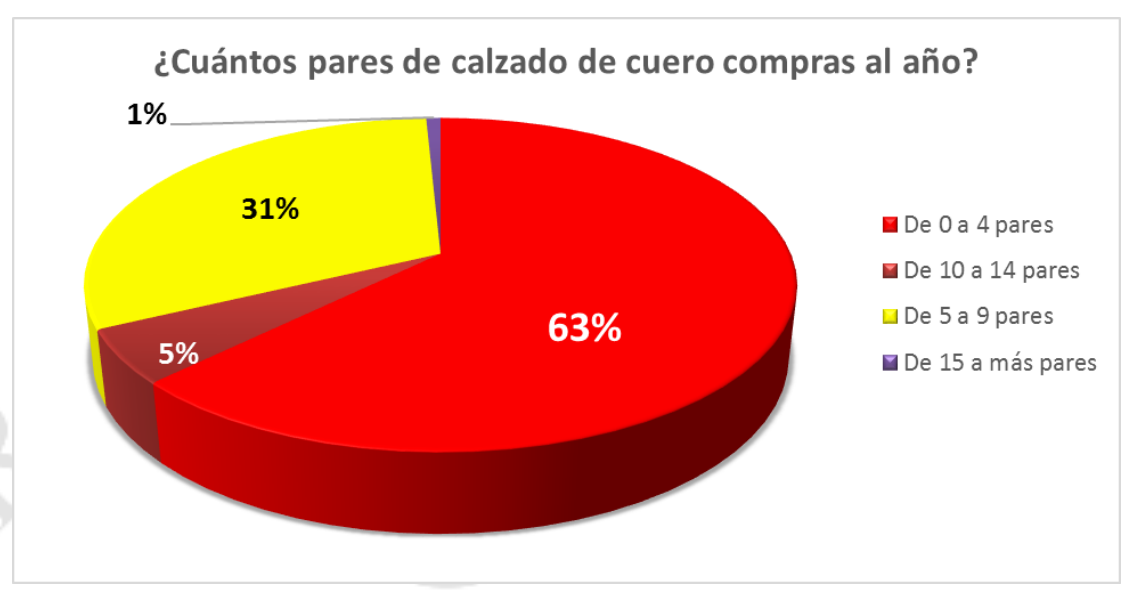

Fuente: Encuestas

Elaboración: Propia

Con estas tres preguntas claves es posible determinar la demanda de nuestro producto de calzado de cuero personalizado a través de una plataforma web.

- Pegunta 1: ¿Utilizarías una aplicación virtual para personalizar y diseñar tus zapatos?

- Resultado: El 81\% de encuestadas sí utilizarían.

- Pregunta 2: ¿Definitivamente compraría nuestro producto?

- Resultado: El 18\% de encuestadas sí compraría.

- Pregunta 3: ¿Qué cantidad de pares compra al año?

- Resultado: Las encuestadas compran 2 pares de calzado de cuero al año. 
Tabla $\mathrm{N}^{\circ} 1.11$

Demanda potencial de Mercado

\begin{tabular}{|c|c|c|c|c|c|c|}
\hline Preguntas & Factor & 2018 & 2019 & 2020 & 2021 & 2022 \\
\hline \multicolumn{2}{|c|}{ MCDO. POTENCIAL (PARES) } & 545,888 & 557,813 & 569,831 & 579,616 & 591,820 \\
\hline \multirow{3}{*}{ Parámetros } & $\begin{array}{c}\text { ¿Utilizarías una } \\
\text { aplicación virtual para } \\
\text { personalizar y diseñar } \\
\text { tus zapatos? }\end{array}$ & $81 \%$ & $81 \%$ & $81 \%$ & $81 \%$ & $81 \%$ \\
\hline & $\begin{array}{l}\text { ¿Definitivamente } \\
\text { compraría? }\end{array}$ & $18 \%$ & $18 \%$ & $18 \%$ & $18 \%$ & $18 \%$ \\
\hline & $\begin{array}{c}\text { ¿Número de pares que } \\
\text { compras al año ? }\end{array}$ & 2 & 2 & 2 & 2 & \\
\hline \multicolumn{2}{|c|}{ DEMANDA PARES } & 159,181 & 162,658 & 166,163 & 169,016 & 172,575 \\
\hline
\end{tabular}

Elaboración: Propia

En la tabla anterior, se parte de un mercado objetivo en pares de zapatos, donde se ha discriminado a través de los resultados de las tres preguntas mencionadas. Donde finalmente se obtiene la demanda potencial en pares.

\subsection{Análisis de la Oferta}

\subsubsection{Análisis de la competencia}

La rivalidad entre empresas se inicia por conseguir una posición en el mercado, utilizando diversas tácticas como la competencia de precios, batallas publicitarias, lanzamientos de productos. Esta rivalidad tiende a aumentar en intensidad cuando las empresas sienten la presión competitiva o ven una oportunidad para mejorar su posición.

Actualmente las mujeres compran su calzado en tiendas por departamento, cadenas de tiendas o minoristas independientes en su mayoría. No obstante, existen atelieres que ofrecen en cierta medida la personalización de calzado y la exclusividad en el diseño, pero con ciertas restricciones, donde el cliente se debe acercar al punto físico para poder realizar 
la compra y no se genera la optimización del tiempo en el proceso de compra para el cliente.

En la medida que se desarrolle el servicio de personalización de calzado en el Perú, se producirá el incremento de la rivalidad entre atelieres, ya que actualmente es una industria fragmentada donde no existe una marca dominante. Por lo que será necesario que las empresas ofrezcan un producto diferenciado para captar a los clientes. Otro factor es el costo del cambio de una marca a otra, que constituye un riesgo, sin embargo, la propuesta de valor que se brinde hará que el cliente evalué otras opciones y migre a otras marcas.

Puede destacarse que no tenemos un competidor directo en el mercado nacional, ya que no existe ninguna empresa que ofrece el servicio de una plataforma web para diseñar calzado de vestir a medida, sin embargo, hemos identificado tres grupos.

Figura $\mathrm{N}^{\circ} 1.23$

Competidores
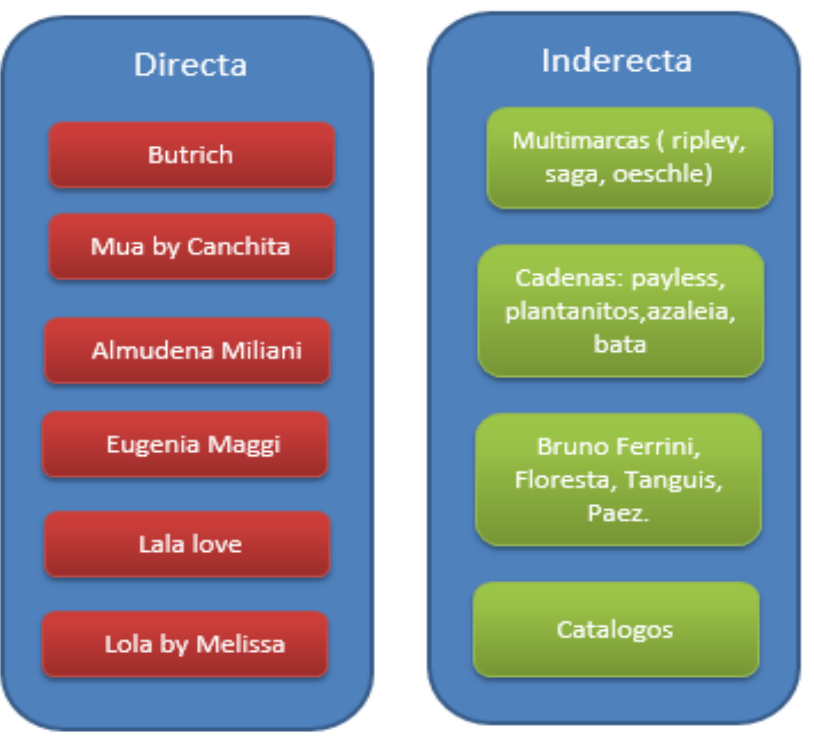

Importaciones

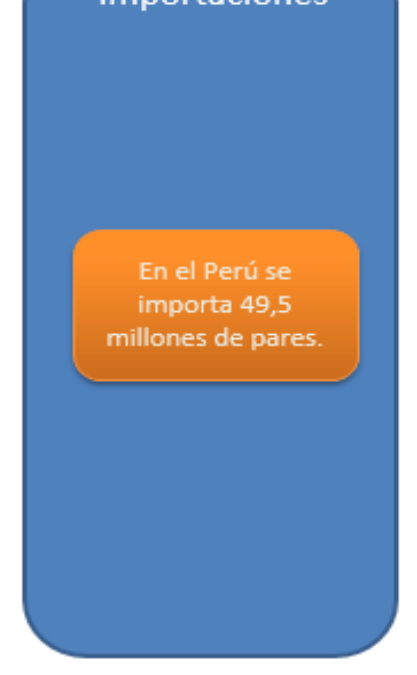

Elaboración: Propia 


\subsubsection{Empresas que ofrecen el producto o servicio}

En este punto vamos a analizar a nuestra competencia directa donde se ha podido identificar 6 competidores que actualmente se encuentran vigentes en el mercado, donde el 50 \% compuesto por Lala Love, Muaby Canchita y Lola by Melissa Del Solar, donde se permite que la clienta haga algunos cambios en el calzado; el otro $50 \%$ se identifican como tiendas que ofrecen un calzado exclusivo en el diseño; las cuales son Butrich, Eugenia Maggi y Almudena Miliani. Ambos grupos ofrecen modelos con edición limitada, debido a que el mensaje que se transmite es la idea que se está comprando un producto único y original con características que otro calzado no las tiene.

En el siguiente cuadro se detalla el tiempo que llevan en el mercado y su modelo de negocio. Así mismo los canales digitales que utilizan para hacer la comunicación de sus productos:

Tabla $\mathrm{N}^{\circ} 1.12$

Matriz de competidores

\begin{tabular}{|c|c|c|c|c|c|}
\hline \multicolumn{6}{|c|}{ COMPETIDORES } \\
\hline MARCA & INICIO & TIEMPO & MODELO DE NEGOCIO & UBICACIÓN & CANALES DIGITALES \\
\hline Butrich & 2004 & 13 años & $\begin{array}{l}\text { Su fundadora Jessica Butrich se ha convertido en una de las diseñadoras más } \\
\text { importantes del Perú gracias a su único estilo de referencia vintage, glamorosa y } \\
\text { divertida. Saca colecciones con un estilo diferente en las } 4 \text { estaciones de años en } \\
\text { cuero natural en los formatos de charol, gamuza y cueros grabados. }\end{array}$ & San Isidro & $\begin{array}{l}\text { Facebook,Twitter y } \\
\text { Instagram }\end{array}$ \\
\hline Mua by Canchita & 2007 & 17 años & $\begin{array}{l}\text { Mariana Edery fundadora de Mua by Canchita de unió su pasión por el diseño de } \\
\text { calzado, la empresaria muestra ahora su variada cartera de productos a través de una } \\
\text { vitrina virtual que ha logrado posicionarla entre las diseñadoras mejor cotizadas en el } \\
\text { sector calzado.Hoy cuenta con taller y maquinaria propios además de un equipo que la } \\
\text { ayuda. }\end{array}$ & Miraflores & Facebook,Instagram \\
\hline Almudena Miliani & 2009 & 8 años & $\begin{array}{l}\text { Almudena Miliani es una marca de zapatos que busca resaltar la belleza de la mujer a } \\
\text { través de sus pies, fundada por sos compañeras de universidad, buscan ofrecer un } \\
\text { calzado sofisticado y que la mujer lo pueda utlizar en cualquier ocasión. }\end{array}$ & San Isidro & $\begin{array}{c}\text { Facebook, Instagram y } \\
\text { Pinterest }\end{array}$ \\
\hline Eugenia Maggi & 2011 & 6 años & Verónica Maggi (dueña de la marca), realiza diseños exclusivos y de calidad. & San Isidro & $\begin{array}{c}\text { Facebook, Pinterest e } \\
\text { Instagram }\end{array}$ \\
\hline Lala love & 2012 & 5 años & $\begin{array}{l}\text { Lala love se inicio en el 2012, donde el diseño de los zapatos tiene una particularidad } \\
\text { en los colores, materiales y mensajes en la suela de los zapatos que son elegidos por } \\
\text { las clientas. Trabaja bajo dos conceptos, lanza por temporada diseños de edición } \\
\text { limitada y la otra modalidad es modificar un modelo existente de acuerdo a su gusto. }\end{array}$ & $\begin{array}{l}\text { Miraflores y } \\
\text { Jockey Plaza }\end{array}$ & $\begin{array}{c}\text { Landing } \\
\text { Page,Facebook,whatsapp,Ins } \\
\text { tagram, Twiter y Pinterest }\end{array}$ \\
\hline $\begin{array}{c}\text { Lola by Melissa Del } \\
\text { Solar }\end{array}$ & 2013 & 4 años & $\begin{array}{l}\text { Melissa Del Solar se inicio en el diseño de calzado por hobby y para un circulo } \\
\text { cercano donde descubrio una oportunidad de nicho de mercado de zapatos de diseño; } \\
\text { cuenta con más de } 50 \text { diseños por colección en verano e invierno, donde el cliente } \\
\text { puede crear su calzado escogiendo un estilo de uno y otro entre diferentes colores de } \\
\text { cuero y textura. }\end{array}$ & Miraflores & $\begin{array}{c}\text { Facebook y Web ( } \\
\text { Desactualizada) }\end{array}$ \\
\hline
\end{tabular}

Elaboración: Propia 
Al analizar el cuadro detallado líneas arriba, podemos observar, que no disponen de una gran cantidad de stock, ya que tienen colecciones exclusivas, que buscan brindar un calzado único, pero bajo ciertos parámetros, lo que limita la creatividad del cliente y no permite que pueda transmitir su estilo completo. Adicional a ello las empresas antes mencionadas trabajan bajo hormas estándar, que pueden generar en un futuro problemas en los pies, como juanetes, callosidad, etc.

Actualmente la tecnología permite estudiar a la competencia desde un punto de vista digital para saber cuáles son las estrategias que están ejecutando a tiempo real, saber cómo se comunican con su audiencia, permite conocer mejor a los clientes y tener una idea si están creciendo a un ritmo lento o alto lo que nos sirve como punto de comparación, para poder medirnos en forma constante. Lo que nos ayudará a tener una mayor visión de que acciones tomar.

A continuación, se muestra un análisis sobre los canales digitales que utilizan para mantener comunicación e interacción con sus clientes:

Tabla $\mathrm{N}^{\circ} 1.13$

Competencia por canales digitales

\begin{tabular}{|c|c|c|c|c|c|}
\hline \multicolumn{6}{|l|}{ MARCA } \\
\hline Butrich & $\theta$ & $\theta$ & $\theta$ & $\theta$ & $\theta$ \\
\hline Mua by Canchita & $\theta$ & 8 & $\theta$ & 8 & 8 \\
\hline Almudena Miliani & 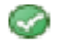 & $\theta$ & $\theta$ & $\infty$ & (8) \\
\hline Eugenia Maggi & $\theta$ & $\theta$ & $\theta$ & 8 & 8 \\
\hline Lalalove & $\theta$ & $\theta$ & $\theta$ & $\theta$ & $\theta$ \\
\hline $\begin{array}{l}\text { Lola by Melissa Del } \\
\text { Solar }\end{array}$ & $\theta$ & 8 & $\theta$ & 8 & 8 \\
\hline
\end{tabular}

Elaboración: Propia 
Como se puede apreciar estás empresas no poseen una Web formal y ponen mucha más fuerza en las redes sociales, siendo Facebook e Instagram las más utilizadas, las cuales se analizarán a mayor profundidad.

Tabla $\mathrm{N}^{\circ} 1.14$

Competencia-alcance por canales digitales

\begin{tabular}{|c|c|c|c|c|c|}
\hline MARCA & & & & & WWW \\
\hline Butrich & 118,135 & 56 & 92,648 & 3,389 & SI \\
\hline Mua by Canchita & 53,151 & NO & 3,555 & NO & NO \\
\hline Almudena Miliani & 72,673 & 57 & 1,303 & 396 & DESACTUALIZADA \\
\hline Eugenia Maggi & 15,234 & 411 & 1,328 & NO & NO \\
\hline $\begin{array}{c}\text { Lola by Melissa Del } \\
\text { Solar }\end{array}$ & 214,197 & 1,037 & 36,934 & 1,767 & SI \\
\hline
\end{tabular}

Elaboración: Propia

\section{- Facebook}

En cuanto a Facebook, podemos concluir que LalaLove, posee una mayor cantidad de comunidad con 5 años de iniciar sus operaciones, logrando superar a otras con mayor tiempo en el mercado. Lo cual se debe a varios factores, la calidad de sus publicaciones y el nivel de interacción con el usuario.

Tabla $\mathrm{N}^{\circ} 1.15$

Matriz de indicadores de Facebook

Fanpage karma

Informe de indicadores 13.08.2016 al 09.09.2017

\begin{tabular}{|c|c|c|c|c|c|c|c|}
\hline Page & $\begin{array}{c}\text { Indice de } \\
\text { Rendimiento de } \\
\text { la Páqina }\end{array}$ & $\begin{array}{c}\text { Número de } \\
\text { fans }\end{array}$ & Compromiso & $\begin{array}{c}\text { Interacción de } \\
\text { las } \\
\text { publicaciones }\end{array}$ & $\begin{array}{c}\text { Porcentaje } \\
\text { de } \\
\text { incremento }\end{array}$ & $\begin{array}{l}\text { Crecimiento } \\
\text { (total) }\end{array}$ & $\begin{array}{l}\text { Número de } \\
\text { Reacciones }\end{array}$ \\
\hline Almudena Miliani & $13.0 \%$ & 72673 & $0.07 \%$ & $0.12 \%$ & - & - & 1305 \\
\hline Butrich & $7.0 \%$ & 118135 & $0.1 \%$ & $0.14 \%$ & $0.96 \%$ & 1127 & 2972 \\
\hline Eugenia Maggi & $8.0 \%$ & 15234 & $0.03 \%$ & $0.08 \%$ & $0.01 \%$ & 1 & 121 \\
\hline LaLaLove & $7.0 \%$ & 214197 & $0.19 \%$ & $0.13 \%$ & $0.41 \%$ & 880 & 10779 \\
\hline Lola by Melissa del Solar & $11.0 \%$ & 127368 & $0.38 \%$ & $0.13 \%$ & $0.62 \%$ & 780 & 12985 \\
\hline MUAbyCanchita & $11.0 \%$ & 53151 & $0.05 \%$ & $0.06 \%$ & $0.01 \%$ & -4 & 653 \\
\hline
\end{tabular}

Fuente: Fanpage Karma 
Figura $\mathrm{N}^{\circ} 1.24$

Número de fans de Facebook

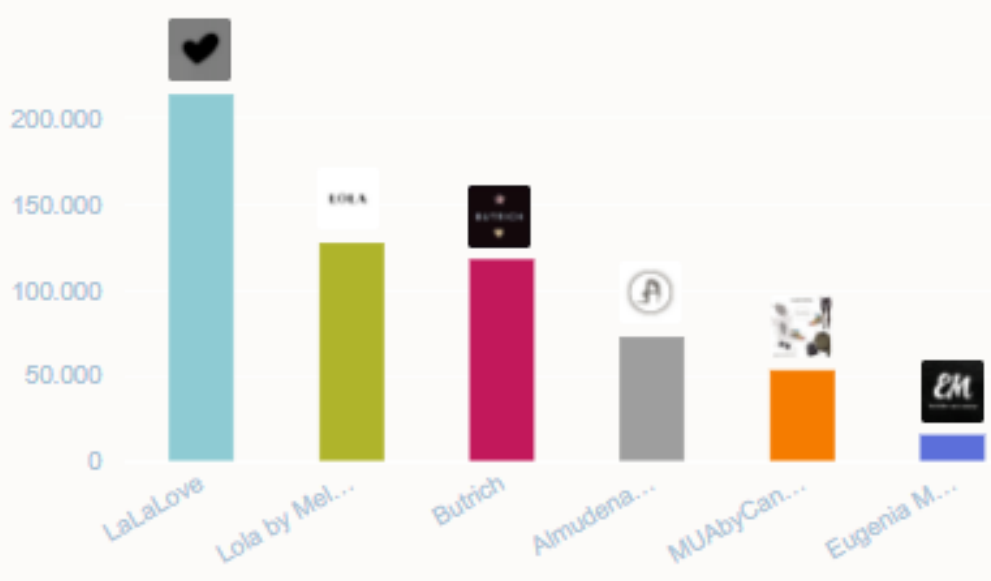

Fuente: Fanpage Karma

\section{Figura $\mathrm{N}^{\circ} 1.25$}

Nivel de compromiso Facebook

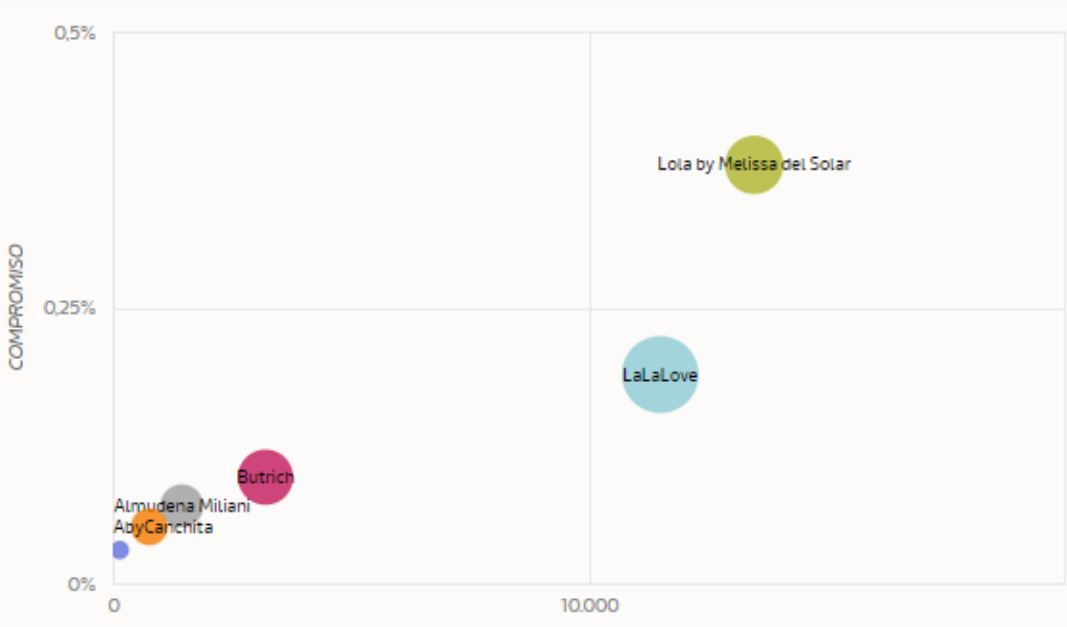

TOTAL DE REACCIONES, COMENTARIOS, COMPARTIDOS

Fuente: Fanpage Karma 


\section{- Instagram}

La segunda red social más utilizada para establecer comunicación y llegar al cliente es instagram, donde tienen una mayor presencia la marca Butrich y un compromiso mayor al resto. Es seguido por LolaLove, sin embargo, su compromiso es del 0\%, esto quiere decir que solo es una plataforma de publicación, pero no brinda una respuesta al cliente y un cliente si no es atendido puede dejar la marca por alguien que si le de la información al momento.

Tabla $\mathrm{N}^{\circ} 1.16$

Matriz de indicadores de Instagram

\section{Fanpage karma}

Informe de indicadores 13.08.2017 al 09.09.2017

\begin{tabular}{lcccc}
\multicolumn{1}{c}{ Page } & Seguidores & Siguiendo & Compromiso & $\begin{array}{c}\text { Interacción de } \\
\text { publicaciones }\end{array}$ \\
\hline Almudena Miliani & 1303 & 201 & $1.24 \%$ & $2.89 \%$ \\
CANCHITA & 3555 & 2227 & $0.34 \%$ & $0.43 \%$ \\
Eugenia Maggi & 1328 & 236 & $0.45 \%$ & $3.18 \%$ \\
Jessica Butrich & 92648 & 892 & $1.47 \%$ & $0.96 \%$ \\
LOLA & 11956 & 1339 & $0.48 \%$ & $0.26 \%$ \\
PAOLA FORD & 36934 & 804 & $0.0 \%$ & $0.0 \%$
\end{tabular}

(@2012-2017 fanpage karma

Fuente: Fanpage Karma 
Figura $\mathrm{N}^{\circ} 1.26$

Número de fans Instagram

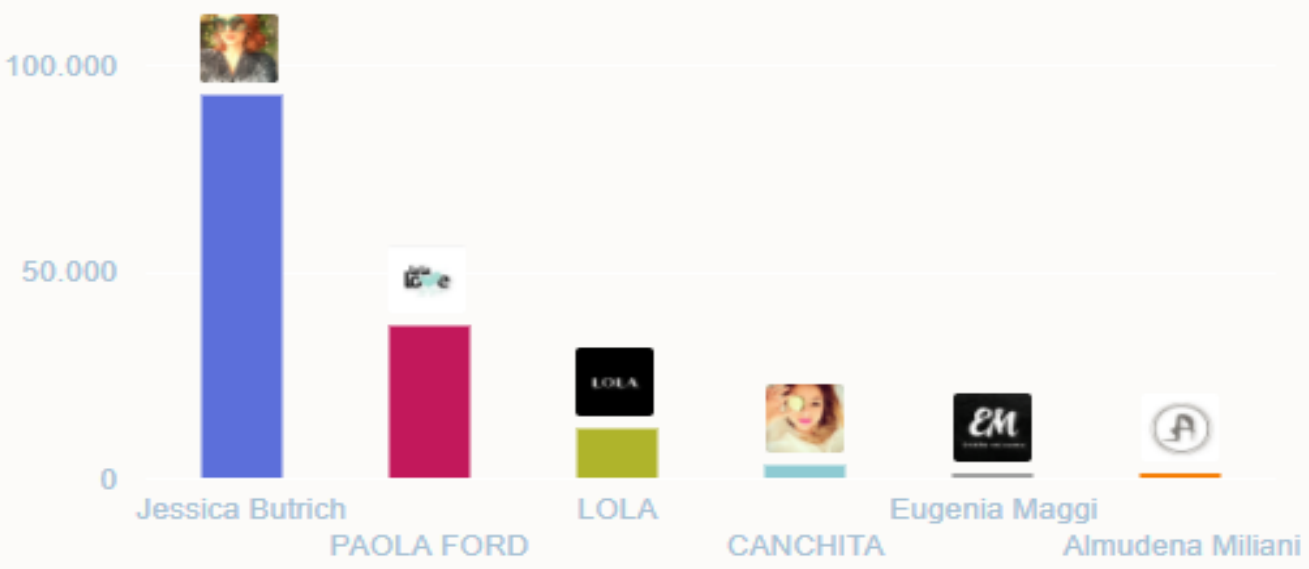

Fuente: Fanpage Karma

Figura $\mathrm{N}^{\circ} 1.27$

Nivel de Compromiso Instagram

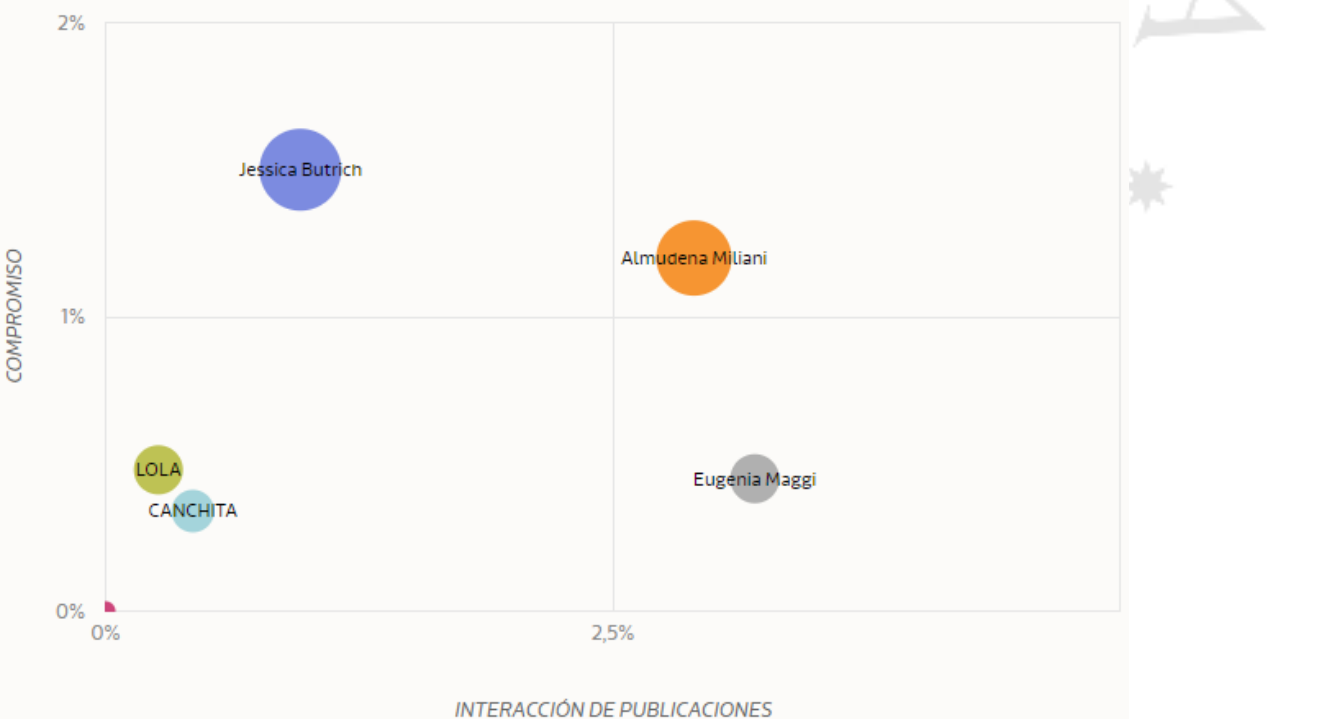

Fuente: Fanpage Karma 


\subsubsection{Proyección de la oferta}

Este punto se analizó bajo la perspectiva de lo que se queda para el consumo nacional, sería la cantidad que se puede ofertar en el país.

Tabla $\mathrm{N}^{\circ} 1.17$

Cantidad Ofertada

\begin{tabular}{|c|c|c|c|c|}
\hline Oferta & $\begin{array}{l}\text { Unidad } \\
\text { Medida }\end{array}$ & 2014 & 2015 & 2016 \\
\hline Fabricacion Nacional & Par & $10,031,852$ & $10,332,808$ & $10,353,473$ \\
\hline Importación & Par & $52,536,000$ & $55,328,000$ & $50,880,000$ \\
\hline Exportación & Par & $6,826,000$ & $7,688,000$ & $5,660,000$ \\
\hline Total Nacional & Par & $55,741,852$ & $\mathbf{5 7 , 9 7 2 , 8 0 8}$ & $55,573,473$ \\
\hline
\end{tabular}

Elaboración: Propia

Tabla $\mathrm{N}^{\circ} 1.18$

Oferta proyectada

\begin{tabular}{|lccccccc|}
\hline Oferta & Unidad Medida & 2017 & 2018 & 2019 & 2020 & 2021 & 2022 \\
\hline Total Nacional & Par & $57,796,412$ & $60,108,269$ & $62,512,599$ & $65,013,103$ & $67,613,627$ & $70,318,173$ \\
\hline
\end{tabular}

Elaboración: Propia

Nota: La cantidad ofertada es igual a la cantidad de producción a nivel nacional.

\subsubsection{Análisis de proveedores}

En el mercado existe una gran cantidad de proveedores de materias primas, los cuales brindan variedad en precio y calidad. Es por esta razón que su poder de negociación es bajo, puesto que se puede cambiar de proveedor sin que afecte al proceso productivo en costos como en tiempos. 
Para el caso de servicios de aparado del cuero o fresado de neolite, los proveedores si tienen un alto poder de negociación en las tarifas de costo, debido a que son pocos los artesanos que pueden realizar un trabajo calificado.

\subsection{Demanda del Negocio}

\subsubsection{Segmentación del mercado}

Nuestro mercado objetivo está orientado hacia un nicho de mercado compuesto por mujeres entre 25 a 59 años de NSE B y C, con un estilo de vida sofisticado donde se preocupan por su imagen.

\section{Figura $\mathrm{N}^{\circ} 1.28$}

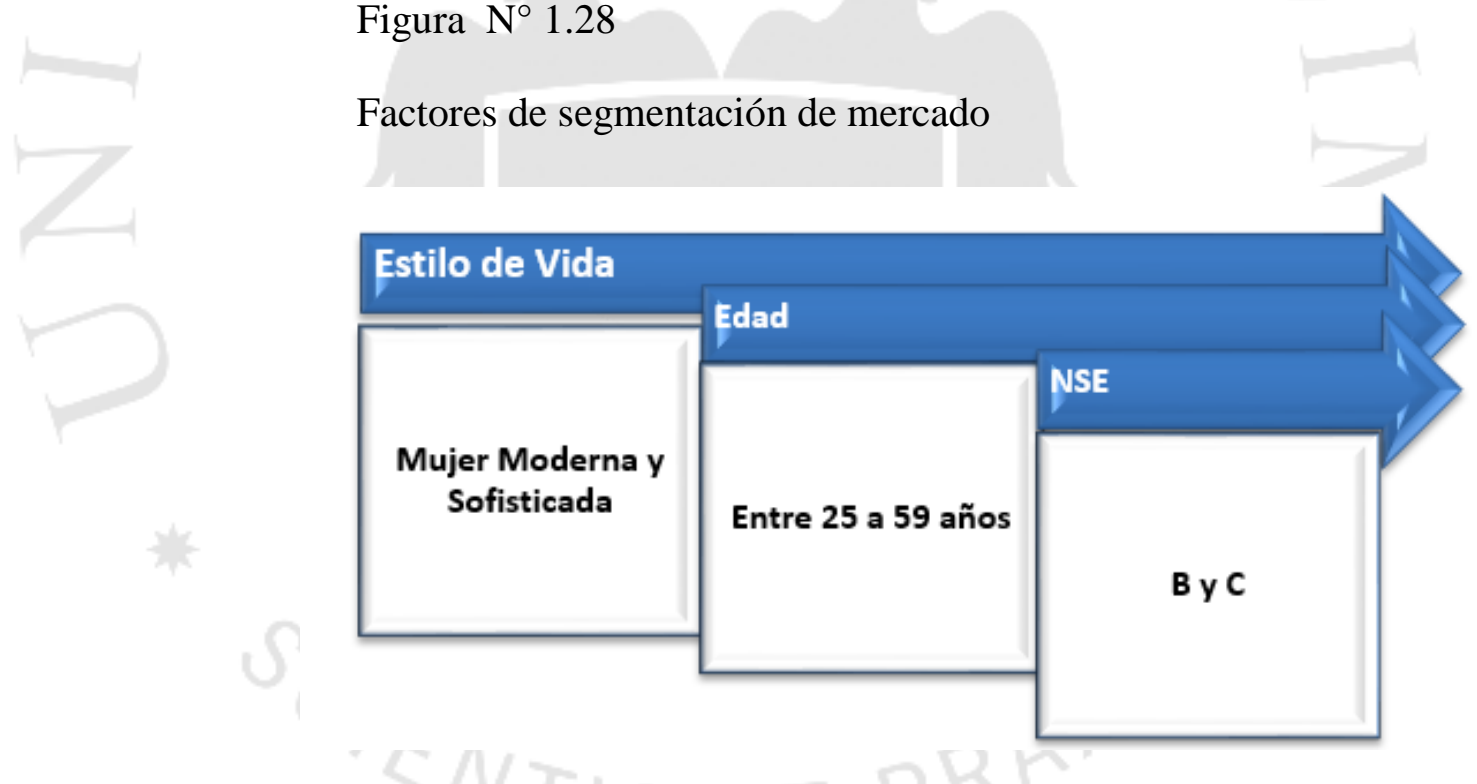

Fuente: Dirección de Estudios Económicos de MYPE e Industria 


\subsubsection{Selección del mercado meta}

- Generalidades:

- Factor 1.- Capacidad máxima de producción:

Se ha calculado la capacidad máxima de producción en base a una cantidad de fabricación de 15 docenas semanales, multiplicado por 52 semanas, obteniendo una cantidad de 9,360 pares al año.

- Factor 2.- Capacidad de producción:

En un escenario conservador, el primer año se va a trabajar a una capacidad de producción de $45 \%$. Para el quinto año, bajo un escenario optimista, se espera llegar a un $95 \%$ de nuestra capacidad.

Tabla $\mathrm{N}^{\circ} 1.19$

Mercado Meta - Demanda

\begin{tabular}{|c|c|c|c|c|c|}
\hline Mercado meta - Demanda & 2018 & 2019 & 2020 & 2021 & 2022 \\
\hline Capacidad Máxima de Producción & 9,360 & 9,360 & 9,360 & 9,360 & 9,360 \\
\hline Capacidadde Producción \% & $45 \%$ & $55 \%$ & $70 \%$ & $85 \%$ & $95 \%$ \\
\hline Capacidad de produccion & 4,210 & 5,148 & 6,552 & 7,956 & 8,892 \\
\hline Tasa de Crecimiento Producción & & $22 \%$ & $27 \%$ & +8 & $12 \%$ \\
\hline Demanda Mensual & 351 & 429 & 546 & 663 & 741 \\
\hline Demanda potencial en pares & 159,181 & 162,658 & 166,163 & 169,016 & 172,575 \\
\hline Participación de mercado & $3 \%$ & 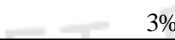 & 10 & $5 \%$ & $5 \%$ \\
\hline Elaboración: Propia & & 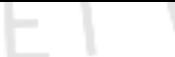 & & & \\
\hline Factor & 2018 & 2019 & 2020 & 2021 & 2022 \\
\hline Objetivo meta (pares) & 4,210 & 5,148 & 6,552 & 7,956 & 8,892 \\
\hline Crecimiento del sector Manfactura & & & & & \\
\hline Mensual & 351 & 429 & 546 & \begin{tabular}{l|l|}
663 & \\
\end{tabular} & 741 \\
\hline
\end{tabular}

Elaboración: Propia 
Como se puede apreciar, iniciamos con una participación de 3\% el primer año, luego de implementar la estrategia de marketing, incrementará a 5\% para el quinto año.

Se presume que para el tercer año el ingreso de nuevos competidores, es por esto que la tasa de crecimiento de producción empieza a decrecer.

Figura $\mathrm{N}^{\circ} 1.29$

PBI por sectores económicos

Cuadro 14

PBI POR SECTORES ECONOMICOS

(Variaciones porcentuales reales)

\begin{tabular}{c}
$\frac{2015}{1 \text { Sem. Año }} \frac{2016^{*}}{\text { I Sem. RI Jun.16 RI Set.16 RI Jun.16 RI Set.16 RI Jun.16 RI Set.16 }}$ \\
\hline
\end{tabular}

Manufactura

Recursos primarios

Manufactura no primaria

$\begin{array}{rrr}-2,7 & -1,7 & -5, \\ 0,4 & 1,7 & -14 \\ -3,5 & -2,7 & -1,\end{array}$

Fuente BCRP 


\subsection{Comercialización}

\subsubsection{Política de comercialización}

Nuestro modelo de negocios se centra en ofrecer al cliente un calzado personalizado. Para ello la comercialización de nuestro producto será a través de nuestra plataforma web, que contará con una versión responsive. ${ }^{9} \mathrm{La}$ propuesta de valor del proyecto se basa en cuatro pilares: diseño, calidad, comodidad y tecnología que serán compatibles con el estilo de cada cliente.

En las encuestas realizadas, se preguntó a las mujeres cuales eran los atributos que consideraban más importantes para comprar un calzado de cuero y los resultados fueron los siguientes:

Figura $\mathrm{N}^{\circ} 1.30$

Pregunta: ¿Que atributos considera importante al momento de comprar un calzado?

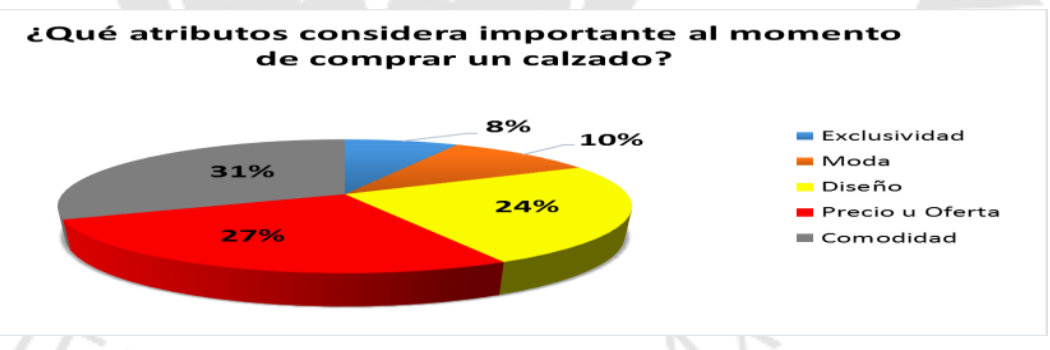

Fuente: Encuestas

Elaboración: Propia

9 Responsive: El diseño web responsive o adaptativo es una técnica de diseño web que busca la correcta visualización de una misma página en distintos dispositivos. Desde ordenadores de escritorio a tablets y móviles. 
Se puede concluir que los tres factores determinantes en la compra son comodidad, precio y diseño, los cuales han sido considerados en nuestra propuesta de valor.

El proyecto que se está planteando se basa en la compra on-line, es por ello dos preguntas abarcaron ese tema en forma puntual:

Figura $\mathrm{N}^{\circ} 1.31$

Pregunta: ¿Comprarías tus zapatos por internet?

\section{¿Comprarías tus zapatos por Internet?}

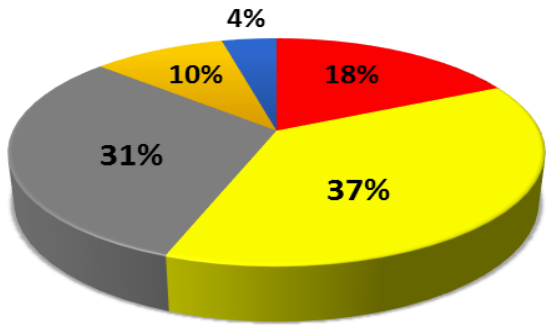

- Definitivamente compraría

๑ Probablemente compraría

- Podria comprar o no comprar

$\square$ Probablemente no compraría

- Definitivamente no compraría

Fuente: Encuestas

Elaboración: Propia.

Como se puede observar solo el $18 \%$ compraría sus zapatos por internet, esto va acompañado de las cifras indicadas por la consultora apoyo, donde se puede observar que existe una tendencia ascendente a las compras on-line, respecto al año 2014. 
Figura $\mathrm{N}^{\circ} 1.32$

Conectividad a internet

Se conecta a internet con mayor frecuencia que años anteriores.

\begin{tabular}{|c|c|c|c|c|c|}
\hline \multirow{2}{*}{2014} & CONEXIÓN & \multirow{2}{*}{$\begin{array}{l}\text { CONEX. HOGAR } \\
\text { 53 } 53 \%\end{array}$} & REDES SOCIALES & \multicolumn{2}{|c|}{ COMPRA ONLINE } \\
\hline & $\begin{array}{l}4 \text { Sesiones } \\
\text { semanales }\end{array}$ & & $83 \%$ & 매태 & Compra $6 \%$ \\
\hline & CONEXIÓN & CONEX. HOGAR & REDES SOCIALES & COMPRA & ONLINE \\
\hline 15 & $\begin{array}{l}4.5 \text { Sesiones } \\
\text { semanales }\end{array}$ & $56 \%$ & $84 \%$ & 매삼 & Compra $20 \%$ \\
\hline & CONEXIÓN & CONEX. HOGAR & REDES SOCIALES & COMPRA & ONUINE \\
\hline & $\begin{array}{l}5.6 \text { Sesiones } \\
\text { semanales }\end{array}$ & $59 \%$ & $82 \%$ & Iㅔㅇㅔ & $\begin{array}{c}{ }^{*} \text { Compra } \\
\text { productos } 16 \%\end{array}$ \\
\hline
\end{tabular}

Fuente: Ipsos Apoyo

Otra pregunta fue sobre el motivo de no realizar la compra de su calzado por internet, donde los resultados indican que el $51 \%$ de las mujeres encuestadas tienen la necesidad de probárselos, seguido por un $31 \%$ que manifiestan tener dudas sobre la calidad del calzado y un $16 \%$ tienen desconfianza en la compra on-line.

Figura $\mathrm{N}^{\circ} 1.33$

Pregunta: ¿Por qué no comprarías tus zapatos por internet?

¿Por qué no comprarías tus zapatos por Internet?

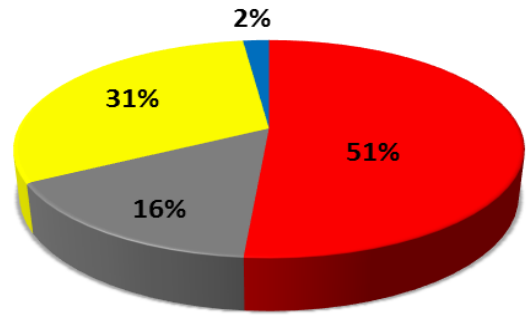

- Necesito probarmelos

Desconfianza de comprar online

$\square$ Dudas sobre la calidad del calzado

- Duda sobre diseño, si el virtual y el físico serán iguales

Fuente: Encuestas

Elaboración: Propia. 
Los tres factores determinantes en la compra antes descritos, juegan en contra de la compra on-line. Es por ello que se ha elaborado nuestra propuesta de valor con 4 factores que va a permitir atender las expectativas e inconformidades del cliente.

Figura $\mathrm{N}^{\circ} 1.34$

Propuesta de valor del modelo de negocio

\begin{tabular}{|c|c|c|c|}
\hline \multicolumn{4}{|c|}{ Propuesta de Valor } \\
\hline \multicolumn{2}{|c|}{ Propuesta de Valor } & \multicolumn{2}{|l|}{ Clientes } \\
\hline Producto & $\begin{array}{c}\text { Atributos que cumplen } \\
\text { expectativas }\end{array}$ & Expectativas & Necesidad \\
\hline $\begin{array}{c}\text { Zapatos de cuero } \\
\text { personalizados }\end{array}$ & $\begin{array}{l}\text { Calidad en los insumos } \\
\text { Precio acorde al mercado } \\
\text { Diseño propio de cliente } \\
\text { Plataforma Virtual }\end{array}$ & $\begin{array}{l}\text { Comodidad } \\
\text { Precio u Oferta } \\
\text { Diseño } \\
\text { Moda } \\
\text { Exclusividad }\end{array}$ & $\begin{array}{c}\text { Calzado acorde con el } \\
\text { estilo de cada mujer }\end{array}$ \\
\hline$=$ & $\begin{array}{l}\text { Atributos compensadores de } \\
\text { necesidades }\end{array}$ & Inconformidades & 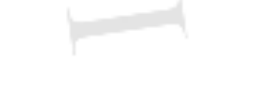 \\
\hline & $\begin{array}{c}\text { El calzado a la medida } \\
\text { Muestras de cuero en nuestra } \\
\text { oficina }\end{array}$ & $\begin{array}{c}\text { Necesidad de probarselos } \\
\text { Duda sobre la calidad de calzado }\end{array}$ & \\
\hline
\end{tabular}

Elaboración: Propia.

La comercialización del calzado se detalla en 4 pasos, donde se le brinda al cliente la seguridad y confianza en el proceso de compra:

\section{- Detalle del servicio}

1. Diseño del Calzado

La usuaria hace uso de la plataforma virtual para poder escoger la categoría de calzado e iniciar la personalización y diseño. 
2. Selección de la modalidad de medida del pie

a. Selecciona una talla preestablecida.

b. Descargar una plantilla para realizar la medida y elegir la talla.

c. Ir al punto físico de atención al cliente, para la medida 3D, donde su medida quedará registrada en nuestra base de datos, para futuras compras.

3. Solicitud del pedido

Nuestra web tendrá el e-commerce, donde el cliente podrá comprar en forma on-line, brindado la seguridad de su transacción. Para ello nos apoyaremos bajo la plataforma Pay $\mathrm{U}$.

\section{Disfrútalos}

Se necesita de 7 a 10 días para poder elaborar un par de zapatos y donde el cliente lo puede recoger en nuestra oficina o lo llevaremos por pedido delivery dentro de nuestra zona de reparto. 
Figura $\mathrm{N}^{\circ} 1.35$

Cuadro Flujograma del Proceso de Personalización del Calzado

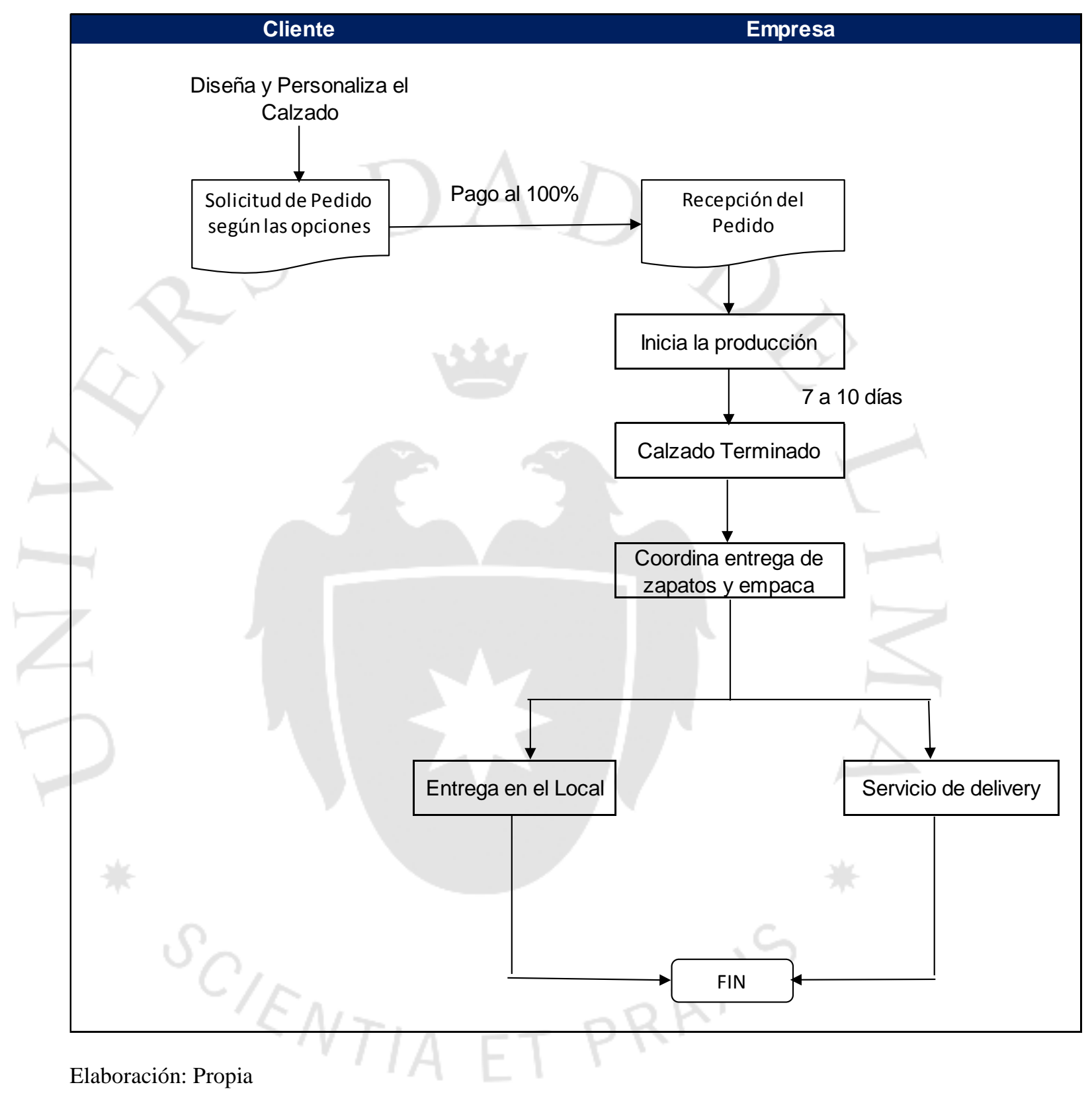




\subsubsection{Canales de distribución y puntos de venta}

Para el proyecto emplearemos una distribución directa, donde una vez que el cliente realiza el pedido on-line, se inicia la elaboración del calzado y se entrega el producto vía delivery o el cliente puede recogerlo en nuestra oficina de atención al cliente.

Figura $\mathrm{N}^{\circ} 1.36$

Tipo de distribución directa

\section{Distribución Directa}
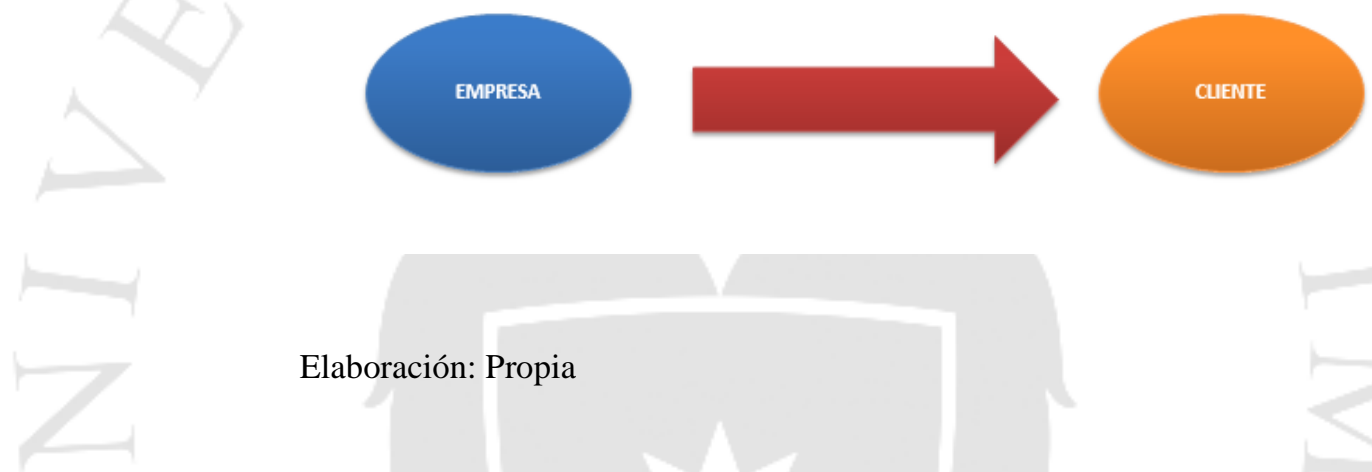

El presente proyecto está ideado para pedidos on-line, es decir una tienda virtual; sin embargo, en el Focus Group realizado; el tercer grupo (36 a 45 años), manifestaron la necesidad de contar con un lugar físico, para que puedan acudir ante dudas o reclamos; con la finalidad de tener un mayor conocimiento de las preferencias de nuestro público objetivo, en las encuetas se incluyó la siguiente pregunta: ¿Que canal de ventas prefieren para la compra de calzado? 


\section{Figura $\mathrm{N}^{\circ} 1.37$}

Pregunta: ¿Qué canal de venta prefieres para comprar tus zapatos?

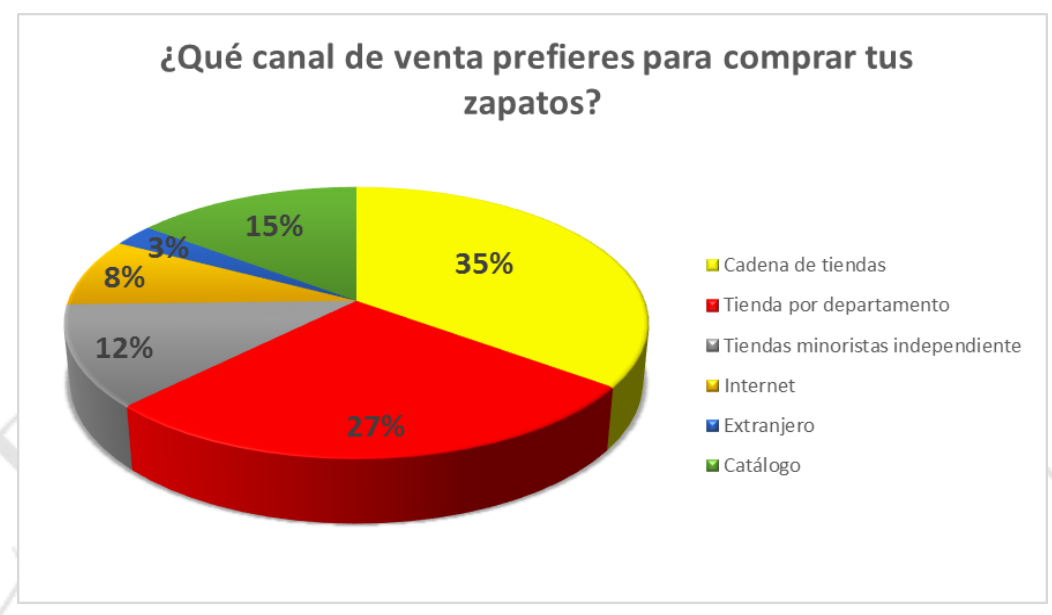

Fuente: Encuestas

Elaboración: Propia

Los resultados de las encuestas indican que el $62 \%$ de las personas prefieren comprar sus zapatos en las tiendas por departamentos y las cadenas de tiendas, las cuales en su mayoría se encuentran en los malls.

Esta cifra nos muestra que, para nuestro público objetivo, es necesario contar con un lugar físico, por lo que se ha efectuado un ranking de factores para determinar la mejor ubicación estratégica.

A continuación, detallamos los factores más importantes que hemos tomado en cuenta para hacer nuestro análisis.

\section{- Seguridad de la Zona}

Es importante que nuestro punto de contacto con el cliente se ubique en una zona segura bien iluminada y limpia. De esta manera nuestros clientes pueden visitarnos sin ningún tipo de preocupación. 


\section{- Parking}

En este tiempo el parque automotor ha crecido y los espacios para estacionar se han reducido, por lo que contar con este servicio es una ventaja competitiva para cualquier negocio o estar cerca de un estacionamiento también es de gran ayuda.

\section{- Accesibilidad a la Zona}

Al elegir la ubicación de nuestro negocio, debemos tomar en cuenta nuestro público objetivo. Mientras nuestro punto de contacto con el cliente esté cerca de donde viven, trabajen o transiten, será mayor la posibilidad que nos visite.

\section{- Costo de inmueble}

Nuestro negocio se basa en una tienda virtual, pero es necesario contar con un punto de contacto con el cliente, es por ello que el inmueble será bajo la modalidad de alquiler mensual.

\section{- Tamaño del inmueble-Área}

Para este proyecto, el punto de contacto con el cliente no requiere de una gran área, por lo que es prudente contar con un espacio de 50 a $60 \mathrm{~m} 2$, para poder atender las citas de nuestros clientes.

\section{- Cercanía con nuestro taller.}

Los pedidos serán atendidos desde la oficina comercial por lo que la cercanía es un punto importante para cumplir con los plazos de entrega. 
Tabla $\mathrm{N}^{\circ} 1.20$

Análisis de ranking de factores

\begin{tabular}{|c|l|}
\hline $\mathbf{N}^{\circ}$ & \multicolumn{1}{|c|}{ Descripción } \\
\hline a & Seguridad de la zona \\
\hline b & Parking \\
\hline c & Accesibilidad de la zona \\
\hline d & Costo del immueble \\
\hline e & Área \\
\hline f & Cercanía a nuestro taller \\
\hline
\end{tabular}

Elaboración: Propia

\begin{tabular}{|r|r|c|c|c|c|c|r|r|}
\hline & $\mathbf{a}$ & $\mathbf{B}$ & $\mathbf{c}$ & $\mathbf{d}$ & $\mathbf{e}$ & $\mathbf{f}$ & Puntaje & Valorización \\
\hline $\mathbf{a}$ & $\mathbf{x}$ & 1 & 1 & 1 & 1 & 1 & 5 & $33 \%$ \\
\hline $\mathbf{b}$ & 0 & $\mathbf{X}$ & 0 & 0 & 1 & 1 & 1 & 2 \\
\hline $\mathbf{c}$ & 0 & 1 & $\mathbf{x}$ & 1 & 1 & 1 & 4 & $27 \%$ \\
\hline $\mathbf{d}$ & 0 & 1 & 0 & $\mathbf{x}$ & 0 & 0 & $13 \%$ \\
\hline $\mathbf{e}$ & 0 & 0 & 0 & 1 & $\mathbf{x}$ & 0 & 1 & $7 \%$ \\
\hline $\mathbf{f}$ & 0 & 0 & 0 & 1 & 1 & $\mathbf{x}$ & & 2 \\
\hline
\end{tabular}

Elaboración: Propia

\begin{tabular}{|c|c|c|c|c|c|c|c|c|c|}
\hline \multicolumn{10}{|c|}{ Calificación de Alternativas } \\
\hline \multirow[t]{2}{*}{ Factor } & \multirow[t]{2}{*}{ Valoración } & \multicolumn{2}{|c|}{$\begin{array}{c}\text { Mall Aventura } \\
\text { Plaza }\end{array}$} & \multicolumn{2}{|c|}{ Rambla } & \multicolumn{2}{|c|}{ Higuereta } & \multicolumn{2}{|c|}{ A viación } \\
\hline & & $\mathbf{C}$ & $\mathbf{P}$ & $\mathbf{C}$ & $\mathbf{P}$ & $\mathbf{C}$ & $\mathbf{P}$ & $\mathbf{C}$ & $\mathbf{P}$ \\
\hline $\mathbf{a}$ & $33 \%$ & 60 & 20.00 & 80 & 26.67 & 60 & 20.00 & 80 & 26.67 \\
\hline c & $27 \%$ & 40 & 10.67 & 80 & 21.33 & 40 & 10.67 & 80 & 21.33 \\
\hline b & $13 \%$ & 80 & 10.67 & 80 & 10.67 & 40 & 5.33 & 60 & 8.00 \\
\hline d & $7 \%$ & 20 & 1.33 & 20 & 1.33 & 60 & 4.00 & 80 & 5.33 \\
\hline f & $13 \%$ & 20 & 2.67 & 60 & 8.00 & 40 & 5.33 & 60 & 8.00 \\
\hline e & $7 \%$ & 40 & 2.67 & 40 & 2.67 & 60 & 4.00 & 80 & 5.33 \\
\hline & $100 \%$ & & 48.00 & & 70.67 & & 49.33 & & 74.67 \\
\hline
\end{tabular}

Elaboración: Propia 
Como se puede analizar del cuadro detallado líneas arriba, el Mall la Rambla y una oficina ubicada a los alrededores de la Av. Aviación con Javier Prado, son las zonas con mejor puntaje. Se ha optado por una oficina en la avenida Aviación, debido a que Artesanas no venderá calzado con diseños pre-determinados, sino a solicitud del cliente; por lo que solo se requiere un área accesible y segura para atender a los clientes.

\subsubsection{Promoción y propaganda}

\section{- Alianzas con Bloggers}

Los bloggers de moda, son una de las mejores opciones para promocionar nuestro producto; lo más recomendable es hacer alianzas con aquellas que tienen una notoriedad media, ya que el aliciente es conseguir productos de marcas para poder recomendarlos u opinar sobre ellos y de esta manera generar un aumento del interés en sus lectores más frecuentes.

En la etapa de lanzamiento y durante el año se hará alianzas con 2 bloggers que se encuentran en el entorno de la moda, a probar la experiencia del diseño, la calidad del cuero a utilizar, la facilidad de uso de la herramienta virtual, la practicidad y ahorro de tiempo que sería apostar por esta nueva oferta de calzado; de esta manera se lograría que escriban un artículo sobre nuestra plataforma virtual en sus blogs; de esta manera toda su comunidad se enteraría de nuestro modelo del negocio. 
Entre las de notoriedad media se encuentran:

- Blog: Divina Ejecutiva

Fiorella García Pacheco, es asesora de imagen y marketing personal encargada del blog "Divina Ejecutiva", un espacio en el que brinda tips para todos aquellos que desean mejorar la imagen personal y destacarse como un producto frente a su "cliente" o futuro jefe.

Número de seguidores: 147,946

- Blog: An.Madame

Comunicadora, periodista y blogger para la revista Blum. "Le motif" de An.Madame es comunicar y dar a conocer marcas nuevas y ya existentes, basado en mi pasión por el arte, salud, y principalmente, la moda.

Número de seguidores: 20,092

\section{- Alianzas con Influenciadores}

Actualmente en nuestro medio local existen varias mujeres que se mueven en el entorno mediático de la televisión, donde se pueden hacer canjes y con ello lograr que nos nombre en sus redes sociales.

Para este tipo de publicidad estaríamos pensando en mujeres entre $25 \mathrm{y}$ 59 años de edad que tengan un gusto por la moda, como Alejandra Baigorria, Melissa Loza y Melissa Club, entre otras. 


\section{- Redes Sociales}

La publicidad de una marca ha sido y será uno de los principales objetivos de una empresa. Se puede demostrar que aquellos negocios con presencia en redes sociales aumentan sus ganancias al incrementar su relación e interacción con sus clientes. Y esa publicidad, gracias a las redes sociales, tiene un bajo costo. Sin embargo, requiere un monitoreo constante y tener a los profesionales adecuados.

Para darnos una idea en el Perú se detalla la penetración de las principales redes sociales utilizadas:

\section{Figura $\mathrm{N}^{\circ} 1.38$}

Penetración- Redes sociales

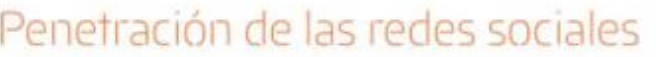
en el Perú
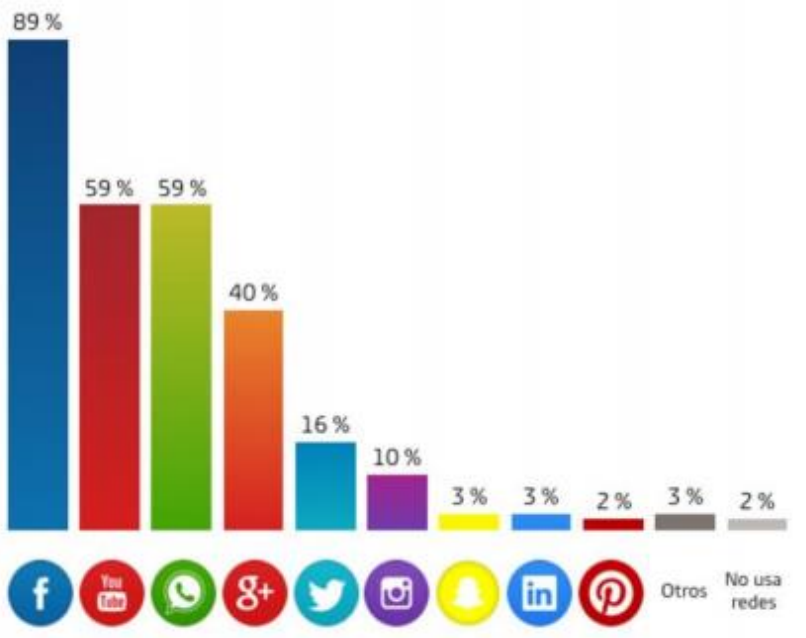

Fuente: GFK 
En un inicio nos apoyaremos en las plataformas digitales como Facebook, Instagram y Pinterest donde se deben plantear los objetivos y como deben ser medidos.

Objetivos:

1) Atraer al target y potenciar el sentimiento de comunidad.

2) Interactuar con la comunidad y redirigirla a la página web.

3) Lograr que la marca sea un referente y posicionarla en nuestro sector.

4) Indicadores.

5) Likes, comentarios, compartidos.

6) Alcance de Total.

7) Engagement.

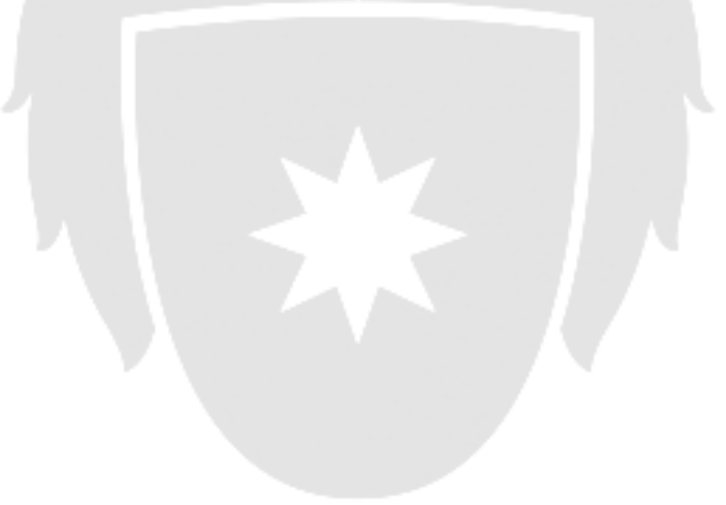


a. Facebook

Figura $\mathrm{N}^{\circ} 1.39$

Plantilla de Facebook de Artesanas

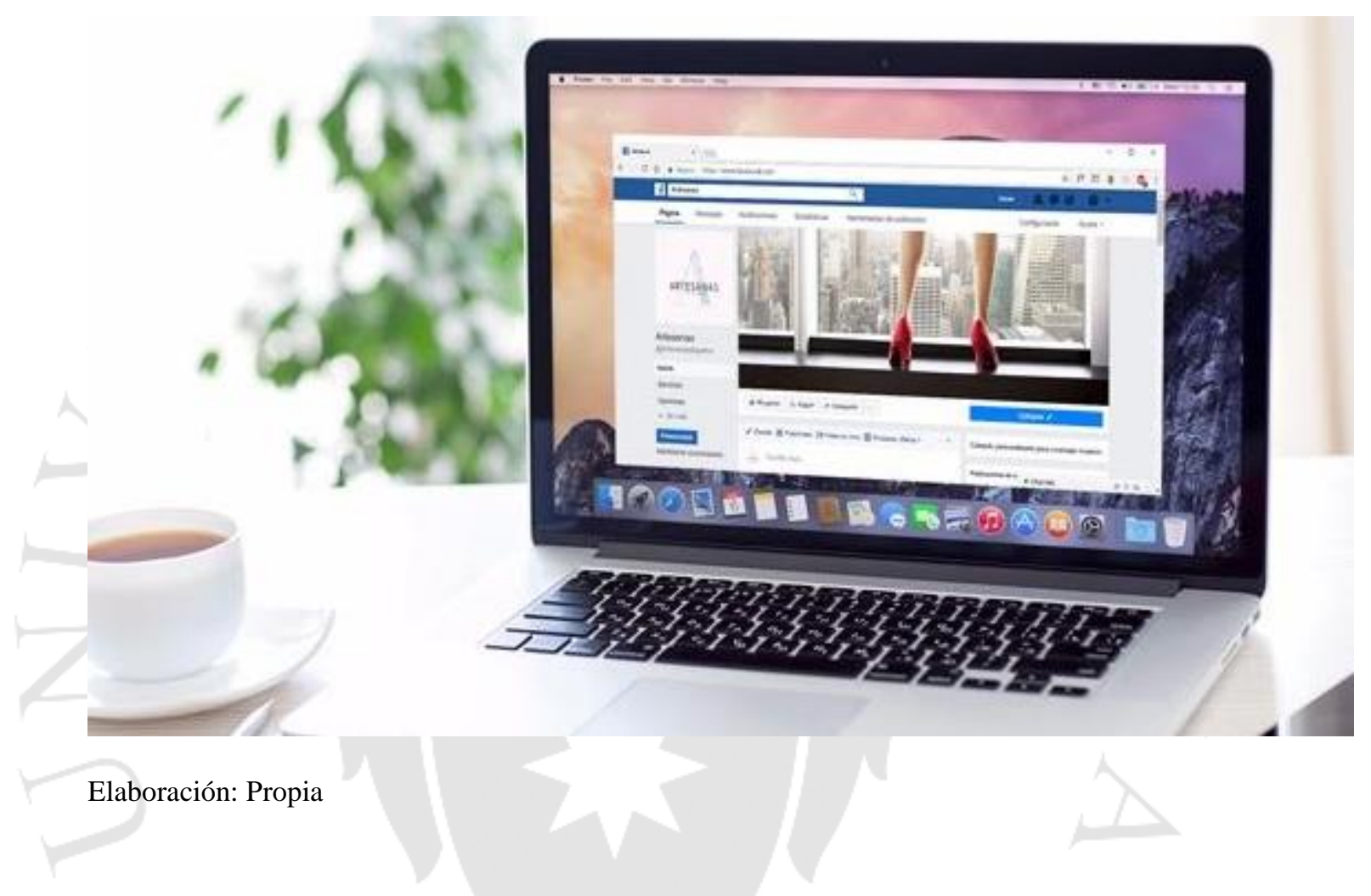

Es sin duda la red social más utilizada en el mundo y de mayor alcance, donde la proporción de mujeres y hombres es similar. Además, llega a todas las generaciones jóvenes como a audiencias mayores (35-59 años).

En esta plataforma puedes generar relaciones más dinámicas con los clientes, utilizar tu perfil como extensión de tu página web y obtener respuesta sobre qué contenidos tiene mejor recepción analizando los likes y los comentarios. 
Sin embargo, para garantizar el alcance de tus publicaciones debes promocionarlas con campañas en Facebook Ads, un servicio pago que te permite segmentar tu público objetivo.

Para mantener a tu comunidad comprometida con tu marca, debes generar un contenido que sea de interés y no solo promocionar el producto, para ello es necesario tener una matriz de contenido que se actualice de manera constante, para mantener el interés en los fans.

Figura $\mathrm{N}^{\circ} 1.40$

Matriz Artesanas

\section{MATRIZ ARTESANAS}

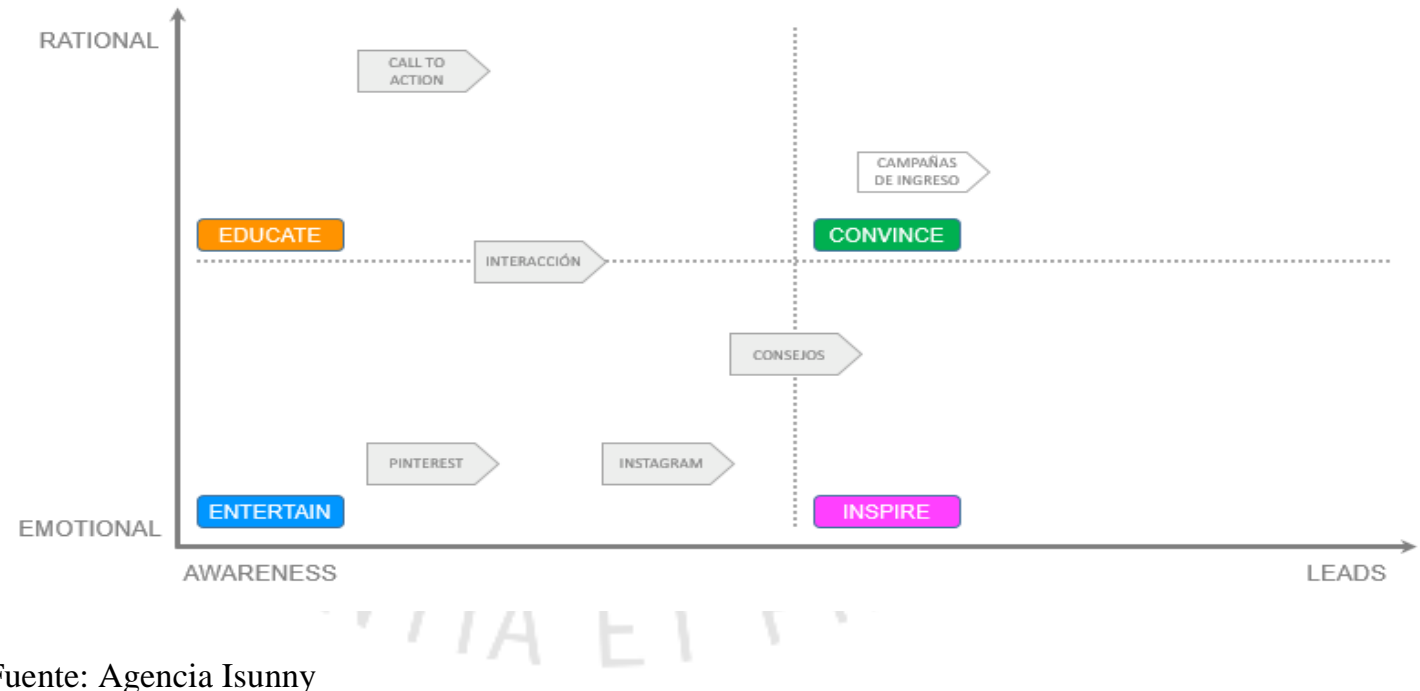


Figura $\mathrm{N}^{\circ} 1.41$

Matriz de contenido Artesanas

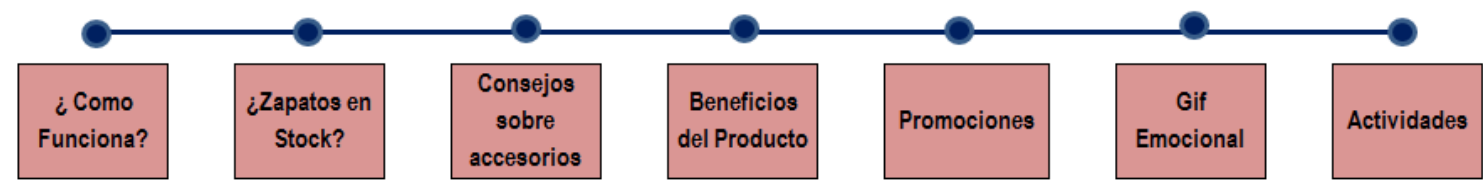

Elaboración: Propia

b. Instagram

Figura $\mathrm{N}^{\circ} 1.42$

Imagen Plataforma Instagram

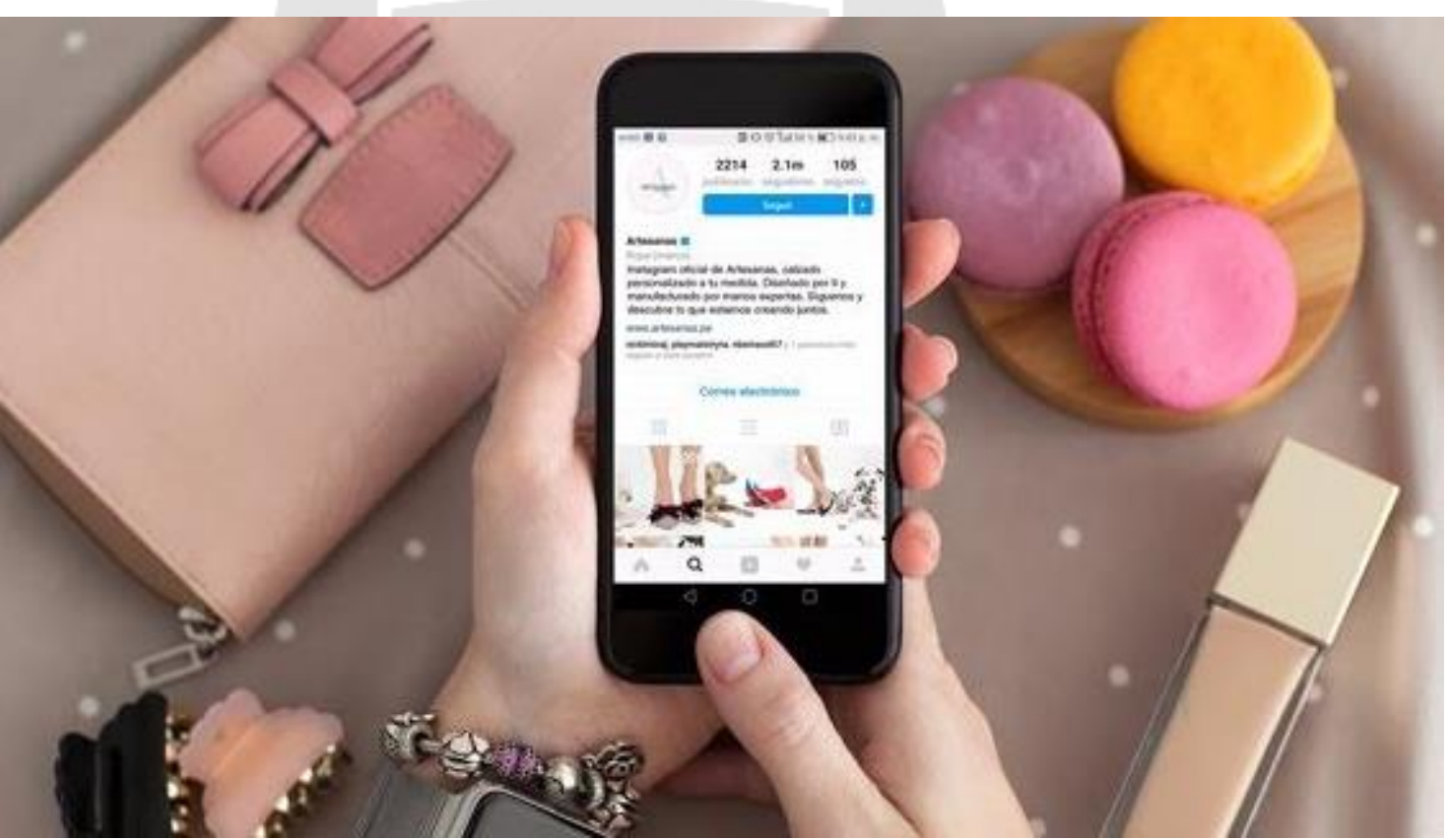

Elaboración: Propia 
Esta aplicación permite compartir fotos y vídeos de 15 segundos. Si tienes tu propia marca, debes estar en Instagram.

Esta red social es usada por más de 150 millones de personas y es la que más está creciendo, sobre todo captando público femenino y joven. Es ideal para promocionar los productos de tiendas online de moda, arte, decoración, viajes, belleza, etc. Se ha convertido en un referente de inspiración y de información.

Además, tanto otras personas como otras marcas podrán "seguir" tu cuenta y enterarse de todas tus actualizaciones para que puedan darle clic a "me gusta", comentar en ellas o darles retweet, lo que permite que tus contenidos sean virales.

\section{c. Pinterest}

\section{Figura $\mathrm{N}^{\circ} 1.43$}

Imagen Plataforma Pinterest

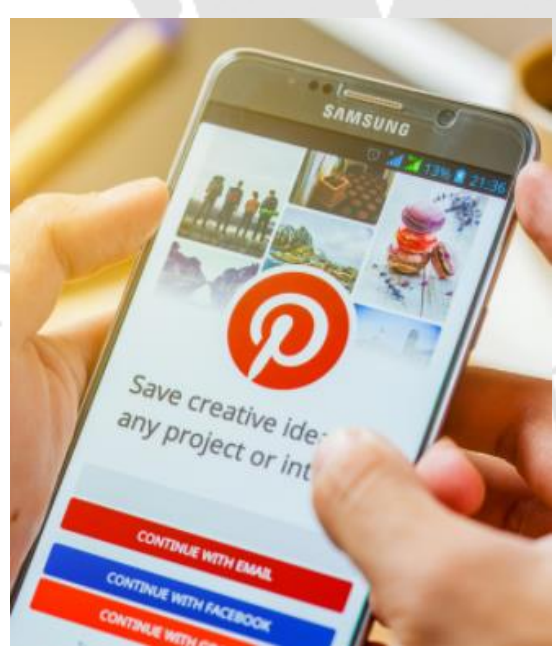

Fuente: Internet 
Esta red social actúa como un auténtico catálogo virtual, permitiendo a los usuarios colgar fotos, enlaces, etc., y organizarlos. Es una red muy visual, por lo que su punto fuerte son las fotos y los usuarios pueden hacer like, comentar y hasta compartirlas.

Es un portal recomendable para los negocios de venta online de servicios tan visibles como la moda o la decoración ya que sirve como una vitrina para mostrar los productos y lograr conversiones en las ecommerce. Esta red social está claramente dominada por las mujeres (83\%)

\section{d. Página Web}

Nuestra marca contará con una página web donde el diseño es atractivo y de fácil uso, donde la distribución de la información, las imágenes y contenido audiovisual ayudará a retener al usuario por más tiempo dentro de la web..

Para ello cada sección de nuestra página web, debe estar relacionada con las palabras clave que son los conceptos que definen el contenido y función de la misma. Una buena optimización de una página o un sitio le dará un mejor posicionamiento web en los buscadores (SEO). 
Figura $\mathrm{N}^{\circ} 1.44$

Imagen Web: Home

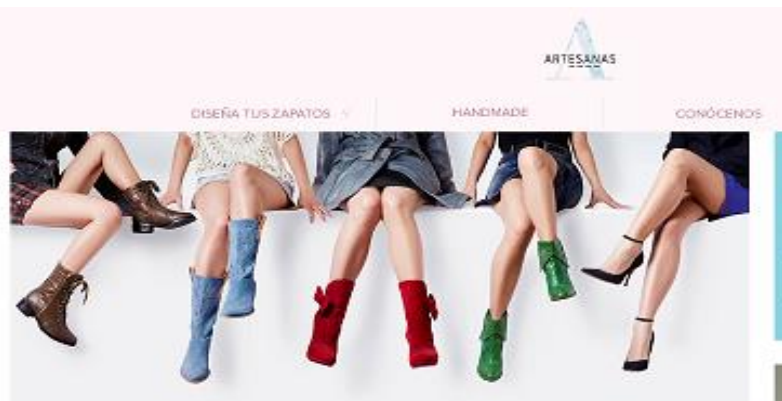

EL ZAPATO JUSTO PARA CADA OCASIÓN

EMPIEZA A OISENAR
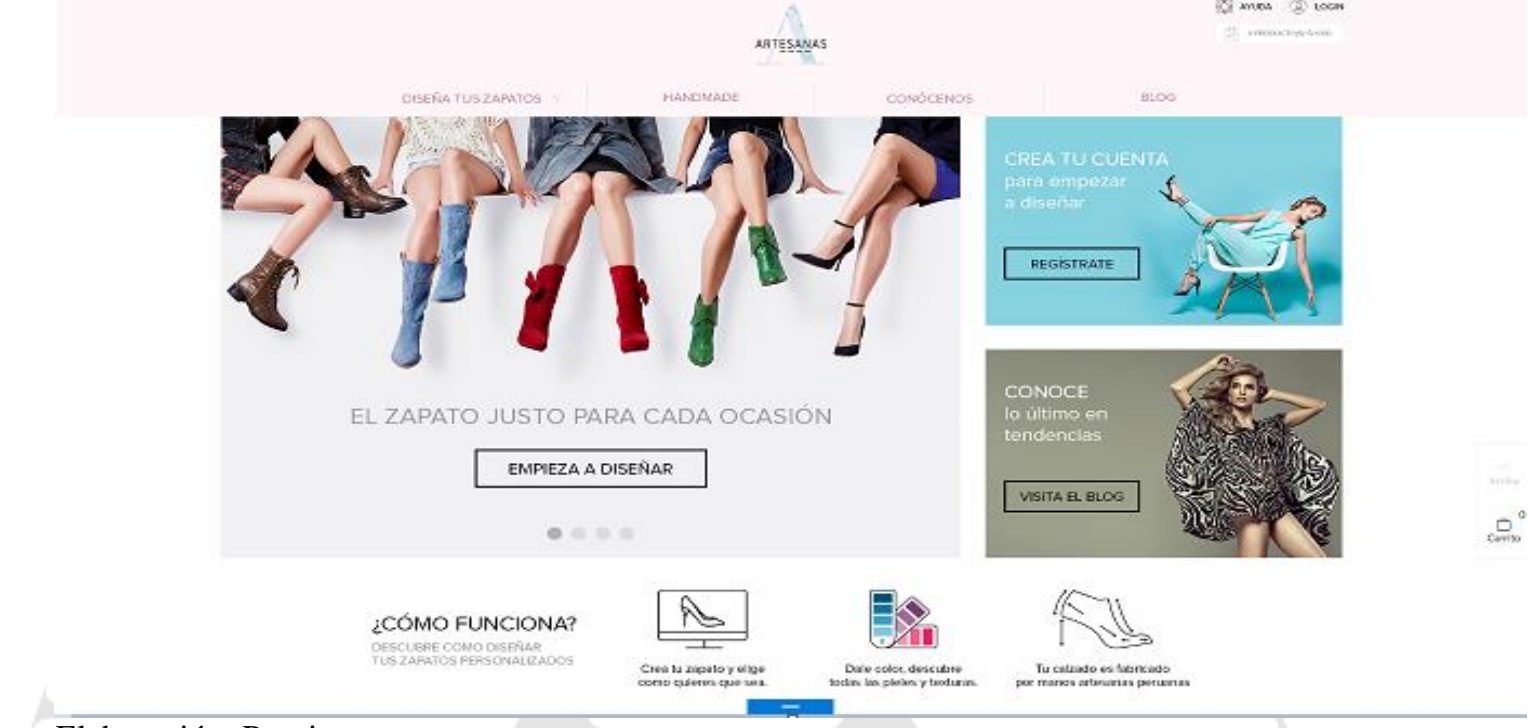

Elaboración: Propia

Figura $\mathrm{N}^{\circ} 1.45$

Web despliegue de menú de opciones
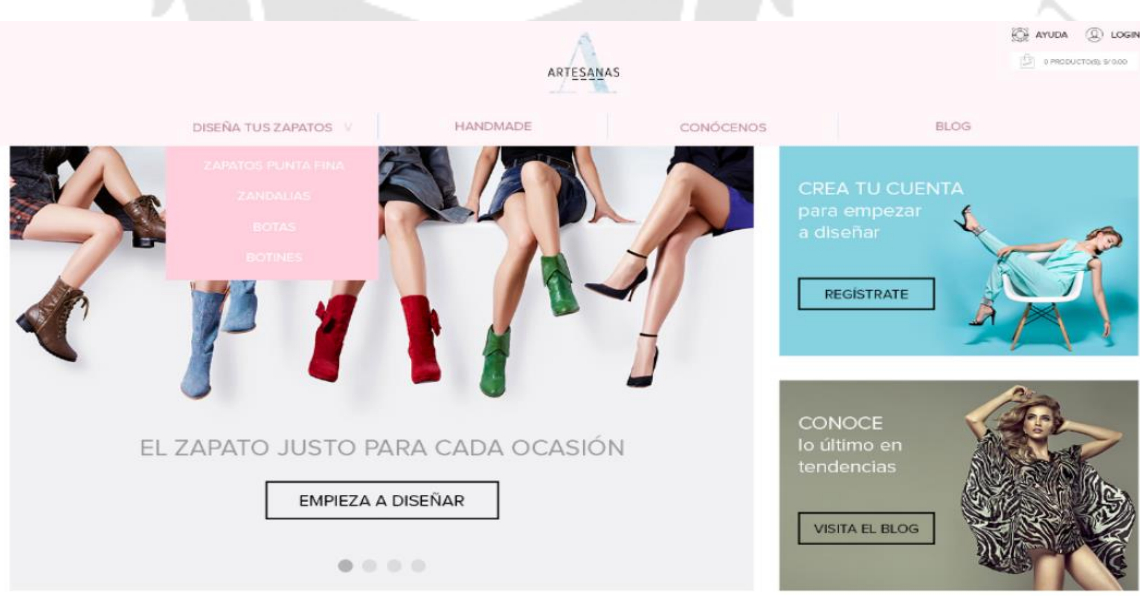

¿CÓMO FUNCIONA?
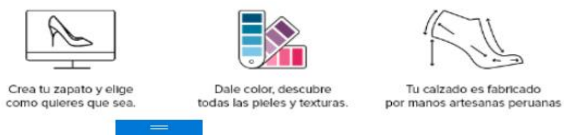

Elaboración: Propia 
Figura $\mathrm{N}^{\circ} 1.46$

Web: Sección inspírate

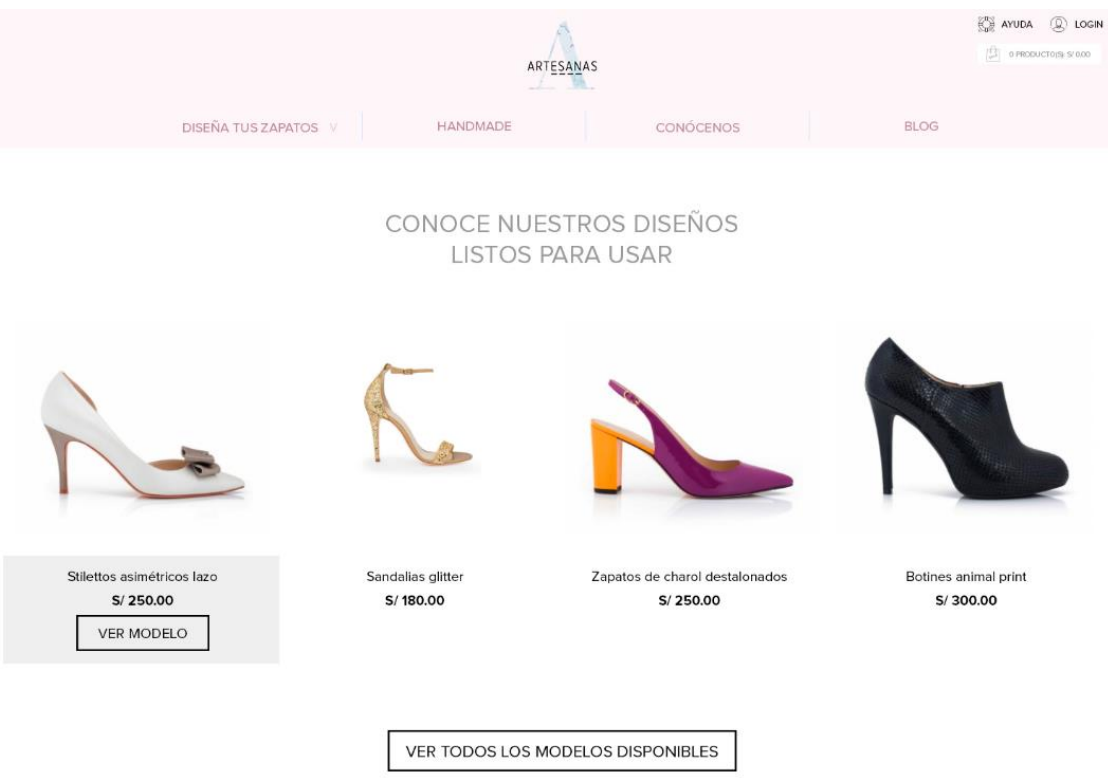

Elaboración: Propia

Figura $\mathrm{N}^{\circ} 1.47$

Imagen Web: Diseño de zapatos

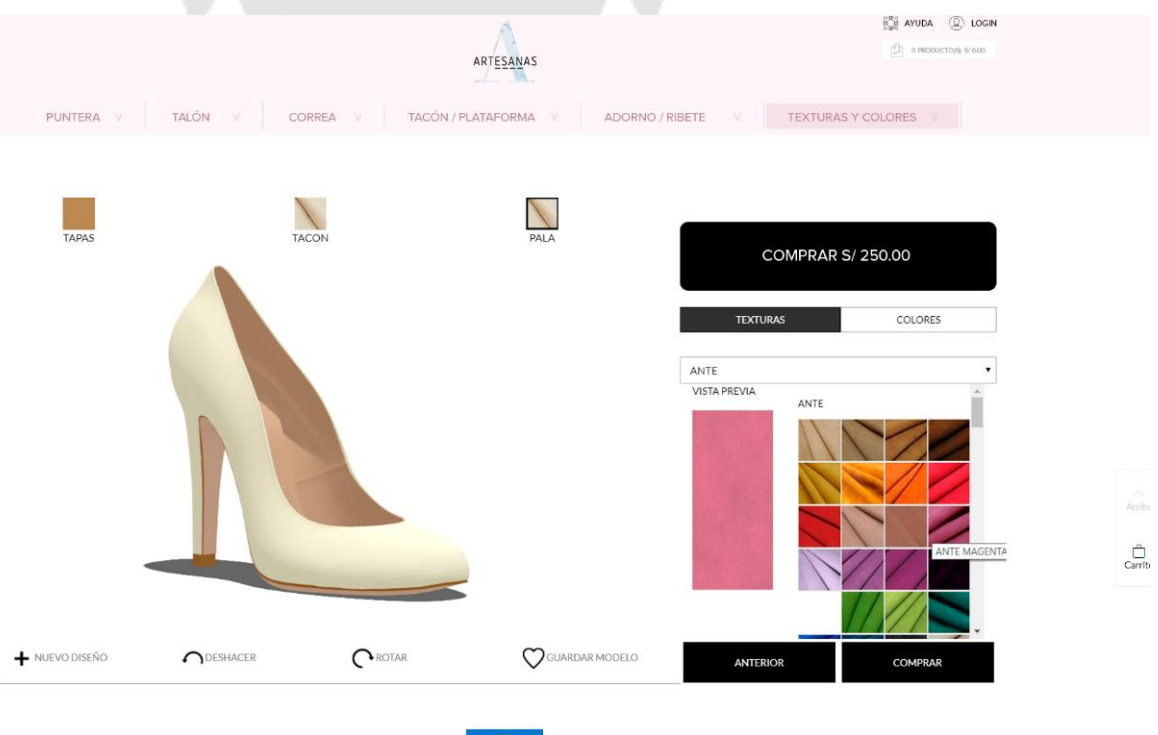

Elaboración: Propia 
Figura $\mathrm{N}^{\circ} 1.48$

Web: Selección de tipo de horma

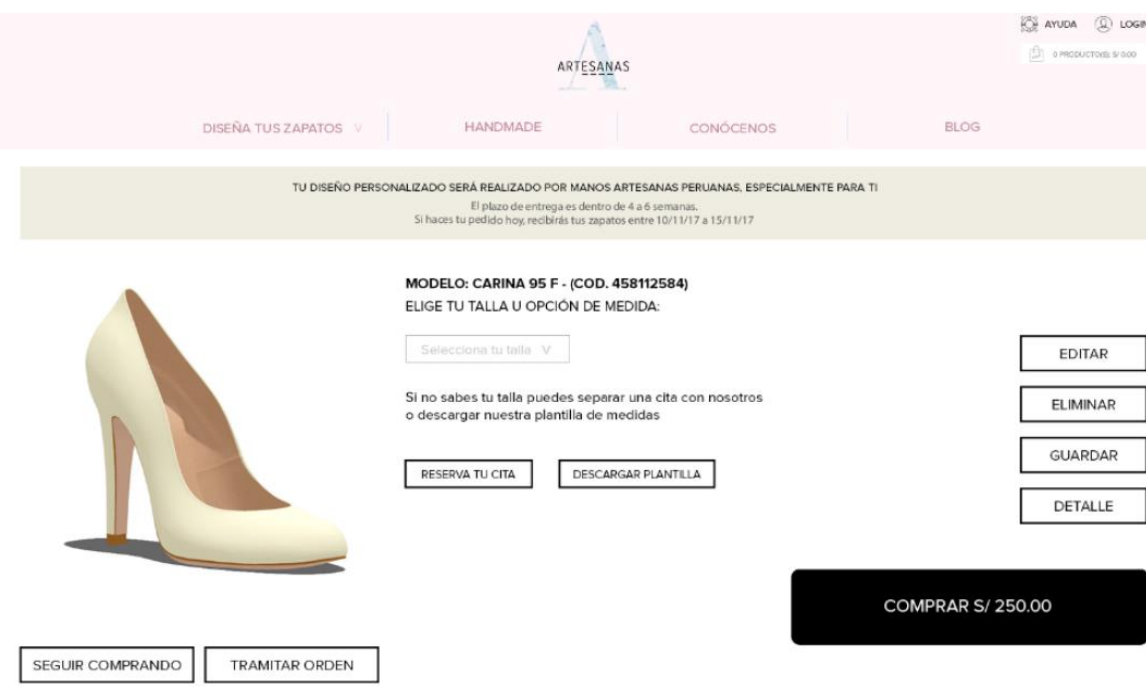

Elaboración: Propia

Figura $\mathrm{N}^{\circ} 1.49$

Imagen Web: Canasta de compra
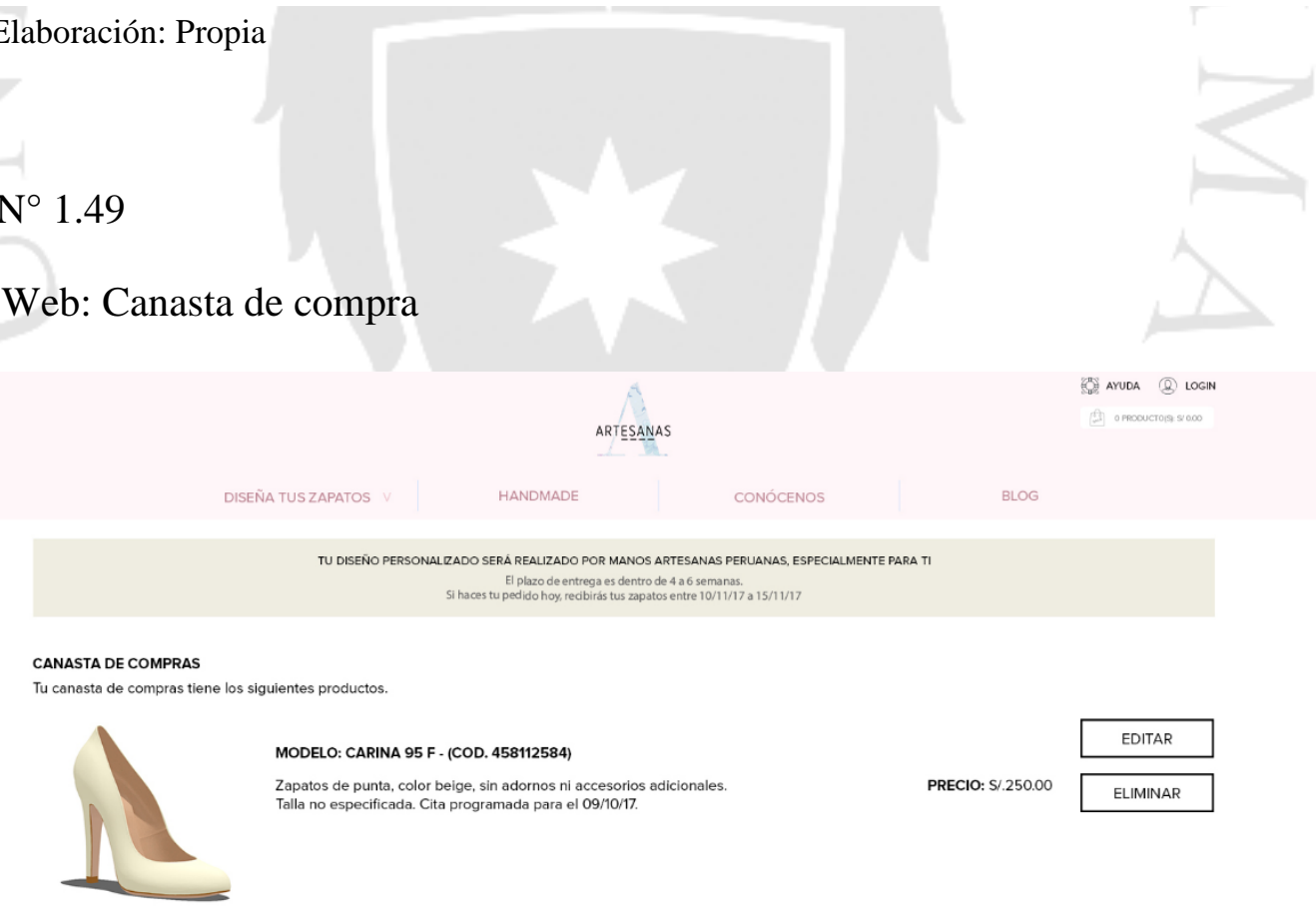

TOTAL: $\mathrm{S} / .250 .00$

Elaboración: Propia 
Figura $\mathrm{N}^{\circ} 1.50$

Imagen Web: Checkout

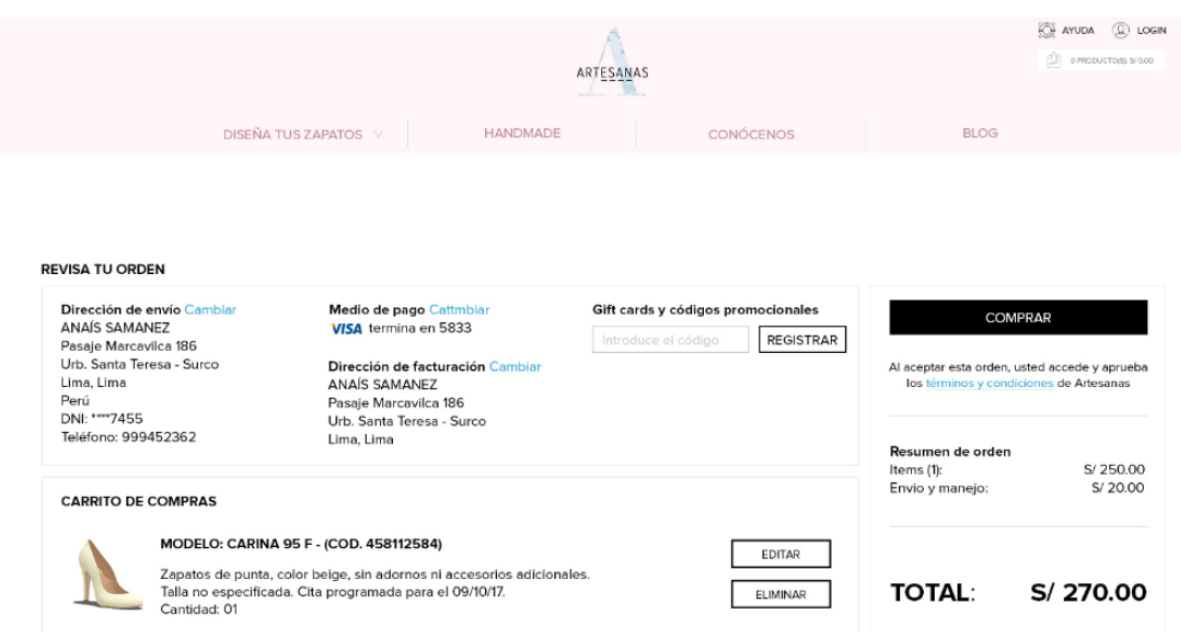

Elaboración: Propia

\section{e. Publicidad Digital}

Se está optando por una nueva herramienta de publicidad a través de paneles virtuales que se encuentran ubicados en los lugares estratégicos como universidades, restaurantes y clubes.

Las ventajas de esta nueva modalidad son:

1) Ahorrar tiempo y dinero, en comparación con un sistema de cartelería tradicional. Una sola programación puede desplegar cientos de contenidos en lugares distintos en un mismo momento. 
2) En tiempo real se podrá transmitir o actualizar tu contenido publicitario y /o informativo.

3) Genera experiencia de marca con el público objetivo a través de equipos digitales.

4) Permite mostrar contenidos dinámicos (gráficos, videos, feeds de noticias)

Figura $\mathrm{N}^{\circ} 1.51$

Panel Virtual en Restaurant

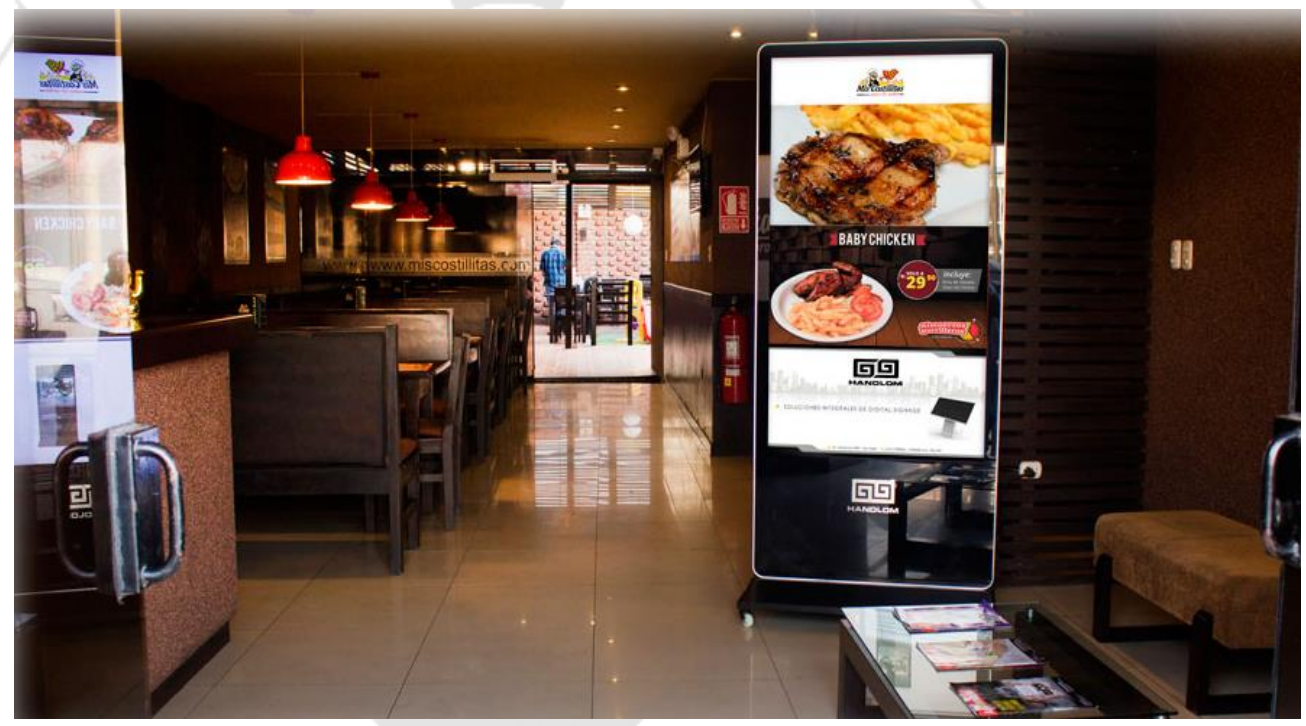

Fuente: Handlom 
Figura $\mathrm{N}^{\circ} 1.52$

Panel Virtual en Euroidiomas

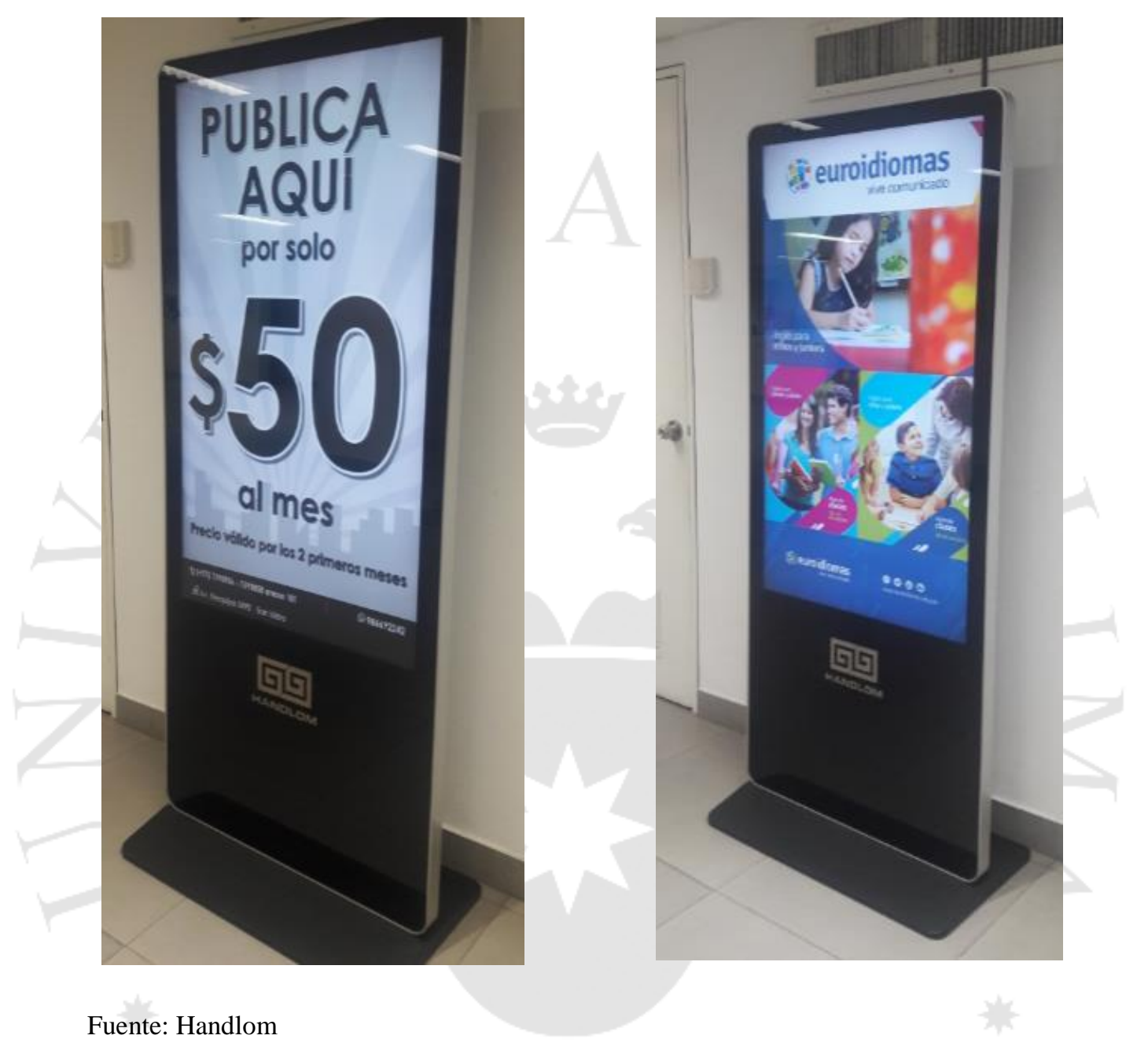

f. Revistas

Se está optando por una nueva propuesta a través de un magazine, donde SH A R E - Media que es el partner exclusivo de Peruvian Airlines para el desarrollo y comercialización de la revista Peruvian, distribuida exclusivamente en todos los aviones de la aerolínea. Actualmente Peruvian Airlines es la segunda aerolínea en el Perú y transporta a más de 120,000 pasajeros mensuales, nacionales y extranjeros. 
Siendo PERUVIAN el único contenido permitido en los vuelos de la aerolínea se convierte en una lectura obligatoria para todos los pasajeros.

La revista es consumida por más de 240,000 pasajeros durante su ciclo de vida y distribuida en todos los vuelos domésticos e internacionales de la aerolínea.

Se destaca por su alta lectoría, penetración y lectura obligatoria en cada vuelo doméstico.

Figura $\mathrm{N}^{\circ} 1.53$

Target de la revista Peruvian de Media

\section{PERÚ}

9 DESTINOS

NACIONALES

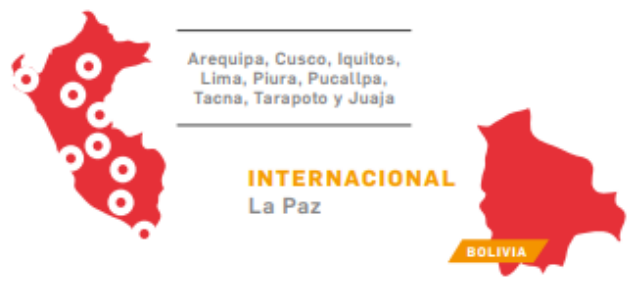

FLOTA: 14 CONTAMOS Boeing 737

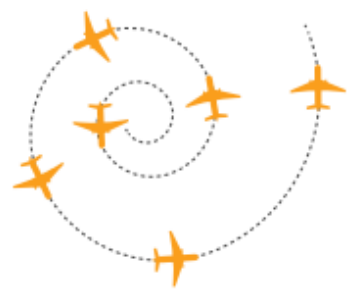

\section{DEMOGRAFÍA}

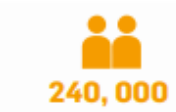

PASAJEROS POR EDICIÓN

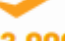

3,000

VUELOS POR EDICIÓN

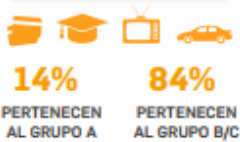

$\begin{array}{ll}\text { PERTENECEN } & \text { PERTENECEN } \\ \text { AL GRUPO A } & \text { AL GRUPO B/C }\end{array}$

ํํำ离

$20 \%$

SON VAAJEROS
DE NEGOCIOS

$40 \%$

SON EXTRANJEROS

-PERUMAN Airlines se encuentra en constante crecimiento y estas cifras podrian variar. - PERUMAN Airlines tiene previsto crecer con más destinos internacionales para el 2017.

Fuente: Revista Peruvian 


\section{- Plan de Medios y Presupuesto de Marketing}

Todas las herramientas que se manejarán para la publicidad del producto ofrecido se han colocado en un cronograma que permitirá tener una mejor visión de las estrategias publicitarías que se deben lleva a cabo.

Tabla $\mathrm{N}^{\circ} 1.21$

Plan de medios

\begin{tabular}{|l|l|l|l|l|l|l|l|l|l|l|l|l|l|}
\hline \multicolumn{1}{|c|}{ Medio } & \multicolumn{1}{|c|}{ Formato } & Ene & Feb & Mar & Abr & May & Jun & Jul & Ago & Sep & Oct & Nov & Dic \\
\hline Peruvian Magazine & Revista & & & & & & & & & & & & \\
\hline Audivisual- Escuela de Edición de Lima & Vídeo & & & & & & & & & & & & \\
\hline Handlom-Publicidad Digital & Digital Signage & & & & & & & & & & & & \\
\hline $\begin{array}{l}\text { Redes Sociales (Facebbok-Instagram- } \\
\text { Pinterest) }\end{array}$ & Internet & & & & & & & & & & & & \\
\hline Google & Display & Banners Digitales & & & & & & & & & & & \\
\hline OLX & Relaciones Públicas & & & & & & & & & & & & \\
\hline Influencers-Bloggers & & & & & & & \\
\hline
\end{tabular}

Elaboración: Propia

Tabla $\mathrm{N}^{\circ} 1.22$

Presupuesto de marketing

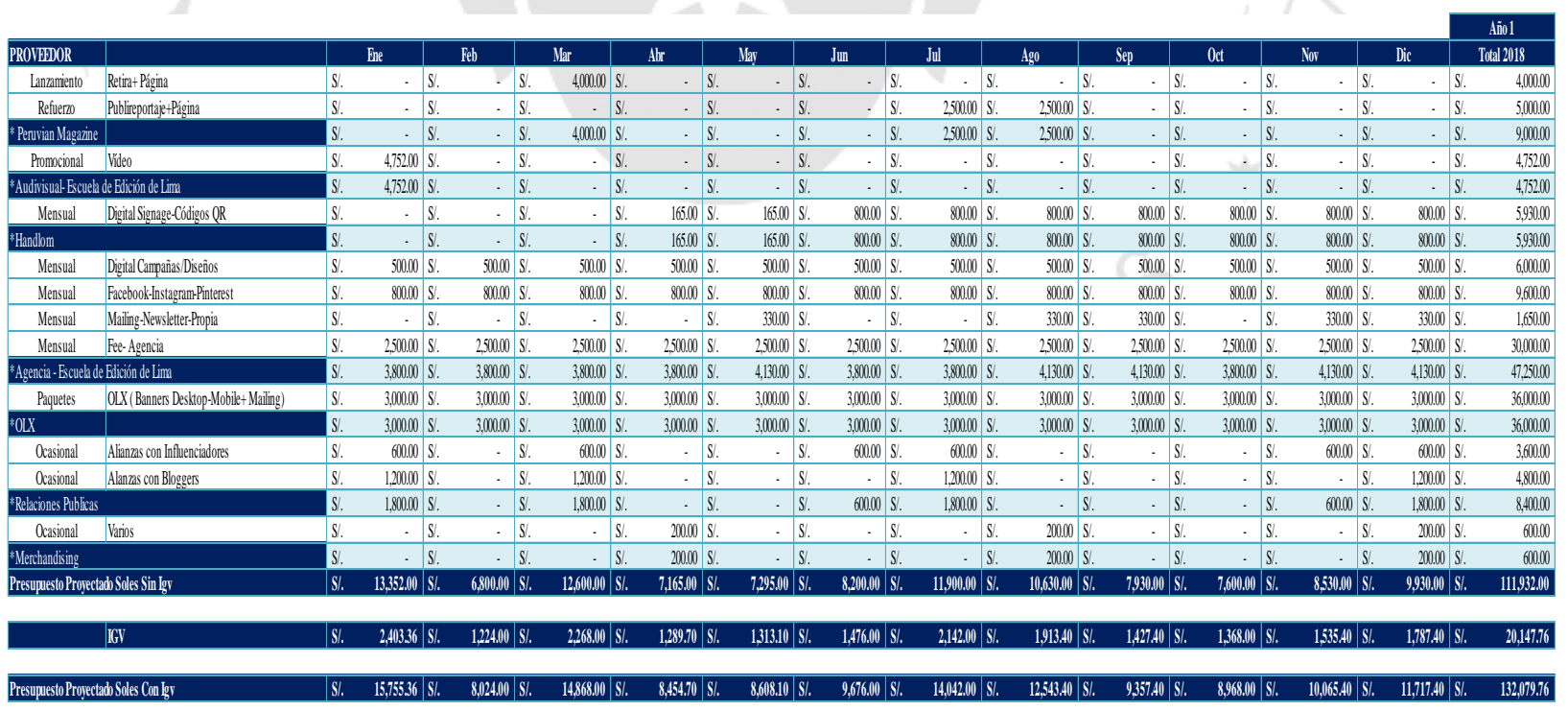

Elaboración: Propia 


\section{- Promoción de Ventas}

Dado que el negocio del calzado personalizado se encuentra en crecimiento y existe bastante competencia, es necesario mantener promociones constantes que nos ayuden a obtener, fidelizar y aumentar clientes.

Objetivos de la promoción:

1) Incrementar el tráfico y el flujo en el negocio.

2) Fomentar la participación en las promociones al consumidor.

3) Incrementar el número y el tamaño de los pedidos.

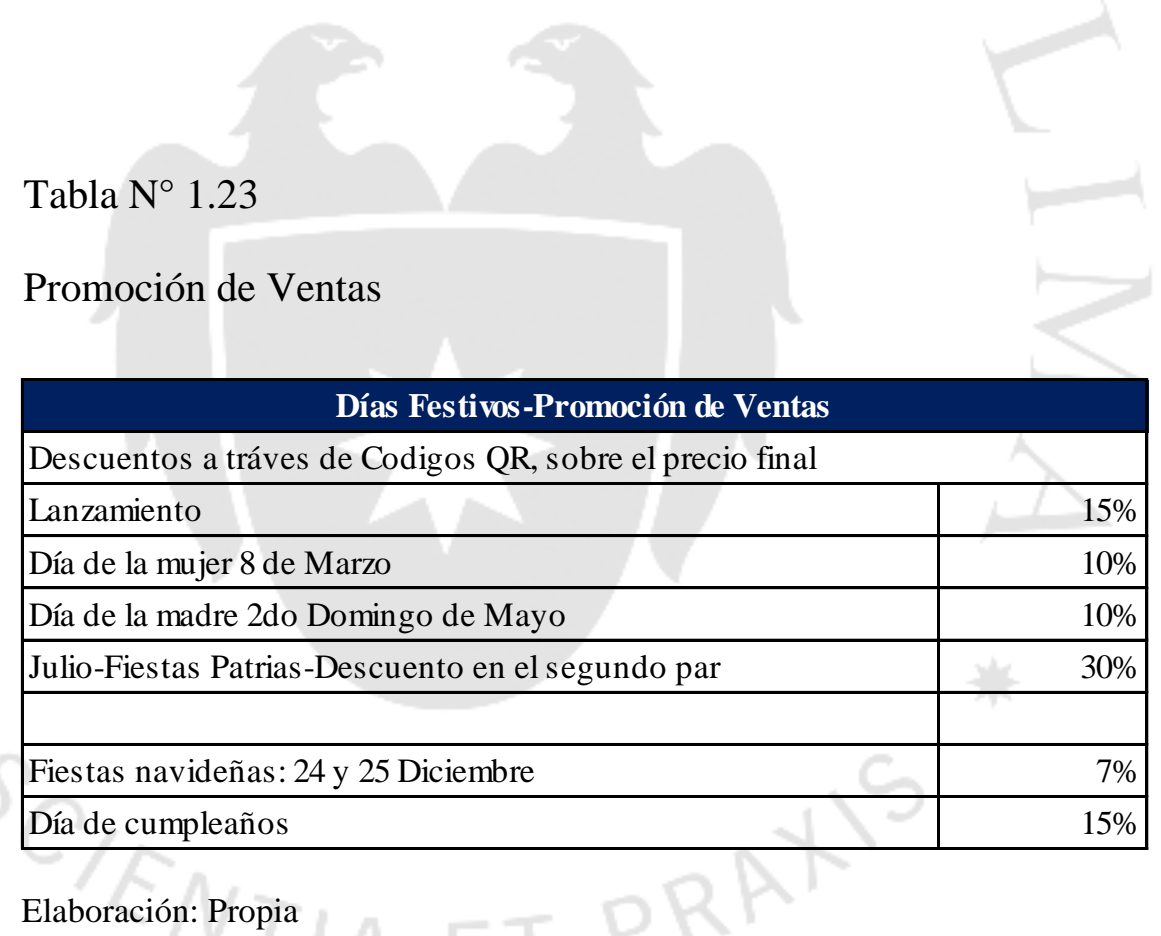

\subsubsection{Análisis de precios}

El enfoque que utilizaremos para la fijación de precios será en base al valor, debido a que nuestro producto será el único en el mercado nacional, lo que permitirá establecer un precio meta basado en el valor percibido por el cliente. 
El valor agregado que daremos a nuestros clientes, será ofrecer un calzado de diseño realizado por el cliente y a su medida. Sin dejar de lado ofrecer una alta calidad de materiales y acabado de primera.

Por todo lo mencionado anteriormente concluimos que nuestros clientes estarán dispuestos a pagar un precio alto, debido a que el valor percibido del producto por ellos será superior al precio.

Por último, es importante mencionar, que nuestra política de precios tendrá que tener en cuenta otros factores importes que podrían afectar el precio final de nuestro producto, por ejemplo:

a. Factores económicos.

b. Aumento o disminución del poder adquisitivo.

c. Disponibilidad de insumos.

d. Tendencias de mercado.

e. Entrada de nuevos competidores.

\subsubsection{Tendencia histórica de los precios}

De acuerdo con IEES - SIN, La evolución de los precios al consumidor de calzado en Lima Metropolitana entre el 2011 y el 2016, muestra un crecimiento relativamente constante alrededor de $2 \%$, con lo cual acumula un incremento de precios de $8,9 \%$ en los últimos cuatro años. 
Figura $\mathrm{N}^{\circ} 1.54$

Precios al consumidor de Calzado en Lima Metropolitana

Gráfico $\mathbf{N}^{\circ}$ 6: Precios al Consumidor de Calzado en Lima Metropolitana

(Variación Porcentual)

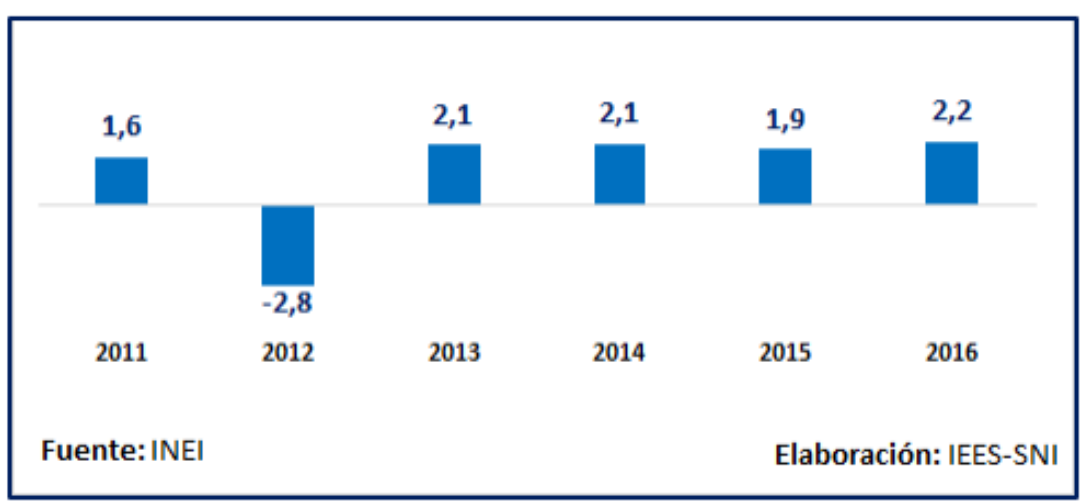

Fuente: Ipsos Perú: Mapinse 2017-INEI: Cartografía Oficial 2007

\subsubsection{Precios actuales internacionales y locales}

A continuación, comparamos los precios de nuestra competencia directa e indirecta para obtener un promedio estimado de cada estilo de calzado.

Tabla $\mathrm{N}^{\circ} 1.24$

Análisis de precios

\begin{tabular}{|c|c|c|c|c|c|c|c|c|c|c|c|c|c|c|c|c|}
\hline \multirow{3}{*}{$\begin{array}{l}\text { Tipo de competencia } \\
\text { Estilo / Tienda } \\
\text { Bota de cuero } \\
\end{array}$} & \multicolumn{4}{|c|}{ Competencia Indirecta } & \multicolumn{6}{|c|}{ Competencia Directa Nacional } & \multicolumn{4}{|c|}{$\begin{array}{c}\text { Competencia Directa } \\
\text { Internacional }\end{array}$} & \multirow{2}{*}{\multicolumn{2}{|c|}{$\begin{array}{l}\text { Precios } \\
\text { Promedio }\end{array}$}} \\
\hline & \multicolumn{2}{|c|}{$\begin{array}{l}\text { Tienda } \\
\text { minorista }\end{array}$} & \multicolumn{2}{|c|}{$\begin{array}{c}\text { Tienda por } \\
\text { departamento }\end{array}$} & \multicolumn{2}{|c|}{ Lalalove } & \multicolumn{2}{|c|}{$\begin{array}{l}\text { Butrich Mua } \\
\text { by Canchita }\end{array}$} & \multicolumn{2}{|c|}{$\begin{array}{l}\text { Lola by } \\
\text { Melissa del } \\
\text { Solar }\end{array}$} & \multicolumn{2}{|c|}{ Made in me } & \multicolumn{2}{|c|}{$\begin{array}{l}\text { Costum and } \\
\text { Chic }\end{array}$} & & \\
\hline & $\mathrm{S} /$. & 331 & S/. & 600 & $\mathrm{~S} /$. & 680 & S/. & 1,069 & $\mathrm{~S} /$. & 936 & $\mathrm{~S} /$. & 1,719 & $\mathrm{~S} /$. & 936 & $\mathrm{~S} /$. & 896 \\
\hline Botin de cuero & $\mathrm{S} /$. & 190 & S/. & 400 & S/. & 570 & S/. & 764 & $\mathrm{~S} /$. & 720 & $\mathrm{~S} /$. & 1,323 & $\mathrm{~S} /$. & 720 & $\mathrm{~S} /$. & 670 \\
\hline Sandalia de cuero & S/. & 112 & S/. & 230 & $\mathrm{~S} /$. & 480 & S/. & 601 & S/. & 490 & $\mathrm{~S} /$. & 1,206 & $\mathrm{~S} /$. & 696 & $\mathrm{~S} /$. & 545 \\
\hline Vestir de Cuero & S/. & 171 & S/. & 220 & S/. & 480 & S/. & 601 & S/. & 520 & $\mathrm{~S} /$. & 1,128 & $\mathrm{~S} /$. & 696 & $\mathrm{~S} /$. & 545 \\
\hline
\end{tabular}

Elaboración: Propia 


\subsubsection{Programa de ventas}

Tabla $\mathrm{N}^{\circ} 1.25$

Programa de Ventas 2018

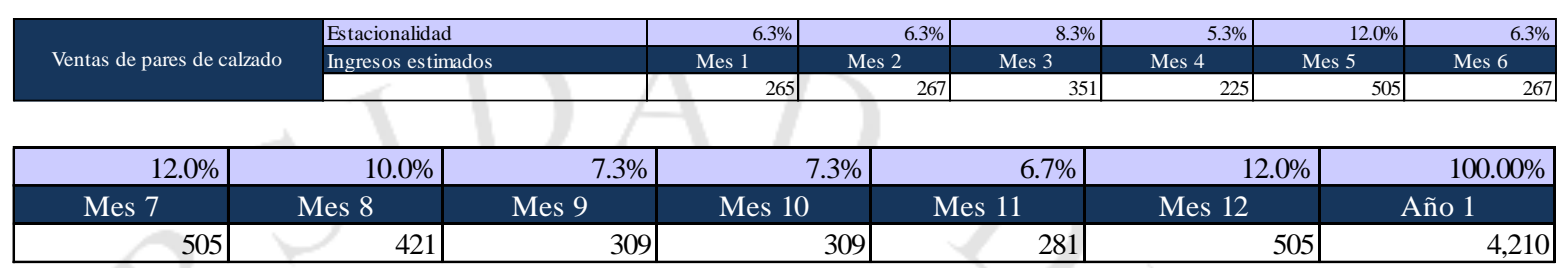

\begin{tabular}{|c|c|c|c|c|c|c|c|c|c|c|c|c|}
\hline Estilo & Ene & Feb & Mar & Abr & May & Jun & Jul & Ago & Set & Oct & Nov & Dic \\
\hline Bota de Cuero & $0 \%$ & $0 \%$ & $0 \%$ & $0 \%$ & $2 \%$ & $15 \%$ & $13 \%$ & $6 \%$ & $6 \%$ & $4 \%$ & $0 \%$ & $0 \%$ \\
\hline Botín de Cuero & $0 \%$ & $1 \%$ & $7 \%$ & $34 \%$ & $74 \%$ & $71 \%$ & $74 \%$ & $76 \%$ & $74 \%$ & $60 \%$ & $21 \%$ & $0 \%$ \\
\hline \begin{tabular}{|l|} 
Sandalia de Cuero \\
\end{tabular} & $67 \%$ & $61 \%$ & $40 \%$ & $23 \%$ & $5 \%$ & $3 \%$ & $2 \%$ & $4 \%$ & $2 \%$ & $0 \%$ & $65 \%$ & $77 \%$ \\
\hline \begin{tabular}{|l|} 
Vestir Cuero \\
\end{tabular} & $33 \%$ & $38 \%$ & $53 \%$ & $44 \%$ & $18 \%$ & $12 \%$ & $10 \%$ & $14 \%$ & $18 \%$ & $36 \%$ & $14 \%$ & $23 \%$ \\
\hline Total & $100 \%$ & $100 \%$ & $100 \%$ & $100 \%$ & $100 \%$ & $100 \%$ & $100 \%$ & $100 \%$ & $100 \%$ & $100 \%$ & $100 \%$ & $100 \%$ \\
\hline
\end{tabular}

\begin{tabular}{|c|c|c|c|c|c|c|c|c|c|c|c|c|}
\hline Estilo & Ene & Feb & Mar & Abr & May & Jun & Jul & Ago & Set & Oct & Nov & Dic \\
\hline Bota de Cuero & & - & - & - & 11 & 39 & 68 & 24 & 19 & 12 & & - \\
\hline Botín de Cuero & - & 3 & 26 & 76 & 375 & 188 & 373 & 321 & 229 & 185 & 59 & - \\
\hline Sandalia de Cuero & 178 & 163 & 140 & 51 & 25 & 8 & 12 & 17 & 6 & - & 183 & 387 \\
\hline Vestir Cuero & 87 & 101 & 185 & 98 & 93 & 32 & 52 & 59 & 56 & 111 & 39 & 118 \\
\hline Total & 265 & 267 & 351 & 225 & 505 & 267 & 505 & 421 & 309 & 309 & 281 & 505 \\
\hline
\end{tabular}

Elaboración: Propia

\subsection{Producción y logística}

\subsubsection{Localización del proyecto}

Con fines de obtener con eficacia productos de alta calidad y lograr una logística eficiente, es necesario analizar la ubicación mediante el método Ranking de Factores para conseguir la mejor locación para el proyecto.

Se analiza a continuación los factores más importantes para el análisis. 


\section{- Costo del Inmueble}

En primera instancia se ha optado por tomar un local en alquiler. El costo de este debe ser moderado considerando que el primer mes de instalación y segundo de inicio de operaciones será un periodo de utilidad nula.

\section{- Suministro de materia prima}

El mercado principal de insumos de materia prima para el calzado es Caquetá ubicado en el Cercado de Lima. También existe un mercado de insumos pequeño en Ciudad de Dios, San Juan de Miraflores.

Adicional a estos dos puntos, uno de los principales proveedores de cuero y badana se ubica en las inmediaciones del puente Atocongo en San Juan de Miraflores. Para elegir la ubicación más idónea, debe tomarse en cuenta estos tres lugares.

\section{- Disponibilidad de la mano de obra}

El taller debe tener cercanía a la residencia de los artesanos que producen calzado de obra fina. Esto significa, armadores y aparadores que produzcan calzado de acabado fino.

\section{- Accesibilidad de la zona}

En los últimos años la ciudad de Lima se ha vuelto caótica por sus altos niveles de tráfico. Es por esto que uno de los factores más importantes es que el local esté en trayecto de vías o carreteras donde el flujo es fluido a diferencia de avenidas y calles. 
El local también debe encontrarse cerca al transporte público, como el tren eléctrico y metropolitano, que son servicios que acortan tiempos de viajes de larga distancia ya que se desplazan por vías exclusivas.

\section{- Seguridad de la zona}

Es importante que la planta se ubique en una zona saneada, que cuente con hidrantes contra incendio, que sea iluminada y limpia. La infraestructura del local debe ser antisísmica y contar con los servicios básicos. Todo esto para proteger las inversiones del proyecto.

\section{- Costos de servicios, agua, electricidad}

Las tarifas de servicios que corresponden a zonas industriales tienden a ser mucho más económicas, ya que, permiten mayor gasto de energía a menos precio a diferencia de zonas urbanizadas.

\section{- Cercanía a nuestro mercado}

Una vez obtenido el producto terminado, este debe ser enviado por delivery vía Olva. Por lo tanto, debe considerase que las oficinas de este servicio deben encontrarse cerca o una distancia próxima del taller.

\section{- Tamaño del Terreno}

El área debe ser no menor a $120 \mathrm{~m} 2$ para poder contar con una adecuada distribución de la planta, almacen de materia prima y de productos terminados. 
Tabla $\mathrm{N}^{\circ} 1.26$

Análisis de Ranking de Factores

\begin{tabular}{|c|l|}
\hline Factor & \multicolumn{1}{|c|}{ Descripción } \\
\hline $\mathbf{a}$ & Costo del inmueble \\
\hline b & Suministro de materia prima \\
\hline c & Disponibilidad de mano de obra \\
\hline $\mathbf{d}$ & Accesibilidad de la zona \\
\hline $\mathbf{e}$ & Seguridad de la zona \\
\hline $\mathbf{f}$ & Costos del servicio de agua y electricidad \\
\hline $\mathbf{g}$ & Cercanía a nuestro mercado \\
\hline h & Tamaño de terreno \\
\hline
\end{tabular}

Elaboración: Propia

\begin{tabular}{|r|r|l|l|l|l|l|r|r|r|r|}
\hline & $\mathbf{a}$ & $\mathbf{b}$ & $\mathbf{c}$ & $\mathbf{d}$ & $\mathbf{e}$ & $\mathbf{f}$ & $\mathbf{g}$ & \multicolumn{1}{l|}{ h } & \multicolumn{1}{l|}{ Puntaje } & \multicolumn{1}{l|}{ Valorización } \\
\hline $\mathbf{a}$ & $\mathbf{x}$ & 0 & 0 & 0 & 0 & 0 & 1 & 0 & 1 & $4 \%$ \\
\hline $\mathbf{b}$ & 1 & $\mathbf{x}$ & 0 & 1 & 1 & 1 & 1 & 0 & 5 & $18 \%$ \\
\hline $\mathbf{c}$ & 1 & 1 & $\mathbf{x}$ & 1 & 1 & 1 & 1 & 1 & 7 & $25 \%$ \\
\hline $\mathbf{d}$ & 1 & 0 & 0 & $\mathbf{x}$ & 1 & 1 & 1 & 0 & 4 & $14 \%$ \\
\hline $\mathbf{e}$ & 1 & 0 & 0 & 0 & $\mathbf{x}$ & 0 & 0 & 1 & 2 & $7 \%$ \\
\hline $\mathbf{f}$ & 1 & 0 & 0 & 0 & 1 & $\mathbf{x}$ & 1 & 1 & 4 & $14 \%$ \\
\hline $\mathbf{g}$ & 0 & 0 & 0 & 0 & 1 & 0 & $\mathbf{x}$ & 0 & 1 & $4 \%$ \\
\hline $\mathbf{h}$ & 1 & 1 & 0 & 1 & 0 & 0 & 1 & $\mathbf{x}$ & 4 & $14 \%$ \\
\hline
\end{tabular}

Elaboración: Propia

\begin{tabular}{|l|r|}
\hline \multicolumn{1}{|c|}{ Concepto } & \multicolumn{2}{c|}{ Calificación } \\
\hline Muy bueno & 80 \\
\hline Bueno & 60 \\
\hline Regular & 40 \\
\hline Malo & 20 \\
\hline
\end{tabular}

Elaboración: Propia 


\begin{tabular}{|c|c|c|c|c|c|c|c|}
\hline \multicolumn{8}{|c|}{ Calificación De Alternativas } \\
\hline \multirow{2}{*}{ Factor } & \multirow{2}{*}{ Valoración } & \multicolumn{2}{|c|}{ Villa el Salvador } & \multicolumn{2}{|c|}{ Los Olivos } & \multicolumn{2}{|c|}{ San Juan de Miraflores } \\
\hline & & $\mathbf{C}$ & $\mathbf{P}$ & C & $\mathbf{P}$ & C & $\mathbf{P}$ \\
\hline c & $25 \%$ & 80 & 20.00 & 40 & 10.00 & 80 & 20.00 \\
\hline b & $18 \%$ & 60 & 10.71 & 40 & 7.14 & 80 & 14.29 \\
\hline d & $14 \%$ & 80 & 11.43 & 60 & 8.57 & 20 & 2.86 \\
\hline e & $7 \%$ & 60 & 4.29 & 40 & 2.86 & 20 & 1.43 \\
\hline h & $14 \%$ & 80 & 11.43 & 60 & 8.57 & 60 & 8.57 \\
\hline $\mathbf{f}$ & $14 \%$ & 80 & 11.43 & 40 & 5.71 & 40 & 5.71 \\
\hline $\mathrm{g}$ & $4 \%$ & 60 & 2.14 & 20 & $\overline{0.71}$ & 60 & 2.14 \\
\hline \multirow[t]{2}{*}{$\mathbf{a}$} & $4 \%$ & 80 & 2.86 & 60 & 2.14 & 80 & 2.86 \\
\hline & $100 \%$ & & 74.29 & & 45.71 & & 57.86 \\
\hline
\end{tabular}

Elaboración: Propia

En conclusión, se ve por conveniente ubicar el taller de producción en la zona industrial de Villa el Salvador.

\subsubsection{El producto}

El proyecto tiene como objetivo abarcar inicialmente 4 líneas de productos, dos por cada temporada:

- Verano: Sandalias casuales y Calzado de vestir de taco.

- Invierno: Botas, Botines y Calzado de vestir de taco.

Para fines del proyecto, se someterá a estudio el botín de cuero, ya que este representa la media en cuanto a costos y tiempos de fabricación entre las líneas mencionadas como puede demostrarse en la Tabla $\mathrm{N}^{\circ} 1.27$. 
Tabla $\mathrm{N}^{\circ} 1.27$

Comparación de indicadores de producción por estilos de calzado

\begin{tabular}{|l|l|r|r|r|r|}
\hline \multicolumn{2}{|c|}{ Características } & \multicolumn{1}{c|}{$\begin{array}{c}\text { Bota de } \\
\text { Cuero }\end{array}$} & $\begin{array}{c}\text { Botin de } \\
\text { Cuero }\end{array}$ & $\begin{array}{l}\text { Sandalia de } \\
\text { Cuero }\end{array}$ & \multicolumn{1}{c|}{$\begin{array}{c}\text { Vestir de } \\
\text { cuero }\end{array}$} \\
\hline MP utilizado & Pies de cuero & 5.25 & 2.5 & 1.25 & 1.5 \\
\hline \multirow{3}{*}{$\begin{array}{l}\text { Producción } \\
\text { de docenas } \\
\text { por día }\end{array}$} & Corte & 2 & 3 & 4 & 4 \\
\cline { 2 - 6 } & Aparado & 1 & 1.3 & 1.5 & 1.5 \\
\cline { 2 - 6 } & Armado & 1 & 0.73 & 1.5 & 1.25 \\
\cline { 2 - 6 } & Acabado & 2 & 2 & 2 & 2 \\
\hline
\end{tabular}

Elaboración: Propia

A continuación, se describe el modelo de botín de cuero seleccionado.

\section{Figura $N^{\circ} 1.55$}

Botín de cuero código BTN101

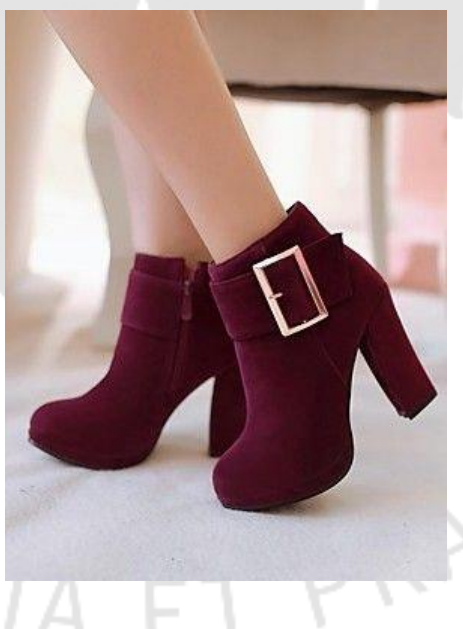

Fuente: Internet 
Tabla $\mathrm{N}^{\circ} 1.28$

Descripción del modelo en piezas de cuero

\begin{tabular}{|c|c|c|l|}
\hline \multicolumn{5}{|c|}{ Código BTN101 } \\
\hline Concepto & U.M & Cantidad & \multicolumn{1}{c|}{ Descripción } \\
\hline Piezas de cuero & Unitario & 4 & $\begin{array}{l}\text { Capellada, talon, taco y } \\
\text { correa. Cuero gamuza. }\end{array}$ \\
\hline Piezas de badana & Unitario & 4 & $\begin{array}{l}\text { Capellada, talonera y cuello } \\
\text { tapa de cierre. Badana } \\
\text { natural }\end{array}$ \\
\hline
\end{tabular}

Elaboración: Propia

\subsubsection{Insumos}

Las materias primas que se utilizan durante el proceso de producción son:

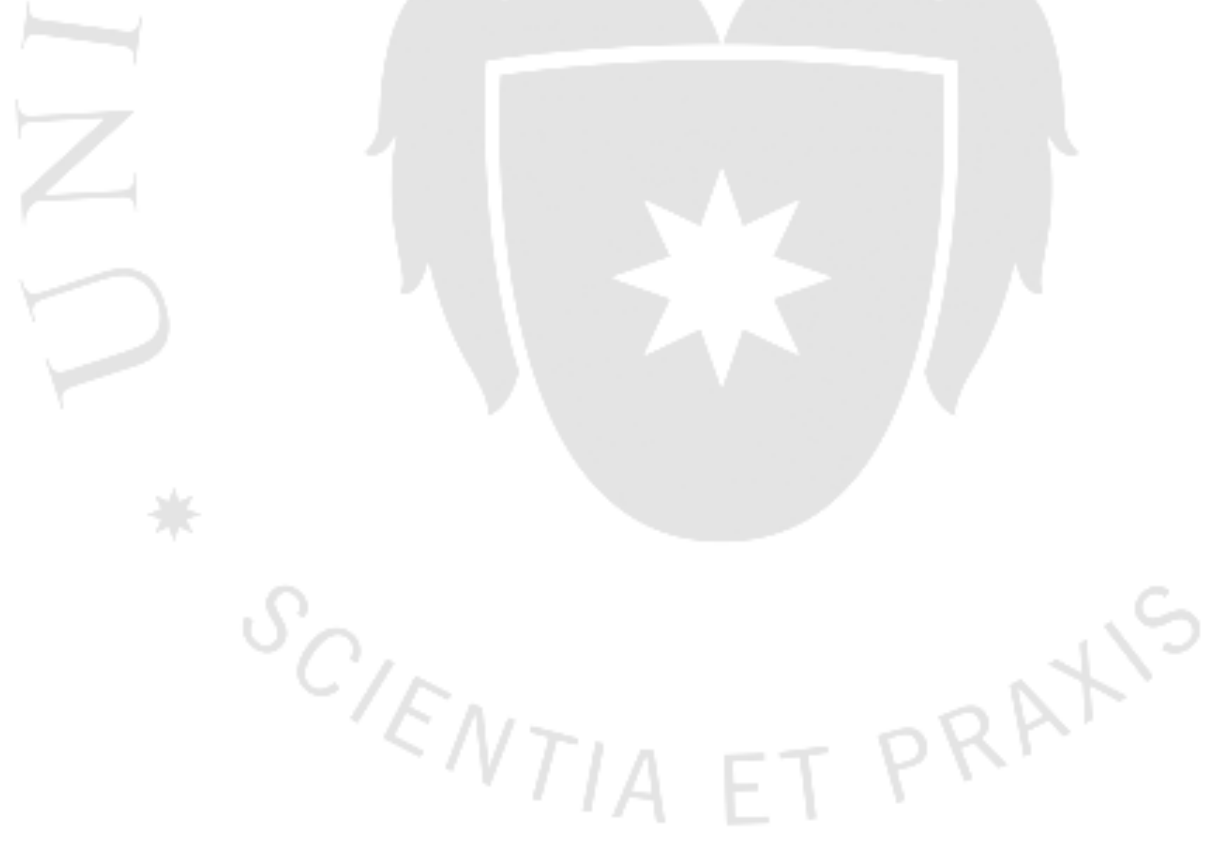


Tabla $\mathrm{N}^{\circ} 1.29$

\section{Materia Prima Total}

\begin{tabular}{|c|c|c|}
\hline \multicolumn{3}{|c|}{ Código BTN101 } \\
\hline Concepto & U.M & Descripción \\
\hline Cuero & Pies & Cuero cabretilla color vino \\
\hline Badana & Pies & Badana color natural \\
\hline Taco & Par & Taco cuadrado $\mathrm{n}^{\circ} 12$ \\
\hline Plataforma & Par & Plataforma $n^{\circ} 22$ \\
\hline Hebilla & Unitario & Color dorado \\
\hline Cierre & Metros & Cierre con atracadera color vino \\
\hline Carrito & Par & Carrito de cierre color vino \\
\hline Huella & Par & Color negro \\
\hline Terokal 1 & Galon & Marca Record \\
\hline Terokal 2 & Galon & Marca Infrapeg \\
\hline Cemento & Galon & Marca Record \\
\hline Latex & Plancha & Descanso de plantilla \\
\hline Falsa & Par & Falsa de invierno \\
\hline Tela Tocuyo & Metros & Tela de refuerzo \\
\hline Contrafuerte & Metros & Contrafuerte \#6 \\
\hline Tinte & Litro & Tinte para borde de huella \\
\hline Caja & Unidad & Caja de cartón \\
\hline Papel Cebolla & Unidad & Papel de protección en la caja \\
\hline Disolvente & Litro & Marca Hacsa \\
\hline Bencina & Litro & Marca Hacsa \\
\hline Alogenante & Litro & Marca Hacsa \\
\hline Hilo & Metro & Marca Piramide \\
\hline Clavo tornillo & Kilo & Para fijado de taco \\
\hline Clavo 3/4 sin cabeza & Kilo & Para fijado de cuero en la horma \\
\hline Clavo chinche $11 / 2$ & Kilo & Para fijado de cuero en la horma \\
\hline Clavo $1 / 2$ con cabeza & Kilo & Para fijado de cuero en la horma \\
\hline Cinta de refuerzo & Metro & Para refuerzo del aparado \\
\hline Filamento de madera & Gramos & Materia prima de la horma \\
\hline
\end{tabular}

Elaboración: Propia 
- Cantidad requerida de materia prima directa:

Tabla $\mathrm{N}^{\circ} 1.30$

Materia Prima Directa

\begin{tabular}{|l|l|r|l|}
\hline \multicolumn{1}{|c|}{ Código BTN101 } \\
\hline \multicolumn{1}{|c|}{ Concepto } & \multicolumn{1}{|c|}{ Cantidad } & \multicolumn{1}{c|}{ Descripción } \\
\hline Cantidad de cuero & Pies & 2.5 & Cuero cabretilla \\
\hline Cantidad de badana & Pies & 2 & Badana natural \\
\hline Taco & Par & 1 & Taco cuadrado ${ }^{\circ} 12$ \\
\hline Plataforma & Par & 1 & Plataforma ${ }^{\circ} 22$ \\
\hline Hebilla & Unitario & 2 & Color dorado \\
\hline Cierre & Metros & 0.3 & Cierre con atracadera \\
\hline Huella & Par & 1 & Color negro \\
\hline Carrito & Par & 1 & Carrito de cierre color vino \\
\hline Falsa & Par & 1 & Falsa de invierno \\
\hline
\end{tabular}

Elaboración: Propia 
- Cantidad requerida de materia prima indirecta:

Tabla $\mathrm{N}^{\circ} 1.31$

Materia Prima Indirecta

\begin{tabular}{|l|l|r|l|}
\hline \multicolumn{3}{|c|}{ Concepto } & \multicolumn{2}{|c|}{ Código BTN101 } & Cantidad & \multicolumn{1}{c|}{ Descripción } \\
\hline Filamento de madera & Gramos & 370 & Materia prima de la horma \\
\hline Tela Tocuyo & Metros & 0.10 & Tela de refuerzo \\
\hline Contrafuerte & Metros & 0.10 & Contrafuerte \#6 \\
\hline Tinte & Litro & 0.002 & Tinte para borde de Huella \\
\hline Caja & Unidad & 1 & Caja de carton \\
\hline Papel Cebolla & Unidad & 1 & Papel de protección en la caja \\
\hline Disolvente & Litro & 0.003 & Marca Hacsa \\
\hline Bencina & Litro & 0.003 & Marca Hacsa \\
\hline Alogenante & Litro & 0.004 & Marca Hacsa \\
\hline Hilo & Metro & 5.6 & Marca Piramide \\
\hline Clavo tornillo & Kilo & 0.001 & Para fijado de taco \\
\hline Clavo 3/4 sin cabeza & Kilo & 0.002 & Para fijado de cuero en la horma \\
\hline Clavo chinche 11/2 & Kilo & 0.002 & Para fijado de cuero en la horma \\
\hline Clavo 1/2 con cabeza & Kilo & 0.002 & Para fijado de cuero en la horma \\
\hline Cinta de refuerzo & Metro & 4.5 & Para refuerzo del aparado \\
\hline Terokal 1 & Galon & 0.0063 & Marca Record \\
\hline Terokal 2 & Galon & 0.0063 & Marca Infrapeg \\
\hline Cemento & Galon & 0.0042 & Marca Record \\
\hline Latex & Plancha & 0.1 & Descanso de plantilla \\
\hline
\end{tabular}

Elaboración: Propia

\subsubsection{Proveedores}

Para la adquisición de plantas y tacos se trabajará con La Varesina S.A y para cueros se trabajará con la curtiembre Curpisco S.A. 
El proveedor de materia prima indirecta es Comercial Flavia SA, ubicado en el CC. Ramon Castilla, en Caquetá.

\subsubsection{Maquinaria y Equipos}

Las maquinarias y equipos básicos requeridos para el taller son las siguientes:

Tabla $\mathrm{N}^{\circ} 1.32$

Maquinaria de producción

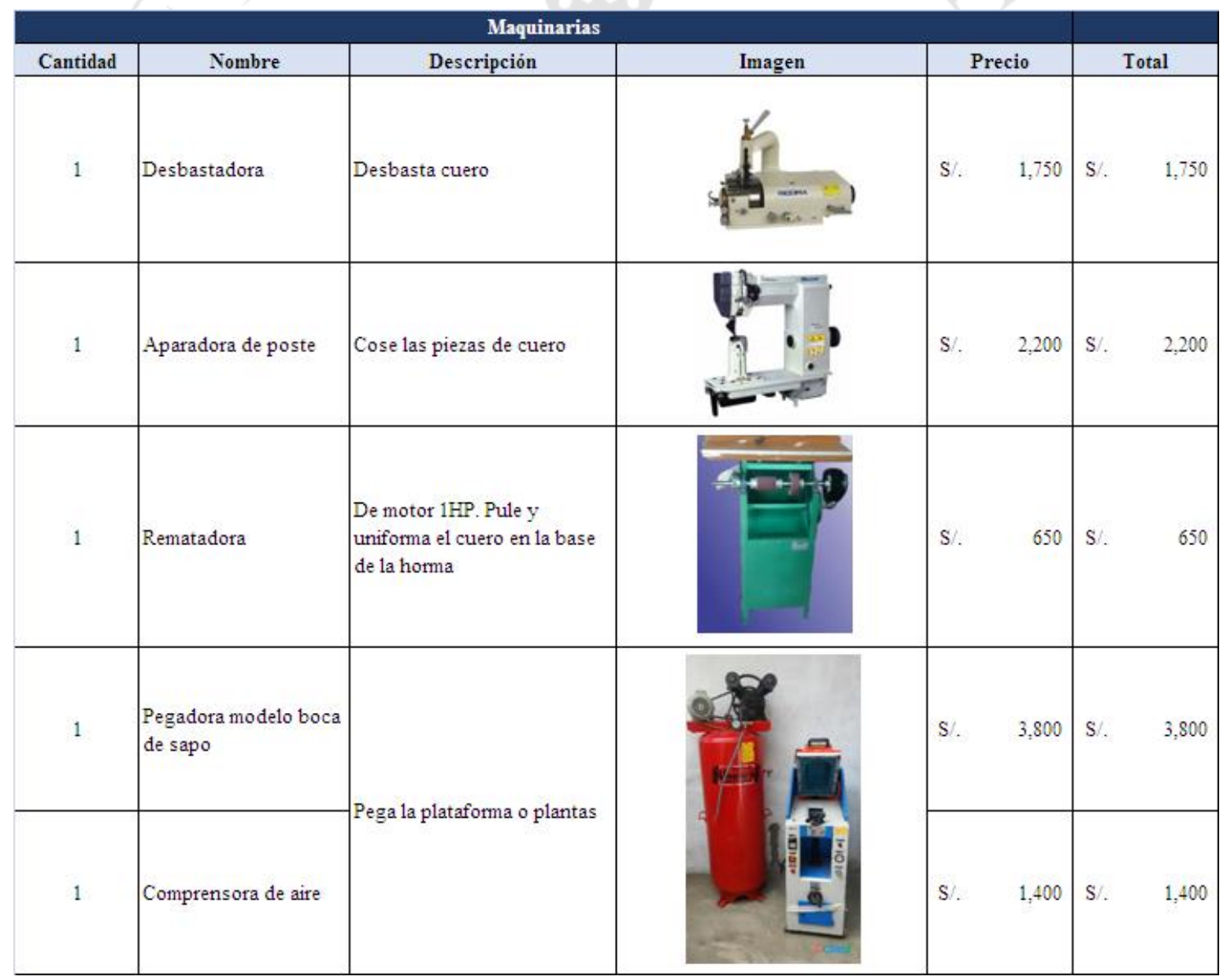




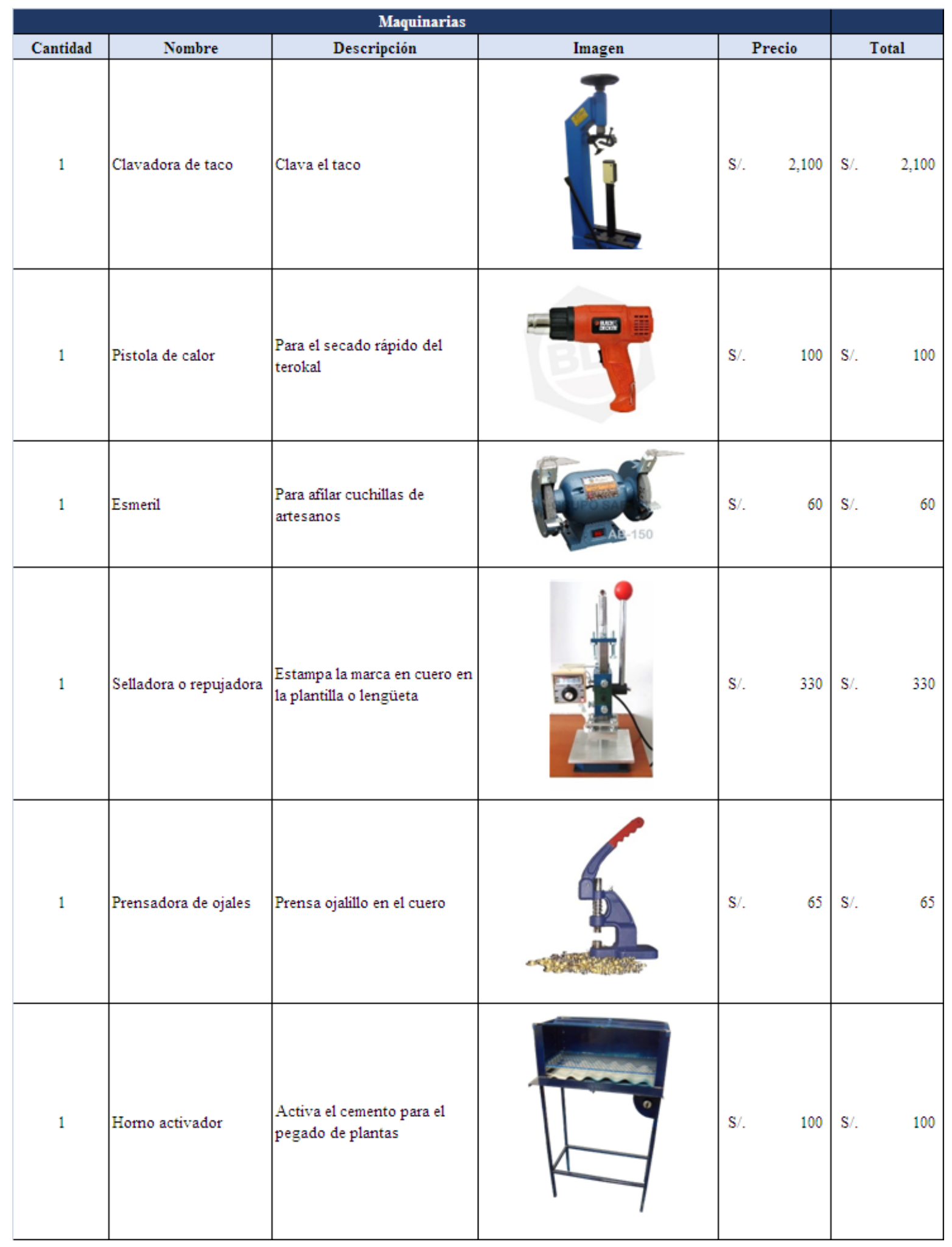




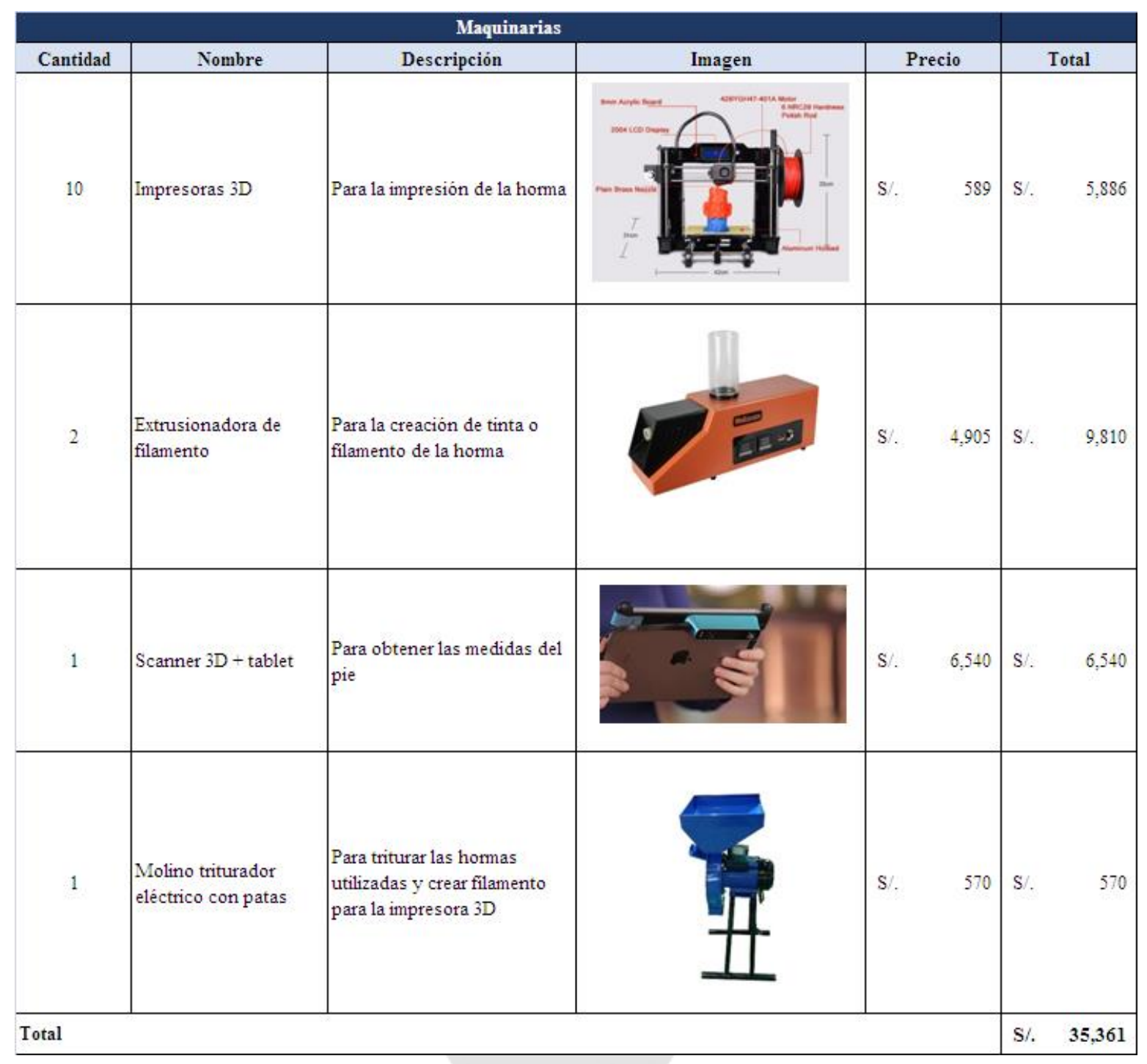

Elaboración: Propia 
Tabla $\mathrm{N}^{\circ} 1.33$

\section{Equipos para producción}

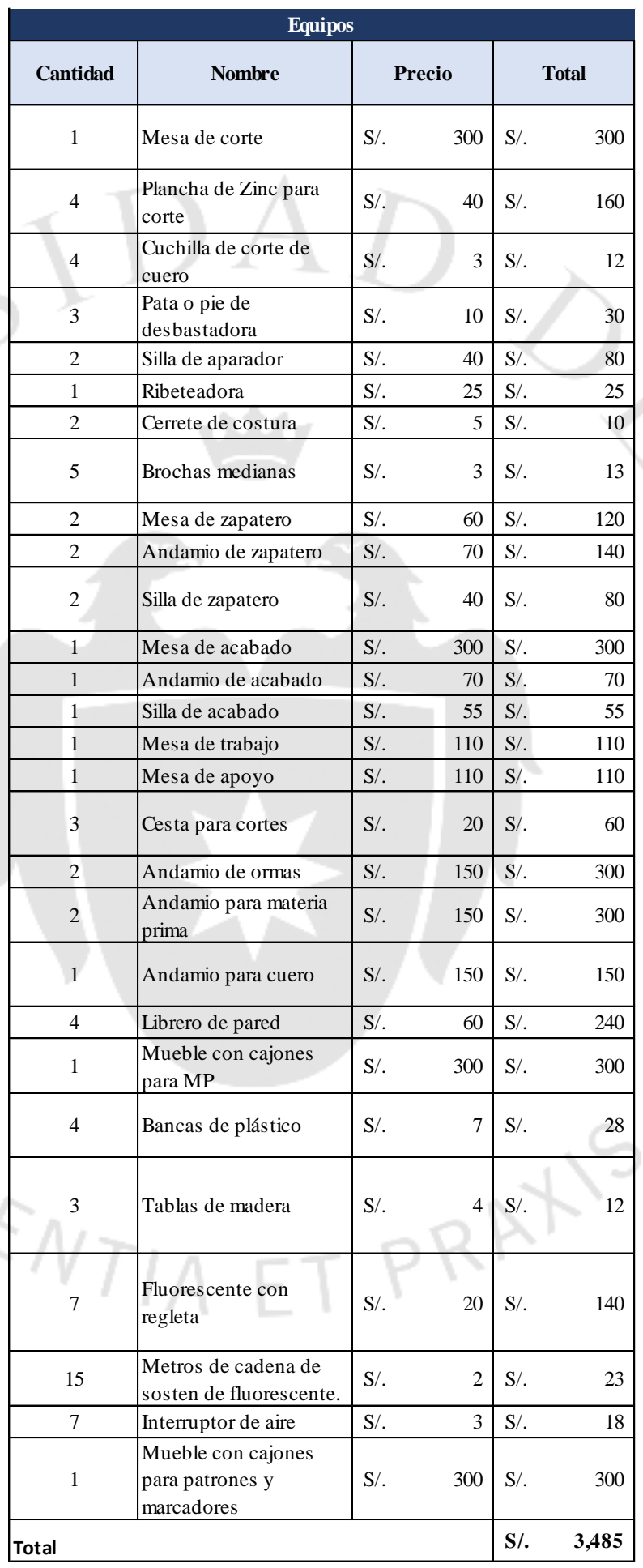

Elaboración: Propia 
Tabla $\mathrm{N}^{\circ} 1.34$

Equipos de oficina

\begin{tabular}{|c|c|c|c|c|c|}
\hline \multicolumn{6}{|c|}{ Muebles y equipo de oficina } \\
\hline Cantidad & Nombre & \multicolumn{2}{|c|}{ Precio } & \multicolumn{2}{|c|}{ Total } \\
\hline 6 & Escritorio de melamine & S/. & 260 & $\mathrm{~S} /$. & 1,560 \\
\hline 12 & Silla giratoria & $\mathrm{S} /$. & 90 & $\mathrm{~S} /$. & 1,080 \\
\hline 1 & Mesa de reuniones & $\mathrm{S} /$. & 400 & $\mathrm{~S} /$. & 400 \\
\hline 2 & Sillon de espera & S/. & 1,100 & $\mathrm{~S} /$. & 2,200 \\
\hline 4 & Computadoras & S/. & 1,450 & $\mathrm{~S} /$. & 5,800 \\
\hline 1 & Laptop & S/. & 1,800 & $\mathrm{~S} /$. & 1,800 \\
\hline 5 & Archivadores & $\mathrm{S} /$. & 150 & $\mathrm{~S} /$. & 750 \\
\hline 6 & Armario de madera & $\mathrm{S} /$. & 180 & $\mathrm{~S} /$. & 1,080 \\
\hline 4 & Reloj de pared & $\mathrm{S} /$. & 35 & $\mathrm{~S} /$. & 140 \\
\hline 4 & Extintores & $\mathrm{S} /$. & 68 & $\mathrm{~S} /$. & 272 \\
\hline 3 & Detector de humo inalámbrico & S/. & 20 & $\mathrm{~S} /$. & 60 \\
\hline 2 & Botiquin de primeros auxilios & $\mathrm{S} /$. & 20 & $\mathrm{~S} /$. & 40 \\
\hline 4 & Impres ora multifuncional & S/. & 325 & $\mathrm{~S} /$. & 1,300 \\
\hline 5 & Calculadoras & $\mathrm{S} /$. & 70 & $\mathrm{~S} /$. & 350 \\
\hline 2 & Cafetera & $\mathrm{S} /$. & 90 & $\mathrm{~S} /$. & 180 \\
\hline 2 & Mini frigobar & S/. & 399 & $\mathrm{~S} /$. & 798 \\
\hline 2 & Kitchen de oficina & $\mathrm{S} /$. & 780 & $\mathrm{~S} /$. & 1,560 \\
\hline 5 & Cestas de basura de escritorio & S/. & 10 & $\mathrm{~S} /$. & 50 \\
\hline 1 & Cesta grande de basura & $\mathrm{S} /$. & 22 & $\mathrm{~S} /$. & 22 \\
\hline 2 & Planchas de trupan & S/. & 125 & $\mathrm{~S} /$. & 250 \\
\hline 2 & Pizarra acrilica & $\mathrm{S} /$. & 85 & $\mathrm{~S} /$. & 170 \\
\hline 10 & Celulares & S/. & 200 & $\mathrm{~S} /$. & 2,000 \\
\hline 4 & Cámaras de seguridad & $\mathrm{S} /$. & 500 & $\mathrm{~S} /$. & 2,000 \\
\hline 30 & Acrilicos de exibición & $\mathrm{S} /$. & 3 & $\mathrm{~S} /$. & 75 \\
\hline \multicolumn{4}{|l|}{ Total } & $\mathbf{S} /$. & 23,936 \\
\hline
\end{tabular}

Elaboración: Propia 


\subsubsection{Personal requerido}

El personal mínimo disponible para los inicios de operación del taller es el siguiente:

\section{Tabla $\mathrm{N}^{\circ} 1.35$}

Personal requerido en planta

\begin{tabular}{|r|l|}
\hline \multicolumn{2}{|c|}{ Personal Producción } \\
\hline 1 & Cortador \\
\hline 1 & Apador \\
\hline 2 & Armador \\
\hline 1 & Acabador \\
\hline 1 & Ingeniero industrial \\
\hline 1 & Ayudante \\
\hline 1 & Asistente de control de \\
& calidad \\
\hline 1 & Modelista \\
\hline 1 & Asistente de modelista \\
\hline
\end{tabular}

Elaboración: Propia

\subsubsection{Proceso de fabricación}

El proceso de producción de calzado es bastante estandarizado, es decir, está establecido para la producción en masa, mas no para obtener un producto final a la medida o personalizado. Ahora, con la aplicación de nuevas tecnologías permitirán un proceso más flexible para la consecución de este propósito.

\section{- Diagrama de flujo}


Figura $\mathrm{N}^{\circ} 1.56$ Diagrama de flujo

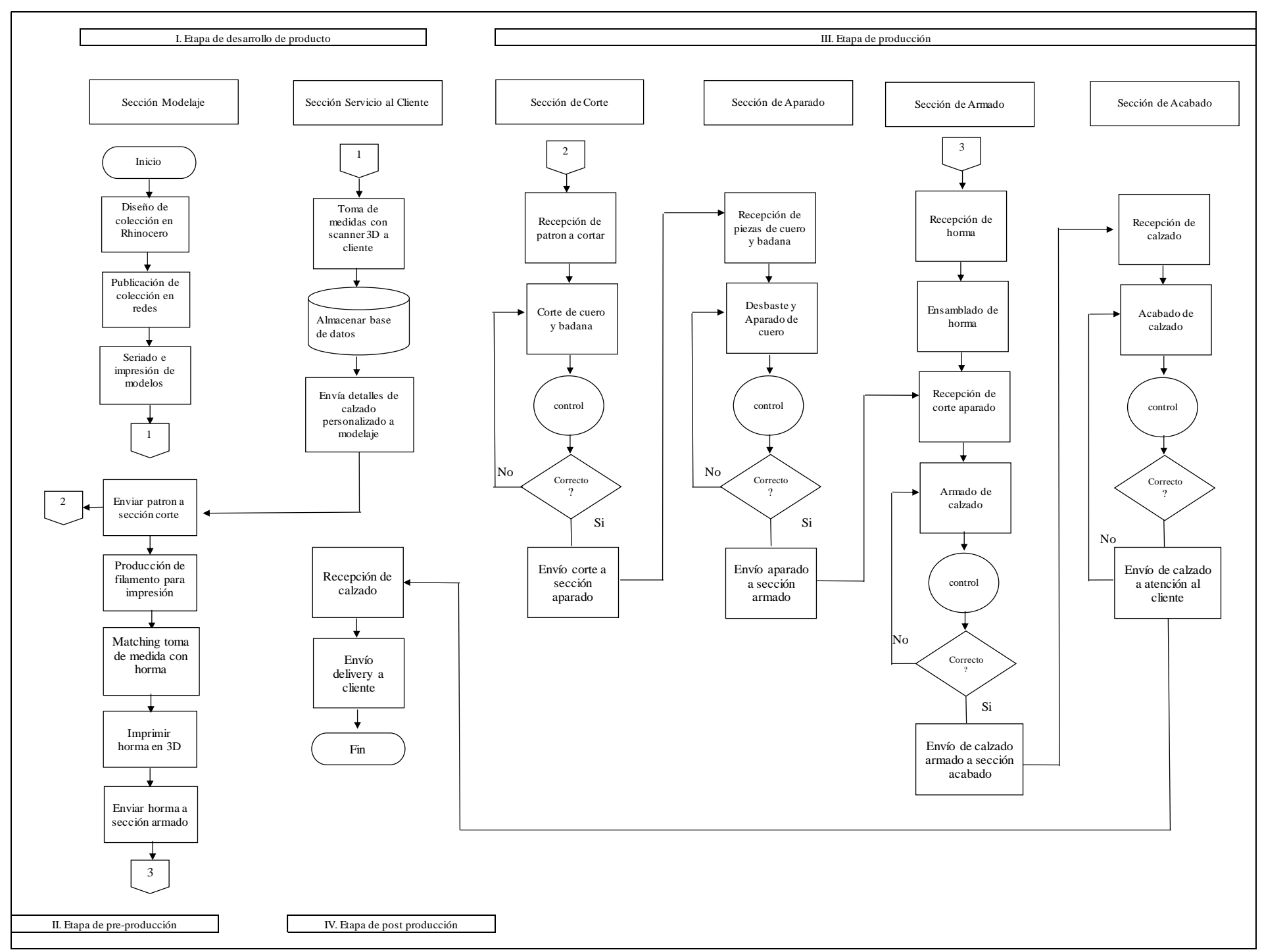

Elaboración: Propia 
- +Proceso del diagrama de flujo

I. Etapa de desarrollo de producto

a. A inicio de cada temporada, el modelista del área de modelaje, haciendo uso del software Rhinocero, diseña los patrones de los modelos a trabajar. Una vez concluidos, estos pasan a ser seriados, impresos y archivados. Finalmente, publica en las plataformas virtuales la colección de estilos de calzado, variedades de cuero, y accesorios.

\section{Figura $\mathrm{N}^{\circ} 1.57$}

Software Rhinoceros para diseño de calzado

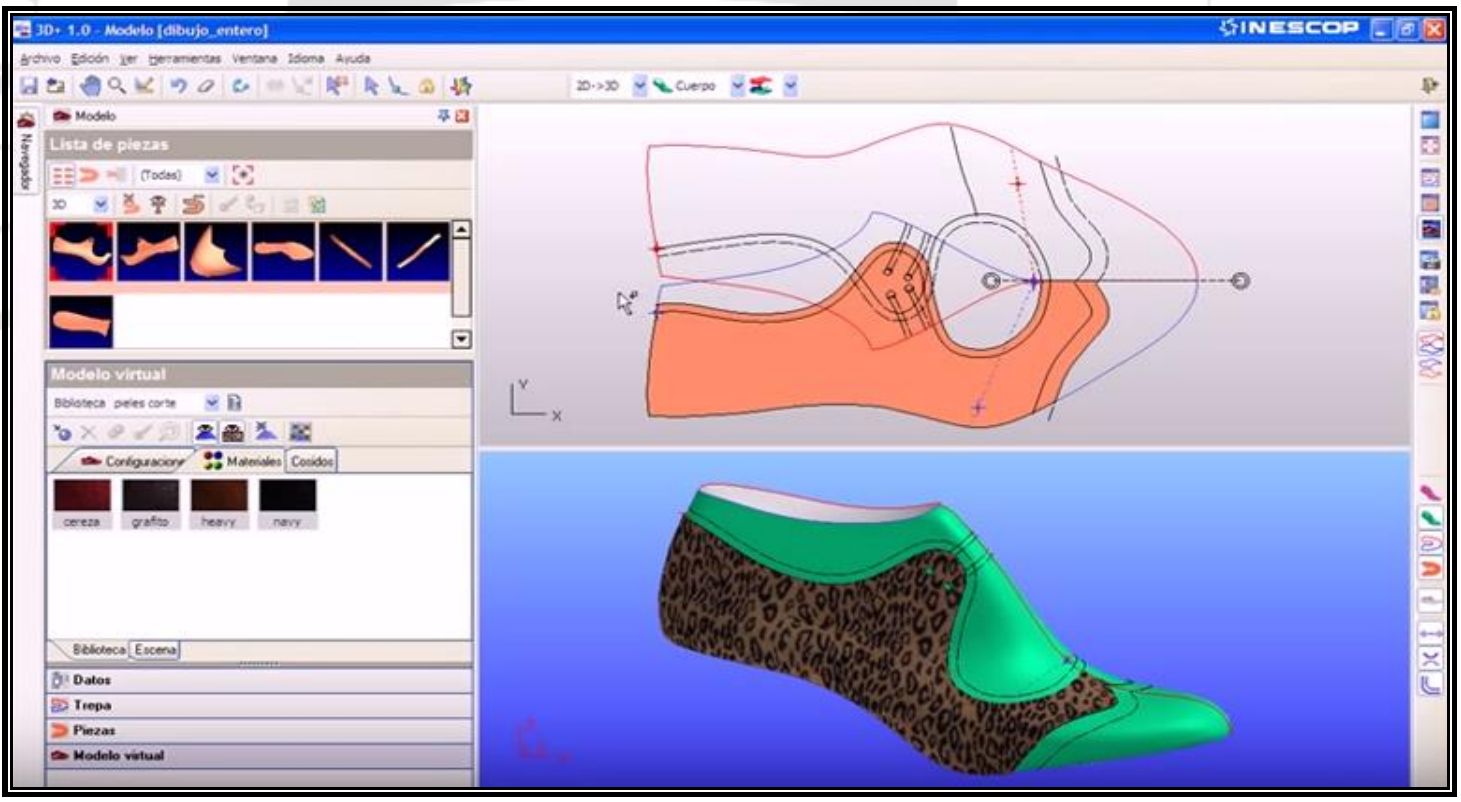

Fuente: Rhinoceros 
Figura $\mathrm{N}^{\circ} 1.58$

Silueta de colección

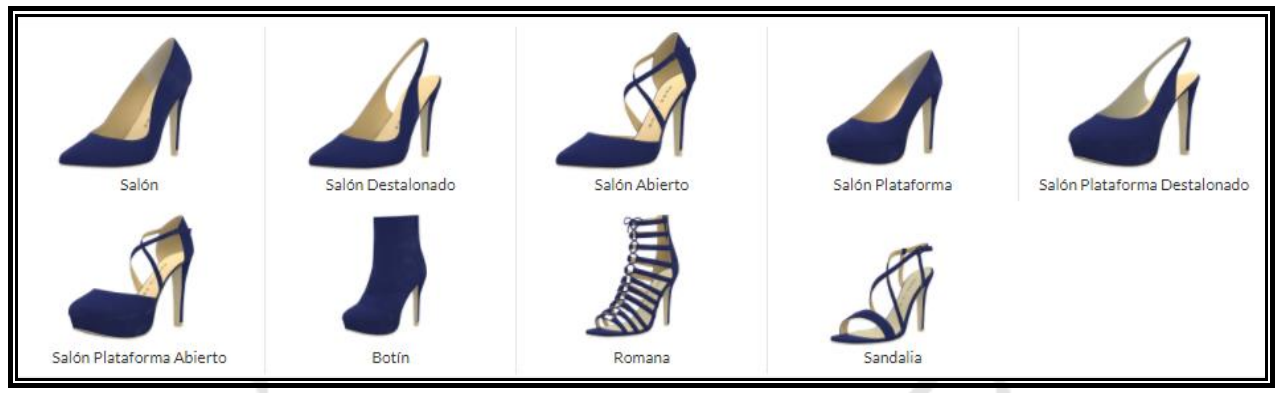

Fuente: Internet

b. El cliente que desee adquirir un par, tendrá tres opciones de medida:

c. Escoger su talla en horma estándar.

d. Descargar de nuestra plataforma e imprimir una plantilla de tallas donde posteriormente a auto medirse, ingresa los datos en su orden de compra.

e. El cliente acude a nuestro punto de venta para realizarle un escaneado 3D de su pie. Esta operación es realizada por servicio al cliente.

f. Generar una compra con su medida 3D almacenada en nuestra base de datos.

g. Luego de obtener la medida, el cliente procede a personalizar el modelo en la plataforma virtual y genera su compra. 
Figura $\mathrm{N}^{\circ} 1.59$

Escáner 3D

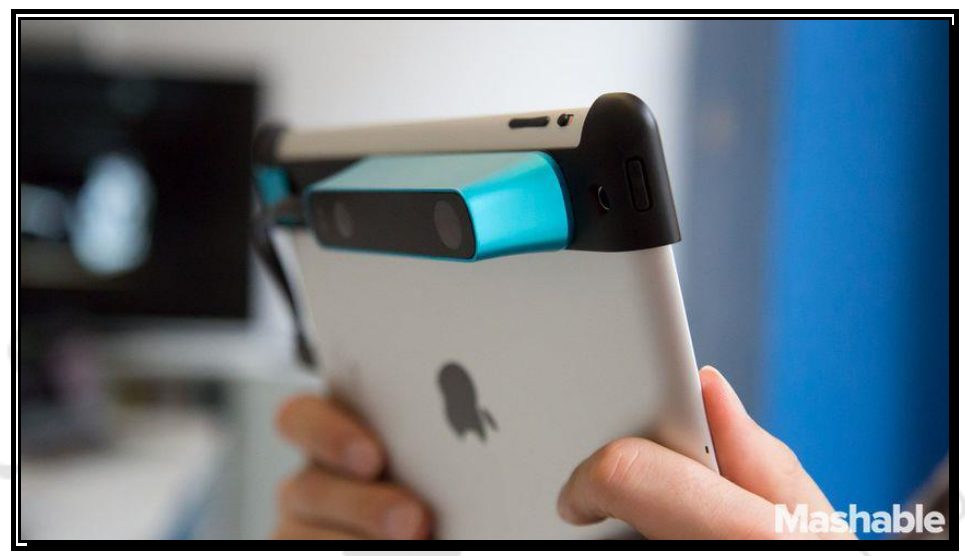

Fuente: Internet

II. Etapa de pre-producción

h. La sección de modelaje envía el patrón de modelo y talla a la sección de corte.

i. Modelaje produce el filamento de madera con la extrusionadora de filamento.

j. Si el cliente decide por la opción de medida a y b, se inicia la etapa de producción. Sea el caso que opte por la opción c o d, el área de modelaje realiza el siguiente proceso:

k. Diseño de la horma: Match en Rhinocero entre scaneado 3D y la horma del modelo.

1. Impresión de horma: La horma es impresa en filamento de madera. Cada pie es impreso en 3 partes las cuales se ensamblan a presión. El tiempo empleado es de 1 hora 10 minutos por cada par. En el caso que el pie sea 
impreso en 2 partes, el tiempo de demora es de 1 hora 45 minutos por cada par.

Gracias a la impresión por capas (Figura 1.65) y a la impresión por partes (Figura 1.63) es que se logra reducir los tiempos de impresión.

m. Envío de la horma a la sección de armado.

\section{Tabla $\mathrm{N}^{\circ} 1.36$}

Tiempos de impresión 3D

\begin{tabular}{|l|c|}
\hline \multicolumn{1}{|c|}{ Descripción } & Tiempo (h) \\
\hline Impresión de un pie de horma & $06: 00$ \\
\hline Ahorro de impresión por capas (\%) & 0.5 \\
\hline Total de impresión de un pie & $03: 00$ \\
\hline Par de horma impresa en tres partes & $01: 00$ \\
\hline Par de horma impresa en dos partes & $01: 30$ \\
\hline
\end{tabular}

Elaboración: Propia

Figura $N^{\circ} 1.60$

Extrusionadora de filamento

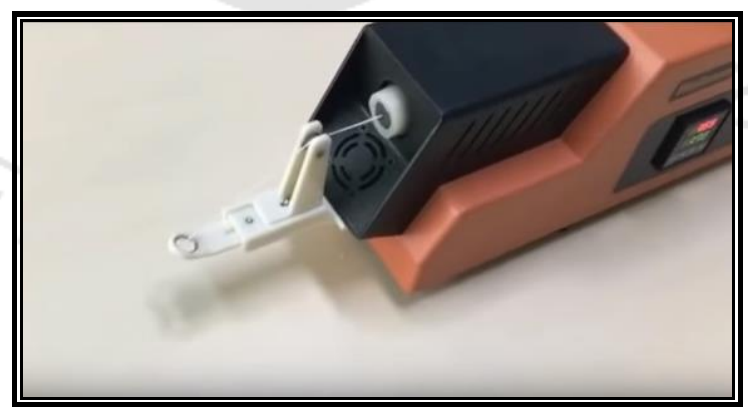

Fuente: Internet 
Figura $\mathrm{N}^{\circ} 1.61$

Filamento de madera

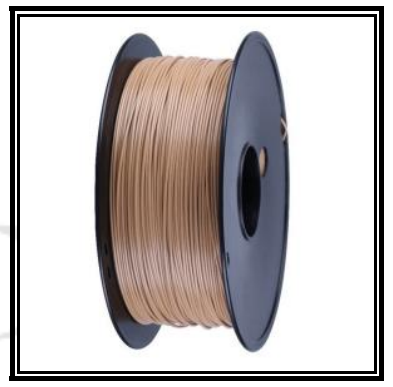

Fuente: Internet

Figura $\mathrm{N}^{\circ} 1.62$

Horma de madera

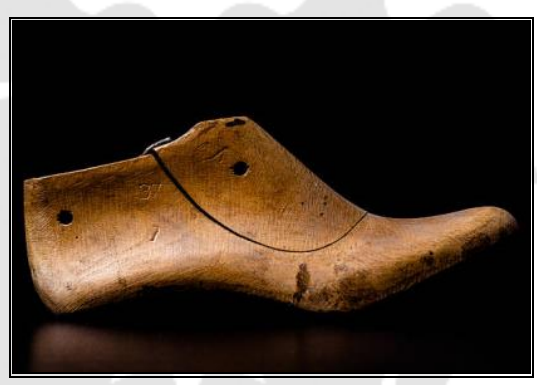

Fuente: Internet

Figura $\mathrm{N}^{\circ} 1.63$

Impresión en filamento de madera

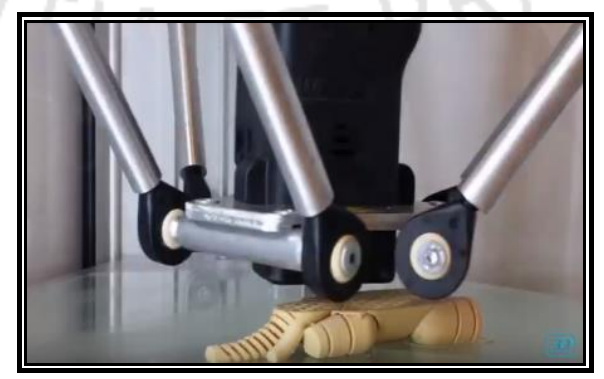

Fuente: Internet 
Figura $\mathrm{N}^{\circ} 1.64$

Referencia de impresión de horma en 3D

Pie izquierdo
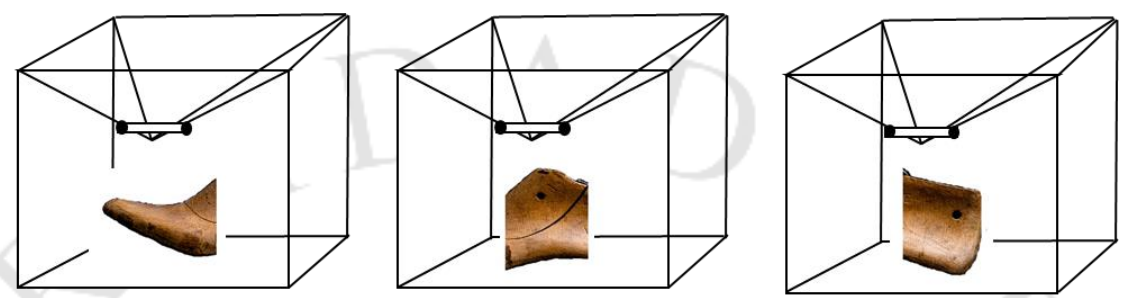

Pie derecho
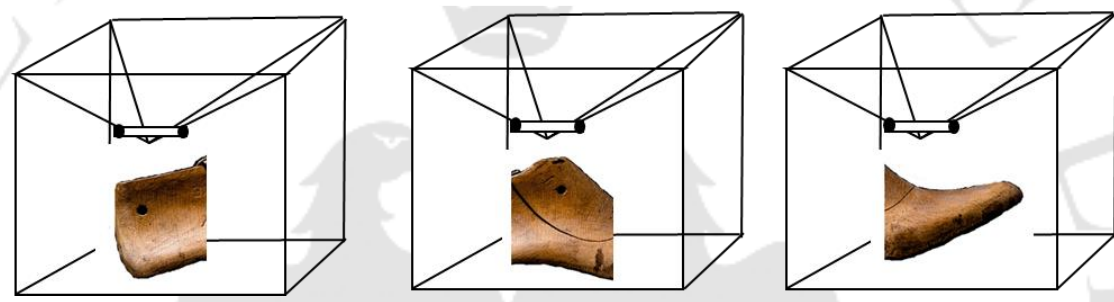

Elaboración: Propia

Figura $\mathrm{N}^{\circ} 1.65$

Ensamble a presión de madera

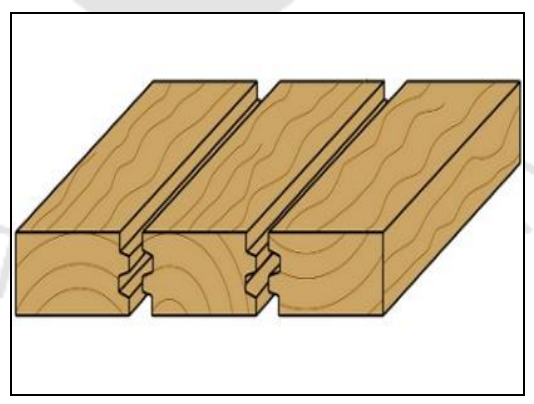

Fuente: Internet 
Figura $\mathrm{N}^{\circ} 1.66$

Ahorro de impresión por capas
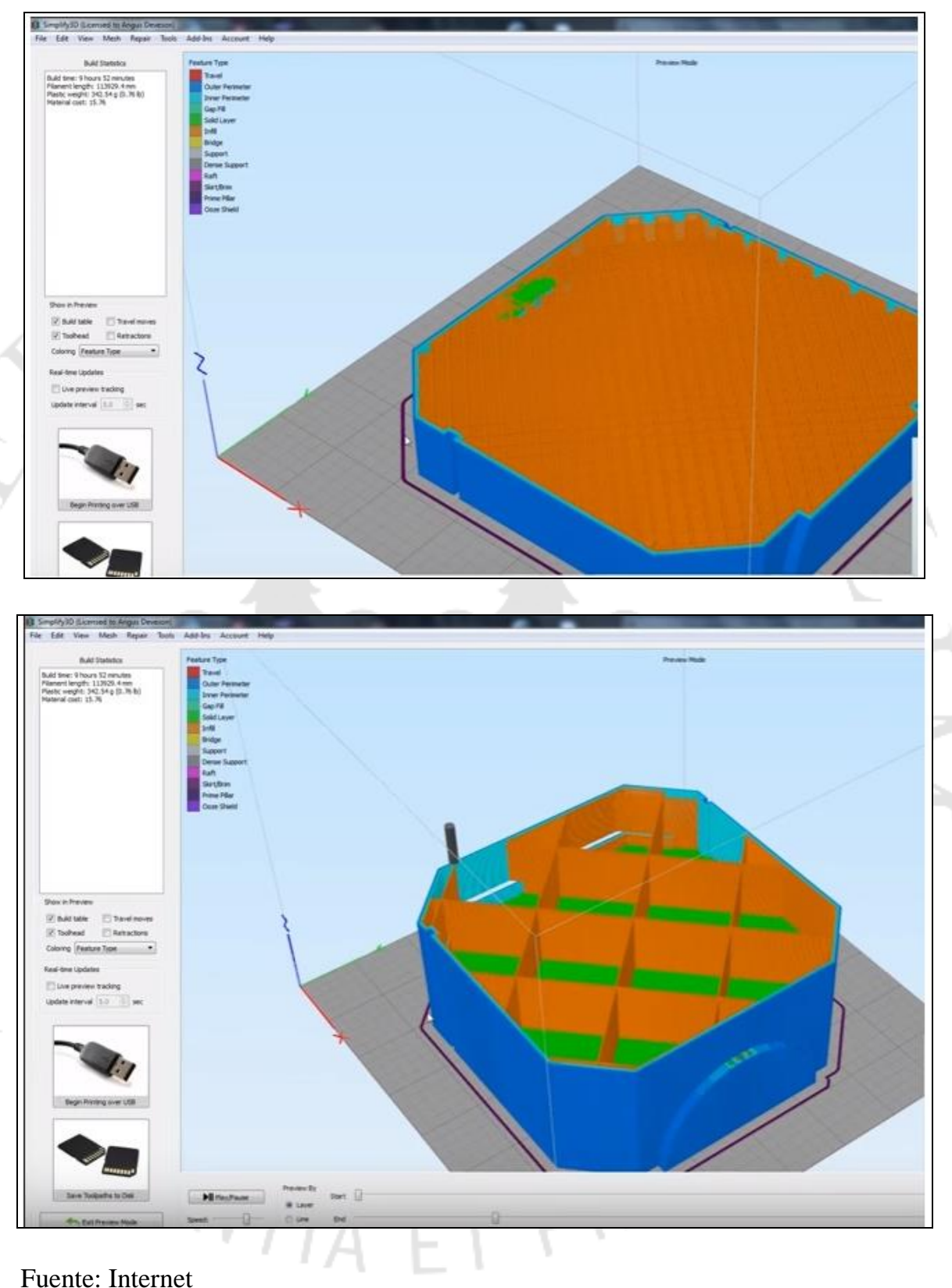

Fuente: Internet 
III. Etapa de producción

n. La sección corte recibe el patrón y realiza el corte del cuero y badana, y se lo entrega a control de calidad.

o. Control de calidad recepciona el corte y realiza la inspección. Pasada la misma, se entrega el corte a la sección de aparado.

p. La sección de aparado recibe las piezas de cuero, realiza primero el desbaste y luego la costura de las partes y se lo entrega a control de calidad.

q. Control de calidad recepciona el aparado y realiza la inspección. Pasada la misma, se entrega el aparado a la sección de armado.

r. La sección de armado realiza las siguientes operaciones:

1. Ensamblado de la horma.

2. Armado del calzado.

3. Entrega de calzado a control de calidad.

s. Control de calidad recepciona el par de calzado y realiza la inspección. Pasada la misma, se entrega el producto a la sección de acabado.

t. La sección de acabado realiza la limpieza del producto, sellado y pegado de plantilla, lo encaja y lo entrega a control de calidad.

u. Control de calidad recepciona el producto final y realiza la inspección. Pasada la misma, se entrega el producto a la sección de servicio al cliente. 
Figura $\mathrm{N}^{\circ} 1.67$

Corte del cuero

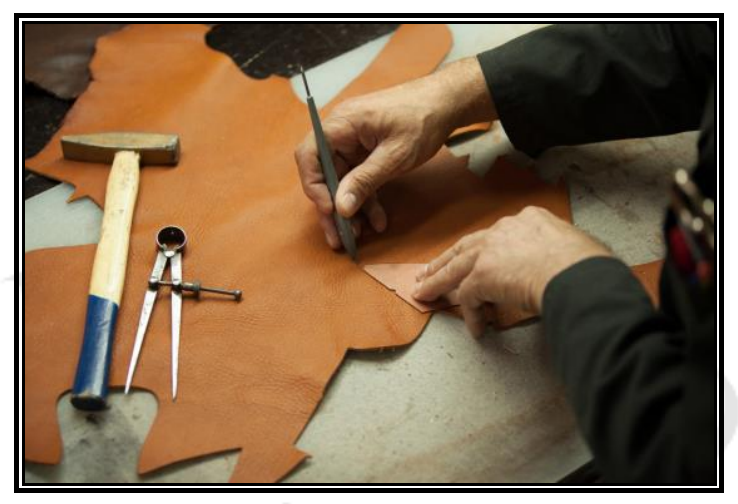

Fuente: Internet

Figura $N^{\circ} 1.68$

Desbaste del cuero

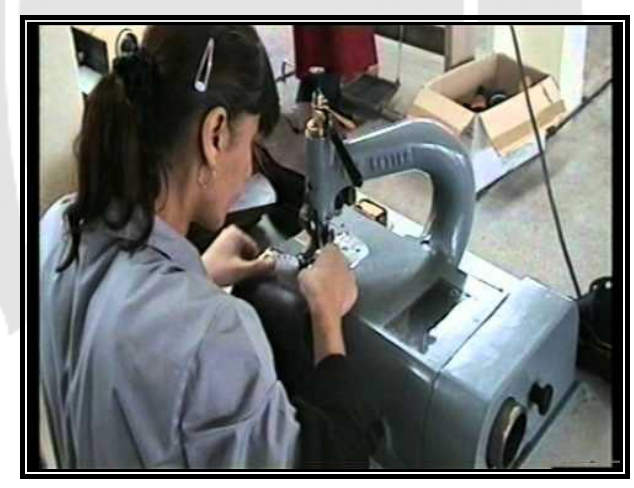

Fuente: Internet 
Figura $N^{\circ} 1.69$

Aparado del cuero

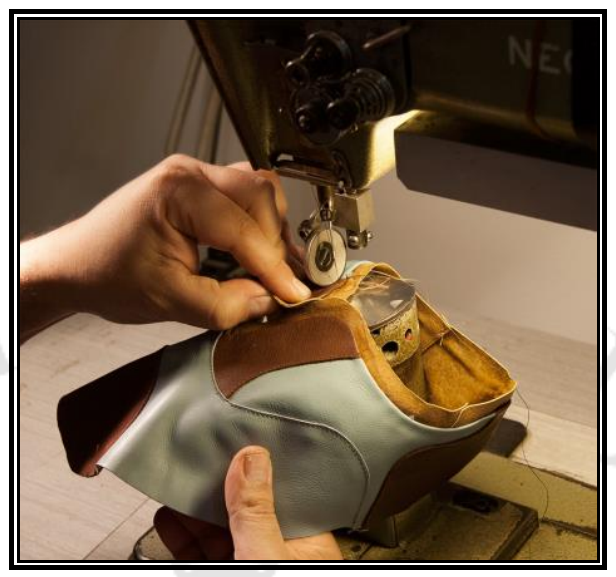

Fuente: Internet

Figura $\mathrm{N}^{\circ} 1.70$

Armado de calzado

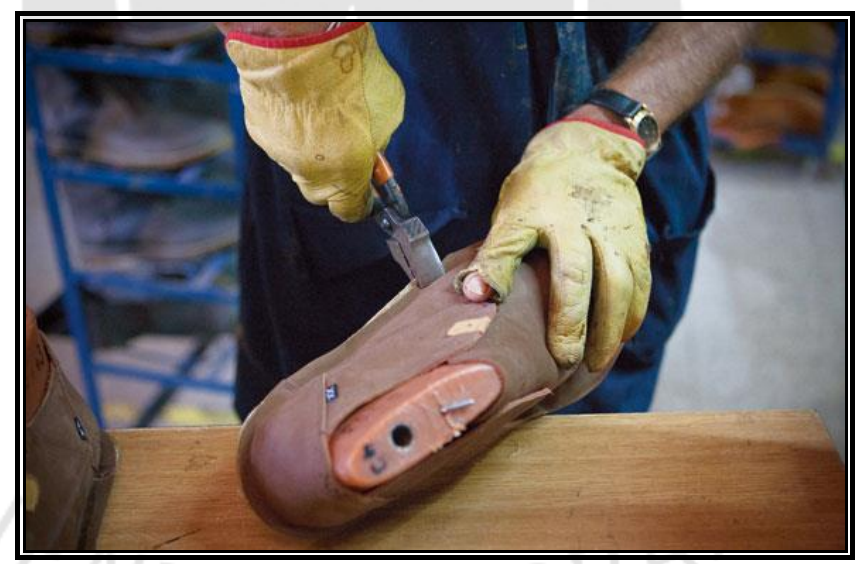

Fuente: Internet 
Figura $\mathrm{N}^{\circ} 1.71$

Acabado de calzado

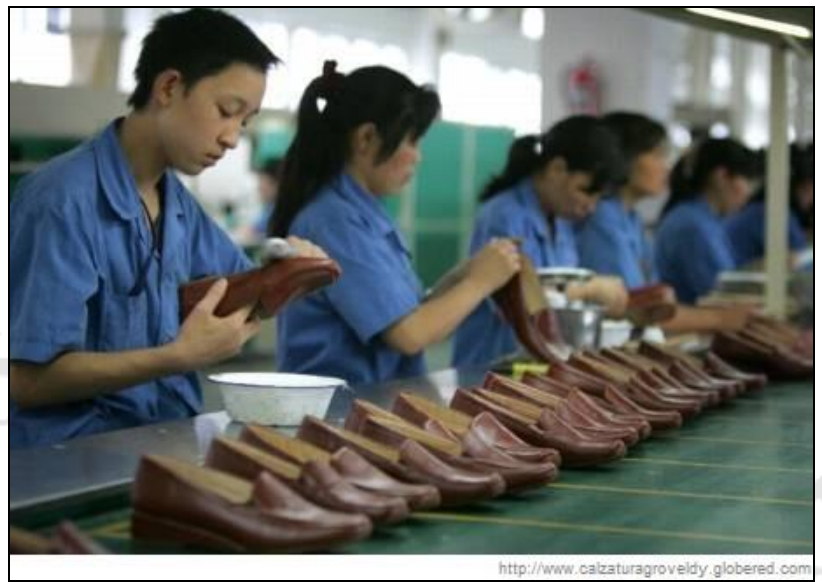

Fuente: Internet

IV. Etapa post producción

v. Servicio al cliente recepciona el producto, lo empaqueta y realiza el envío vía Courier al cliente final.

\subsubsection{Tiempo del proceso de producción del modelo de negocio}

Los tiempos han sido estimados en base a la producción de un par de calzado del modelo seleccionado.

El diagrama DAP del modelo de negocio considera dos tipos de proceso de producción: 


\section{a. Producto fabricado con horma 3D}

De acuerdo al análisis, el tiempo del proceso del modelo de negocio desde la orden de pedido del cliente, producción y envío, es de 38 horas con 53 minutos.

Tabla $\mathrm{N}^{\circ} 1.37$

Resumen de tiempo de proceso de proceso de producción fabricado con horma 3D

\begin{tabular}{|l|l|r|r|}
\hline & RESUMEN & $\#$ & \multicolumn{1}{c|}{ Tiempo } \\
\hline $\mathbf{D}$ & Operaciones & 10 & 05:00:00 \\
\hline $\mathbf{\square}$ & Transporte & 7 & $25: 25: 00$ \\
\hline $\mathbf{D}$ & Controles & 4 & $00: 28: 00$ \\
\hline $\mathbf{\nabla}$ & Esperas & 1 & $08: 00: 00$ \\
\hline TOTAL & Almacenamiento & 0 & $00: 00: 00$ \\
\hline
\end{tabular}

Elaboración: Propia 
Tabla $\mathrm{N}^{\circ} 1.38$

Diagrama DAP calzado fabricado con horma 3D

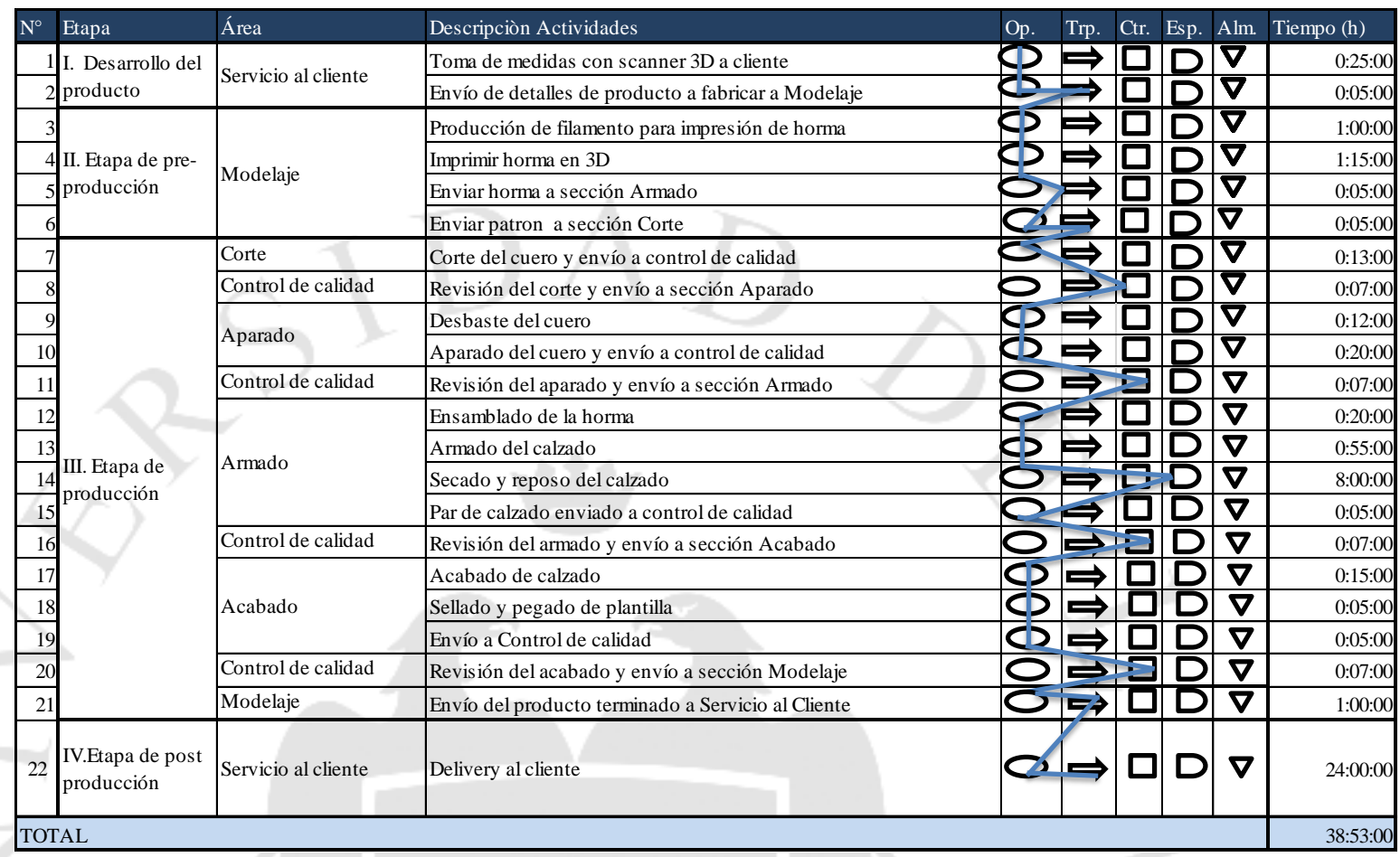

Elaboración: Propia

\section{b. Producto fabricado con horma estándar}

El tiempo del proceso del modelo de negocio para el proceso de producción con horma estándar desde la orden de pedido del cliente, producción y envío, es de 35 horas con 53 minutos. 
Tabla $\mathrm{N}^{\circ} 1.39$

Resumen de tiempo de proceso de proceso de producción fabricado con horma estándar

\begin{tabular}{|c|c|c|c|}
\hline & RESUMEN & $\#$ & Tiempo \\
\hline$\infty$ & Operaciones & 6 & 2:00:00 \\
\hline$\Rightarrow$ & Transporte & 7 & $25: 25: 00$ \\
\hline$\square$ & Controles & 4 & 0:28:00 \\
\hline$D$ & Esperas & 1 & 8:00:00 \\
\hline 7 & Almacenamiento & 0 & 0:00:00 \\
\hline \multicolumn{3}{|l|}{ TOTAL } & $35: 53: 00$ \\
\hline
\end{tabular}

Elaboración: Propia

Tabla $\mathrm{N}^{\circ} 1.40$

Diagrama DAP calzado fabricado con horma estándar

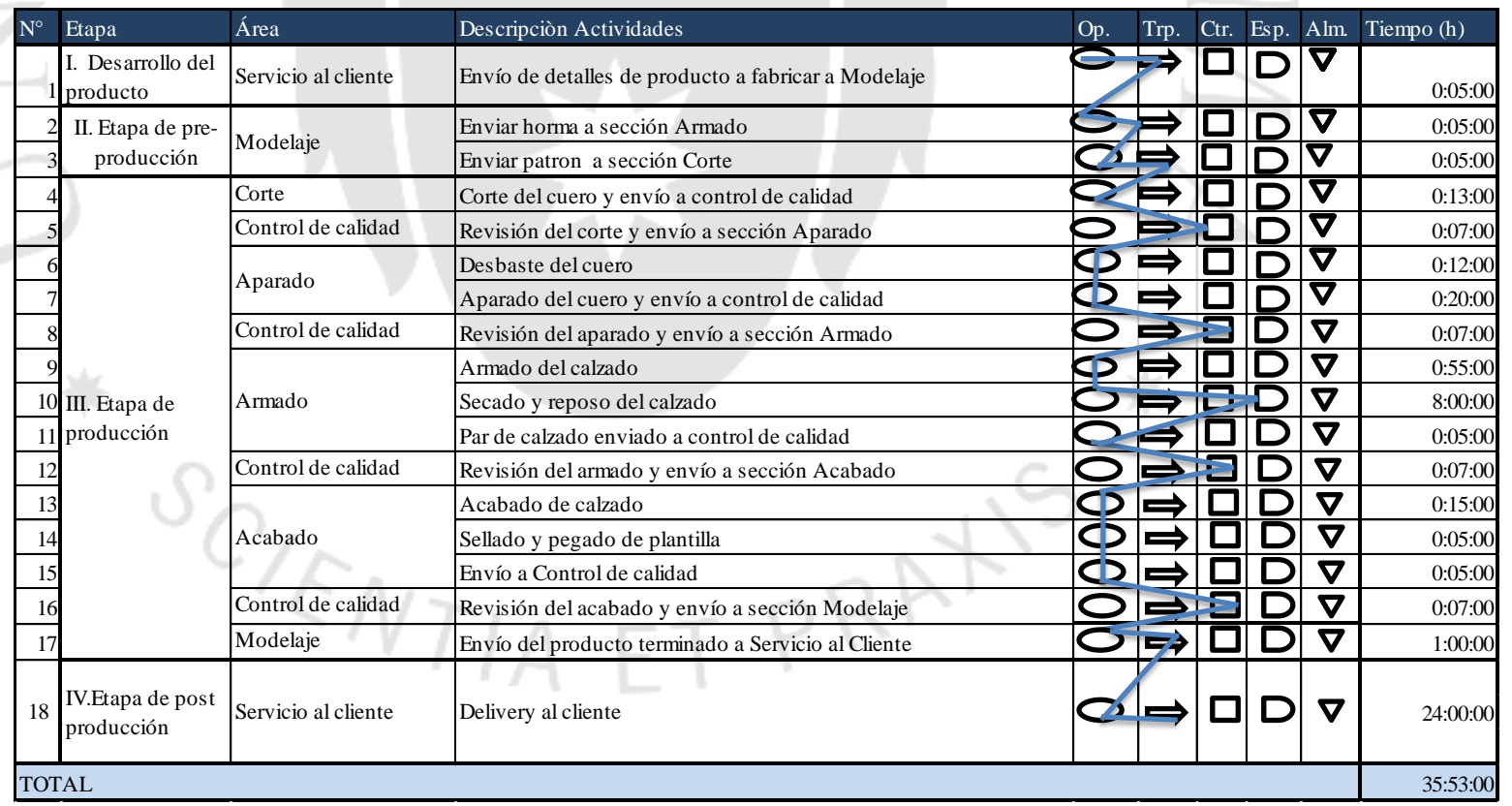

Elaboración: Propia 


\section{- Tiempo de entrega}

- Producto fabricado con horma 3D

El tiempo que dura el proceso para el caso de fabricación a la medida es de 38 horas con 53 minutos, tomando el supuesto de horas trabajadas por semana (45) que representan a 8 horas de lunes a viernes y 4 horas el sábado, puede concluirse que la entrega del producto final al cliente es en 5 días hábiles.

\section{- Producto fabricado con horma estándar}

El tiempo que dura el proceso para el caso de fabricación bajo la horma estándar es de 35 horas con 53 minutos, tomando el supuesto de horas trabajadas por semana (45) que representan a 8 horas de lunes a viernes y 5 horas el sábado, puede concluirse que la entrega del producto final al cliente es en 4.5 días hábiles.

\subsubsection{Capacidad de producción}

A continuación, se presenta la cantidad de producción en pares por mes por cada proceso de producción.

Tabla $\mathrm{N}^{\circ} 1.41$

Análisis de tiempos de producción de cada proceso productivo.

\begin{tabular}{|l|r|}
\hline \multicolumn{2}{|c|}{ Supuestos } \\
\hline Días de trabajo semana & 5.5 \\
\hline Días de trabajo por mes & 22 \\
\hline Horas de trabajo por semana & 45 \\
\hline Horas de trabajo por mes & 180 \\
\hline Pares por docena & 12 \\
\hline Semanas por año & 52 \\
\hline
\end{tabular}




\begin{tabular}{|l|r|}
\hline \multicolumn{2}{|c|}{ Producción de Cortador } \\
\hline Docenas por día & 3 \\
\hline Docenas por semana & 16.5 \\
\hline Pares por semana & 198 \\
\hline Total de pares de corte por mes & 792 \\
\hline
\end{tabular}

\begin{tabular}{|l|r|}
\hline \multicolumn{2}{|c|}{ Producción de Desbaste y Aparado } \\
\hline Docenas por día & 1.3 \\
\hline Docenas por semana & 7 \\
\hline Pares por semana & 84 \\
\hline Duplica producción por ayudante & 168 \\
\hline Total pares de aparado por mes & 672 \\
\hline
\end{tabular}

\begin{tabular}{|l|r|}
\hline \multicolumn{2}{|c|}{ Producción Armadores } \\
\hline Docenas semanales por armador & 4 \\
\hline Docenas de 2 armadores & 8 \\
\hline Duplica la producción con ayudante & 15 \\
\hline Pares por semana & 180 \\
\hline Pares por mes & 720 \\
\hline
\end{tabular}

\section{Producción de Acabado}

\begin{tabular}{|l|r|}
\hline Docenas por día & 2.0 \\
\hline Docenas por semana & 11 \\
\hline Pares por semana & 132 \\
\hline Ayudante medio tiempo & 0.45 \\
\hline Total pares de acabado por mes & 766 \\
\hline
\end{tabular}

\begin{tabular}{|l|r|}
\hline \multicolumn{2}{|c|}{ Producción de Hormas 3D } \\
\hline \multicolumn{2}{|c|}{ Horma 3D dividida en 3 partes } \\
\hline Tiempo de impresión de un par & $01: 00$ \\
\hline Horas trabajadas por mes & 200 \\
\hline Pares de hormas impresas por mes & 200 \\
\hline \multicolumn{2}{|c|}{ Horma 3D dividida en 2 partes } \\
\hline Tiempo de impresión de un par & 200 \\
\hline Horas trabajadas por mes & 133 \\
\hline Pares de hormas impresas por mes & 333 \\
\hline Total de hormas impresas en 3D por mes &
\end{tabular}

Elaboración: Propia

Nota: Impresoras activas durante el almuerzo acumula a 200 horas por mes.

La demanda mensual del proyecto es de 351 pares mensuales en promedio sin considerar la estacionalidad. De acuerdo a la pregunta $\mathrm{N}^{\circ} 13$ de la encuesta, al $47 \%$ de clientes optan por una horma estándar para la preparación de su calzado personalizado, mientras que el $53 \%$ lo prefieren a la medida. 
Figura $\mathrm{N}^{\circ} 1.72$

Distribución de demanda

\section{3. ¿Si realizaras la compra de una marca nueva de calzado por Internet, cuál de las siguientes opciones de medida prefieres para que el producto te calce a la perfección?}

- Descargar e imprimir una plantilla de la página web, para tomar las medidas del pie y registrarlo en la base de dato

- Toma de la medida del pie a domicilio, por un personal de la empresa

- Acudir a un punto de venta físico

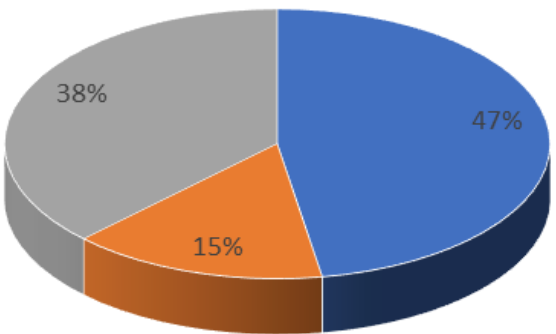

Fuente Encuestas

Elaboración Propia

La capacidad de producción se resume en el siguiente cuadro:

Tabla $\mathrm{N}^{\circ} 1.42$

Capacidad de producción en pares por mes

\begin{tabular}{|l|r|}
\hline \multicolumn{2}{|c|}{ Capacidad de producción en pares por mes } \\
\hline Demanda mensual & 351 \\
\hline Necesidad en Hormas 3D (53\%) & 186 \\
\hline Necesidad en Horma Estandar (47\%) & 165 \\
\hline Capacidad de producción de hormas 3D & 333 \\
\hline Capacidad de producción con hormas estandar & 387 \\
\hline Total de capacidad de producción en pares por mes & 720 \\
\hline
\end{tabular}

Elaboración: Propia 
Puede observarse que para la producción de pares a la medida bajo la horma 3D se tiene una capacidad superior a la demanda de 147 pares y en producción bajo la horma estándar en 222 pares.

\subsubsection{Productos en cola}

Analizaremos la producción en cola en base a la cantidad demandada por mes:

\section{Tabla $\mathrm{N}^{\circ} 1.43$}

Producción de pares por día

\begin{tabular}{|l|r|}
\hline \multicolumn{2}{|c|}{ Pares fabricado por día } \\
\hline Demanda & 351 \\
\hline Producción en hormas 3D (53\%) & 186 \\
\hline Producción en hormas estándar (47\%) & 165 \\
\hline Días trabajados por mes & 22 \\
\hline Pares 3D por día & 9 \\
\hline Pares estándar por día & 7 \\
\hline Total de pares fabricados por día & 16 \\
\hline
\end{tabular}

Elaboración: Propia

\section{Tabla $\mathrm{N}^{\circ} 1.44$}

Plan de producción de pares por semana

\begin{tabular}{|l|r|r|r|r|r|r|r|}
\hline & \multicolumn{1}{|c|}{ L } & \multicolumn{1}{c|}{ M } & M & J & V & S & Total \\
\hline S1 & 16 & 16 & 16 & 16 & 16 & 8 & 88 \\
\hline S2 & 16 & 16 & 16 & 16 & 16 & 8 & 88 \\
\hline S3 & 16 & 16 & 16 & 16 & 16 & 8 & 88 \\
\hline S4 & 16 & 16 & 16 & 16 & 16 & 7 & 87 \\
\hline \multicolumn{7}{|l}{ Total de pares por mes }
\end{tabular}

Elaboración: Propia 
Tabla $\mathrm{N}^{\circ} 1.45$

Exceso de capacidad mensual

\begin{tabular}{|l|r|r|}
\hline \multicolumn{3}{|c|}{ Exceso de capacidad mensual } \\
\hline & 3D & Estándar \\
\hline Demanda 351 pares & 186 & 165 \\
\hline Capacidad máxima 720 pares & 333 & 387 \\
\hline Exceso de capacidad mensual & 147 & 222 \\
\hline
\end{tabular}

Elaboración: Propia

Cómo puede observarse, en días particulares puede fabricarse 16 pares ( 9 en 3D y 7 en estándar), mientras que los días sábado entre 8 y 7 pares.

Si existiera un exceso de demanda sobre los 16 u 8 pares en orden de producción en días particulares y sábados respectivamente, pueden cubrirse en hasta 147 pares en horma 3D y 222 pares en horma estándar por mes.

\subsubsection{Diseño y distribución de planta}

Para el desarrollo de las operaciones, se estima que el área mínima del taller debe ser no menor a $120 \mathrm{~m} 2$. 
Figura $N^{\circ} 1.73$

Diseño de plano de planta de producción

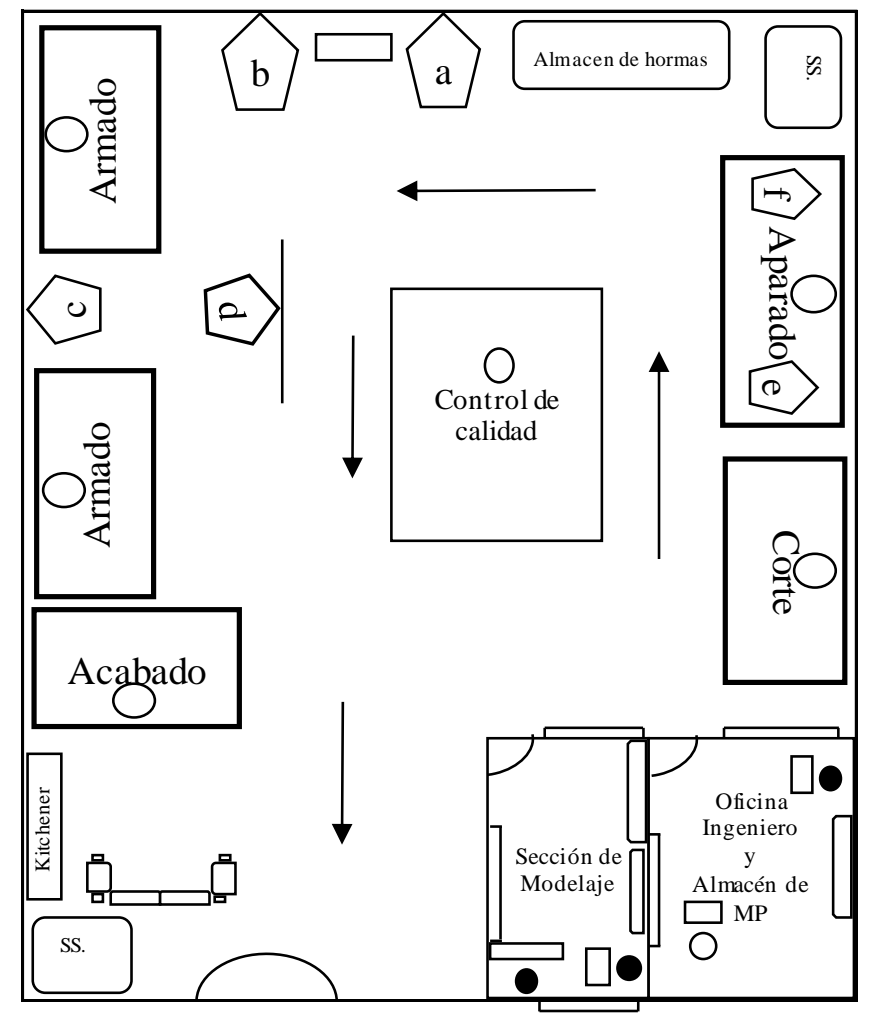

Puerta principal

\begin{tabular}{|l|l|}
\hline \multicolumn{2}{|c|}{ Maquinaria } \\
\hline a & Rematadora \\
\hline b & Pegadora \\
\hline c & Horno \\
\hline d & Clavadora \\
\hline e & Desbastadora \\
\hline f & Aparadora \\
\hline
\end{tabular}

\begin{tabular}{|l|c|}
\hline $\begin{array}{l}\text { Mesa de apoyo / } \\
\text { escritorio }\end{array}$ & $\square$ \\
\hline Operarios & $\bigcirc$ \\
\hline Personal adminis trativo & \\
\hline
\end{tabular}

Elaboración: Propia 
Tabla $N^{\circ} 1.46$

Distribución de áreas de planta

\begin{tabular}{|l|r|}
\hline \multicolumn{1}{|c|}{ Área } & m2 \\
\hline Corte & 3 \\
\hline Aparado & 4 \\
\hline Armado 1 & 2.7 \\
\hline Armado 2 & 2.7 \\
\hline Acabado & 3 \\
\hline Control de calidad & 4 \\
\hline Maquina a & 1 \\
\hline Maquina b & 2 \\
\hline Maquina c & 0.5 \\
\hline Maquina d & 0.5 \\
\hline Almacen MP & 25 \\
\hline Sección Modelaje & 16 \\
\hline Recepción & 12 \\
\hline Almacén de hormas estándar & 6 \\
\hline SS.HH 1 & 5 \\
\hline SS.HH 2 & 5 \\
\hline Pasillos & 25 \\
\hline Mesa de apoyo & 118.4 \\
\hline Total & \\
\hline
\end{tabular}

Elaboración: Propia 


\subsubsection{Diseño y distribución de oficina o punto de venta/exhibición}

Para el desarrollo de las operaciones de ventas, se estima que el área mínima de la oficina debe ser no menor a $59.5 \mathrm{~m} 2$.

Figura $\mathrm{N}^{\circ} 1.74$

Diseño de plano de punto de venta

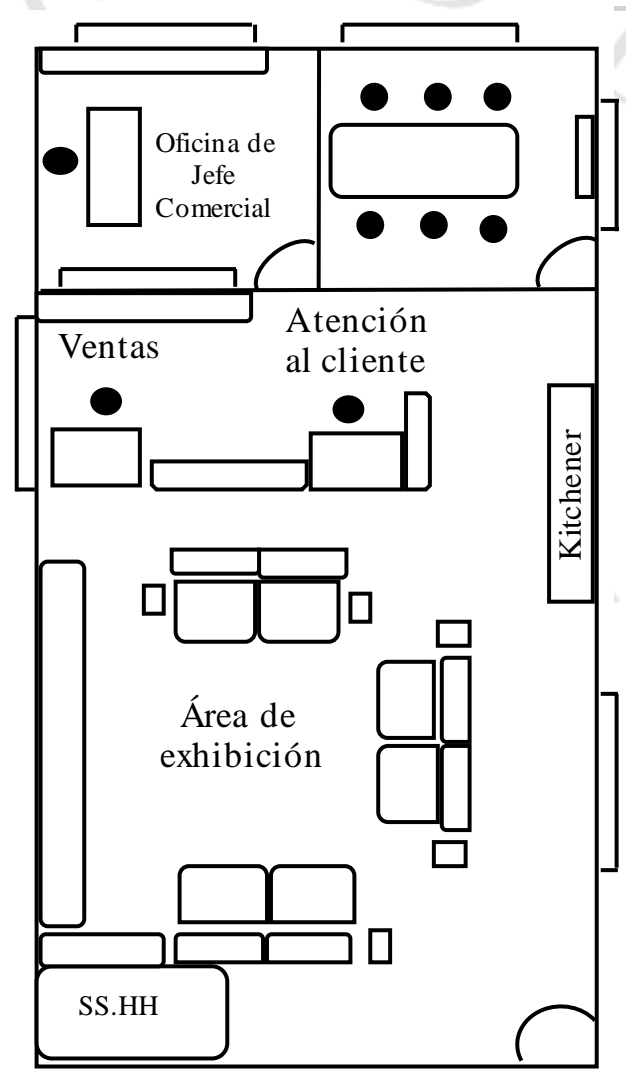

P uerta principal

Elaboración: Propia 
Distribución de las áreas de punto de venta

\begin{tabular}{|l|r|}
\hline \multicolumn{1}{|c|}{ Área } & m2 \\
\hline Sala de reuniones & 12 \\
\hline Escritorios de ventas & 12 \\
\hline Área de exhibición & 15 \\
\hline Kitchener & 1.5 \\
\hline SS.HH & 3 \\
\hline Área de ventas & 4 \\
\hline Área de Atención al & 4 \\
cliente & 8 \\
\hline Pasillos o áreas libres & 59.5 \\
\hline Total & \\
\hline
\end{tabular}

Elaboración: Propia

\subsubsection{Datos adicionales}

Es importante mencionar que, como valor agregado extra al producto final, las impresoras 3D permiten también la impresión de tacos en filamento de plástico o PVC. Gracias a su flexibilidad pueden ser de formas únicas y colores variados permitiendo dar un plus exclusivo y por consecuencia conseguir un precio añadido. 
Figura $\mathrm{N}^{\circ} 1.75$

Impresión de tacos en 3D en filamento de PVC
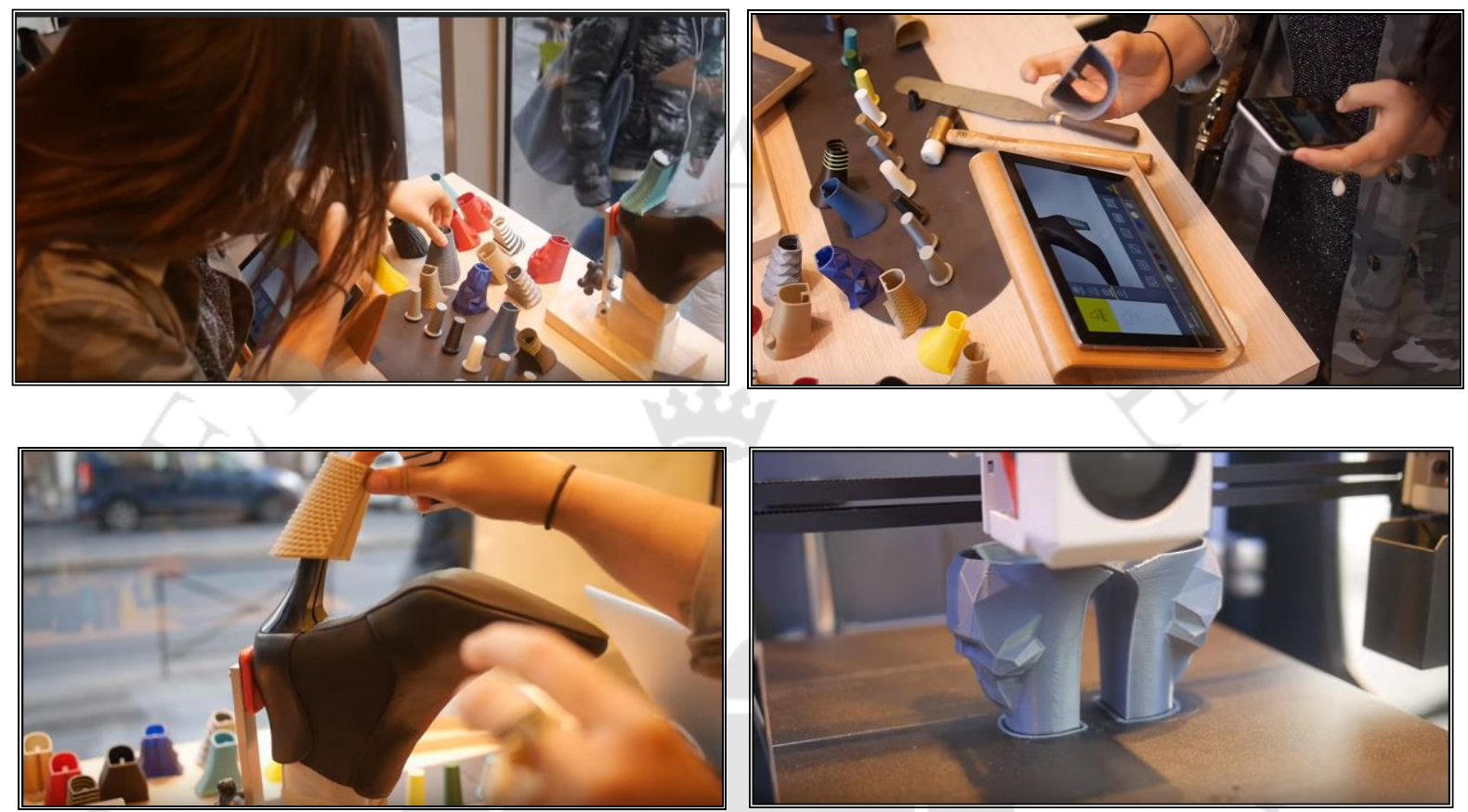

rar

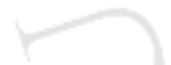

Otro dato importante es que el filamento tanto de madera cómo de plástico es $100 \%$ reciclable, es decir que, gracias a la extrusionadora de filamento, una vez molido el artículo impreso, éste puede convertirse nuevamente en filamento para poder imprimir, en nuestro caso, nuevas hormas. De esta manera se logra reducir el costo de materia prima indirecta, ya que el filamento puede rehusarse hasta en tres oportunidades. 


\section{CAPÍTULO II. ESTRUCTURA DE LA ORGANIZACIÓN}

\subsection{Análisis de la organización}

\subsubsection{Organización de los puestos de trabajo}

Para el desarrollo de las actividades se solicita de personal administrativo que se encontrarán en planilla y operarios de producción. Cabe recordar que los operarios de producción trabajan bajo la modalidad de destajo.

\section{- Gerente General}

- Responsable de la administración de la empresa.

- Responsable de las compras requeridas por el Jefe de Producción y Jefe Comercial.

- Supervisa los movimientos comerciales y operativos de la empresa.

- Desarrolla y verifica la estrategia corporativa.

- Jefe Comercial

- Responsable de desarrollar la marca.

- Responsable del plan de marketing.

- Responsable de mantener la participación esperada y ejecutar estrategias decrecimiento.

- Responsable de la fijación de precios y de definir la política de descuentos y bonificaciones. 
- Capacita a los vendedores sobre el modelo de negocio.

- Selecciona personal.

- Contacto principal con la cartera de clientes.

- Ventas

- Responsable de la gestión de ventas, comunicación presencial y virtual con el cliente.

- Encargado de comunicar al Jefe Comercial mejoras o inconvenientes en base al feedback de los clientes.

- Atención al cliente

- Encargado de la distribución del producto final.

- Atender y resolver quejas y reclamaciones.

- Transmitir a los responsables de cada sector las mejoras que los clientes les trasladan.

- Ofrecer a los clientes aquella información que han pedido.

- Recoger y analizar las quejas de los clientes.

- Archivar y mantener un registro de las quejas que hayan recibido.

- Jefe de Producción

- La planificación y supervisión del trabajo de los maestros.

- La supervisión de los procesos de producción o fabricación en empresas manufactureras.

- El control de stocks y la gestión de almacenes. 
- La resolución de las incidencias (como las averías de la maquinaria, por ejemplo).

- La gestión de los recursos materiales.

- La búsqueda de estrategias para aumentar la eficiencia y eficacia de la producción.

- Costeo de producción

- Monetiza el informe de producción semanal y realiza el pago a destajeros.

\section{- Ayudante de producción}

- Registro de avance de producción.

- Distribución de MP.

- Registro de distribución de MP.

- Actualizar la documentación asignada bajo su responsabilidad(Planes, instructivos, procedimientos).

- Ejecutar actividades relacionadas a labores de orden y limpieza.

- Proveer, supervisa e inspecciona el uso de implementos de seguridad del personal; así como el cumplimiento de las normativas de seguridad.

- Supervisar las normas de higiene y conducta personal.

- Coordinar la labor inherente al mantenimiento correctivo, preventivo y predictivo de los equipos.

- Asistir en todas las labores que le delegue el Jefe de Producción.

- Modelaje y Multimedia

- Encargado de desarrollar la colección por temporada.

- Responsable de perfilar e imprimir la horma a la medida. 
- Realiza seguimiento a las compras de clientes.

- Coordina con Jefe de producción sobre el desarrollo del producto.

- Asistente de modelaje

- Encargado de producir filamento de madera.

- Asistir en todas las labores que le delegue el encargado de Modelaje y Multimedia.

- Recepción de ventas y coordina con su superior para inicio del desarrollo del calzado.

- Entrega al área de corte los moldes del modelo a fabricar.

\section{- Ayudante de control de calidad}

- Monitoreo de la calidad de cada fase de producción.

- Coordina e informa a Ayudante de producción sobre incidencias de productos en proceso o terminados defectuosos.

- Registra la producción semanal de operarios de producción y entrega el informe al Jefe de producción.

- Participar activamente en los procesos de diseño y elaboración y en el lanzamiento de nuevos productos.

- Operarios de producción

- 1 Cortador

- 1 Aparador

- 2 Armadores

- 1 Acabador 
- Jefe de Recursos Humanos (para el tercer año)

- Elaborar y controlar el proceso de reclutamiento, selección, ingreso e inducción del personal, a fin de asegurar la elección de los candidatos más idóneos para los puestos de la organización.

- Proyectar y coordinar programas de capacitación y entrenamiento para los empleados.

- Supervisar y controlar los pasivos laborales del personal activo (vacaciones, anticipos de prestaciones sociales, fideicomiso, etc.) y liquidaciones de prestaciones sociales, a objeto de cumplir con los procedimientos establecidos en la Empresa.

- Pago de planilla a personal administrativo y operarios.

\subsubsection{Análisis de la estructura propuesta.}

La organización cuenta con área de producción y venta. Es por esta razón que se ha decidido por una estructura plana de tres niveles de tipo funcional.

\section{Figura 2.1}

Organigrama

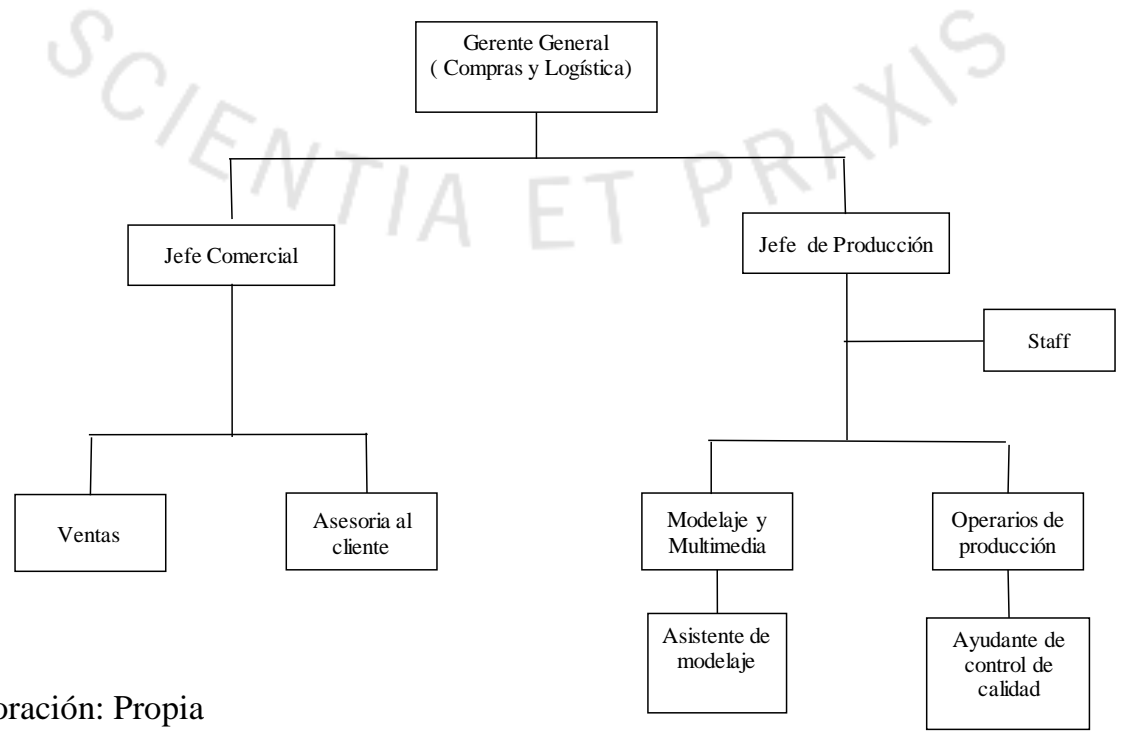




\subsubsection{Requerimiento de recurso humano necesario anualmente}

La necesidad de recurso humano va relacionada con el crecimiento de las ventas e ingresos.

El detalle a continuación:

Tabla 2.1

Planilla requerida por año

\begin{tabular}{|c|c|c|c|c|c|}
\hline AÑo & 1 & 2 & 3 & 4 & 5 \\
\hline Trabajajdor & $N^{\circ}$ Trabajajdores & N Trabajadores & $N^{\circ}$ Trabajgdores & $N$ Trabajadores & $N$ Tabajatores \\
\hline Gerenta General. & & & & & \\
\hline Jefe Comercial & 20 & & 1 & $D$ & \\
\hline Tefe de Producción y Logis tica & & & & & \\
\hline JefedeRRH & & & & & \\
\hline Técnico da Modelaje y Multimed & & & & & \\
\hline Asistente $d=$ noldaor & D & E & & $\square$ & \\
\hline Awd ante de producción & E & $=$ & & 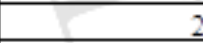 & \\
\hline Avdantedecontrol decalid ad & & Z & & 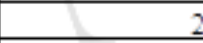 & \\
\hline Asistente da atención al clienta & $\mathrm{E}$ & & & & \\
\hline Vendadores & & & & 2 & \\
\hline
\end{tabular}

Elaboración: Propia

En materia de producción, el personal requerido anualmente es el siguiente:

Tabla 2.2

Personal de destajeros requerido por año

\begin{tabular}{|l|r|r|r|r|r|}
\hline \multicolumn{1}{|c|}{ Detalle } & AÑO 1 & AÑO 2 & AÑO 3 & AÑO 4 & AÑO 5 \\
\hline Cortador & 1 & 1 & 1 & 1 & 1 \\
\hline Aparador & 1 & 1 & 1 & 2 & 2 \\
\hline Armador & 2 & 2 & 2 & 2 & 2 \\
\hline Acabador & 1 & 1 & 1 & 1 & 1 \\
\hline
\end{tabular}

Elaboración: Propia 


\subsection{Misión, visión y objetivos estratégicos}

\subsubsection{Misión}

Materializamos los gustos, preferencias y la comodidad del andar en calzado de nuestros clientes.

\subsubsection{Visión}

Ser reconocida como la empresa pionera y líder nacional de producción de calzado de damas personalizado y a la medida.

\subsubsection{Objetivos estratégicos}

- Alcanzar una participación de mercado de 5\% para el quinto año.

- Optimizar el proceso de producción anualmente para reducir el Lead Time en un 2\% con respecto al año anterior.

- Desarrolla una experiencia de diseño virtual de producto más dinámica y real al cliente para el tercer año.

\subsection{Aspectos legales de constitución}

\subsubsection{Determinación de la forma societaria}

La PYME será registrada como una Sociedad Anónima Cerrada (SAC) y contará con 2 accionistas. El capital social se conforma por 500 acciones que la empresa emitirá de valor nominal de S/. 410.00 (doscientos soles) cada uno. 
Se decide por esta forma societaria considerando el número de accionistas y no exige un mínimo de participación del capital social.

\subsubsection{Trámites legales de constitución}

\section{- PASO I}

Primer Requisito: La reserva del nombre en Registros Públicos. Se debe realizar 3 operaciones:

- Buscar en los índices.

- Solicitar la inscripción del nombre o título.

- Obtener la Reserva de Preferencia Registral.

Segundo Requisito: Presentación de los documentos personales.

Se acompaña copia simple del DNI vigente del titular o de los socios.

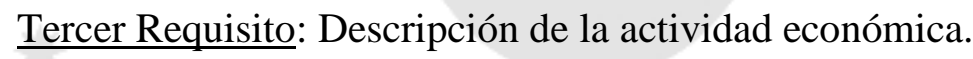

Se presenta en una hoja suelta redactada y firmada por los interesados.

Cuarto Requisito: Capital de la empresa:

Se debe de indicar el aporte del titular o de los socios que se hace para la constitución de la empresa.

Los aportes se deben de detallar en Bienes Dinerarios y Bienes no Dinerarios. 
Se aportará bienes dinerarios (efectivo), una vez elaborada la minuta, y con una copia de ésta, efectuaremos el depósito bancario a nombre de la empresa. Se tienen que adjuntar la "Constancia de Depósito" en original y copia.

\section{- PASO II}

Quinto Requisito: Estatuto

Se debe acompañar el estatuto que regirá a nuestra empresa (régimen del directorio, la gerencia, la junta general, los deberes y derechos de los socios o accionistas, entre otros, según corresponda).

Lista la MINUTA de constitución de la empresa, se puede tramitar la elaboración de su ESCRITURA PÚBLICA ante un notario y, a continuación, presentarla ante las oficinas registrales de la SUNARP para su inscripción en el registro de personas jurídicas.

\section{- PASO III}

\section{Inscripción en el Registro de Personas o Registro Público}

\section{Jurídica:}

Registro de Sociedades en nuestro caso es una Sociedad Anónima Cerrada.

Para inscribirse en el REGISTRO DE SOCIEDADES se cuenta con los siguientes documentos:

- Formato de solicitud de inscripción debidamente llenado y suscrito. 
- Copia del documento de identidad del representante, con la constancia de haber sufragado en las últimas elecciones o haber solicitado la dispensa respectiva.

- Escritura pública que contenga el Pacto Social y el Estatuto.

- Comprobante de depósito por el pago de derechos registrales (tasas).

- Otros documentos según calificación registral y disposiciones vigentes.

\section{DERECHOS REGISTRALES - TASAS}

$1.08 \%$ UIT por derechos de calificación.

3/1000 del valor del capital por derechos de inscripción: 3 soles por cada 1000 soles.

Luego de calificar el título, la oficina registral hace entrega de:

- Una constancia de inscripción.

- Copia simple del asiento registral

\section{- PASO IV}

Luego de que Registros Públicos - SUNARP - ha entregado el asiento registral de la inscripción de la empresa como Persona Jurídica, se tramita, como siguiente paso, la inscripción en el RUC, registro a cargo de la SUNAT, es un registro que contiene información del contribuyente.

Por ejemplo: datos de identificación, actividades económicas, domicilio fiscal, así como los tributos a los que se encuentra afecto, entre otros datos, este registro se encuentra a cargo de la Superintendencia Nacional de Administración Tributaria - SUNAT, entidad que tiene por finalidad administrar, fiscalizar y 
recaudar los tributos con que se contribuye para que el Estado pueda cumplir con sus fines.

La SUNAT identifica como contribuyente otorgando de manera inmediata, un número de RUC, que consta de once (11) dígitos.

Se inscribe en el RUC si se tiene proyectado iniciar las actividades dentro de los 12 meses siguientes a la fecha de inscripción.

En segundo lugar, el tipo de régimen de Impuesto a la Renta al cual se acogerá nuestra empresa es la tercera categoría.

\section{- PASO V}

\section{Planillas de Pago}

Ya inscrita la empresa en la SUNAT y tramitado la autorización en el sector correspondiente. Ahora se debe de llevar planillas de pago. En ellas se debe de registrar diversos conceptos; por ejemplo, los pagos que se realizan a los trabajadores de manera semanal, quincenal o mensual. Se necesita que las planillas sean autorizadas (aprobadas para su uso) por la Autoridad Administrativa de Trabajo -cuya sigla es AAT-del lugar donde se encuentra el centro de trabajo de la empresa. Si la empresa se encuentra en Lima, la AAT está en el Ministerio de Trabajo y Promoción del Empleo.

Una de las principales obligaciones como empleador es llevar planillas de pago, debidamente autorizadas por la AAT. Hacerlo levanta positivamente la imagen de nuestra empresa y su prestigio en la comunidad. Estos son pasos para 
posicionar a la empresa, ampliar el mercado y tener acceso a asesoría técnica y apoyo financiero de instituciones de promoción. Por otro lado, cumplir la legislación vigente y hacer efectiva una medida de beneficio para nuestros trabajadores eleva la solidez de las relaciones internas y es un excelente comienzo para la instalación de un programa de calidad.

\section{- PASO VI}

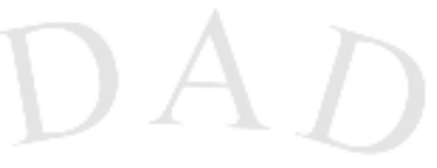

\section{EsSalud}

En el 6to paso, se registra a los trabajadores dependientes ante EsSalud. Con este registro ellos podrán acceder a las prestaciones que otorga dicha entidad.

\section{- PASO VII}

\section{Autorizaciones y/o Permisos}

Son permisos o requisitos que pide la autoridad competente, según el área de especialización del negocio, para garantizar que las prácticas sean compatibles con el interés colectivo y la calidad de vida ciudadana. Por ejemplo, INDECOPI para la protección y uso de la marca.

\section{- PASO VIII}

\section{Evaluación y requisitos para obtención}

Para evitar multas o el cierre de nuestro establecimiento, que perturben el funcionamiento de nuestro negocio, se debe solicitar la licencia de funcionamiento ante la municipalidad localizada en Villa el Salvador, lugar 
donde realizamos nuestras actividades. Esta autorización permitirá el desarrollo de actividades económicas, el respeto al derecho a la tranquilidad y seguridad de los vecinos, y su obtención se encuentra regulada en la Ley Marco de Licencias de Funcionamiento, Ley 28976.

\section{Licencia Municipal de funcionamiento}

Es la autorización que otorga la municipalidad para el desarrollo de actividades económicas (comerciales, industriales o de prestación de servicios profesionales) en su jurisdicción, ya sea como persona natural o jurídica, entes colectivos, nacionales o extranjeros.

\section{Evaluación y requisitos para la obtención de la licencia de funcionamiento:}

Para el otorgamiento de la licencia de funcionamiento, la municipalidad evaluará los siguientes aspectos:

- Zonificación y compatibilidad de uso.

- Condiciones de seguridad en Defensa Civil, cuando dicha evaluación constituya facultad, cualquier aspecto adicional será materia de fiscalización.

\section{Requisitos:}

Para el otorgamiento de la licencia de funcionamiento serán exigibles, como máximo, los siguientes requisitos:

- Solicitud de Licencia de Funcionamiento con carácter de declaración jurada, que incluya: Número de RUC.

- Vigencia de poder del representante legal, en el caso de personas jurídicas u otros entes colectivos. Tratándose de representación de personas naturales, se requerirá carta poder con firma legalizada. 
- Declaración Jurada de Observancia de Condiciones de Seguridad o Inspección Técnica de Seguridad en Defensa Civil de Detalle o Multidisciplinaria, según corresponda.

Adicionalmente, de ser el caso, serán exigibles los siguientes requisitos:

- Copia simple de título profesional en el caso de servicios relacionados con la salud.

- Informar sobre el número de estacionamientos de acuerdo con la normativa vigente, en la declaración jurada.

- Copia simple de la autorización sectorial respectiva en el caso de aquellas actividades que, conforme a ley, la requieran de manera previa al otorgamiento de la licencia de funcionamiento.

- Copia simple de la autorización expedida por el Instituto Nacional de Cultura, conforme a la Ley No 28296, Ley General del Patrimonio Cultural de la Nación. Verificados los requisitos señalados, se procederá al pago de la tasa respectiva fijada por cada municipalidad.

La licencia de funcionamiento tiene vigencia indeterminada. El otorgamiento de una licencia no obliga a la realización de la actividad económica en un plazo determinado.

\section{Costo de la licencia de funcionamiento:}

La tasa por licencia de funcionamiento deberá reflejar el costo real del procedimiento vinculado a su otorgamiento, el cual incluye los siguientes conceptos a cargo de la municipalidad:

A. Evaluación por Zonificación, Compatibilidad de Uso. 


\section{B. Inspección Técnica de Seguridad en Defensa Civil Básica.}

Para fines de lo anterior, la municipalidad deberá acreditar la existencia de la respectiva estructura de costos y observar lo dispuesto por la Ley de Tributación Municipal, Decreto Legislativo $\mathrm{N}^{\circ} 776$ y la Ley del Procedimiento Administrativo General, Ley No 27444.

El operar un negocio sin la licencia de funcionamiento dará lugar a sanciones y la posibilidad que nos cierren la planta.

\section{- PASO IX}

\section{Legalización de Libros Contables}

Este es el último paso que se realiza para formalizar nuestra empresa. De acuerdo con el tipo de empresa que se ha decidido constituir, se puede llevar determinados libros contables, ya sea por medios manuales o computarizados. Estos libros son legalizados ante un notario o, donde no lo haya, ante un juez de paz letrado del lugar.

La legalización es la constancia, puesta por un notario, en la primera hoja útil del libro contable. Si se usa registros por medio computarizado, esta constancia debe estar en la primera hoja suelta. La constancia asigna un número y contiene el nombre o la denominación de la razón social, el objeto del libro, el número de folios, el día y el lugar en que se otorga, y el sello y firma del notario (o juez de paz si no hay notario en el lugar). Además, cada hoja, debidamente foliada (o sea, numerada en forma consecutiva) debe contar con el sello del notario o juez de paz, de ser el caso. 
Para solicitar la legalización de un segundo libro, o de las hojas sueltas, debemos acreditar que se ha concluido el libro o las hojas anteriores. En caso de pérdida, se tiene que demostrar en forma fehaciente (indiscutible, con evidencias) que así ha sucedido.

La legalización, de libros u hojas, se debe efectuar ante notario (Ley $\mathrm{N}^{\circ}$ 26501, artículo 112), excepto en los lugares donde no existe, en ese caso, la legalización la realizarán los jueces de paz. 


\section{CAPÍTULO III: EVALUACIÓN ECONÓMICA Y \\ FINANCIERA}

\subsection{Planeamiento}

\subsubsection{Inversión}

Tabla 3.1 Inversiones

\begin{tabular}{|l|rr|rr|rr|}
\hline Inversiones & \multicolumn{2}{|c|}{ Valor de venta } & \multicolumn{2}{c|}{ IGV } & \multicolumn{2}{c|}{ Precio de venta } \\
\hline Muebles y accesorios & S/. & 11,364 & S/. & 2,046 & S/. & 13,410 \\
\hline Maquinas y Equipos & S/. & 41,610 & S/. & 7,490 & S/. & 49,100 \\
\hline Vehículos & S/. & 41,628 & S/. & 7,493 & S/. & 49,121 \\
\hline Acondicionamiento de local & S/. & 8,644 & S/. & 1,556 & S/. & 10,200 \\
\hline Alquiler 1*1 & S/. & 11,959 & S/. & - & S/. & 11,959 \\
\hline Intangibles & S/. & 25,229 & S/. & 4,541 & S/. & 29,771 \\
\hline Capital de Trabajo & S/. & 90,000 & S/. & - & S/. & 90,000 \\
\hline Total Inversiones & S/. & 230,435 & S/. & 23,126 & S/. & 253,561 \\
\hline
\end{tabular}

Elaboración: Propia

- Gastos pre operativos

Los gastos pre operativos están conformados por los gastos de acondicionamiento de local y alquiler, que asciende a S/. 22, 159 soles.

\section{- Capital de trabajo}

El monto de capital de trabajo se ha calculado para cubrir el desfase entre las compras de inversiones y las compras de inventario, así como cualquier imprevisto que se presente durante el primer año hasta que el proyecto logre autofinanciarse. 


\section{- Activo Fijo}

Lo que conforma el activo fijo es muebles, enseres, maquinarias y equipos, y vehículos, cuya inversión asciende a S/. 111,631 soles.

\section{Tabla 3.2 Muebles y enseres}

\begin{tabular}{|c|c|c|c|c|c|}
\hline Muebles y enseres & Cantidad & Costo & Valor de venta & IGV & Precio de venta \\
\hline Escritorio de melamine & 6 & $\mathrm{~S} /$. & 1,322 & 238 & 1,560 \\
\hline Silla giratoria & 12 & $\mathrm{~S} /$. & 915 & S/. & 1,080 \\
\hline Mesa de reuniones & 2 & 400 & 339 & $\mathrm{~S} /$. & 400 \\
\hline Sillon de espera & 2 & 1,100 & 1,864 & $\mathrm{~S} /$. & 2,200 \\
\hline Archivadores & 5 & 150 & 636 & 114 & 750 \\
\hline Armario de madera & 6 & S/. $\quad 180$ & 915 & 165 & 1,080 \\
\hline Reloj de pared & 4 & S/. $\quad 35$ & 119 & 21 & 140 \\
\hline Botiquin de primeros auxilios & 2 & $\mathrm{~S} /$. & $\mathrm{S} / \mathrm{s}$ & $\mathrm{S} /$. & S/. \\
\hline Cafetera & 2 & $\mathrm{~S} /$. & $\mathrm{S} /$. & $\mathrm{S} /$. & 180 \\
\hline Mini frigobar & 2 & 399 & $\mathrm{~S} /$. & 122 & 798 \\
\hline Kitchen de oficina & 2 & 780 & 1,322 & $\mathrm{~S} /$. & 1,560 \\
\hline Cestas de basura de escritorio & 5 & 10 & S/. & S/. & S/. \\
\hline Cesta grande de basura & 1 & $\mathrm{~S} /$. & $\mathrm{S} /$. & $\mathrm{S} /$. & $\mathrm{S} /$. \\
\hline Planchas de trupan & 2 & 125 & $\mathrm{~S} /$. & S/. & 250 \\
\hline Pizarra acrilica & 2 & $\mathrm{~S} /$. & $\mathrm{S} /$. & $\mathrm{S} /$. & 170 \\
\hline Acrilicos de exibición & 30 & $\mathrm{~S} /$. & $\mathrm{S} /$. & $\mathrm{S} /$. & S/. \\
\hline Mesa de corte & 1 & 300 & $\mathrm{~S} /$. & $\mathrm{S} /$. & $\mathrm{S} /$ \\
\hline Silla de aparador & 2 & $\mathrm{~S} /$. & $\mathrm{S} /$. & $\mathrm{S} /$. & S/. \\
\hline Mesa de zapatero & 2 & $\mathrm{~S} /$. & $\mathrm{S} /$. & $\mathrm{S} /$. & 120 \\
\hline Andamio de zapatero & 2 & $\mathrm{~S} /$. & $\mathrm{S} /$. & $\mathrm{S} /$. & 140 \\
\hline \begin{tabular}{|l|} 
Silla de zapatero \\
\end{tabular} & 2 & S/. & $\mathrm{S} /$. & $\mathrm{S} /$. & $\mathrm{S} /$. \\
\hline Mesa de acabado & 1 & 300 & $\mathrm{~S} /$. & $\mathrm{S} /$. & S/. \\
\hline Andamio de acabado & 1 & $\mathrm{~S} /$. & $\mathrm{S} /$. & $\mathrm{S} /$. & $\mathrm{S} /$. \\
\hline Silla de acabado & 1 & $\mathrm{~S} /$. & $\mathrm{S} /$. & $\mathrm{S} /$. & $\mathrm{S} /$. \\
\hline Mesa de trabajo & 1 & 110 & $\mathrm{~S} /$. & $\mathrm{S} /$. & 110 \\
\hline Mesa de apoyo & 1 & 110 & $\mathrm{~S} /$. & $\mathrm{S} /$. & 110 \\
\hline Cesta para cortes & 3 & $\mathrm{~S} /$. & $\mathrm{S} /$. & $\mathrm{S} /$. & $\mathrm{S} /$. \\
\hline Andamio de ormas & 2 & 150 & $\mathrm{~S} /$. & $\mathrm{S} /$. & 300 \\
\hline Andamio para materia prima & 2 & 150 & $\mathrm{~S} /$. & $\mathrm{S} / \mathrm{L}$ & 300 \\
\hline Andamio para cuero & $\mathrm{Az}$ & 150 & $\mathrm{~S} /$. & $\mathrm{S} /$. & 150 \\
\hline Librero de pared & 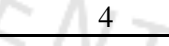 & $\mathrm{S} /$. & \begin{tabular}{|ll} 
S/. & 203 \\
\end{tabular} & $\mathrm{~S} /$. & 240 \\
\hline Mueble con cajones para MP & 1 & -300 & S/. & S/. & S/. \\
\hline Bancas de plástico & 4 & $\mathrm{~S} /$. & $\mathrm{S} /$. & $\mathrm{S} /$. & $\mathrm{S} /$. \\
\hline Tablas de madera & 3 & $\mathrm{~S} /$. & $\mathrm{S} /$. & $\mathrm{S} /$. & $\mathrm{S} /$. \\
\hline $\begin{array}{l}\text { Mueble con cajones para } \\
\text { patrones y marcadores }\end{array}$ & 1 & S/. & S/. & $\mathrm{S} /$. & $\mathrm{S} /$. \\
\hline Total & & & 11,364 & 2,046 & 13,410 \\
\hline
\end{tabular}

Elaboración: Propia 
Tabla 3.3 Maquinarias y Equipos

\begin{tabular}{|c|c|c|c|c|c|c|c|c|c|}
\hline Maquinas y Equipos & Cantidad & & & & enta & & & & enta \\
\hline Desbastadora & 1 & S/. & 1,750 & $\mathrm{~S} /$. & 1,483 & S/. & 267 & $\mathrm{~S} /$. & 1,750 \\
\hline Aparadora de poste & 1 & S/. & 2,200 & $\mathrm{~S} /$. & 1,864 & $\mathrm{~S} /$. & 336 & S/. & 2,200 \\
\hline Rematadora & 1 & $\mathrm{~S} /$. & 650 & $\mathrm{~S} /$. & 551 & S/. & 99 & S/. & 650 \\
\hline Pegadora modelo boca de sapo & 1 & S/. & 3,800 & $\mathrm{~S} /$. & 3,220 & $\mathrm{~S} /$. & 580 & $\mathrm{~S} /$. & 3,800 \\
\hline Comprensora de aire & 1 & S/. & 1,400 & $\mathrm{~S} /$. & 1,186 & $\mathrm{~S} /$. & 214 & $\mathrm{~S} /$. & 1,400 \\
\hline Clavadora de taco & 1 & S/. & 2,100 & $\mathrm{~S} /$. & 1,780 & $\mathrm{~S} /$. & 320 & $\mathrm{~S} /$. & 2,100 \\
\hline Pistola de calor & 1 & $\mathrm{~S} /$. & 100 & $\mathrm{~S} /$. & 85 & $\mathrm{~S} /$. & 15 & $\mathrm{~S} /$. & 100 \\
\hline Esmeril & 1 & $\mathrm{~S} /$ & 60 & $\mathrm{~S} /$. & 51 & $\mathrm{~S} /$. & 9 & $\mathrm{~S} /$. & 60 \\
\hline Selladora o repujadora & 1 & $\mathrm{~S} /$. & 330 & S/. & 280 & $\mathrm{~S} /$. & 50 & $\mathrm{~S} /$. & 330 \\
\hline Prensadora de ojales & 1 & $\mathrm{~S} /$. & 65 & $\mathrm{~S} /$. & 55 & S/. & 10 & $\mathrm{~S} /$. & 65 \\
\hline Horno activador & 1 & $\mathrm{~S} /$. & 100 & $\mathrm{~S} /$. & 85 & $\mathrm{~S} /$. & 15 & $\mathrm{~S} /$. & 100 \\
\hline Computadoras & 4 & $\mathrm{~S} /$. & 1,382 & $\mathrm{~S} /$. & 4,685 & $\mathrm{~S} /$. & 843 & $\mathrm{~S} /$. & 5,528 \\
\hline Laptop & 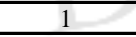 & S/. & 1,800 & $\mathrm{~S} /$. & 1,525 & $\mathrm{~S} /$. & 275 & $\mathrm{~S} /$. & 1,800 \\
\hline Impresora multifuncional & 4 & $\mathrm{~S} /$. & 325 & $\mathrm{~S} /$. & 1,102 & $\mathrm{~S} /$. & 198 & $\mathrm{~S} /$. & 1,300 \\
\hline Calculadoras & 5 & $\mathrm{~S} /$ & 70 & S/. & 297 & S/. & 53 & S/. & 350 \\
\hline Celulares & 10 & $\mathrm{~S} /$. & 200 & $\mathrm{~S} /$. & 1,695 & $\mathrm{~S} /$. & 305 & $\mathrm{~S} /$. & 2,000 \\
\hline Impresoras 3D & 10 & $\mathrm{~S} /$. & 589 & $\mathrm{~S} /$. & 4,988 & $\mathrm{~S} /$. & 898 & $\mathrm{~S} /$. & 5,886 \\
\hline Extrusionadora de filamento & 2 & S/. & 4,905 & $\mathrm{~S} /$. & 8,314 & $\mathrm{~S} /$. & 1,496 & $\mathrm{~S} /$. & 9,810 \\
\hline Scanner 3D + tablet & 1 & S/. & 6,540 & $\mathrm{~S} /$. & 5,542 & $\mathrm{~S} /$. & 998 & $\mathrm{~S} /$. & 6,540 \\
\hline Molino triturador eléctrico con patas & 1 & $\mathrm{~S} /$. & 570 & S/. & 483 & $\mathrm{~S} /$. & 87 & S/. & 570 \\
\hline Plancha de Zinc para corte & 4 & $\mathrm{~S} /$. & 40 & S/. & 136 & $\mathrm{~S} /$. & 24 & $\mathrm{~S} /$. & 160 \\
\hline Cuchilla de corte de cuero & 4 & $\mathrm{~S} /$. & 3 & $\mathrm{~S} /$. & 10 & $\mathrm{~S} /$. & 2 & S/. & 12 \\
\hline Pata o pie de desbastadora & 3 & $\mathrm{~S} /$. & 10 & $\mathrm{~S} /$. & 25 & $\mathrm{~S} /$. & 5 & $\mathrm{~S} /$. & 30 \\
\hline Ribeteadora & 1 & $\mathrm{~S} /$. & 25 & $\mathrm{~S} /$. & 21 & $\mathrm{~S} /$. & 4 & S/. & 25 \\
\hline Carrete de costura & 2 & $\mathrm{~S} /$. & 5 & $\mathrm{~S} /$. & 8 & $\mathrm{~S} /$. & 2 & $\mathrm{~S} /$. & 10 \\
\hline Brochas medianas & 5 & $\mathrm{~S} /$. & 3 & S/. & 11 & $\mathrm{~S} /$. & 2 & $\mathrm{~S} /$. & 13 \\
\hline Fluorescente con regleta & 7 & $\mathrm{~S} /$. & 20 & S/. & 119 & $\mathrm{~S} /$. & 21 & S/. & 140 \\
\hline Metros de cadena de sosten de fluorescente & 15 & S/. & 2 & S/. & 19 & $\mathrm{~S} /$. & 3 & S/. & 23 \\
\hline Interruptor de aire & 7 & S/. & 3 & $\mathrm{~S} /$. & 15 & $\mathrm{~S} /$. & 3 & S/. & 18 \\
\hline Extintor & 4 & $\mathrm{~S} /$. & 68 & S/. & 231 & $\mathrm{~S} /$. & 41 & S/. & 272 \\
\hline Camara de Video seguridad & 4 & $\mathrm{~S} /$. & 500 & $\mathrm{~S} /$. & 1,695 & $\mathrm{~S} /$. & 305 & $\mathrm{~S} /$. & 2,000 \\
\hline Detector de humo inalámbrico & 3 & $\mathrm{~S} /$. & 20 & $\mathrm{~S} /$. & 51 & S/. & 9 & S/. & 60 \\
\hline Total & & & & S/. & 1,610 & S/. & 7,490 & S/. &, 100 \\
\hline
\end{tabular}

Elaboración: Propia

Tabla 3.4 Vehículos

\begin{tabular}{|l|c|rr|rr|rr|r|r|}
\hline Vehículos & \multicolumn{2}{|c|}{ Cantidad } & \multicolumn{2}{c|}{ Costo } & \multicolumn{2}{c|}{ Valor de venta } & \multicolumn{2}{c|}{ Precio de venta } \\
\hline Camiones Hino con carrocería & 1 & S/. & 48,510 & S/. & 41,110 & S/. & 7,400 & S/. & 48,510 \\
\hline Instalación GPS & 1 & S/. & 611 & S/. & 517 & S/. & 93 & S/. & 611 \\
\hline Total & \multicolumn{4}{|c|}{ S/. } & 41,628 & S/. & 7,493 & S/. & 49,121 \\
\hline
\end{tabular}

Elaboración: Propia

- Intangibles

Los intangibles están conformado por un monto de S/. 29,771 soles. 
Tabla 3.5 Intangibles

\begin{tabular}{|c|c|c|c|c|c|c|c|c|c|}
\hline Intangibles & Cantidad & \multicolumn{2}{|c|}{ Costo } & \multicolumn{2}{|c|}{ Valor de venta } & \multicolumn{2}{|c|}{ IGV } & \multicolumn{2}{|c|}{ Precio de venta } \\
\hline Desarrollo plataforma web & 1 & S/. & 14,160 & $\mathrm{~S} /$. & 12,000 & $\mathrm{~S} /$. & 2,160 & $\mathrm{~S} /$. & 14,160 \\
\hline Software RHINOCEROS & 1 & S/. & 3,719 & $\mathrm{~S} /$. & 3,152 & $\mathrm{~S} /$. & 567 & $\mathrm{~S} /$. & 3,719 \\
\hline Constitución de la empresa & 1 & S/. & 3,357 & $\mathrm{~S} /$. & 2,845 & $\mathrm{~S} /$. & 512 & $\mathrm{~S} /$. & 3,357 \\
\hline Notaría y regis tros públicos & 1 & $\mathrm{~S} /$. & 2,178 & $\mathrm{~S} /$. & 1,846 & $\mathrm{~S} /$. & 332 & S/. & 2,178 \\
\hline Licencias y autorizaciones & 2 & $\mathrm{~S} /$. & 1,178 & $\mathrm{~S} /$. & 1,997 & $\mathrm{~S} /$. & 360 & $\mathrm{~S} /$. & 2,357 \\
\hline Campaña de Lanzamiento & 1 & S/. & 4,000 & $\mathrm{~S} /$. & 3,390 & S/. & 610 & S/. & 4,000 \\
\hline Total & & & & S/. & 25,229 & S/. & 4,541 & S/. & 29,771 \\
\hline
\end{tabular}

Elaboración: Propia

\subsubsection{Inversiones Futuras}

La inversión futura consta en mantener un inventario en materia prima correspondiente a dos semanas de producción considerando un supuesto de $1 \%$ de merma.

Tabla 3.6 Inversión futura en materia prima

\begin{tabular}{|c|c|c|c|c|c|}
\hline Descripción & Año 1 & Año 2 & Año 3 & Año 4 & Año 5 \\
\hline Producción pares de calzado & 4,416 & 5,400 & 6,872 & 8,345 & 9,327 \\
\hline Ventas pares de calzado & 4,210 & 5,148 & 6,552 & 7,956 & 8,892 \\
\hline Inventario + merma & 206 & 252 & 320 & 389 & 435 \\
\hline Merma 1\% & 42 & 51 & 66 & 80 & 89 \\
\hline Inventario pares de calzado & 164 & 200 & 255 & 309 & 346 \\
\hline Inventario + merma & 206 & 252 & 320 & 389 & 435 \\
\hline Costo unitario (par) & 66 & 68 & 70 & 72 & S/. \\
\hline Inventario soles & 13,516 & 17,024 & 22,316 & 27,911 & 32,131 \\
\hline
\end{tabular}

Elaboración: Propia

Para el tercer año se ha considerado una inversión en impresoras 3D y extrusionadora de filamento para poder abastecer la demanda en pares. Puesto que con las maquinas actuales sólo permite imprimir 333 pares de hormas mensuales y si se consideran los picos de estacionalidad sería insuficiente para el proyecto para el tercer año como puede observarse en el ANEXO N³. 
Tabla 3.7 Inversión futura en impresora 3D

\begin{tabular}{|c|c|c|c|c|c|c|c|c|c|}
\hline Maquinas y Equipos & Cantidad & \multicolumn{2}{|c|}{ Costo } & \multicolumn{2}{|c|}{ V.V. } & \multicolumn{2}{|c|}{ IGV } & \multicolumn{2}{|c|}{ P.V. } \\
\hline Impresoras 3D & 3 & S/. & 589 & S/. & 1,496 & S/. & 269 & $\mathrm{~S} /$. & 1,766 \\
\hline Extrusionadora de filamento & 1 & $\mathrm{~S} /$. & 4,905 & S/. & 4,157 & $\mathrm{~S} /$. & 748 & $\mathrm{~S} /$. & 4,905 \\
\hline Total & & & & S/. & 5,653 & $\mathrm{~S} /$. & 1,018 & $\mathrm{~S} /$. & 6,671 \\
\hline
\end{tabular}

Elaboración: Propia

\subsection{Financiamiento}

\subsubsection{Endeudamiento y condiciones}

Se va a solicitar un préstamo por S/.49,110.00 soles que representa un 19\% de la inversión, cuya tasa de interés promedio es $17 \%$ aplicado para pequeñas empresas, de acuerdo con el Sistema Bancario, a un plazo de 5 años.

Tabla 3.8 Estructura de capital

\begin{tabular}{|c|c|c|c|c|c|c|c|}
\hline \multicolumn{8}{|c|}{ Estructura de Capital en nuevos soles } \\
\hline Inversiones & & & Participación \% & & & & imo \\
\hline Muebles & $\mathrm{S} /$. & 13,410 & $5 \%$ & $\mathrm{~S} /$. & 13,410 & & \\
\hline Maquinaria y equipo & $\mathrm{S} /$. & 49,100 & $19 \%$ & S/. & 24,550 & S/. & 24,550 \\
\hline Camioneta & $\mathrm{S} /$. & 49,121 & $19 \%$ & $\mathrm{~S} /$. & 24,560 & $\mathrm{~S} /$. & 24,560 \\
\hline Acondicionamiento de local & $\mathrm{S} /$. & 10,200 & $4 \%$ & $\mathrm{~S} /$. & 10,200 & & \\
\hline \begin{tabular}{|l|} 
Alquiler $1 * 1$ \\
\end{tabular} & $\mathrm{~S} /$. & 11,959 & $5 \%$ & S/. & 11,959 & & \\
\hline Intangibles & $\mathrm{S} /$. & 29,771 & $12 \%$ & $\mathrm{~S} /$. & 29,771 & & \\
\hline Capital de trabajo & $\mathrm{S} /$. & 90,000 & $35 \%$ & $\mathrm{~S} /$. & 90,000 & & \\
\hline Total & S/. & 253,561 & $100 \%$ & S/. & 204,450 & S/. & 49,110 \\
\hline
\end{tabular}

\begin{tabular}{|c|lr|r|}
\hline Fuente & \multicolumn{2}{|c|}{ Monto en soles } & \multicolumn{2}{c|}{$\%$} \\
\hline Préstamo & S/. & 49,110 & $19 \%$ \\
\hline Aporte accionistas & S/. & 204,450 & $81 \%$ \\
\hline Total & S/. & 253,561 & $100 \%$ \\
\hline
\end{tabular}

Elaboración: Propia 
Tabla 3.9 Estructura de amortización de la deuda

\begin{tabular}{|c|c|c|c|c|c|c|c|c|c|c|c|c|}
\hline Año & \multicolumn{2}{|c|}{ Año 0} & \multicolumn{2}{|c|}{ Año 1} & \multicolumn{2}{|c|}{ Año 2} & \multicolumn{2}{|c|}{ Año 3} & \multicolumn{2}{|c|}{ Año 4} & \multicolumn{2}{|c|}{ Año 5} \\
\hline Préstamo & $\mathrm{S} /$. & 49,110 & & & & & & & & & & \\
\hline Saldo & $\mathrm{S} /$. & - & S/. & 42,109 & S/. & 33,917 & S/. & 24,333 & S/. & 13,120 & $\mathrm{~S} /$. & - \\
\hline Amortización & $\mathrm{S} /$. & - & $\mathrm{S} /$. & 7,001 & S/. & 8,192 & $\mathrm{~S} /$. & 9,584 & S/. & 11,213 & $\mathrm{~S} /$. & 13,120 \\
\hline Interés & $\mathrm{S} /$. & - & $\mathrm{S} /$. & 7,268 & S/. & 6,078 & S/. & 4,686 & $\mathrm{~S} /$. & 3,056 & S/. & 1,150 \\
\hline Cuota & S/. & - & S/. & 14,270 & S/. & 14,270 & S/. & 14,270 & S/. & 14,270 & S/. & 14,270 \\
\hline
\end{tabular}

Elaboración: Propia

\subsubsection{Presupuesto Base}

\section{- Presupuesto de ventas}

La fuente de ingreso proveniente de la venta de pares de calzado es variable cada mes debido a la estacionalidad, es por esto que se ha asignado un porcentaje de ventas por mes considerando las temporadas altas y meses festivos del año.

Tabla 3.10 Presupuesto de ventas

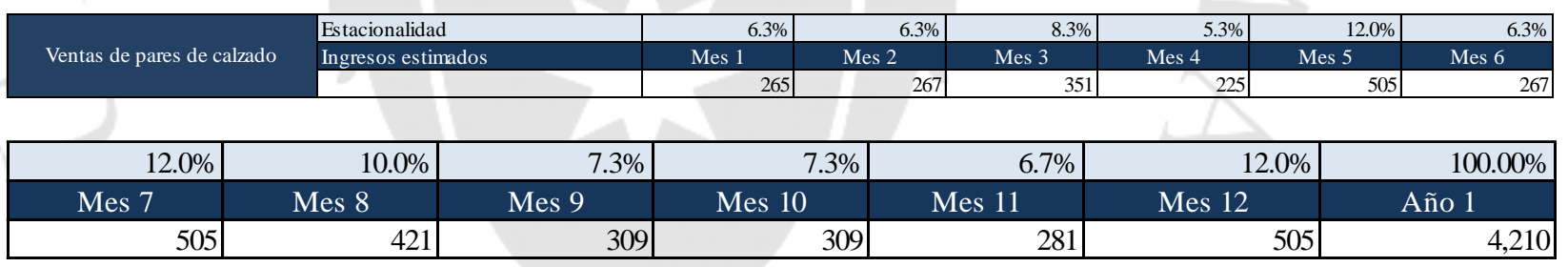

\begin{tabular}{|c|c|c|c|c|c|c|c|c|c|c|}
\hline Ingresos estimados & \multicolumn{2}{|c|}{ Año 1} & \multicolumn{2}{|c|}{ Año 2} & \multicolumn{2}{|r|}{ Año 3} & \multicolumn{2}{|c|}{ Año 4} & \multicolumn{2}{|c|}{ Año 5} \\
\hline Ventas pares de calzado & & 4,210 & & 5,148 & & 6,552 & & 7,956 & & 8,892 \\
\hline Precio promedio sin igv & S/. & 241 & $\mathrm{~S} /$. & 248 & $\mathrm{~S} /$. & 253 & $\mathrm{~S} /$. & 260 & $\mathrm{~S} /$. & 268 \\
\hline Total ingresos valor de venta & $\mathrm{S} /$. & $1,013,254$ & $\mathrm{~S} /$. & $1,276,180$ & $\mathrm{~S} /$. & $1,655,768$ & $\mathrm{~S} /$. & $2,070,893$ & $\mathrm{~S} /$. & $2,383,963$ \\
\hline$x_{2}$ & $\mathrm{~S} /$. & 182,386 & S/. & 229,712 & $\mathrm{~S} /$. & 298,038 & S/. & 372,761 & $\mathrm{~S} /$. & 429,113 \\
\hline Total ingresos por ventas & S/. & $1,195,640$ & S/. & $1,505,893$ & S/. & $1,953,806$ & S/. & $2,443,654$ & S/. & $2,813,076$ \\
\hline Tasa de crecimiento de las & & $0 \%$ & & $26 \%$ & & $30 \%$ & & $25 \%$ & & $15 \%$ \\
\hline
\end{tabular}

Elaboración: Propia

La tasa de crecimiento de las ventas para el cuarto y quinto año va decreciendo puesto que se estima el ingreso de competencia para ese periodo. 


\section{- Presupuesto de costo de producción}

El costo del producto se ha determinado con la Materia Prima Directa, Materia Prima Indirecta, Maquila, Depreciación, Mano de Obra Directa, Mano de Obra Indirecta y Gastos Operativos y Diversos.

Se ha obtenido dos tipos de costo. En el ANEXO No 4 que corresponde al calzado elaborado con horma a la medida impresa en 3D y en el ANEXO $\mathrm{N}^{\circ} 5$ elaborado con horma estándar. Al obtener ambos resultados se obtuvo un promedio de costo como puede observarse en la Tabla 3.11.

Tabla 3.11 Costo de venta

\begin{tabular}{|l|lr|}
\hline \multicolumn{1}{|c|}{ Costo de ventas } & \multicolumn{2}{c|}{ Costo unit } \\
\hline Botin modelo 101 Horma 3D & S/. & 123.66 \\
\hline Botin modelo 101 Horma Estandar & S/. & 102.45 \\
\hline Costo unitario par de calzado CON IGV & S/. & 114.54 \\
\hline Precio de venta par de calzado CON IGV & S/. & 284.00 \\
\hline Margen bruto & & $60 \%$ \\
\hline
\end{tabular}

Elaboración: Propia

\section{- Presupuesto de costo de venta}

El costo de venta está constituido por los costos de Mano de Obra Directa, Mano de Obra Indirecta, Costos de Producción más Gastos Operativos vinculados a la producción. 
Tabla 3.12 Presupuesto de costo de venta

\begin{tabular}{|c|c|c|c|c|c|c|c|c|c|c|c|c|}
\hline Costo de venta & \multicolumn{2}{|c|}{ Total Año 0} & \multicolumn{2}{|c|}{ Total Año 1} & \multicolumn{2}{|c|}{ Año 2} & \multicolumn{2}{|c|}{ Año 3} & \multicolumn{2}{|c|}{ Año 4} & \multicolumn{2}{|c|}{ Año 5} \\
\hline Costos Directos & $\mathrm{S} /$. & - & $\mathrm{S} /$. & 282,190 & $\mathrm{~S} /$. & 354,157 & $\mathrm{~S} /$. & 462,409 & $\mathrm{~S} /$. & 576,864 & $\mathrm{~S} /$. & 663,194 \\
\hline MOD & $\mathrm{S} /$. & - & $\mathrm{S} /$. & 39,424 & S/. & 40,607 & $\mathrm{~S} /$. & 62,737 & $\mathrm{~S} /$. & 64,620 & $\mathrm{~S} /$. & 66,558 \\
\hline MOI & $\mathrm{S} /$. & - & $\mathrm{S} /$. & 183,979 & $\mathrm{~S} /$. & 189,498 & $\mathrm{~S} /$. & 216,095 & $\mathrm{~S} /$. & 222,578 & $\mathrm{~S} /$. & 229,256 \\
\hline Gastos Operativos & $\mathrm{S} /$. & - & $\mathrm{S} /$. & 66,466 & $\mathrm{~S} /$. & 70,851 & $\mathrm{~S} /$. & 77,207 & $\mathrm{~S} /$. & 84,124 & $\mathrm{~S} /$. & 89,330 \\
\hline Gastos Diversos & $\mathrm{S} /$. & - & $\mathrm{S} /$. & 9,465 & $\mathrm{~S} /$. & 9,465 & $\mathrm{~S} /$. & 9,465 & $\mathrm{~S} /$. & 9,465 & $\mathrm{~S} /$. & 9,465 \\
\hline Depreciación y Amort. & $\mathrm{S} /$. & - & $\mathrm{S} /$. & 6,659 & $\mathrm{~S} /$. & 6,659 & $\mathrm{~S} /$. & 7,224 & $\mathrm{~S} /$. & 7,224 & $\mathrm{~S} /$. & 7,224 \\
\hline Total & S/. & - & S/. & 588,183 & S/. & 671,237 & S/. & 835,138 & $\mathrm{~S} /$. & 964,875 & S/. & $1,065,027$ \\
\hline
\end{tabular}

Elaboración: Propia

\section{- Presupuesto de gastos administrativos}

Para obtener los gastos administrativos proyectados que corresponden a la Tabla 3.13, previamente se resuelven la Planilla, Gastos Operativos, Gastos Diversos, Depreciación y Amortización que corresponden a las Tablas 3.14, 3.15, 3.16 y 3.17 respectivamente.

Tabla 3.13 Presupuesto de gastos administrativos

\begin{tabular}{|c|c|c|c|c|c|c|c|c|c|c|c|c|}
\hline Gastos Administrativos & \multicolumn{2}{|c|}{ Total Año 0} & \multicolumn{2}{|c|}{ Total Año 1} & \multicolumn{2}{|c|}{ Año 2} & \multicolumn{2}{|c|}{ Año 3} & \multicolumn{2}{|c|}{ Año 4} & \multicolumn{2}{|c|}{ Año 5} \\
\hline Sueldos & S/. & - & S/. & 131,413 & S/. & 135,356 & $\mathrm{~S} /$. & 240,933 & $\mathrm{~S} /$. & 248,161 & $\mathrm{~S} /$. & 255,606 \\
\hline Gastos Operativos & S/. & - & $\mathrm{S} /$. & 33,327 & $\mathrm{~S} /$. & 33,327 & S/. & 33,527 & $\mathrm{~S} /$. & 33,527 & S/. & 33,527 \\
\hline Gastos Diversos & S/. & - & S/. & 7,266 & $\mathrm{~S} /$. & 7,266 & $\mathrm{~S} /$. & 7,266 & $\mathrm{~S} /$. & 7,266 & $\mathrm{~S} /$. & 7,266 \\
\hline Depreciación y Amortización & S/. & - & S/. & 7,911 & S/. & 7,911 & S/. & 7,911 & $\mathrm{~S} /$. & 7,911 & S/. & 7,911 \\
\hline Total & S/. & - & S/. & 179,918 & S/. & 183,860 & S/. & 289,638 & S/. & 296,866 & S/. & 304,311 \\
\hline
\end{tabular}

Elaboración: Propia

Tabla 3.14 Planilla

\begin{tabular}{|l|r|}
\hline \multicolumn{2}{|c|}{ Supuestos } \\
\hline Tasa Estimada de Inflacion por año & $3 \%$ \\
\hline Mes de Pago Gratificación & 7 y 12 \\
\hline Mes de Pago CTS & 5 y 11 \\
\hline
\end{tabular}

Elaboración: Propia 


\begin{tabular}{|l|c|c|c|c|c|}
\hline ANO & 1 & 2 & 3 & 4 \\
\hline Trabajador & $\mathrm{N}^{\circ}$ Trabajadores & $\mathrm{N}^{\circ}$ Trabajadores & $\mathrm{N}^{\circ}$ Trabajadores & $\mathrm{N}^{\circ}$ Trabajadores & $\mathbf{N}^{\circ}$ Trabajadores \\
\hline Gerente General & 1 & 1 & 1 & 1 \\
\hline Jefe Comercial & 1 & 1 & 1 & 1 \\
\hline Jefe de Producción y Logística & 1 & 1 & 1 & 1 \\
\hline Jefe de RRHH & 0 & 0 & 1 & 1 \\
\hline Técnico de Modelaje y Multimedia & 1 & 1 & 1 & 1 \\
\hline Asistente de moldeo & 1 & 1 & 1 & 1 \\
\hline Ayudante de producción & 1 & 1 & 2 & 1 \\
\hline Ayudante de control de calidad & 1 & 1 & 2 & 1 \\
\hline Asistente de atención al cliente & 1 & 1 & 1 & 2 \\
\hline Vendedores & 1 & 2 & 2 & 2 \\
\hline
\end{tabular}

\section{Elaboración: Propia}

PLANILLA TOTAL

\begin{tabular}{|c|c|c|c|c|c|c|c|c|c|c|}
\hline \multirow{2}{*}{\begin{tabular}{|l} 
Detalle \\
Gerente General
\end{tabular}} & \multicolumn{2}{|c|}{ AÑ̃ 1} & \multicolumn{2}{|c|}{ AÑO 2} & \multicolumn{2}{|c|}{ AÑ̃ 3} & \multicolumn{2}{|c|}{ AÑO 4} & \multicolumn{2}{|c|}{ AÑ̃ 5} \\
\hline & S/. & 96,000 & $\mathrm{~S} /$. & 98,880 & $\mathrm{~S} /$. & 101,846 & S/. & 104,902 & S/. & 108,049 \\
\hline Jefe Comercial & $\mathrm{S} /$. & 72,000 & $\mathrm{~S} /$. & 74,160 & $\mathrm{~S} /$. & 76,385 & $\mathrm{~S} /$. & 78,676 & $\mathrm{~S} /$. & 81,037 \\
\hline Jefe de Producción y Logística & $\mathrm{S} /$. & 72,000 & $\mathrm{~S} /$. & 74,160 & $\mathrm{~S} /$. & 76,385 & $\mathrm{~S} /$. & 78,676 & $\mathrm{~S} /$. & 81,037 \\
\hline Jefe de RRHH & $\mathrm{S} /$. & 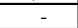 & $\mathrm{S} /$. & - & S/. & 74,160 & $\mathrm{~S} /$. & 76,385 & $\mathrm{~S} /$. & 78,676 \\
\hline Técnico de Modelaje y Multimedia & $\mathrm{S} /$. & 48,000 & $\mathrm{~S} /$. & 49,440 & $\mathrm{~S} /$. & 50,923 & $\mathrm{~S} /$. & 52,451 & $\mathrm{~S} /$. & 54,024 \\
\hline Asistente de moldeo & $\mathrm{S} /$. & 14,400 & $\mathrm{~S} /$. & 14,832 & $\mathrm{~S} /$. & 15,277 & $\mathrm{~S} /$. & 15,735 & $\mathrm{~S} /$. & 16,207 \\
\hline Ayudante de producción & $\mathrm{S} /$. & 14,400 & $\mathrm{~S} /$. & 14,832 & $\mathrm{~S} /$. & 30,554 & $\mathrm{~S} /$. & 31,471 & $\mathrm{~S} /$. & 32,415 \\
\hline Ayudante de control de calidad & $\mathrm{S} /$. & 14,400 & S/. & 14,832 & S/. & 30,554 & S/. & 31,471 & $\mathrm{~S} /$. & 32,415 \\
\hline Asistente de atención al cliente & S/. & 14,400 & S/. & 14,832 & $\mathrm{~S} /$. & 15,277 & $\mathrm{~S} /$. & 15,735 & S/. & 16,207 \\
\hline Vendedores & S/. & 10,200 & $\mathrm{~S} /$. & 21,012 & $\mathrm{~S} /$. & 21,642 & S/. & 22,292 & S/. & 34,441 \\
\hline Total & St. & 355,800 & $\mathrm{~S} /$. & 376,980 & St. & 493,003 & $\mathrm{~S} /$. & 507,793 & St. & 534,507 \\
\hline Gratificaciones & St. & 59,300 & St. & 62,830 & St. & 82,167 & St. & 84,632 & St. & 89,085 \\
\hline Total & St. & 415,100 & St. & 439,810 & S\%. & 575,171 & St. & 592,426 & St. & 623,592 \\
\hline CTS & $\mathrm{S} /$. & 34,592 & $\mathrm{~S} /$. & 36,651 & $\mathrm{~S} / \mathrm{.}$ & 47,931 & S/. & 49,369 & $\mathrm{~S} /$. & 51,966 \\
\hline ESSALUD & $\mathrm{S} /$. & 37,359 & $\mathrm{~S} /$. & 39,583 & $\mathrm{~S} /$. & 51,765 & $\mathrm{~S} /$. & 53,318 & S/. & 56,123 \\
\hline Costo salarial planilla & S/. & 487,051 & S/. & 516,044 & S/. & 674,867 & S/. & 695,113 & S/. & 731,681 \\
\hline Costo salarial anual & S/. & 487,051 & S/. & 516,044 & S/. & 674,867 & S/. & 695,113 & S/. & 731,681 \\
\hline Beneficios provisionados & S/. & 5,765 & S/. & 6,108 & S/. & 7,988 & S/. & 8,228 & S/. & 8,661 \\
\hline Desembolso & S/. & 481,285 & S/. & 515,701 & S/. & 672,987 & S/. & 694,873 & S/. & 731,248 \\
\hline
\end{tabular}

Elaboración: Propia

SUELDOS MOD

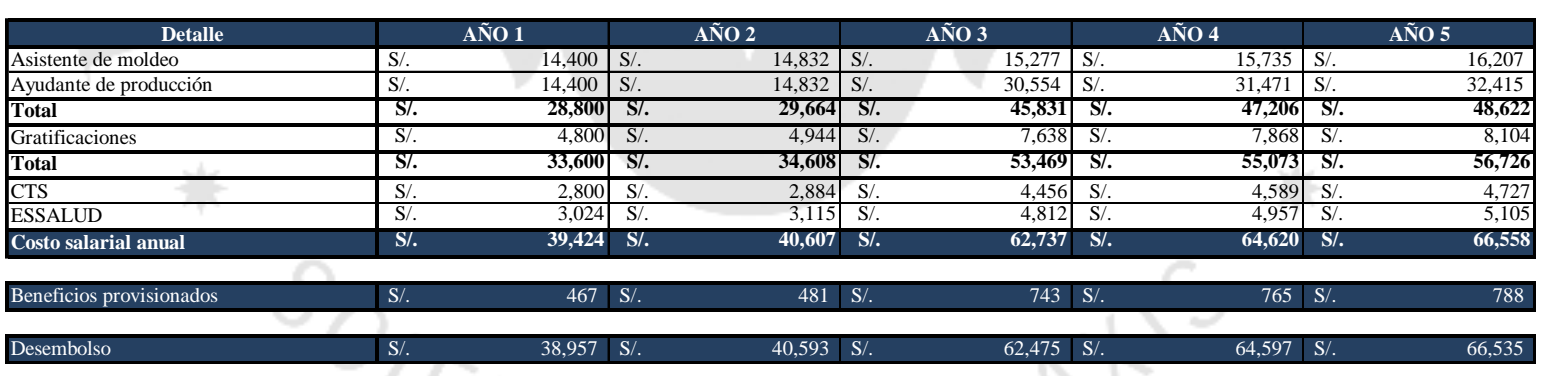

Elaboración: Propia 
SUELDOS MOI

\begin{tabular}{|c|c|c|c|c|c|c|c|c|c|c|}
\hline Detalle & \multicolumn{2}{|c|}{ AÑO 1} & \multicolumn{2}{|c|}{ AÑO 2} & \multicolumn{2}{|c|}{ AÑO 3} & \multicolumn{2}{|c|}{ AÑO 4} & \multicolumn{2}{|c|}{ AÑO 5} \\
\hline Jefe de Producción y Logística & $\mathrm{S} /$. & 72,000 & S/. & 74,160 & $\mathrm{~S} /$. & 76,385 & S/. & 78,676 & S/. & 81,037 \\
\hline Técnico de Modelaje y Multimedia & $\mathrm{S} /$. & 48,000 & S/. & 49,440 & $\mathrm{~S} /$. & 50,923 & S/. & 52,451 & S/. & 54,024 \\
\hline Ayudante de control de calidad & $\mathrm{S} /$. & 14,400 & S/. & 14,832 & $\mathrm{~S} /$. & 30,554 & S/. & 31,471 & S/. & 32,415 \\
\hline Total & $\mathrm{S} /$. & 134,400 & $\mathrm{~S} /$. & 138,432 & $\mathrm{~S} /$. & 157,862 & S/. & 162,598 & S/. & 167,476 \\
\hline Gratificaciones & $\mathrm{S} /$. & 22,400 & S/. & 23,072 & $\mathrm{~S} /$. & 26,310 & S/. & 27,100 & S/. & 27,913 \\
\hline Total & $\mathrm{S} /$. & 156,800 & S/. & 161,504 & $\mathrm{~S} /$. & 184,172 & S/. & 189,697 & S/. & 195,388 \\
\hline CTS & $\mathrm{S} /$. & 13,067 & S/. & 13,459 & $\mathrm{~S} /$. & 15,348 & S/. & 15,808 & S/. & 16,282 \\
\hline ESSALUD & $\mathrm{S} /$. & 14,112 & S/. & 14,535 & $\mathrm{~S} /$. & 16,576 & S/. & 17,073 & S/. & 17,585 \\
\hline Costo salarial anual & S/. & 183,979 & S/. & 189,498 & S/. & 216,095 & S/. & 222,578 & S\%. & 229,256 \\
\hline Beneficios provisionados & S/. & 2,178 & S/. & 2,243 & S/. & 2,558 & S/. & 2,635 & S/. & 2,714 \\
\hline Desembolso & $\mathrm{S} /$. & 181,801 & S/. & 189,433 & S/. & 215,781 & S/. & 222,502 & S/. & 229,177 \\
\hline
\end{tabular}

Elaboración: Propia

MO ADMINISTRATIVA

\begin{tabular}{|c|c|c|c|c|c|c|c|c|c|c|}
\hline \multirow{2}{*}{\begin{tabular}{|r|} 
DETALLE \\
Gerente General
\end{tabular}} & \multicolumn{2}{|c|}{ AÑ̃ 1} & \multicolumn{2}{|c|}{ AÑ̃ 2} & \multicolumn{2}{|c|}{ AÑ̃O 3} & \multicolumn{2}{|c|}{ AÑO 4} & \multicolumn{2}{|c|}{ AÑ̃ 5} \\
\hline & $\mathrm{S} /$. & 96,000 & $\mathrm{~S} /$. & 98,880 & $\mathrm{~S} /$. & 101,846 & S/. & 104,902 & $\mathrm{~S} /$. & 108,049 \\
\hline Jefe de RRHH & $\mathrm{S} /$. & - & $\mathrm{S} /$. & - & $\mathrm{S} /$. & 74,160 & $\mathrm{~S} /$. & 76,385 & $\mathrm{~S} /$. & 78,676 \\
\hline Total & St. & 96,000 & S\%. & 98,880 & St. & 176,006 & St. & 181,287 & St. & 186,725 \\
\hline Gratificaciones & St. & 16,000 & S/. & 16,480 & S/. & 29,334 & St. & 30,214 & St. & 31,121 \\
\hline Total & St. & 112,000 & S/. & 115,360 & St. & 205,341 & St. & 211,501 & St. & 217,846 \\
\hline CTS & $\mathrm{S} /$. & 9,333 & $\mathrm{~S} /$. & 9,613 & $\mathrm{~S} /$. & 17,112 & $\mathrm{~S} /$. & 17,625 & $\mathrm{~S} /$. & 18,154 \\
\hline ESSALUD & $\mathrm{S} /$. & 10,080 & S/. & 10,382 & S/. & 18,481 & $\mathrm{~S} /$. & 19,035 & $\mathrm{~S} /$. & 19,606 \\
\hline Costo salarial anual & St. & 131,413 & S/. & 135,356 & S/. & 240,933 & St. & 248,161 & St. & 255,606 \\
\hline Beneficios provisionados & S/. & 1,556 & S/. & 1,602 & S/. & 2,852 & S/. & 2,938 & S/. & 3,026 \\
\hline Desembolso & S/. & 129,858 & S/. & 135,309 & S/. & 239,683 & $\mathrm{~S} / \mathrm{.}$ & 248,076 & $\mathrm{~S} / \mathrm{.}$ & 255,518 \\
\hline
\end{tabular}

Elaboración: Propia

O VENTA

\begin{tabular}{|c|c|c|c|c|c|c|c|c|c|c|}
\hline DETALLE & \multicolumn{2}{|c|}{ AÑO 1} & \multicolumn{2}{|c|}{ AÑO 2} & \multicolumn{2}{|c|}{ AÑO 3} & \multicolumn{2}{|c|}{ AÑ̃ 4} & \multicolumn{2}{|c|}{ AÑ̃ 5} \\
\hline Jefe Comercial & S/. & 72,000 & $\mathrm{~S} /$. & 74,160 & $\mathrm{~S} /$. & 76,385 & S/. & 78,676 & S/. & 81,037 \\
\hline Asistente de atención al cliente & S/. & 14,400 & $\mathrm{~S} /$. & 14,832 & S/. & 15,277 & S/. & 15,735 & S/. & 16,207 \\
\hline Vendedores & S/. & 10,200 & S/. & 21,012 & $\mathrm{~S} /$. & 21,642 & $\mathrm{~S} /$. & 22,292 & $\mathrm{~S} /$. & 34,441 \\
\hline Total & $\mathrm{ST}$ & 96,600 & ST. & 710,004 & S\%. & 113,304 & ST. & 716,703 & St. & 131,685 \\
\hline Gratificaciones & St. & 16,100 & St. & 18,334 & St. & 78,884 & St. & 19,451 & St. & 21,947 \\
\hline Total & St. & 112,700 & St. & 128,338 & S\%. & 132,188 & St. & 136,154 & S\%. & 153,632 \\
\hline CTS & $\mathrm{S} /$. & 9,392 & $\mathrm{~S} / \mathrm{.}$ & 10,695 & $\mathrm{~S} /$. & 11,016 & $\mathrm{~S} /$. & 11,346 & $\mathrm{~S} /$. & 12,803 \\
\hline ESSALUD & $\mathrm{S} / \mathrm{s}$ & 10,143 & S/. & 11,550 & $\mathrm{~S} / \mathrm{s}$ & 11,897 & S/. & 12,254 & $\mathrm{~S} /$. & 13,827 \\
\hline Costo salarial anual & St & 132,235 & St. & 150,583 & S/. & 155,101 & St. & 159,754 & S/. & 180,261 \\
\hline Beneficios provisionados & S/. & 1,565 & S/. & 1,782 & $\mathrm{~S} /$. & 1,836 & $\mathrm{~S} /$. & 1,891 & S/. & 2,134 \\
\hline Desembolso & $\mathrm{S} /$. & 130,669 & S/. & 150,366 & $\mathrm{~S} /$. & 155,047 & $\mathrm{~S} /$. & 159,699 & S/. & 180,019 \\
\hline
\end{tabular}

Elaboración: Propia 
Tabla 3.15 Gastos operativos

\begin{tabular}{|l|r|}
\hline Concepto & $\begin{array}{c}\text { Veces al } \\
\text { año }\end{array}$ \\
\hline Alquileres & 12 \\
Seguro SCTR & 1 \\
SOAT Camión & 1 \\
Software de Operaciones & 12 \\
Revision técnica & 1 \\
Comison de ventas & 1 \\
Comision por produccion & 2 \\
Uniforme de Personal & 2 \\
Contabilidad & 12 \\
Limpieza & 12 \\
Seguridad & 12 \\
Muestras de Colección & 2 \\
Mantenimiento & 12 \\
\hline
\end{tabular}

Elaboración: Propia

\begin{tabular}{|c|c|c|c|c|c|c|c|c|c|c|c|c|}
\hline Gastos operativos & \multicolumn{2}{|c|}{ Año 0} & \multicolumn{2}{|c|}{ Año 1} & \multicolumn{2}{|c|}{ Año 2} & \multicolumn{2}{|c|}{ Año 3} & \multicolumn{2}{|c|}{ Año 4} & \multicolumn{2}{|c|}{ Año 5} \\
\hline Alquileres & $\mathrm{S} /$. & 11,959 & $\mathrm{~S} /$. & 47,837 & $\mathrm{~S} /$. & 47,837 & $\mathrm{~S} /$. & 47,837 & $\mathrm{~S} /$. & 47,837 & $\mathrm{~S} /$. & 47,837 \\
\hline Seguro CTR & $\mathrm{S} /$. & - & $\mathrm{S} /$. & 981 & $\mathrm{~S} /$. & 981 & $\mathrm{~S} /$. & 981 & $\mathrm{~S} /$. & 981 & $\mathrm{~S} /$. & 981 \\
\hline SOAT Camión & $\mathrm{S} /$. & - & $\mathrm{S} /$. & 126 & $\mathrm{~S} /$. & 126 & S/. & 126 & $\mathrm{~S} /$. & 126 & $\mathrm{~S} /$. & 126 \\
\hline Software de Operaciones & $\mathrm{S} /$. & - & $\mathrm{S} /$. & 14,126 & $\mathrm{~S} /$. & 14,126 & S/. & 14,126 & $\mathrm{~S} /$. & 14,126 & $\mathrm{~S} /$. & 14,126 \\
\hline Revicion técnica & $\mathrm{S} /$. & - & $\mathrm{S} /$. & 100 & $\mathrm{~S} /$. & 100 & $\mathrm{~S} /$. & 100 & $\mathrm{~S} /$. & 100 & $\mathrm{~S} /$. & 100 \\
\hline Comisión de ventas & S/. & - & $\mathrm{S} /$. & 50,663 & $\mathrm{~S} /$. & 63,809 & S/. & 82,788 & $\mathrm{~S} /$. & 103,545 & $\mathrm{~S} /$. & 119,198 \\
\hline Comisión por producción & $\mathrm{S} /$. & - & $\mathrm{S} /$. & 6,585 & $\mathrm{~S} /$. & 8,319 & $\mathrm{~S} /$. & 10,923 & $\mathrm{~S} /$. & 13,636 & $\mathrm{~S} /$. & 15,644 \\
\hline Uniforme de Personal & $\mathrm{S} /$. & - & $\mathrm{S} /$. & 700 & $\mathrm{~S} /$. & 700 & $\mathrm{~S} /$. & 700 & $\mathrm{~S} /$. & 700 & $\mathrm{~S} /$. & 700 \\
\hline Contabilidad & $\mathrm{S} /$. & - & $\mathrm{S} /$. & 3,600 & $\mathrm{~S} /$. & 3,600 & $\mathrm{~S} /$. & 3,800 & $\mathrm{~S} /$. & 3,800 & $\mathrm{~S} /$. & 3,800 \\
\hline Limpieza & S/. & - & $\mathrm{S} /$. & 24,000 & $\mathrm{~S} /$. & 24,000 & $\mathrm{~S} /$. & 24,000 & $\mathrm{~S} /$. & 24,000 & $\mathrm{~S} /$. & 24,000 \\
\hline Seguridad & $\mathrm{S} /$. & - & $\mathrm{S} /$. & 30,000 & $\mathrm{~S} /$. & 30,000 & $\mathrm{~S} /$. & 30,000 & $\mathrm{~S} /$. & 30,000 & $\mathrm{~S} /$. & 30,000 \\
\hline Muestras de Colección & $\mathrm{S} /$. & - & $\mathrm{S} /$. & 3,000 & $\mathrm{~S} /$. & 3,000 & S/. & 3,000 & $\mathrm{~S} /$. & 3,000 & $\mathrm{~S} /$. & 3,000 \\
\hline Mantenimiento web & $\mathrm{S} /$. & - & $\mathrm{S} /$. & 3,600 & $\mathrm{~S} /$. & 3,600 & S/. & 3,600 & $\mathrm{~S} /$. & 3,600 & $\mathrm{~S} /$. & 3,600 \\
\hline Total & S/. & 11,959 & S/. & 185,319 & S/. & 200,199 & S/. & 221,982 & S/. & 245,451 & S/. & 263,112 \\
\hline
\end{tabular}

Elaboración: Propia 
Tabla 3.16 Gastos diversos

\begin{tabular}{|l|c|}
\hline Concepto & Veces al año \\
\hline Útiles de oficina & 2 \\
\hline Artículos de limpieza & 12 \\
\hline Formato guia remision transportista & 1 \\
\hline Arbitrios & 4 \\
\hline Luz & 12 \\
\hline Agua & 12 \\
\hline Internet & 12 \\
\hline Hosting página web & 1 \\
\hline GAS industrial & 12 \\
\hline Celulares RPC & 12 \\
\hline Capacitación & 2 \\
\hline Outsourcing Legal & 12 \\
\hline
\end{tabular}

Elaboración: Propia

\begin{tabular}{|c|c|c|c|c|c|c|c|c|c|c|c|c|}
\hline Gastos diversos / Precio Venta & \multicolumn{2}{|c|}{ Año 0} & \multicolumn{2}{|c|}{ Año 1} & \multicolumn{2}{|c|}{ Año 2} & \multicolumn{2}{|c|}{ Año 3} & \multicolumn{2}{|c|}{ Año 4} & \multicolumn{2}{|c|}{ Año 5} \\
\hline Útiles de oficina & $\mathrm{S} /$. & - & $\mathrm{S} /$. & 400 & $\mathrm{~S} /$. & 400 & $\mathrm{~S} /$. & 400 & $\mathrm{~S} /$. & 400 & $\mathrm{~S} /$. & 400 \\
\hline Artículos de limpieza & $\mathrm{S} /$. & - & $\mathrm{S} /$. & 3,600 & $\mathrm{~S} /$. & 3,600 & $\mathrm{~S} /$. & 3,600 & $\mathrm{~S} /$. & 3,600 & $\mathrm{~S} /$. & 3,600 \\
\hline Formato guia remision transportista & $\mathrm{S} /$. & - & $\mathrm{S} /$. & 100 & $\mathrm{~S} /$. & 100 & $\mathrm{~S} /$. & 100 & $\mathrm{~S} /$. & 100 & $\mathrm{~S} /$. & 100 \\
\hline Arbitrios & $\mathrm{S} /$. & - & $\mathrm{S} /$. & 360 & $\mathrm{~S} /$. & 360 & $\mathrm{~S} /$. & 360 & $\mathrm{~S} /$. & 360 & $\mathrm{~S} /$. & 360 \\
\hline Luz & $\mathrm{S} /$. & - & $\mathrm{S} /$. & 6,000 & $\mathrm{~S} /$. & 6,000 & $\mathrm{~S} /$. & 6,000 & $\mathrm{~S} /$. & 6,000 & $\mathrm{~S} /$. & 6,000 \\
\hline Agua & $\mathrm{S} /$. & - & $\mathrm{S} /$. & 960 & $\mathrm{~S} /$. & 960 & $\mathrm{~S} /$. & 960 & $\mathrm{~S} /$. & 960 & $\mathrm{~S} /$. & 960 \\
\hline Internet & $\mathrm{S} /$. & - & $\mathrm{S} /$. & 2,160 & $\mathrm{~S} /$. & 2,160 & $\mathrm{~S} /$. & 2,160 & $\mathrm{~S} /$. & 2,160 & $\mathrm{~S} /$. & 2,160 \\
\hline Hosting página web & $\mathrm{S} /$. & - & $\mathrm{S} /$. & 165 & $\mathrm{~S} /$. & 165 & $\mathrm{~S} /$. & 165 & $\mathrm{~S} /$. & 165 & $\mathrm{~S} /$. & 165 \\
\hline GAS industrial & $\mathrm{S} /$. & - & $\mathrm{S} /$. & - & $\mathrm{S} /$. & - & $\mathrm{S} /$. & - & $\mathrm{S} /$. & - & $\mathrm{S} /$. & - \\
\hline Celulares RPC & $\mathrm{S} /$. & - & $\mathrm{S} /$. & 720 & $\mathrm{~S} /$. & 720 & $\mathrm{~S} /$. & 720 & $\mathrm{~S} /$. & 720 & $\mathrm{~S} /$. & 720 \\
\hline Capacitación & $\mathrm{S} /$. & - & $\mathrm{S} /$. & 4,000 & $\mathrm{~S} /$. & 4,000 & $\mathrm{~S} /$. & 4,000 & $\mathrm{~S} /$. & 4,000 & $\mathrm{~S} /$. & 4,000 \\
\hline Outsourcing Legal & $\mathrm{S} /$. & - & $\mathrm{S} /$. & 6,000 & $\mathrm{~S} /$. & 6,000 & $\mathrm{~S} /$. & 6,000 & $\mathrm{~S} /$. & 6,000 & $\mathrm{~S} /$. & 6,000 \\
\hline Marketing & & & $\mathrm{S} /$. & 132,080 & $\mathrm{~S} /$. & 132,080 & S/. & 132,080 & S/. & 132,080 & $\mathrm{~S} /$. & 132,080 \\
\hline Total & S/. & - & S/. & 156,545 & S/. & 156,545 & S/. & 156,545 & S/. & 156,545 & S/. & 156,545 \\
\hline
\end{tabular}

Elaboración: Propia 
Tabla 3.17 Depreciación y Amortización

\begin{tabular}{|l|c|}
\hline Activo fijo bruto & $\begin{array}{c}\text { Vida } \\
\text { útil / }\end{array}$ \\
\hline Muebles & 5 \\
\hline Maquinaria y equipo & 10 \\
\hline Vehículos & 5 \\
\hline Intangibles & 5 \\
\hline
\end{tabular}

Elaboración: Propia

\begin{tabular}{|c|c|c|c|c|c|c|c|c|c|c|c|c|}
\hline Depreciación & \multicolumn{2}{|c|}{ Total Año 0} & \multicolumn{2}{|c|}{ Total Año 1} & \multicolumn{2}{|c|}{ Año 2} & \multicolumn{2}{|c|}{ Año 3} & \multicolumn{2}{|c|}{ Año 4} & \multicolumn{2}{|c|}{ Año 5} \\
\hline Muebles & $\mathrm{S} /$. & - & $\mathrm{S} /$. & 2,273 & $\mathrm{~S} /$. & 2,273 & $\mathrm{~S} /$. & 2,273 & $\mathrm{~S} /$. & 2,273 & $\mathrm{~S} /$. & 2,273 \\
\hline Maquinaria y equipo & $\mathrm{S} /$. & - & $\mathrm{S} /$. & 4,161 & $\mathrm{~S} /$. & 4,161 & $\mathrm{~S} /$. & 4,161 & $\mathrm{~S} /$. & 4,726 & $\mathrm{~S} /$. & 4,726 \\
\hline Vehículos & $\mathrm{S} /$. & - & $\mathrm{S} /$. & 8,326 & $\mathrm{~S} /$. & 8,326 & $\mathrm{~S} /$. & 8,326 & S/. & 8,326 & S/. & 8,326 \\
\hline Intangibles & $\mathrm{S} /$. & - & S/. & 6,775 & $\mathrm{~S} /$. & 6,775 & $\mathrm{~S} /$. & 6,775 & S/. & 6,775 & S/. & 6,775 \\
\hline Total & S/. & - & S/. & 21,534 & S/. & 21,534 & $\mathrm{~S} /$. & 21,534 & $\mathrm{~S} /$. & 22,099 & S/. & 22,099 \\
\hline
\end{tabular}

Elaboración: Propia

\subsection{Presupuesto de Resultado}

\subsubsection{Estado de Ganancias y Pérdidas}

El primer año tendrá una pérdida del S/. 90,097.00 soles como consecuencia del inicio de las operaciones. Una vez empleada la estrategia de marketing, a partir del segundo año la utilidad neta tendrá un incremento de 3\% hasta alcanzar un 17\% para el quinto año. 
Tabla 3.18 Estado de ganancias y pérdidas

\begin{tabular}{|c|c|c|c|c|c|c|c|c|c|c|}
\hline \multicolumn{11}{|l|}{$\begin{array}{l}\text { Estado de resultados } \\
\text { (En nuevos soles) }\end{array}$} \\
\hline Estado de resultados & \multicolumn{2}{|c|}{ Año 1} & \multicolumn{2}{|c|}{ Año 2} & \multicolumn{2}{|c|}{ Año 3} & \multicolumn{2}{|c|}{ Año 4} & \multicolumn{2}{|c|}{ Año 5} \\
\hline Ingresos netos & S/. & $1,013,254$ & $\mathrm{~S} /$. & $1,276,180$ & $\mathrm{~S} /$. & $1,655,768$ & $\mathrm{~S} /$. & $2,070,893$ & $\mathrm{~S} /$. & $2,383,963$ \\
\hline Costo de Ventas & $-\mathrm{S} /$. & 588,183 & $-\mathrm{S} /$. & 671,237 & $-\mathrm{S} /$. & 834,573 & $-\mathrm{S} /$. & 964,875 & $-\mathrm{S} /$. & $1,065,027$ \\
\hline Utilidad Bruta & S/. & 425,071 & $\mathrm{~S} /$. & 604,944 & $\mathrm{~S} /$ & 821,195 & $\mathrm{~S} /$. & $1,106,018$ & S/. & $1,318,937$ \\
\hline Gastos administrativos & $-\mathrm{S} /$. & 179,918 & $-\mathrm{S} /$. & 183,860 & $-\mathrm{S} /$. & 289,638 & $-\mathrm{S} /$. & 296,866 & $-\mathrm{S} /$. & 304,311 \\
\hline Sueldos & $-\mathrm{S} /$ & 131,413 & $-\mathrm{S} /$ & 135,356 & $-\mathrm{S} /$ & 240,933 & $-\mathrm{S} /$. & 248,161 & $-\mathrm{S} /$. & 255,606 \\
\hline Gastos Operativos & $-\mathrm{S} /$. & 33,327 & $-\mathrm{S} /$. & 33,327 & $-\mathrm{S} /$. & 33,527 & $-\mathrm{S} /$. & 33,527 & $-\mathrm{S} /$. & 33,527 \\
\hline Gastos Diversos & $-\mathrm{S} /$. & 7,266 & $-\mathrm{S} /$. & 7,266 & $-\mathrm{S} /$. & 7,266 & $-\mathrm{S} /$. & 7,266 & $-\mathrm{S} /$. & 7,266 \\
\hline Depreciación y Amortización & $-\mathrm{S} /$. & 7,911 & $-\mathrm{S} /$. & 7,911 & $-\mathrm{S} /$. & 7,911 & $-\mathrm{S} /$. & 7,911 & $-\mathrm{S} /$. & 7,911 \\
\hline Gastos de ventas & $-\mathrm{S} /$. & 327,983 & $-\mathrm{S} /$. & 356,562 & $-\mathrm{S} /$. & 375,910 & $-\mathrm{S} /$. & 396,702 & $-\mathrm{S} /$. & 429,358 \\
\hline Sueldos & $-\mathrm{S} /$. & 132,235 & $-\mathrm{S} /$. & 150,583 & $-\mathrm{S} /$. & 155,101 & $-\mathrm{S} /$. & 159,754 & $-\mathrm{S} /$. & 180,261 \\
\hline Gastos Operativos & $-\mathrm{S} / \mathrm{.}$ & 72,850 & $-\mathrm{S} /$. & 83,081 & $-\mathrm{S} /$. & 97,911 & $-\mathrm{S} /$. & 114,050 & $-\mathrm{S} /$. & 126,198 \\
\hline Gastos Diversos & $-\mathrm{S} /$ & 115,934 & $-\mathrm{S} /$. & 115,934 & $-\mathrm{S} /$. & 115,934 & $-\mathrm{S} /$. & 115,934 & $-\mathrm{S} /$. & 115,934 \\
\hline Depreciación y Amortización & $-\mathrm{S} /$. & 6,964 & $-\mathrm{S} /$. & 6,964 & $-\mathrm{S} /$. & 6,964 & $-\mathrm{S} /$. & 6,964 & $-\mathrm{S} /$. & 6,964 \\
\hline Utilidad operativa & $-\mathrm{S} / \mathrm{s}$ & 82,829 & $\mathrm{~S} /$ & 64,522 & $\mathrm{~S} /$ & 155,648 & $\mathrm{~S} /$. & 412,451 & S/. & 585,268 \\
\hline Gastos Financieros & $-\mathrm{S} /$. & 7,268 & $-\mathrm{S} /$. & 6,078 & $-\mathrm{S} /$. & 4,686 & $-\mathrm{S} /$. & 3,056 & $-\mathrm{S} /$. & 1,150 \\
\hline Utilidad antes de impuestos & $-\mathrm{S} /$. & 90,097 & $\mathrm{~S} /$. & 58,443 & $\mathrm{~S} /$. & 150,962 & $\mathrm{~S} /$. & 409,394 & S/. & 584,118 \\
\hline Impuesto a la renta & S/. & - & $-\mathrm{S} /$ & 17,241 & $-\mathrm{S} /$ & 44,534 & $-\mathrm{S} /$. & 120,771 & $-\mathrm{S} /$. & 172,315 \\
\hline Utilidad neta & $-\mathrm{S} /$. & 90,097 & S/. & 41,203 & S/. & 106,428 & $\mathrm{~S} /$. & 288,623 & S/. & 411,803 \\
\hline
\end{tabular}

Elaboración: Propia

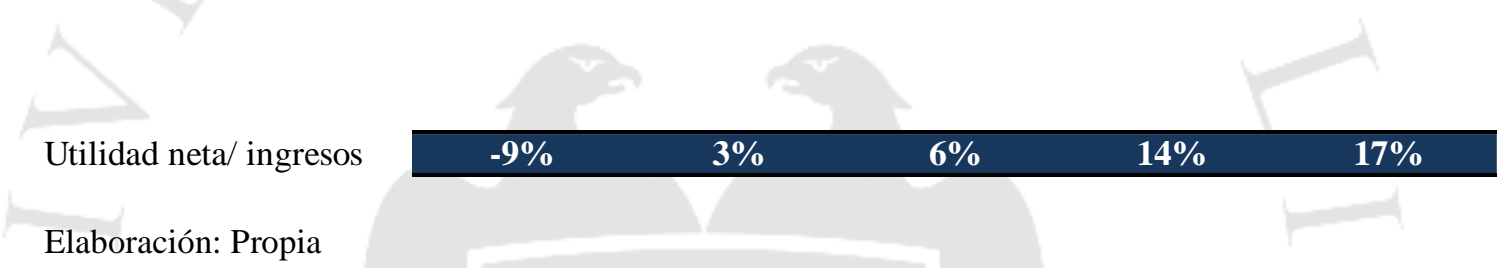

\subsubsection{Balance Proyectado}

Se puede observar que la caja el año cero cuenta con un monto de S/. 90,000 soles para financiar el déficit de caja del primer año. Al quinto año, incrementa a S/.1,075,914 soles para el quinto año como consecuencia que la empresa tendrá como política no repartir dividendos, dado que, si el negocio sigue en auge, se resuelve por la ampliación o crecimiento de la firma. 
Tabla 3.19 Balance general

\begin{tabular}{|c|c|c|c|c|c|c|c|c|c|c|c|c|}
\hline Balance general & & & & & & & & & & & & 105 \\
\hline Activo & & & & & & & & & & & & \\
\hline Caja & $\mathrm{S} / \mathrm{s}$ & 90,000 & S/. & 29,530 & S/. & $\begin{array}{l}98,505 \\
16051\end{array}$ & $\mathrm{~S} /$. & $\begin{array}{r}235,559 \\
21705\end{array}$ & S/. & & S/. & $\begin{array}{r}1,075,914 \\
30185\end{array}$ \\
\hline Inventario & $\mathrm{S} /$. & - & S/. & 13,796 & $\mathrm{~S} /$. & 16,951 & S/. & 21,795 & S/. & 26,772 & $\mathrm{~S} /$ & 30,185 \\
\hline Alquiler $1 * 1$ & $\mathrm{~S} /$. & 11,959 & S/. & 11,959 & S/. & 11,959 & $\mathrm{~S} /$. & 11,959 & S/. & 11,959 & S/. & 11,959 \\
\hline Activo Fijo + Intangible & $\mathrm{S} /$. & 128,476 & $\mathrm{~S} /$. & 128,476 & $\mathrm{~S} /$. & 128,476 & $\mathrm{~S} /$ & 128,476 & $\mathrm{~S} /$. & 134,129 & $\mathrm{~S} /$. & 134,129 \\
\hline Dep. y Amort. Acum & S/. & - & $-\mathrm{S} /$. & 21,534 & $-\mathrm{S} /$. & 43,068 & $-\mathrm{S} /$ & 64,602 & $-\mathrm{S} /$. & 86,702 & $-\mathrm{S} /$ & 108,801 \\
\hline Total activo & $\mathrm{S} /$. & 230,435 & S/. & 162,227 & S/. & 212,822 & S/. & 333,186 & S/. & 692,726 & S/. & $1,143,386$ \\
\hline Pasivo & & & & & & & & & & & & \\
\hline CTS por pagar & $\mathrm{S} /$. & - & $\mathrm{S} /$. & 5,765 & $\mathrm{~S} /$. & 6,108 & S/. & 7,988 & $\mathrm{~S} /$. & 8,228 & $\mathrm{~S} /$. & 8,661 \\
\hline IGV por pagar & $-\mathrm{S} /$. & 23,126 & $\mathrm{~S} /$. & - & $\mathrm{S} /$. & - & $\mathrm{S} /$. & - & $\mathrm{S} /$. & - & $\mathrm{S} /$. & - \\
\hline Tributos por pagar & S/. & - & $\mathrm{S} /$. & - & $\mathrm{S} /$. & 17,241 & $\mathrm{~S} /$. & 44,534 & $\mathrm{~S} /$. & 120,771 & S/. & 172,315 \\
\hline Deuda & $\mathrm{S} /$. & 49,110 & $\mathrm{~S} /$. & 42,109 & $\mathrm{~S} /$. & 33,917 & $\mathrm{~S} /$. & 24,333 & $\mathrm{~S} /$. & 13,120 & S/. & - \\
\hline Total pasivo & S/. & 25,985 & S/. & 47,874 & S/. & 57,267 & S/. & 76,856 & S/. & 142,119 & S/. & 180,976 \\
\hline Patrimonio neto & & & & & & & & & & & & \\
\hline Capital Social & $\mathrm{S} /$. & 204,450 & $\mathrm{~S} /$. & 204,450 & $\mathrm{~S} /$. & 204,450 & $\mathrm{~S} /$. & 204,450 & $\mathrm{~S} /$. & 204,450 & $\mathrm{~S} /$. & 204,450 \\
\hline Reserva Legal & S/. & - & $\mathrm{S} /$. & - & $\mathrm{S} /$. & - & $\mathrm{S} /$. & - & $\mathrm{S} /$. & - & $\mathrm{S} /$. & - \\
\hline Utilidades Retenidas & $\mathrm{S} /$. & - & $-\mathrm{S} /$. & 90,097 & $-\mathrm{S} /$. & 48,895 & $\mathrm{~S} /$. & 57,534 & $\mathrm{~S} /$. & 346,157 & $\mathrm{~S} /$. & 757,960 \\
\hline Total patrimonio & S/. & 204,450 & S/. & 114,353 & $\mathrm{~S} /$. & 155,555 & S/. & 261,984 & $\mathrm{~S} /$. & 550,607 & S/. & 962,410 \\
\hline Total pasivo y patrimonio & S/. & 230,435 & S/. & 162,227 & S/. & 212,822 & S/. & 338,839 & S/. & 692,726 & S/. & $1,143,386$ \\
\hline
\end{tabular}

Elaboración: Propia

\subsection{Flujo de Caja}

\subsubsection{Flujo de Caja de Dinero}

Tabla 3.20 Flujo de caja de dinero

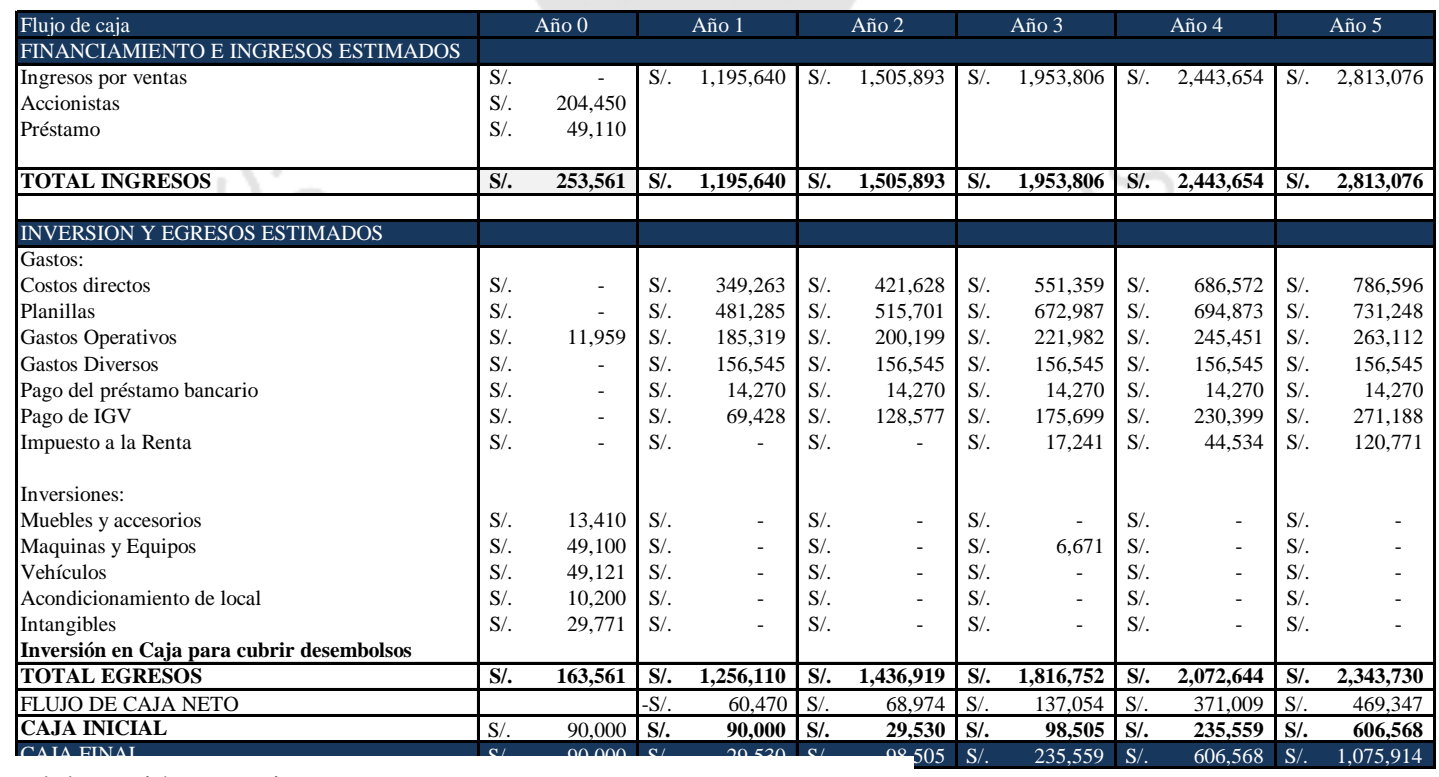

Elaboración: Propia

Nota: Cuadro de presupuesto de caja de ingresos y gastos 


\subsubsection{Flujo de Caja Económico}

Tabla 3.21 Flujo de caja económico

\begin{tabular}{|l|r|r|r|r|r|r|}
\hline FLUJO DE CAJA ECONOMICA & AÑO 0 & AÑO 1 & AÑO 2 & AÑO 3 & AÑO 4 & AÑO 5 \\
\hline Utilidad Neta & & $-90,097$ & 41,203 & 106,428 & 288,623 & 411,803 \\
Depreciación Activos & & 21,534 & 21,534 & 21,534 & 22,099 & 22,099 \\
Gast Finan * (1-T) & & 5,124 & 4,285 & 3,303 & 2,155 & 811 \\
- Activo nuevo & & 0 & 0 & $-6,671$ & 0 & 0 \\
Valor de recup. (1-T) & & 0 & 0 & 0 & 0 & 678,499 \\
\hline FLUJO DE CAJA ECONOMICA & $-253,561$ & $-63,439$ & 67,022 & 124,595 & 312,877 & $1,113,213$ \\
\hline
\end{tabular}

\begin{tabular}{|l|r|r|}
\hline Estructura de capital & INVERSION & \multicolumn{1}{|c|}{$\%$ TASA } \\
\hline Préstamo banco & 49,110 & $17.00 \%$ \\
\hline Socios & 204,450 & $21.78 \%$ \\
\hline TOTAL & 253,561 & $19.88 \%$ \\
\hline
\end{tabular}

VAN ECON

$413,524.49$

TOTAL

$19.88 \%$

WACC

TIR ECON

$47.3 \%$

Elaboración: Propia

\subsubsection{Flujo de Caja Financiero}

Tabla 3.22 Flujo de caja financiero

\begin{tabular}{|c|c|c|}
\hline FLUJO DE CAJA FINANCIERO & AÑO 0 & AÑO 1 \\
\hline FCE & $-253,561$ & $-63,439$ \\
\hline Amortización de Deuda & & $-7,001$ \\
\hline Préstamo del py & 49,110 & \\
\hline Gast Finan $*(1-\mathrm{T})$ & 0 & 5,124 \\
\hline FLUJO DE CAJA FINANCIERO & $-204,450$ & $-61,562$ \\
\hline & INVERSION & $\%$ TASA \\
\hline Socios & 204,450 & $21.78 \%$ \\
\hline
\end{tabular}

\begin{tabular}{r|r|r|r|}
\multicolumn{1}{c|}{ AÑO 2 } & \multicolumn{1}{c|}{ AÑO 3 } & \multicolumn{1}{c|}{ AÑO 4 } & \multicolumn{1}{c|}{ AÑO 5 } \\
\hline 67,022 & 124,595 & 312,877 & $1,113,213$ \\
$-8,192$ & $-9,584$ & $-11,213$ & $-13,120$ \\
& & & \\
4,285 & 3,303 & 2,155 & 811 \\
\hline 70,928 & 130,876 & 321,936 & $1,125,522$ \\
\hline
\end{tabular}

VAN FIN

$431,895.91$

TIR FINAN

Elaboración: Propia

Como se puede observar el proyecto debe llevarse a cabo porque incrementa valor para los accionistas generando un TIRE de $47.3 \%$ y un TIRF de 55.3\%. 
Para el análisis de sensibilidad se varió la demanda en un escenario pesimista en menos $10 \%$ y en un escenario optimista en un 10\% adicional. El resultante del análisis puede observarse en la tabla 3.22 .

Tabla 3.23 Análisis de escenarios

\begin{tabular}{|l|r|r|r|}
\hline Escenario & \multicolumn{1}{|c|}{ Pesimista } & \multicolumn{1}{c|}{ Normal } & \multicolumn{1}{c|}{ Optimista } \\
\hline Variable de entrada & & & \\
Var \% volumen ventas en pares de zapatos & $-10 \%$ & $0 \%$ & $10 \%$ \\
Variables de salida & & & \\
VANE & $50,266.41$ & $413,524.49$ & $768,925.05$ \\
TIRE & $23.53 \%$ & $47.33 \%$ & $68.37 \%$ \\
VANF & $88,510.48$ & $431,895.91$ & $767,768.83$ \\
TIRF & $29.20 \%$ & $55.33 \%$ & $79.19 \%$ \\
Cambio del VANE & $-88 \%$ & & $86 \%$ \\
\hline
\end{tabular}

Elaboración: Propia

Tabla 3.24 Estimación de la tasa de descuento del plan de negocio COK y WACC

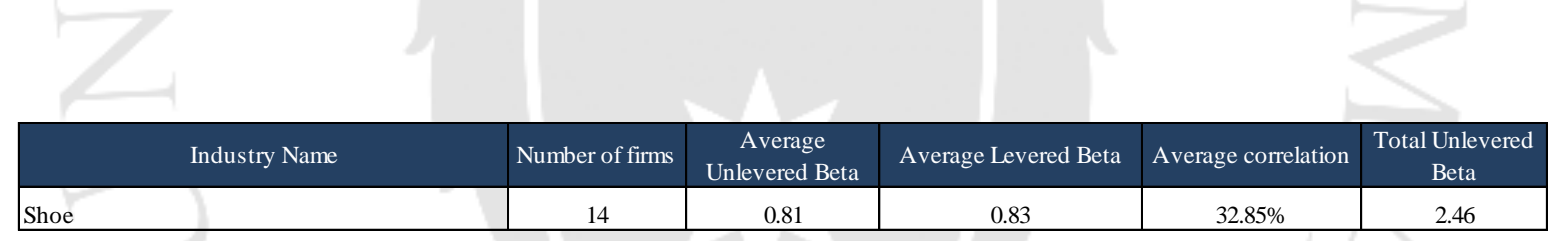

Elaboración: Propia

Nota: Tasa de descuento Beta Demodarán para negocios no relacionados. 


\begin{tabular}{|l|r|}
\hline Año & 0 \\
\hline Tasa Impuesto a la renta & $29.5 \%$ \\
Beta Desapalancado & 2.46 \\
\hline Estructura de capital & \\
\hline Deuda & 49,110 \\
Patrimonio $€ E)$ & 204,450 \\
\hline D+E & 253,561 \\
\hline D/E & 0.24 \\
Beta Apalancado (2) & 2.88 \\
Rf: tasa libre de riesgo (1) & $2.1 \%$ \\
Prima Riesgo de Mercado (Rm - RF) (3) & $6.24 \%$ \\
Riesgo Pais & $1.74 \%$ \\
\hline Re (COK - tasa mínima del accionista) & $21.78 \%$ \\
\hline Rd (costo de la deuda) & $17.00 \%$ \\
D/ (D+E) & $19.37 \%$ \\
E/(D+E) & $80.63 \%$ \\
Tasa Impuesto a a la renta & $29.5 \%$ \\
\hline WACC (tasa mínima para la empresa) & \\
\hline Re (COK) & $19.88 \%$ \\
\hline & $21.78 \%$ \\
\hline Factor de Descuento WACC & 0.83 \\
\hline Factor de Descuento Re & 0.82 \\
\hline
\end{tabular}

Elaboración: Propia

Según el análisis de sensibilidad el número de ventas de pares de zapatos es una variable sensible puesto que en el escenario pesimista ante la disminución de esta variable en un $-10 \%$ hace que el VANE disminuya en un $88 \%$, sin embargo el proyecto sigue generando valor para los accionistas ya que el VANE es igual a S/.50,266.41 soles, siendo mayor que cero y la TIRE es mayor que el WACC.

Como medida de contingencia ante la disminución del número de ventas, se optaría por ampliar nuestra cartera de clientes fuera de Lima Moderna e incluso optar por atender a un público masculino. 


\subsection{Factibilidad del proyecto}

\subsubsection{Viabilidad técnica}

De acuerdo al estudio del proyecto, puede afirmarse que es viable técnicamente, puesto que es factible producir calzado a la medida y personalizado utilizando los recursos mencionados, los cuales se encuentran disponibles en el mercado, tanto la materia prima, mano de obra cómo la maquinaria requerida.

\subsubsection{Viabilidad comercial}

En cuanto a la viabilidad comercial, es factible realizar el proyecto puesto que el estudio de mercado demuestra una demanda existente y nichos de mercado insatisfechos sobre la necesidad de obtener un calzado personalizado y a la medida.

También es importante destacar que la demanda irá en crecimiento con los años de acuerdo con las proyecciones del Ministerio de Producción sobre el sector calzado.

Adicionalmente, de acuerdo a la Dirección de Estudios Económicos de MYPE del sector calzado y vestir, existe una tendencia ascendente durante el periodo 2015-2016 de $4.6 \%$, lo cual marca un factor predominante en el presente proyecto.

\subsubsection{Viabilidad legal y ambiental}

El proyecto presentado es viable legalmente debido a que no incurre en ninguna infracción o violación en el marco legal.

Ambientalmente también es viable en el sentido que reduce el impacto ambiental al reutilizar el filamento de madera para generar nuevas hormas. Adicionalmente el cuero 
natural es una materia prima renovable a diferencia de la cuerina o sintético que está basada en el petróleo, convirtiéndola en una alternativa mucho más amigable con el medio ambiente.

\subsubsection{Viabilidad financiera}

De acuerdo al análisis de los estados financieros proyectados, se puede afirmar que el proyecto es viable financiera y económicamente

Desde el análisis financiero el proyecto debe llevarse a cabo, ya que genera valor a los accionistas y stakeholdes, ya que el VAN económico es de S/. 413,524.49 y el TIR de 47.3\% que es mayor al Wacc, que es la tasa mínima exigida por el accionista.

En el análisis de sensibilidad efectuado ante una disminución del 10\% la demanda del producto, el proyecto sigue siendo rentable ya que el VAN es positivo. Por lo que podemos afirmar que el proyecto sigue siendo rentable es un escenario pesimista, con lo que se puede concluir que el proyecto es rentable. 


\section{CONCLUSIONES}

- De acuerdo con el trabajo de investigación de estudio de mercado realizado en el capítulo I, el análisis de la estructura organizacional expuesta en el capítulo II y los resultados obtenidos en el estudio económico - financiero del capítulo II puede afirmarse la factibilidad tecnológica y rentabilidad económica del proyecto.

- De acuerdo al estudio de mercado se ha comprobado mediante las encuestas realizadas que el negocio en propuesta tendrá aceptación de nuestro target, según las siguientes cifras:

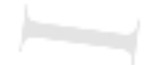

- El $81 \%$ de nuestro público objetivo estaría dispuesto a utilizar una plataforma web para personalizar su calzado, demostrando que al fusionar la tecnología, gustos y estilos de cada cliente el proyecto gozará de aceptación.

- La propuesta de valor de nuestro negocio cumple con las expectativas del cliente, que se encuentran en función a los atributos que buscan al momento de comprar un calzado, donde la comodidad, precio y diseño son los factores con mayor peso porcentual.

- Según el estudio técnico realizado, es factible introducir nuevas tecnologías al proceso productivo tradicional de calzado, como la impresora 3D, ya que no genera ningún tipo de dificultad o complicación en las operaciones. Sino que genera un valor agregado para el consumidor. 
- Por otro lado, en nuestro país la práctica tradicional de producción es el método Pull, sin embargo, nuestra propuesta apunta por una cadena de valor bajo el sistema Push. Lo cual representa ventajas en costos de inventario y almacenamiento.

- Los resultados obtenidos del estudio económico-financiero del VAN y TIR, realizados en el capítulo III, se puede afirmar que es viable la creación de una empresa orientada a la producción y comercialización de calzado personalizado de vestir en cuero para damas.
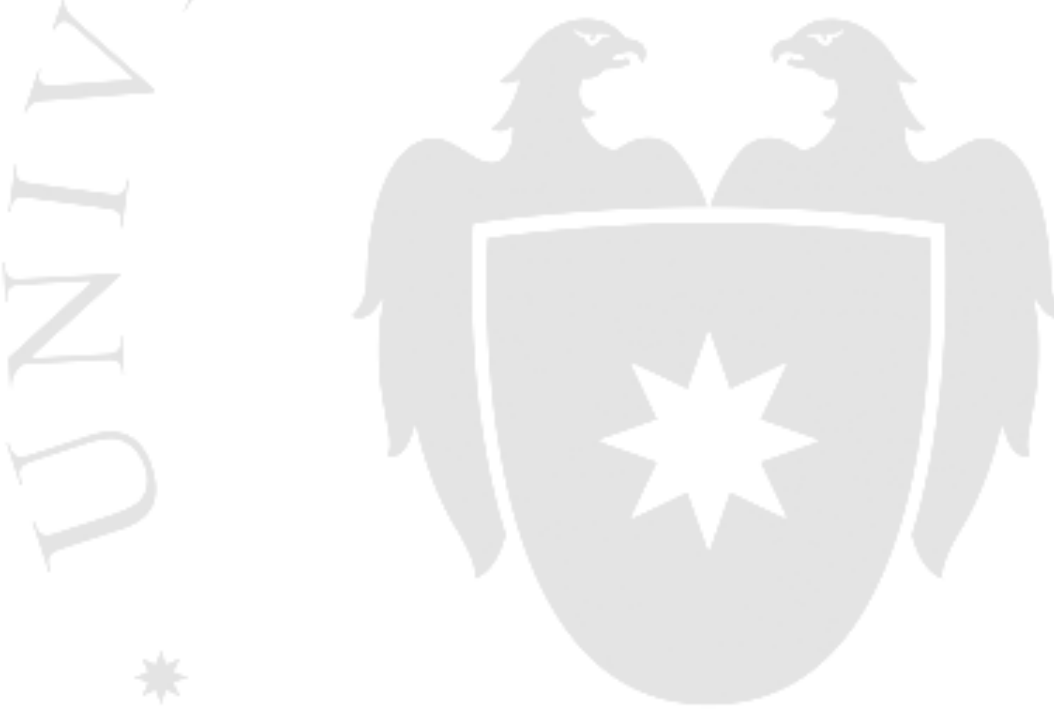


\section{RECOMENDACIONES}

- Con la finalidad de reducir los tiempos de espera del cliente, evaluar una mayor inversión en maquinaria y tecnología para mantener el liderazgo de mercado en la producción y comercialización de calzado personalizado y a la media.

- En un mediano plazo introducir productos con materiales vegetales para la fabricación de calzado, con el propósito de brindar una imagen socialmente responsable hacia la comunidad protectora del medio ambiente.

- El mundo del e-commerce no posee fronteras. Por lo que es necesario realizar los ajustes necesarios a nivel de la cadena de valor para facilitar el abasto tanto a provincias en el mediano plazo y extranjero en el largo plazo.

- Reforzar el logo de la marca "Artesanas" a través de toda comunicación publicitaria bajo el concepto peruvian custom-handmade. Para impulsar el reconocimiento de la calidad en la manufactura del producto peruano. 


\section{REFERENCIAS}

APEIM. Asociación Peruana de Marketing. Recuperado en Agosto de 2017, de APEIM: www.apeim.com.pe

Arellano Marketing. Arellano Marketing. Recuperado en Mayo de 2017, de www.arellanomarketing.com

Diario El Comercio. (16 de Abril del 2015). El 52\% de los hogares peruanos serían de clase media en el 2021. El Comercio. Recuperado de https://elcomercio.pe/economia/peru/52-hogares-peruanos-serian-clase-media$\underline{2021-188663}$

Diario Gestión (03 de Marzo del 2017). Comercio Electrónico en el Perú 2017. Gestión. Recuperado de http://blogs.gestion.pe/innovaciondisrupcion/2017/03/comercioelectronico-en-el-peru-2017.html

Diario Gestión (05 de Septiembre del 2017). Scotiabank: Tipo de cambio cerrará el 2017 en S/ 3.20. Gestión. Recuperado de http://gestion.pe/mercados/scotiabank-tipocambio-cerrara-2017-s-320-2199295

Diario Gestión. (17 de Marzo del 2016). Oportunidades de inversión: Una clase media dispuesta a buscar nuevos productos y servicios. Gestión. Recuperado de https://gestion.pe/economia/oportunidades-inversion-clase-media-dispuestabuscar-nuevos-productos-y-servicios-2156554

Informe Dirección de Estudios Económicos de MYPE e Industria

Instituto de Estudios Económicos y Sociales. IEES. Recuperado el Enero 2017, de Reporte Sectorial de Calzado-Enero-2017, de http://www.sni.org.pe/wpcontent/uploads/2017/03/Reporte-Sectorial-de-Calzado-Enero-2017.pdf.

Instituto Nacional de Estadística e Informática. (s.f.). INEI. de www.inei.gob.pe

Ipsos. (2017). Ipsos Apoyo. Lima: Ipsos: Perfiles Zonales (2017), Perfil del usuario de redes sociales (2016), Perfil de Internauta Limeño (2016). 


\section{BIBLIOGAFRÍA}

Charles W.L. Hill- Gareth R. Jones (2011). Administración Estratégica (9na ed.). México, Cengage Learning

Fred R. David (2003).Administración Estratégica(9na ed.). México, Prentice Hall.

Manuera, J., Rodriguez, A. (1998).Marketing Estratégico. Madrid, Pirámide.

Kotler, P, Amstrong, G (2004) Fundamentos de Marketing (10ª ed.). México, Prentice Hall.

Ross, Stephen A. (2007) Finanzas Corporativas. (7ª ed.) México, McGraw-Hill. 


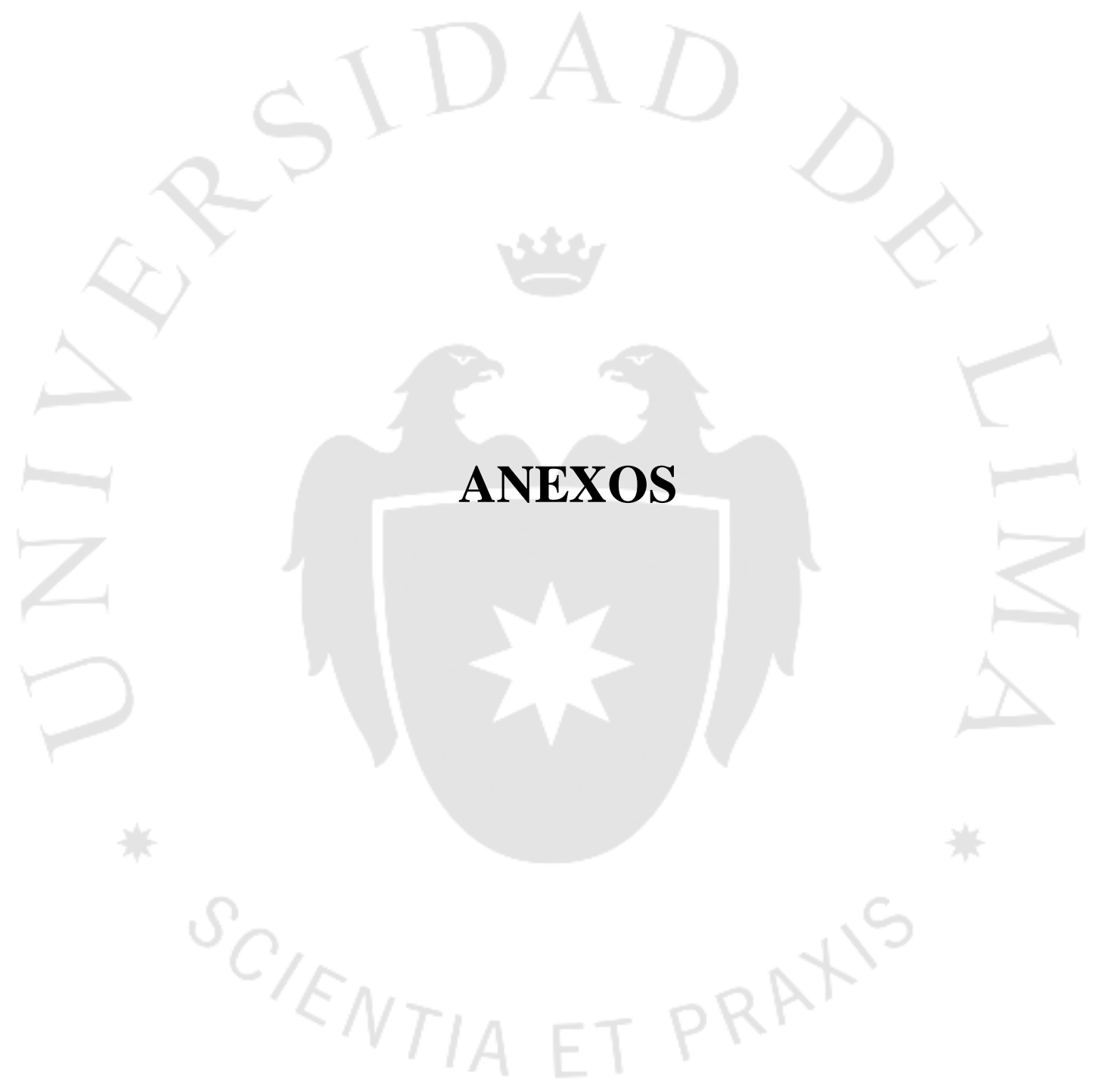




\section{ANEXO 1: Guía de Indagación para el Focus Group}

\section{$\underline{\text { Introducción }}$}

El siguiente focus se está llevando a cabo para conocer las preferencias, intención de consumo y características que debería tener un producto para el cuidado de las manos. Asimismo, se analizan las reacciones de cada persona participante, así como sus intervenciones. Se tratarán 3 temas en general: Uso de productos del cuidado de la salud, preferencias del consumidor del uso de productos para el cuidado de manos, preferencias del consumidor sobre el producto.

Foco de Investigación 1: Uso de productos del cuidado de la salud

\section{$\underline{\text { Objetivo General }}$}

Conocer las características del consumidor que suele utilizar productos para la salud, así como del que no los utiliza de forma regular, para poder establecer las preferencias de consumo.

\section{Preguntas Específicas:}

¿Suelen cuidar de su salud?

¿Utilizan algún producto de prevención en específico?

¿Qué factores creen que son los principales del traspaso de enfermedades? 
¿Qué diferentes alternativas del cuidado de la salud conocen?

¿Qué tipo de enfermedades han tenido en los últimos meses?

¿Por qué contrajeron y como lograron curarlas?

Foco de Investigación 2: Preferencias del consumidor del uso de productos para el cuidado de manos.

Objetivo General: Indagar sobre las preferencias que se tienen sobre el uso de productos para el cuidado de manos.

\section{Preguntas Específicas:}

¿Qué tipo de productos para el cuidado de sus manos usan?

¿Gustos y disgustos de los productos para el cuidado de las manos?

¿Cuánto gastan en promedio mensualmente en productos para el cuidado de las manos?

¿Tienen alguna preferencia de marca?

¿Que se podría mejorar en los productos para el cuidado para manos?

¿Cuál es su opinión sobre la manera en que el estado esta interviniendo para proteger su salud?

¿Qué evoca la frase cuidado de sus manos en sus mentes?

Foco de investigación 3: Preferencias del consumidor sobre el producto.

Objetivo General: Conocer las observaciones del grupo luego de darles a conocer la idea del producto la cual es: Un gel desinfectante para manos, con pigmentos limpiadores y 
distintas fragancias; el cual, dejara las manos humectadas y totalmente desinfectadas y limpias.

\section{Preguntas Específicas:}

¿Creen que el uso de un gel desinfectante para manos ayuda a la prevención de la salud? ¿Estarían dispuestos a utilizarlo regularmente?

¿Qué tipo de envase creen que sería el adecuado para el producto?

Uno por uno escriba una marca de gel desinfectante para manos que conozca. La marca les da a conocer un producto que brinda salud.

¿Qué es lo que no les gusta del gel desinfectante para manos?

¿Cuánto estarían dispuestos a pagar por el producto?

¿Cuáles creen que deberían de ser las características base del gel desinfectante para manos? 


\section{ANEXO 2: Encuesta}

\section{Calzado Personalizado Virtual}

\section{Estimadas}

En esta oportunidad estamos reslizando una encuesta de opinión sobre una propuesta de compra de zapatos mediante el uso de una aplicación que permita al usuario disefiar y personalizar su calzado.

Al realizar esta encuesta participards en un sorteo donde podras ganar tres pares de calzado.

MUCHAS GRACIAS!

"Obligatorio

1. Dirección de correo electrónico

2. 1. Tienes entre 23 y 40 años de edad *

Marca solo un óvalo.

Si (Pasa a la siguiente peegunta)

No (Fin de la encuesta)

3. 2. Distrito en que laboras *

Marca solo un óvalo.

La Molina

San Berja

Miraflores

San Isidro

Surco

Otro:

4. 3. ¿De qué material prefieres tu calzado? Marque uno * Marca solo un óvaío.

Cuero simtetico

Cuero Natural 
5. 4. ¿Qué marca de zapatos sueles comprar? Mencione tres de su preferencia. * Seleceiona fodor lor que eovrespondan.

Druna Ferini

Daez

Lalalove

Tanguis

Foresta

Dtro:

6. 5. ¿Qué atributos considera importante al momento de comprar un calzado? Marque Ud. tres de mayor importancia. *

Seleccions fodos las que correspondart.
Precio u oferts
D Comodidad
D Exclusividad
$\square$ Moda
Disefo

7. 6. ¿Cuántos pares de calzado de cuero compras al año? Marcar solo una. " Marca soib un divaio.

De 0 a 4 pares

De 5 a 9 pares

De 10 a 14 pares

De 15 a más pares

8. 7. ¿Cuánto pagas por un par de zapatos de cuero? Marcar solo una. * Marca soib un 6vaio.

De 100 a 200 soles

De 201 a 300 soles

Mas de 301

9. 8. ¿Que canal de venta prefieres para comprar tus zapatos? Marque dos de mayor importancia.

Selecciona fodas las que comespondan.

Cadera de tiendas

D Tienda por departamento

Catalogos

- Extranjero

intemet

T Tiendas mincristas independiente. 
10. 9. Indique tres estilos que utiliza más en la temporada de verano. * Selecciona fodos los que correspondan.

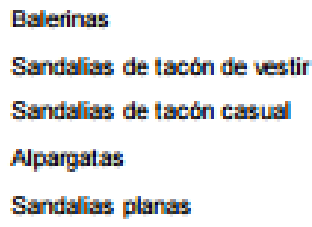

11. 10. Indique tres estilos que utiliza más en la temporada de invierno. * Selecciona fodas las que conrespondan.
Balerinas
Botines
Botas
Apargatas
Zapato de vestir

12. 11. Nivel de Ingreso Mensual (X) * Marca solo un óvalo.
$X<=S / .2500$
$\mathrm{S} / .2500<\mathrm{X}<\mathrm{S} / 3500$
S/. $3601<\mathrm{X}<=\mathrm{S} / 4000$
SI. $4001<X<-S I 5000$
> $S / 5000$

13. 12. ¿Utilizarias una aplicación virtual para personalizar y diseñar tus zapatos? * Marca solo un óvala.
Si (Pasa a la siguiente pregunta)
No (Pasa a la pregunta * 15 y enviar encuesta)

14. 13. ¿Si realizaras la compra de una marca nueva de calzado por Internet, cuál de las siguientes opeiones de medida prefieres para que el producto te calce a la perfección?

Marca solo un óvaí.

Descargar e imprimir una plantilla de la pagina web, para tomar las medidas del pie y registrarlo en la base de datos

Toma de la medida del pie a domicilio, por un personal de la empresa

Acudir a un punto de venta fisico 
15. 14. ¿Comprarias tus zapatos por Internet?

Marca solo un óvaío.

Defritivamente compraria (Enviar encuesta)

Probablemente compraria (Enviar encuesta)

Podría comprar o no comprar (Eniar encuesta)

Probablemente no compraria (Pasa a la pregunta $\# 16$ y emiar encuesta)

Defritivamente no compraria (Pasa a la pregunta * 16 y emiar encuesta)

16. 15. ¿Por qué no utilizarias una aplicación virtual para diseñar tus zapatos? Seleccions fodos los que correspondan.

$\square$ Poca familiaridad con la tecnologia

$\square$ Falta de tiempo

$\square$ La aplicación puede ser difíil de entender

$\square$ Otro:

17. 16. ¿Por qué no comprarias tus zapatos por Intemet? Selecciona fodos las que correspondan.

$\square$ Necesilto probdrmelos

$\square$ Desconfianza a comprar orline

$\square$ Duda sobre la calidad del zapato

$\square$ Otro:

18. Cómo se enteró de esta encuesta * Marta solo un óvaía.

Asistente CC

Tienda fisica

Asistente $O G$

Link virtusl

Asistente CO

Dsistente AM

$\square$ Recibir una copia de mis respuestas

Con la tecnologla de

ta Google Forms 


\section{ANEXO 3: Proyección de pares vendidos por año}
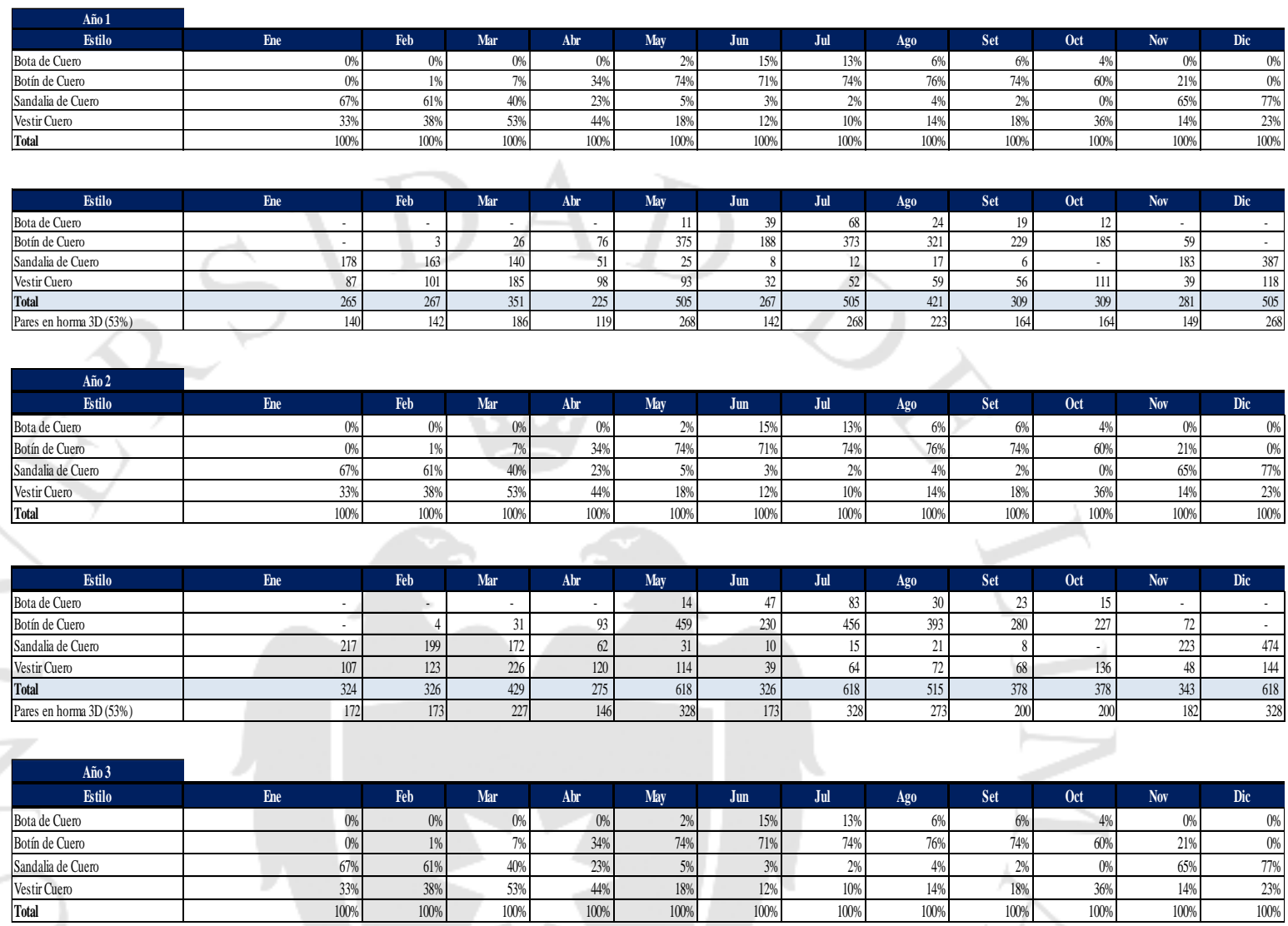

\begin{tabular}{|c|c|c|c|c|c|c|c|c|c|c|c|c|}
\hline Estilo & Ene & Feb & Mar & Abr & May & Jun & Jul & $\mathrm{Ag} 0$ & Set & Oct & Nov & Dic \\
\hline Bota de Cuero & - & - & - & - & 18 & 60 & 105 & 38 & 29 & 19 & - & - \\
\hline \begin{tabular}{|l} 
Botín de Cuero \\
\end{tabular} & - & 5 & 40 & 118 & 584 & 293 & 580 & 499 & 355 & 288 & 92 & - \\
\hline \begin{tabular}{|l|} 
Sandalia de Cuero \\
\end{tabular} & 280 & 254 & 218 & 79 & 40 & 12 & 19 & 27 & 10 & - & 284 & 603 \\
\hline \begin{tabular}{|l|} 
Vestir Cuero \\
\end{tabular} & 137 & 156 & 288 & 152 & 145 & 50 & 81 & 91 & 86 & 173 & 61 & 183 \\
\hline \begin{tabular}{|l} 
Total \\
\end{tabular} & 417 & 415 & 546 & 349 & 786 & 415 & 786 & 655 & 480 & 480 & 437 & 786 \\
\hline Pares en horma 3D (53\%) & 221 & 220 & 289 & 185 & 417 & 220 & 417 & 347 & 254 & 254 & 232 & 417 \\
\hline
\end{tabular}




\section{ANEXO 4: Costo de producción en horma 3D}

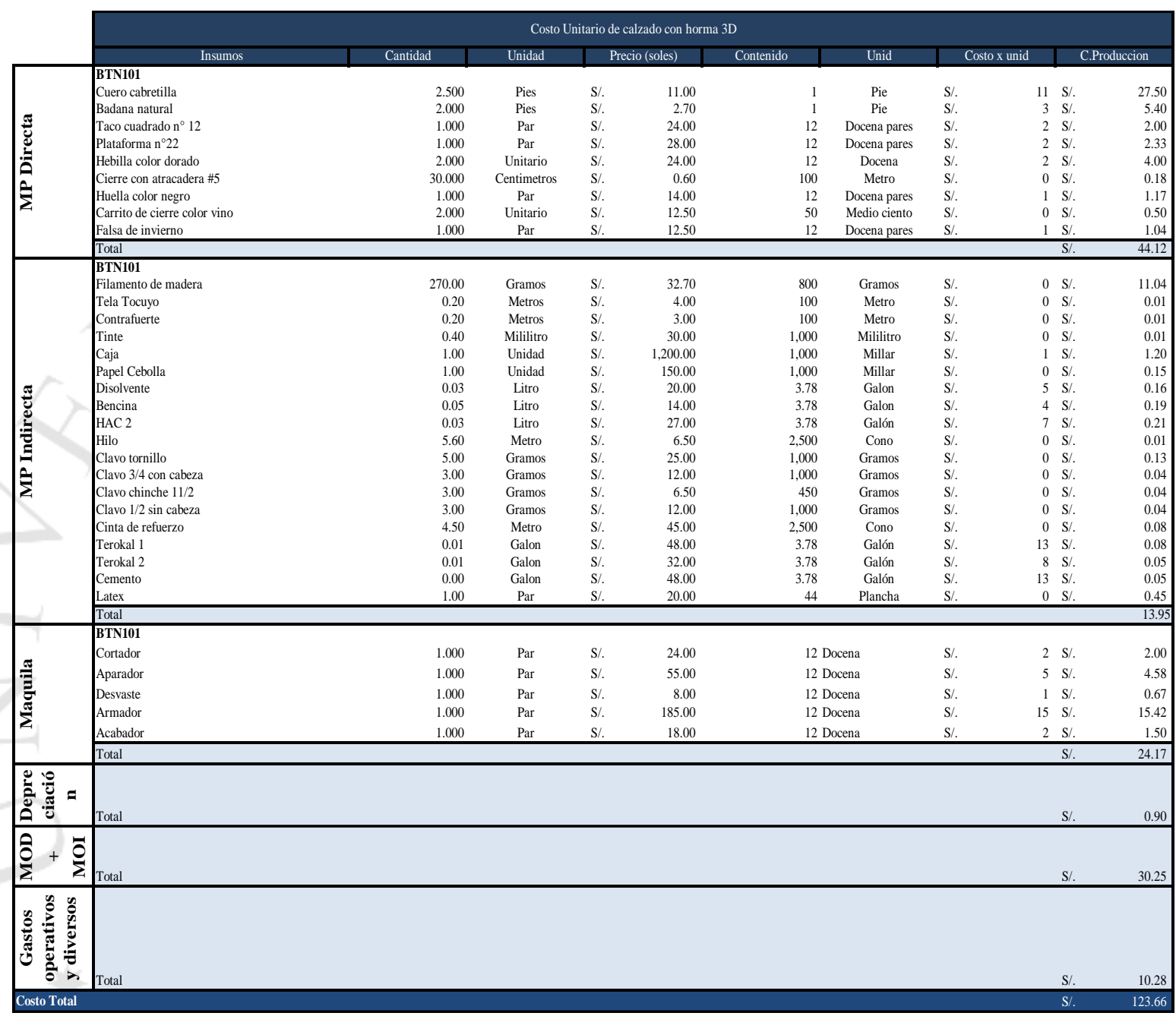




\section{ANEXO 5: Costo de producción en horma estándar}

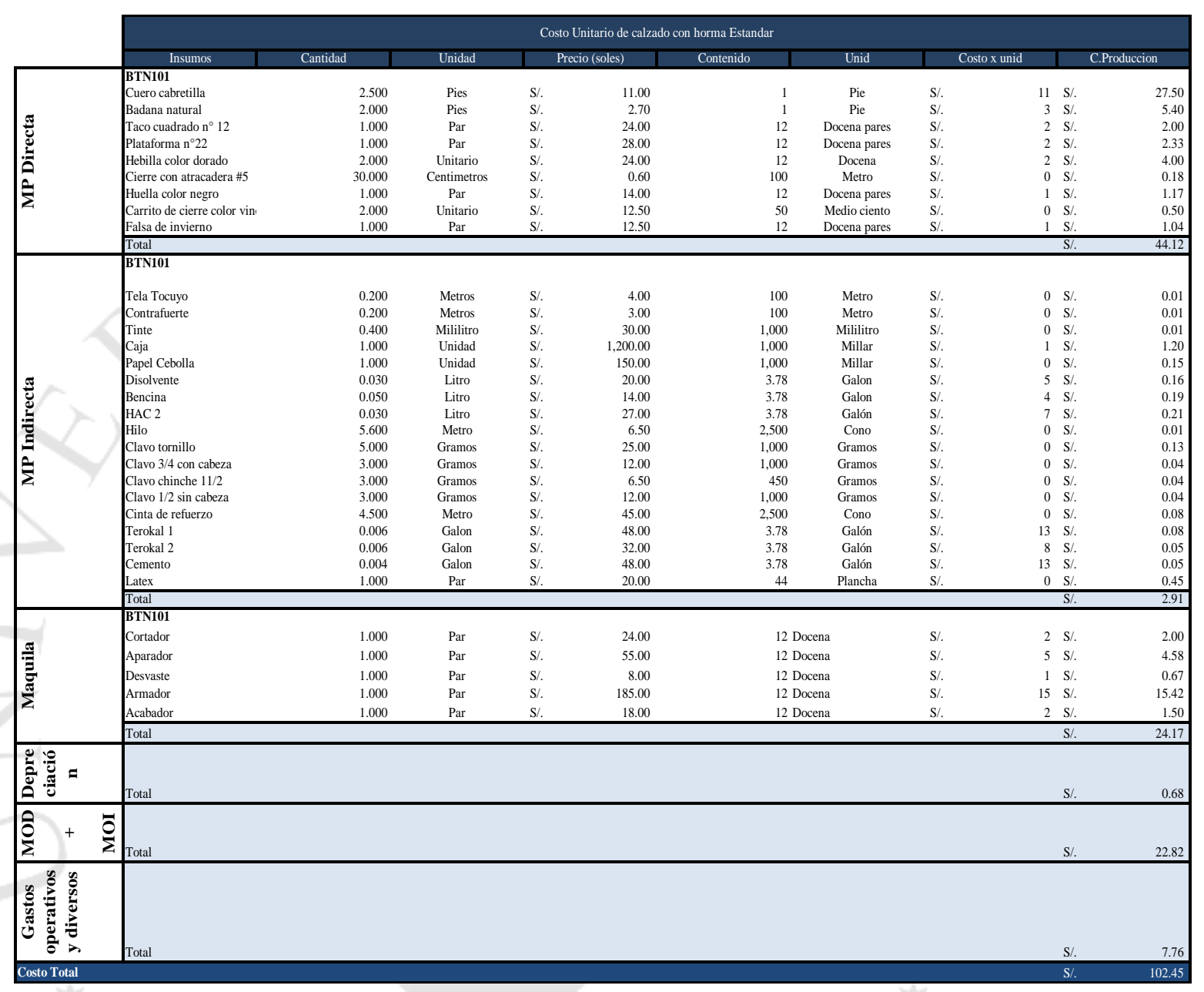

